VITOR RAFAEL DE ANDRADE ASSUNÇÃO

PROPOSTA DE METODOLOGIA DE CÁLCULO PARA RESERVATÓRIOS DE DETENÇÃO EM BACIAS HIDROGRÁFICAS URBANIZADAS

ORIENTADOR: Prof. Rodrigo de Melo Porto

VERSÃO CORRIGIDA

SÃO CARLOS

2012 

VITOR RAFAEL DE ANDRADE ASSUNÇÃO

\title{
PROPOSTA DE METODOLOGIA DE CÁLCULO PARA RESERVATÓRIOS DE DETENÇÃO EM BACIAS HIDROGRÁFICAS URBANIZADAS
}

\author{
Dissertação apresentada à \\ Escola de Engenharia de São Carlos da \\ Universidade de São Paulo, como parte \\ dos requisitos para obtenção do título \\ de Mestre em Engenharia (Hidráulica e \\ Saneamento).
}

ORIENTADOR: Prof. Rodrigo de Melo Porto

SÃO CARLOS 
AUTORIZO A REPRODUÇÃO E DIVULGAÇÃO TOTAL OU PARCIAL DESTE TRABALHO, POR QUALQUER MEIO CONVENCIONAL OU ELETRÔNICO, PARA FINS DE ESTUDO E PESQUISA, DESDE QUE CITADA A FONTE.

Ficha catalográfica preparada pela Seção de Atendimento ao Usuário do Serviço de Biblioteca EESC/USP

Assunção, Vitor Rafael de Andrade.

A851p Proposta de metodologia de cálculo para reservatórios de detenção em bacias hidrográficas urbanizadas. / Vitor Rafael de Andrade Assunção; orientador Rodrigo de Melo Porto. São Carlos, 2012.

Dissertação - Mestrado (Programa de Pós-Graduação em Engenharia de Hidráulica e Saneamento)-- Escola de Engenharia de São Carlos da Universidade de São Paulo, 2012. 


\section{FOLHA DE IULGAMENTO}

Candidato: Engenheiro VITOR RAFAEL DE ANDRADE ASSUNÇÃO.

Título da dissertação: "Proposta de metodologia de cálculo para reservatórios de detenção em bacias hidrográficas urbanizadas".

Data da defesa: 29/05/2012

Comissão Julgadora:

Prof. Associado Rodrigo de Melo Porto (Orientador)

(Escola de Engenharia de São Carlos/EESC)

Prof ${ }^{\text {a }}$. Dr ${ }^{\mathrm{a}}$. Márcia Helena Rissato Zamariolli Damianovic (Escola de Engenharia de São Carlos/EESC)

Prof. Dr. José Rodolfo Scarati Martins

(Escola Politécnica/EP-USP) $\underline{\text { Resultado: }}$
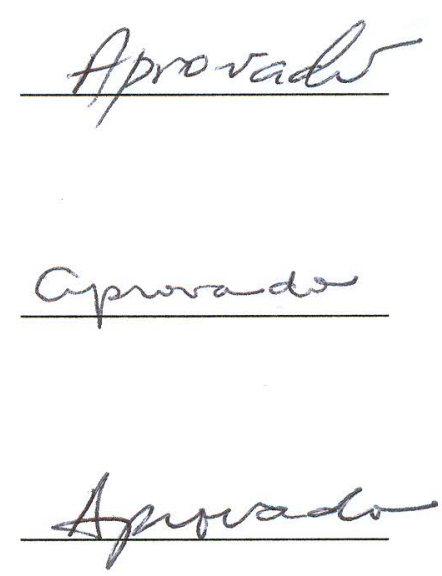

Coordenador do Programa de Pós-Graduação em Engenharia Hidráulica e Saneamento:

Prof. Titular Edson Cezar Wendland

Presidente da Comissão de Pós-Graduação:

Prof. Associado Paulo Cesar Lima Segantine 
A todos que de alguma forma contribuíram para este momento, em especial familiares e amigos. 


\section{AGRADECIMENTOS}

Agradeço aos meus familiares em especial ao meu pai - Sr. José Cícero da Silva Assunção - pelo caráter e incentivo, minha querida avó, Sra. Maria (Nina) Fortunato de Assunção, minha tia - Sra. Sâmia da Silva Assunção - e minha mãe Sra. Peronilda Batista de Andrade, maiores responsáveis por minha formação.

As Sras. Maria Pereira Lemos e Maria Vespertina "In Memorian", queridas avós pelo carinho incondicional. Aos meus irmãos Pablo Jorge de Andrade Prentice, Natália da Silva Assunção e João Paulo da Silva Assunção pelos excelentes momentos e alegrias compartilhadas.

Ao prof. Rodrigo de Melo Porto pelos ensinamentos, conselhos, confiança, oportunidade de trabalho, paciência e ainda engraçados momentos compartilhados.

Ao grande amigo prof. Marcio Gomes Barboza, responsável por minha vinda à São Carlos, pelos ensinamentos, conversas e bons momentos compartilhados na Universidade Federal de Alagoas.

Aos professores e funcionários da Escola de Engenharia de São Carlos (EESC/USP) e ao CNPq pelo apoio institucional e financeiro durante $\mathrm{o}$ desenvolvimento deste trabalho. À Universidade Federal de Alagoas por minha formação.

Aos amigos que compartilharam mais momentos divertidos que perrengues em São Carlos e faço questão de mencioná-los: Rodrigo Soares, David Leonardo, Priscila Camiloti, Lenin Matos, Irene Chaves, Guilherme "Piu" Barbosa, Leandro Baís, Vinícius "Bidjei” Rocha, Marjolly Shinzato, Thiago "Mineiro" Santos, Ivie Emi, André Soares, Felipe "Minêro" Maia, Danilo "Bomba" dos Santos, Roger Rodas, Osvaldo "Nêgo" Mamprim, Guilherme Laurentis, Rodrigo "Bobo" Martins, Nayara Falanca, Thiago "Marisco" Galvão, Caio Pires e Uirá Piá-Uaçu.

Aos queridos amigos do Rio em especial: Davyd Vidal, Alberto Douglas, Edson Falcão, Rafaela Silva, Ericson Borges, Hugo Luna, Renata Ramos, Jacqueline Giori, Ernani Cleiton, Selena Carvalho, Leonardo Tristão e Laura Rêdes.

Aos amigos para mais que toda hora Lívia Lima, Valquíria Calheiros, Eugênio Bastos, Samuel Tenório, Luiz Neto e Hudson Pedrosa.

Aos amigos da Pref. Municipal de Campinas Alan, Caio, Lindenberg, Elizandra, Heloísa, Carolina, Soraya, Rodrigo, Guilherme, Alexandre, Jana, Ângela, Verô, Irani, Juçara, Daniel e demais companheiros.

Ao prof. Benedito A. Santos Rodrigues e ao pessoal da ESA, Engenharia Sanitária e Ambiental, pela prestatividade e colaboração ao trabalho realizado.

Aos demais que por descuido não citei fica com todos os méritos meu obrigado. 
“A felicidade não é uma estação na qual chegamos, mas uma maneira de viajar.” Margareth Lee Rimbeuk 


\section{RESUMO}

Diversos são os transtornos causados pelas inundações dentre os quais se destacam problemas ambientais, sanitários, de perdas materiais e humanas. Os maiores agentes destas inundações são o crescimento urbano não planejado, que ocasiona a impermeabilização indiscriminada das áreas urbanas gerando maior volume escoado, e a ocupação de várzeas. As bacias de detenção são caracterizadas por sua destinação ao amortecimento dos picos de cheias por meio da contenção de parte do volume escoado superficialmente. No presente trabalho fez-se uma proposta de pré-dimensionamento de bacias de detenção, fundamentada no método racional e associada a relações IDF, que permite o cálculo dos volumes de detenção. A viabilidade e segurança do modelo foram verificadas comparando a proposta desenvolvida com metodologias consagradas entre projetistas, sendo utilizado como referência o procedimento desenvolvido por Porto (2002). De modo a permitir uma melhor avaliação dos métodos estudados foram analisadas interferências relativas às mudanças no tempo de concentração da bacia e na duração dos eventos chuvosos. O processo proposto apresentou resultados satisfatórios quando aplicado à bacia do córrego do Andrezinho na cidade de Pirassununga, São Paulo, assegurando em seus melhores ajustes diferenças máximas da ordem de $5 \%$ do volume estimado como ideal.

Palavras-chave: Bacias de detenção, Drenagem urbana, método racional, tempo de concentração. 



\begin{abstract}
Several disorders are occurred by the floods of which are highlighted environmental issues, sanitary, of human and material losses. The main agent of these floods is the unplanned urban growth which causes sealing of urban areas generating higher volumes disposed. The detention ponds are characterized by their allocation to the dampening of flood peaks through retention of part of surface runoff. The present work proposes the pre-sizing of detention basins, based on rational method and associated with IDF relations which allows the calculation of the volumes of detention. The feasibility and safety of the model were verified by comparing the proposal with methods traditionally developed between designers, being used as reference the procedure developed by Porto (2002). In order to allow a better evaluation of the methods studied were analyzed interferences related to changes in the watershed concentration time and duration of rainfall events. The proposed method showed good results when applied to the basin of the Andrezinho stream in the city of Pirassununga, Sao Paulo, ensuring in their optimum settings with maximum differences about $5 \%$ of the volume estimated as ideal.
\end{abstract}

Key-words: detention basins, urban drainage, rational method, time of concentration. 



\section{SUMÁRIO}

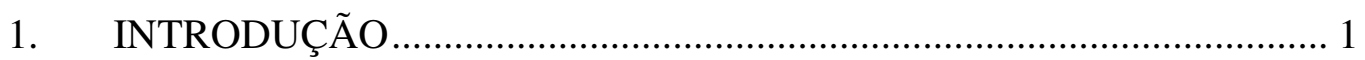

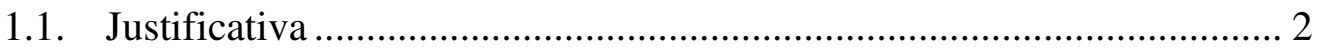

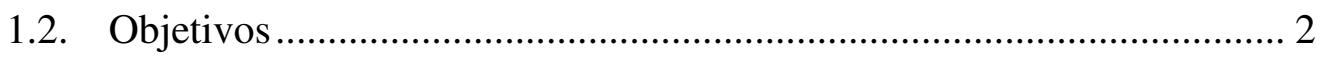

1.2.1. Objetivo geral......................................................................... 2

1.2.2. Objetivos específicos ............................................................... 2

2. REVISÃO BIBLIOGRÁFICA ….......................................................... 4

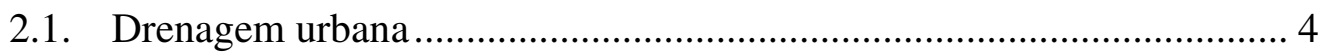

2.2. Planejamento e gerenciamento de sistemas de drenagem...................... 5

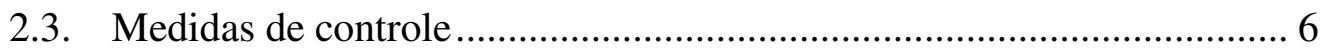

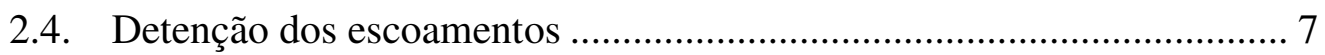

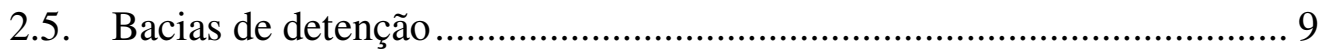

2.5.1. Funções de bacias de detenção........................................................ 10

2.5.2. Tipos de bacias de detenção ......................................................... 11

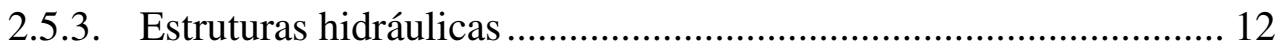

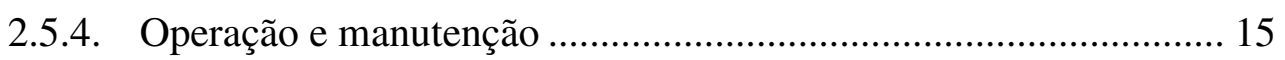

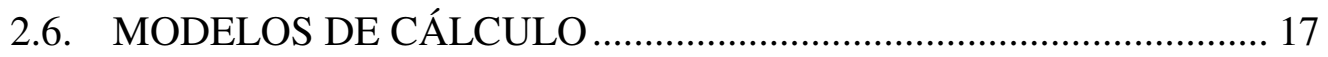

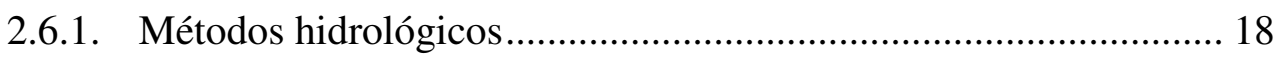

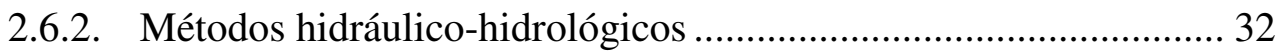

2.7. Relações Intensidade - Duração - Frequência .................................... 37

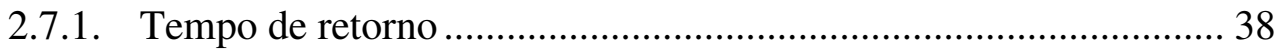

2.7.2. Duração da chuva crítica.............................................................. 41

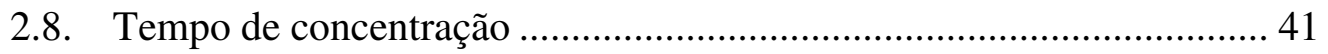

2.8.1. Formulações empíricas …............................................................ 43

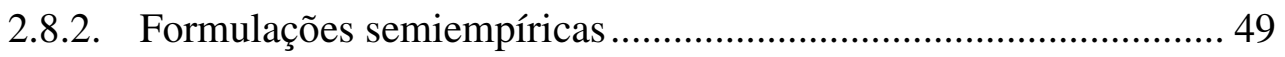

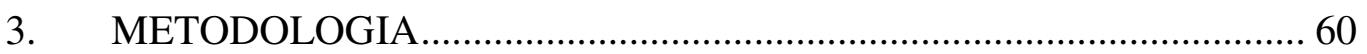

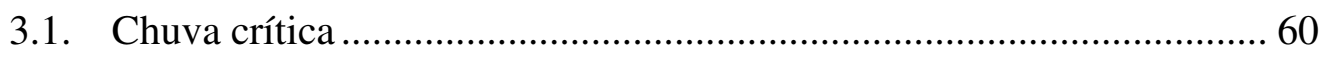




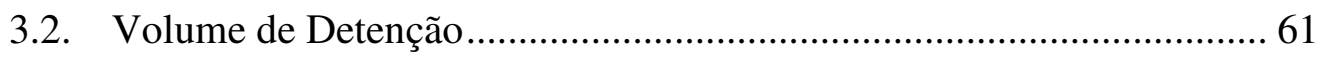

3.2.1. Volume de detenção para hipótese b........................................... 62

3.2.2. Volume de detenção para hipótese c.......................................... 63

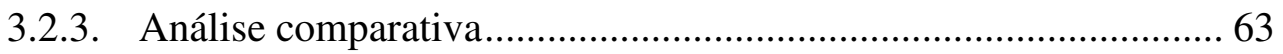

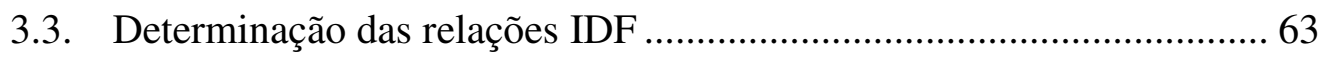

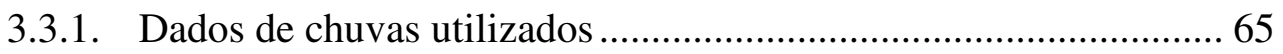

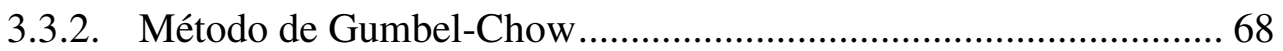

3.4. Tempo de concentração ................................................................. 72

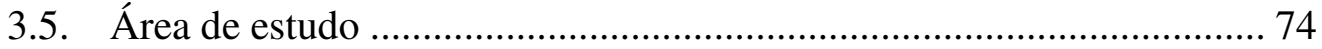

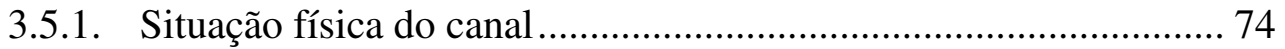

3.5.2. Capacidade de escoamento do canal ........................................... 76

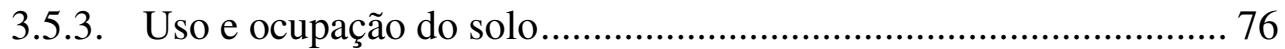

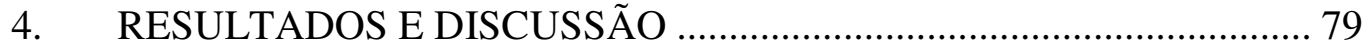

4.1. Uso e ocupação do solo .................................................................... 79

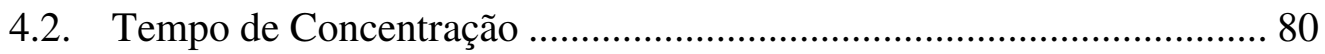

4.2.1. Estudo das formulações empíricas ............................................ 82

4.2.2. Estudo das formulações semiempíricas ..................................... 84

4.2.3. Considerações sobre as estimativas de tempo de concentração.....87 87

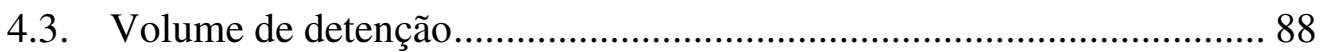

4.3.1. Volume de detenção em função do parâmetro $\beta$........................... 88

4.3.2. Volume de detenção: comparação de procedimentos .................... 94

5. APLICAÇÃO DO MÉTODO PROPOSTO ......................................... 108

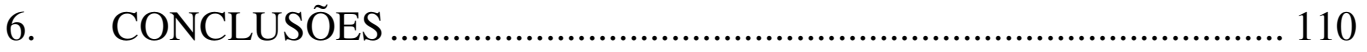

7. REFERÊNCIAS BIBLIOGRÁFICAS …............................................ 114

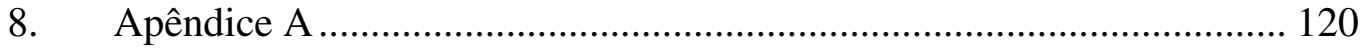




\section{LISTA DE FIGURAS}

Figura 2.1: representação gráfica da aplicação do método generalizado para estimativa do volume retido (Fonte: MCCUEN, 1989).

Figura 2.2: representação gráfica da estimativa do volume detido resultante do emprego do método da fórmula racional (Fonte: PORTO, 2002).

Figura 2.3: representação gráfica da utilização do método de Baker (1979) para estimativa do volume detido (Fonte: PORTO, 2002).

Figura 2.4: representação gráfica para estimativa do volume de detenção proposto por Abt e Grigg (adaptado de: ABT E GRIGG, 1978).

Figura 2.5: relações entre risco, tempo de recorrência e vida útil de obras de drenagem urbana (Fonte: BRASIL, 2005).

Figura 3.1: representação gráfica dos hidrogramas afluente e efluente durante um evento chuvoso crítico.

Figura 3.2: idealização gráfica da estimativa do volume de detenção pelo método proposto.

Figura 3.3: relação entre os logaritmos da intensidade $(\mathrm{mm} / \mathrm{min})$ e da duração das precipitações (min).

Figura 3.4: ajuste dos valores dos logaritmos naturais de $T$ e $k^{*} T^{m}$

Figura 3.5: obras de retificação no trecho inicial do canal do Andrezinho, à jusante da Alameda das Açucenas.

Figura 3.6: obstrução do canal, por entulhos e vegetação, e ocupação das margens por residências

Figura 3.7: destaca-se a presença de coletor tronco, com efluentes sanitários, e algumas de suas ligações.

Figura 4.1: comparação entre o tempo de concentração estimado por fórmulas empíricas e o calculado pela formulação de George-Ribeiro, para a área estudada. .....................................83

Figura 4.2: comparação entre o tempo de concentração estimado por metodologias semiempíricas e o calculado pela formulação de George-Ribeiro..............................................8 85

Figura 4.3: comparação entre volumes detido pela metodologia proposta e o método de Porto (2002) para tempo de retorno de 25 anos, duração de precipitação de 30 minutos e CN de 85.

Figura 4.4: comparação entre volumes detido pela metodologia proposta e o método de Porto (2002) para tempo de retorno de 100 anos, duração de precipitação de 30 minutos e CN de 85.

Figura 4.5: comparação entre volumes detido pela metodologia proposta e o método de Porto (2002) para tempo de retorno de 25 anos, duração de precipitação de 30 minutos e CN de 98.

Figura 4.6: comparação entre volumes detido pela metodologia proposta e o método de Porto (2002) para tempo de retorno de 100 anos, duração de precipitação de 30 minutos e CN de 98.

Figura 4.7: comparação gráfica de volumes de detenção para tempo de concentração de 15 minutos, duração da chuva de 30 minutos e CN de 85............................................................96

Figura 4.8: comparação gráfica de volumes de detenção para tempo de concentração de 15 minutos, duração da chuva de 30 minutos e $\mathrm{CN}$ de 98 ..............................................................96

Figura 4.9: comparação gráfica de volumes de detenção para tempo de concentração de 26 minutos, duração da chuva de 30 minutos e CN de 85..............................................................98

Figura 4.10: comparação gráfica de volumes de detenção para tempo de concentração de 26 minutos, duração da chuva de 30 minutos e CN de 98 ...........................................................99

Figura 4.11: comparação gráfica de volumes de detenção para tempo de concentração de 37 minutos, duração da chuva de 30 minutos e CN de 85 ....................................................... 101

Figura 4.12: comparação gráfica de volumes de detenção para tempo de concentração de 37 minutos, duração da chuva de 30 minutos e $\mathrm{CN}$ de 98. 101

Figura 4.13: comparação gráfica de volumes de detenção para tempo de concentração de 75 minutos, duração da chuva de 30 minutos e CN de 85 ........................................................... 103

Figura 4.14: comparação gráfica de volumes de detenção para tempo de concentração de

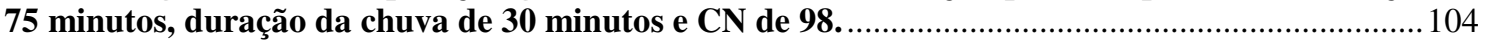




\section{LISTA DE TABELAS}

Tabela 3.1: relação entre os valores do tempo de retorno, e do termo $k^{*} T^{m}$

Tabela 4.1: relação entre valores do coeficiente de escoamento da fórmula racional, tempo de retorno e duração do evento chuvoso para $\mathrm{CN}=85$.

Tabela 4.2: relação entre valores do coeficiente de escoamento da fórmula racional, tempo de retorno e duração do evento chuvoso para $\mathrm{CN}=98$.

Tabela 4.3: erros percentuais das formulações empíricas para estimativas do tempo de concentração da área estudada.

Tabela 4.4: erros percentuais das formulações semiempíricas para estimativas do tempo de concentração da área estudada.

Tabela 4.5: resumo dos valores estimados para tempo de concentração em minutos e seus erros percentuais quando comparados à fórmula desenvolvida por George-Ribeiro.....................87

Tabela 4.6: avaliação percentual dos volumes obtidos pelo método proposto e pela metodologia de Porto (2002) para $\mathrm{CN}$ 85, para diversas durações de chuvas e tempo de retorno de 25 e 100 anos.

Tabela 4.7: avaliação percentual dos volumes obtidos pelo método proposto e pela metodologia de Porto (2002) para $\mathrm{CN}$ 98, para diversas durações de chuvas e tempo de retorno de 25 e 100 anos.

Tabela 4.8: erro médio e erro padrão obtidos da comparação dos volumes detidos calculados pelo método proposto e do método de Porto (2002).

Tabela 4.9: diferenças percentuais entre os processos de cálculo de volume de detenção, para tempo de concentração de 15 minutos, tempo de duração da chuva de 30, 60 e 90 minutos e $\mathrm{CN}=85$.

Tabela 4.10: diferenças percentuais entre os processos de cálculo de volume de detenção, para tempo de concentração de 15 minutos, tempo de duração da chuva de 30, 60 e 90 minutos e $\mathrm{CN}=98$.

Tabela 4.11: diferenças percentuais entre os processos de cálculo de volume de detenção, para tempo de concentração de 26 minutos, duração da chuva de 30, 60 e 90 minutos e $\mathrm{CN}=85$....97

Tabela 4.12: diferenças percentuais entre os processos de cálculo de volume de detenção, para tempo de concentração de 26 minutos, duração da chuva de 30, 60 e 90 minutos e $\mathrm{CN}=98$....97

Tabela 4.13: diferenças percentuais entre os processos de cálculo de volume de detenção, para tc de 37 minutos, duração da chuva de 30, 60 e 90 minutos e $\mathrm{CN}=85$.

Tabela 4.14: diferenças percentuais entre os processos de cálculo de volume de detenção, para tc de 37 minutos, duração da chuva de 30, 60 e 90 minutos e $\mathrm{CN}=98$.

Tabela 4.15: diferenças percentuais entre os processos de cálculo de volume de detenção, para tempo de concentração de 75 minutos, duração da chuva de 30, 60 e 90 minutos e $\mathbf{C N}=85$... 102

Tabela 4.16: diferenças percentuais entre os processos de cálculo de volume de detenção, para tempo de concentração de 75 minutos, duração da chuva de 30, 60 e 90 minutos e $\mathrm{CN}=98$... 102 


\section{LISTA DE ABREVIATURAS E SIGLAS}

AMC - Antecedent Moisture Condition

ANA - Agência Nacional de Águas

ASCE - American Society of Civil engineers

CETESB - Companhia de Tecnologia de Saneamento Ambiental

$\mathrm{CN}$ - Curve Number

DAEE - Departamento de Águas e Energia Elétrica

DER - Departamento de Estradas e Rodagem

DNIT - Departamento Nacional de Infraestrutura de Transporte

DNOS - Departamento Nacional de Obras de Saneamento

FAA - Federal Aviation administration

FCTH - Fundação Centro Tecnológico de Hidráulica

IDF - Intensidade - Duração - Frequência

INMET - Instituto Nacional de Meteorologia

SCS - Soil Conservation Service

USACE - United States Army Corps of Engineers 


\section{INTRODUÇÃO}

Diversos são os transtornos causados pelas inundações dentre os quais se destacam problemas ambientais, sanitários, de perdas materiais e humanas. Um dos agentes destas inundações é o crescimento urbano não planejado, que causa a impermeabilização das áreas urbanas gerando maiores volumes escoados. Outro fator que contribui para o aumento dos problemas decorrentes das enchentes é a ocupação de várzeas.

Os sistemas de drenagem que combatem enchentes têm por principio básico duas vertentes: a primeira procura escoar o mais rápido possível as águas pluviais e a segunda, mais recente, busca o retardo no escoamento destes volumes. Enquanto os sistemas que promovem o aumento na velocidade de afastamento dos picos de vazão utilizam canalizações, as técnicas que buscam a contenção dos escoamentos são consideradas inovadoras e combatem às inundações com o aumento dos tempos de concentração, mitigação das vazões máximas e redução dos volumes escoados.

Dentre os dispositivos utilizados no retardamento das vazões máximas encontram-se os pavimentos porosos e as trincheiras de infiltração, estruturas destinadas a infiltração e percolação das águas, coletores e pequenos reservatórios instalados em cobertas, pátios e estacionamentos — que retêm pequenos volumes de chuva - e bacias de detenção/retenção que servem para conter volumes provenientes de áreas consideráveis.

As bacias de detenção - obras destinadas inicialmente ao amortecimento dos picos de cheias por meio da reservação de parte do volume escoado superficialmente são caracterizadas por servirem também a fins como remoção de detritos e poluentes carreados pelos escoamentos, funções paisagísticas e recreativas.

Porém o dimensionamento destas estruturas não é simples e diversos engenheiros enfrentam problemas na avaliação de tais projetos, seja por falta de conhecimento técnico ou por falta de informações. Surge então a necessidade da busca de métodos que simplifiquem o processo de cálculo das bacias de detenção, mormente no aspecto de pré-dimensionamento.

O presente trabalho propõe o estudo e aplicação de uma metodologia de cálculo de volumes de detenção em uma bacia urbana. O método é baseado no método racional 
e utiliza parâmetros da curva Intensidade - Duração - Frequência para determinação dos montantes reservados.

\subsection{Justificativa}

O dimensionamento de estruturas voltadas para drenagem urbana requer conhecimentos complexos e multidisciplinares - hidrologia, hidráulica, topografia, geologia e conhecimentos sanitários - sensibilidade numérica do projetista e, além disso, de informações que nem sempre estão disponíveis.

Diversas são as metodologias utilizadas para dimensionamento de bacias de amortecimento, o que torna o trabalho de fiscalização exaustivo e árduo para profissionais não habituados ao serviço. Isso é identificado principalmente quando o projeto envolve uma pequena área, e os projetistas utilizam os chamados "métodos simplificados" (TASSI, 2005).

Uma avaliação rápida, prática e segura de projetos de obras de bacias de contenção faz-se então necessária - auxiliando o trabalho de diversos corpos técnicos de prefeituras de pequeno e médio porte, bem como de profissionais que necessitem realizar serviços semelhantes - e uma proposta baseada no método racional é incumbida para realização de tal.

Neste sentido foi desenvolvida uma proposta de pré-dimensionamento de bacias de detenção, fundamentada no método racional e associada a relações IDF, que permitirá o cálculo dos volumes de detenção. A viabilidade e segurança do método serão verificadas comparando a proposta desenvolvida com metodologias consagradas entre os projetistas.

\subsection{0bjetivos}

\subsubsection{Objetivo geral}

Estudar a aplicabilidade da metodologia de cálculo proposta para determinação do volume de reservatórios de detenção alocados em bacias hidrográficas urbanas, sendo definido como procedimento referência o método desenvolvido por Porto (2002).

\subsubsection{Objetivos específicos}

- Atualizar os parâmetros da curva Intensidade - Duração - Frequência definindo assim uma curva que possa ser utilizada em projetos futuros na região de Pirassununga; 
- definir valores do parâmetro $\beta$ do modelo proposto que melhor ajustam ao caso estudado;

- avaliar a utilização do método proposto através da comparação com métodos conhecidos e difundidos entre os projetistas de bacias de amortecimento;

- observar o comportamento de metodologias de cálculo de tempo de concentração para bacias com características semelhantes à do córrego do Andrezinho;

- avaliar a influência de variados métodos de cálculo do tempo de concentração no volume final de reservação da bacia de contenção, em função dos períodos de retorno;

- estudar a influência da duração da precipitação crítica na determinação de volumes detidos em reservatórios de contenção; 


\section{REVISÃO BIBLIOGRÁFICA}

\subsection{Drenagem urbana}

Todos impactos causados pela drenagem urbana são decorrentes do uso e ocupação do solo, do planejamento da infraestrutura urbana, bem como sua legislação e implantação (MATIAS, 2006). A drenagem urbana deve evitar o acontecimento de situações calamitosas como inundações, reduzindo para valores aceitáveis os riscos de vida, os problemas de saúde e as perdas de bens materiais associados às enxurradas (BARREIRO E FELEX, 1995). Outra função mais recentemente atribuída aos dispositivos de drenagem é a de evitar impactos ambientais causados pelo carregamento de poluentes e sedimentos nas águas escoadas superficialmente (ANMALA et al., 2000; BERQUE \& RUPERD, 2000; CANHOLI, 2005; HOSSAIN et al., 2005; STARZEC et al., 2005; GOFF \& GENTRY, 2006).

Diversos são os problemas detectados no controle de cheias no Brasil e a solução destes problemas passa pelo planejamento sistêmico nos programas de drenagem, assim como pela consolidação de políticas públicas voltadas para o assunto. Para consolidação de tais políticas a disposição de critérios gerais de projeto, operação e manutenção dos dispositivos apresentam fundamental importância. A solução destes problemas não é simples e requer planejamento de ações - preventivas ou corretivas - para que gerem resultados positivos (CANHOLI, 2005).

Dentre as informações que podem ser levadas em consideração para solucionar problemas de drenagem urbana Santos et al. (2007) citaram dados cadastrados por prefeituras, fotografias aéreas, imagens de satélites e informações sobre o tipo de solo como imprescindíveis.

Canholi (2005) tratou da importância da implantação de Planos de Drenagem, e afirma que caso este não se encontre atrelado ao Plano de Saneamento Básico, Uso do Solo e Transportes dificilmente se alcançará êxito nas atividades. Santos et al. (2007) conferiram validade à afirmação de Canholi (2005) ao passo que afirmaram que os danos causados por enchentes estão associados ao tipo de uso e ocupação do solo, de modo que inundações ocorridas em regiões de intenso tráfego de veículos serão mais sentidas que em regiões com baixo tráfego.

A adoção de medidas menos convencionais em projetos de drenagem urbana, onde se enquadra o armazenamento temporário de águas pluviais, tem se tornado mais frequente. A metodologia mais utilizada nas últimas décadas tem por objetivo o rápido 
escoamento das águas, com a construção de canalizações e retificações de córregos, o que transfere os deflúvios para jusante. Em contrapartida as medidas que procuram o armazenamento das águas pluviais retardam seu escoamento, reduzindo os picos de cheias (TUCCI et al., 1995; PORTO, 2002; CANHOLI, 2005; MATIAS, 2006; FONSECA \& NASCIMENTO, 2007).

\subsection{Planejamento e gerenciamento de sistemas de drenagem}

O planejamento da drenagem de uma cidade, assim como qualquer outro tipo de infraestrutura, deve ser sempre criterioso, uma vez que sempre envolverá características técnicas, sociais, políticas e econômicas. Diferentemente dos demais componentes de infraestrutura o planejamento de sistemas de drenagem possui uma peculiaridade que o torna mais complicado, o fato da unidade de gerenciamento, a bacia hidrográfica, nem sempre estar totalmente nos limites da administração - municípios, estados e países.

Tomaz (2002) afirmou que no Brasil um dos principais problemas dos sistemas de drenagem encontra-se no gerenciamento das obras de drenagem. $\mathrm{O}$ autor prossegue afirmando que a solução destes problemas passa pelo perfeito entendimento, dentre outros, dos critérios hidráulicos e hidrológicos, da segurança, manutenção, limpeza pública e saúde.

Tucci et al. (1995) citaram como princípios para programas de drenagem urbana fatores como: tomada de medidas de controle no conjunto da bacia hidrográfica, que deve ser vista como a unidade de gestão, definição de horizontes de expansão — que devem ser determinados através da definição de planos diretores e legislações, controle permanente das condições estipuladas nos horizontes de expansão, educação e conscientização da população, de administradores e de técnicos, manter sempre atualizados estudos de possíveis impactos e soluções, bem como gerenciar de maneira adequada o sistema.

No tocante ao planejamento da drenagem urbana os planos diretores assumem vital importância uma vez que devem ser vistos como imprescindíveis para disciplinar e controlar a dinâmica de uma bacia. A concretização de planos diretores se torna possível à medida que este passa a ser visto como um instrumento regulador, que sirva de referencial técnico e estratégico para implantações de intervenções. Um plano diretor de drenagem assume característica multidisciplinar ao passo que deve direcionar a ocupação do solo da cidade e harmonizar projetos de drenagens com estruturas de transportes, de abastecimento de água e esgotos sanitários (CANHOLI, 2005). 
A elaboração de um plano de drenagem passa, para Canholi (2005), por 5 etapas básicas sendo elas: informações básicas, diagnóstico da situação atual, intervenções imediatas, ações prioritárias e por último ações sistemáticas. Dentre os objetivos de um plano de drenagem urbana destacam-se a definição de medidas que minimizem as consequências das inundações e definição de prioridades de implantação de medidas. Tucci et al. (1995) afirmaram que a elaboração de planos de drenagem devem estabelecer normas de ocupação e obras urbanas, maneiras de controle das áreas legisladas, estabelecer normas de operação, manutenção dos sistemas e fiscalização de projetos.

A falta de planejamento da unidade gestão de enchentes, bacia hidrográfica, é comum em países em desenvolvimento, fato este que tende a aumentar custos de ações futuras. O planejamento de ações numa bacia apesar de ser complexo apresenta importância vital no controle de cheias, recomendando medidas prioritárias e apresentando alternativas tecnológicas, se constituindo na melhor maneira de combate a incidentes que envolvam eventos chuvosos. Apesar de ser tarefa árdua os órgãos gestores - a níveis federal, estadual e municipal - devem preconizar ações de gerenciamento e planejamento da dinâmica urbana a fim de mitigar os efeitos de precipitações intensas.

\subsection{Medidas de controle}

As medidas de controle utilizadas na drenagem urbana são classificadas como estruturais - obras que visam corrigir ou prevenir problemas relacionados a enchentes — e não estruturais caracterizadas pela adoção de normas, regulamentos ou programas que procuram melhorar a relação população/enchente (TUCCI, 2001; CANHOLI, 2005).

TUCCI (2001) classificou as medidas estruturais em extensivas e intensivas. As medidas estruturais extensivas atuam em toda a bacia hidrográfica alterando a resposta decorrente de uma precipitação. As medidas estruturais intensivas agem no curso d'água podendo acelerar, retardar ou ainda desviar o escoamento das águas. Canholi (2005) adicionou à classificação das medidas estruturais intensivas as ações individuais que deixem a edificação à prova de enchentes.

As medidas não estruturais apresentam custos mais baixos e possuem horizontes de atuação mais longos que as medidas estruturais (CANHOLI, 2005). Tucci (2001) relatou que em Denver - cidade no Estado do Colorado, Estados Unidos da América 
— no ano de 1972 o custo da implantação de medidas estruturais em 25\% da área era equivalente ao custo da implantação de medidas não estruturais nos $75 \%$ restantes da área inundável.

Fonseca \& Nascimento (2007) enfatizaram que o controle de sistemas de drenagem urbana deve ser feito com auxílio de medidas estruturais e não estruturais, e o balanço entre as medidas deve ser realizado de maneira consciente e organizada, devendo levar em consideração aspectos de ordem sanitária e ambiental, de viabilidade técnica e econômica.

\subsection{Detenção dos escoamentos}

Os dispositivos que promovem a retenção/detenção das águas - medidas estruturais intensivas - reduzem o pico de cheia pelo armazenamento temporário e conveniente do volume escoado. Estas soluções têm se estendido, de maneira pensada e apropriada, para diversas finalidades tais como recreação e lazer ou ainda melhoria da qualidade da água pelo controle de sedimentos e poluentes (PORTO, 2002).

Canholi (2005) enfatizou que sistemas de detenção de águas pluviais podem ser implantados em lotes - em reservatórios de pequena escala - associada a áreas permeáveis ou ainda em escala de sub-bacias, onde o armazenamento é realizado em reservatórios de maior porte. A classificação dada dentre outros autores por Tucci et al. (1995), Porto (2002) e Canholi (2005), para obras deste tipo são de contenção na fonte, realizada em pequenos reservatórios, ou contenção a jusante realizada em bacias de detenção/retenção de porte considerável.

As estruturas de contenção do escoamento na fonte possuem como vantagens a facilidade na alocação de recursos, visto que as unidades são pequenas e padronizadas, e possibilitam redução de fluxos nas galerias da área controlada. Dentre as desvantagens podem-se sobressaltar os altos custos de manutenção e operação, devido ao elevado número de unidades implantadas, e complexa avaliação de desempenho global, que causa incertezas em projetos futuros (PORTO, 2002).

Já a classificação dos dispositivos de contenção na fonte segundo Canholi (2005) e Porto (2002) pode ser feita como segue:

- Disposição "in loco": técnicas que proporcionam a infiltração e percolação, tendo como exemplos os pavimentos porosos e trincheiras de infiltração. 
- Controle de entrada: são dispositivos que impedem a entrada dos volumes escoados no sistema de drenagem. A contenção da água pode ser permanente ou temporária, existindo basicamente dois tipos de controle: no telhado e em áreas impermeáveis.

- Detenção no local: formada por pequenos reservatórios que têm como função o armazenamento temporário. Utilizado para áreas restritas e próximas ao local de instalação do reservatório como condomínios e pequenos loteamentos.

A contenção das águas a jusante tem por finalidade o controle advindo de áreas significativas das bacias. A detenção dos escoamentos amortece os picos de vazão por meio da reservação temporária de certo volume escoado. Os dispositivos utilizados neste tipo de contenção são classificados em "in line", quando o reservatório está situado em série com a linha principal de drenagem, ou "off line", situação na qual a bacia está em paralelo com a linha principal de drenagem (PORTO, 2002; CANHOLI, 2005; MATIAS, 2006).

Os dispositivos de detenção locados em série e em paralelo à rede drenagem apresentam peculiaridades. As bacias locadas "off line" apresentam em geral menores dimensões, uma vez que nem todo o volume escoado afluirá ao dispositivo, exigem menores custos de manutenção - por serem menos afetados pela acumulação de sedimentos. As bacias posicionadas em série apresentam como característica principal o fato de todo o escoamento por elas passarem. As bacias locadas em série são mais favoráveis à manutenção de lâmina d'água e possuirão volume de espera para detritos geralmente maior que as bacias em paralelo. Matias (2006) em seus estudos apresenta hidrógrafas características para ambas localizações de bacias.

Dentre as características dos reservatórios "off line" destaca-se a entrada por meio de vertedores laterais, e em diversos casos a devolução da água à linha de drenagem necessita de bombas e/ou válvulas controladoras após redução do pico de vazão (CANHOLI, 2005). Canholi (2005) cita como principal exemplo deste tipo de dispositivo alguns túneis-reservatórios subterrâneos da cidade de Tóquio Np Japão.

A prática de detenção de águas é bastante difundida no tocante ao aproveitamento hidrelétrico e reservatórios voltados para múltiplos usos. Canholi (2005) alertou para o caráter multidisciplinar adquirido na reservação de águas pluviais, 
já que as obras destinadas à solução dos problemas de drenagem devem harmonizar com o ambiente e comunidade na qual estão inseridas.

As obras de contenção de escoamentos a jusante são classificadas em bacias de detenção, bacias de retenção e bacias de sedimentação. As bacias de detenção caracterizam-se por armazenar temporariamente os escoamentos, sendo dimensionadas para permanecerem secas durante os períodos de estiagem. O tempo de detenção dos escoamentos está relacionado à máxima vazão afluente e com o volume a ser armazenado. As bacias de retenção são dimensionadas para sempre apresentarem volume de água. Este tipo de reservatório possui a propriedade de atender a outros fins além de amortecerem os picos de fluxos. Já as bacias de sedimentação têm como principal função a retirada de sólidos em suspensão, detritos e absorção de poluentes carreados pela água pluvial (PORTO, 2002; CANHOLI, 2005).

\subsection{Bacias de detenção}

Criar a jusante dos novos loteamentos urbanos bacias de detenção de águas pluviais, que permitam restituir vazões compatíveis com os limites de capacidade da rede existente pode ser uma solução técnico-econômica mais vantajosa que reforçar, em plena malha urbana, os coletores existentes (MATIAS, 2006). A comprovação do fato pode ser feita de modo que a partir da mudança da vazão de entrada de água num sistema, toda e qualquer linha de drenagem a jusante do ponto de acréscimo de fluxo deverá ser redimensionada, já que terá que escoar uma vazão maior.

O objetivo principal da implantação de bacias de detenção é controlar o impacto causado pelas águas pluviais escoadas superficialmente. Estes impactos podem ser tanto de ordem quantitativa, redução dos picos de fluxos, como qualitativa, no que diz respeito à redução de sedimentos e poluentes presentes na água escoada (BERQUE \& RUPERD, 2000).

A utilização de bacias de detenção em projetos de drenagem urbana no Brasil se intensificou nas últimas duas décadas, o uso destes dispositivos se deu em maior parte pelo fato de permitirem a redistribuição temporal e atenuação dos fluxos (FONSECA \& NASCIMENTO, 2007). Dentre as vantagens da utilização de bacias de detenção cita-se: redução de custos do sistema de drenagem, uma vez que promove a redução das dimensões das galerias à jusante da bacia; mitigação da erosão em pequenos tributários; aumento do tempo de resposta do escoamento superficial a jusante e retardo do pico de vazão. 
Apesar da intensificação ocorrida na utilização de bacias de detenção apenas 7,5\% dos municípios brasileiros utilizam-nas como instrumento de drenagem urbana, este déficit faz com que cerca de $75 \%$ dos municípios despejem suas águas pluviais em cursos d'água permanentes (SANTOS et al., 2007). Matias (2006) constatou que através da construção de bacias de retenção de águas pluviais podemos contribuir à resolução de duas situações extremas e antagônicas: as cheias e as secas.

\subsubsection{Funções de bacias de detenção}

Diversas são as funções e usos das bacias de detenção, Starzed et al. (2005) citaram que na Suécia a construção de bacias de detenção englobam pelo menos oito motivos, dentre eles motivos de drenagem, proteção do solo (erosão e poluição) e demanda de água. A principal função de bacias de detenção é o controle de vazões, como no Brasil o uso destes reservatórios ainda não se encontra totalmente difundido e os problemas sanitários do país ainda são outros, pode-se afirmar que a única função a eles atribuída é o controle de enchentes (CANHOLI, 2005).

Outra função bastante conferida a bacias de detenção é o tratamento das águas drenadas. Segundo Berque \& Ruperd (2000) esta função por muitas vezes é conflitante com a principal devido ao fato de que o tempo necessário para se atingir níveis satisfatórios de remoção de poluentes é bastante superior ao tempo exigido para conter pico de vazões.

O escoamento superficial das águas pluviais ocasiona lavagem do pavimento e erosão do solo - principal meio de perda de qualidade das águas pluviais — que faz com que sólidos suspensos, nutrientes, metais pesados, matéria orgânica, óleos, gorduras, microrganismos patogênicos e outros poluentes cheguem aos corpos hídricos (MATIAS, 2006). As bacias de detenção removem os poluentes presentes na água primeiramente por meio da sedimentação e posteriormente pela atuação de algas e microrganismos (HARRELL \& RANJITHAN, 2003). Berque \& Ruperd (2000) salientaram que bacias com função de tratamento da água pluvial apresentam geometria diferenciada das demais.

Matias (2006) afirmou que as transformações ocorridas nos reservatórios que apresentam maior importância são: redução da turbidez da água (sedimentação de sólidos suspensos), variação da concentração de oxigênio da água (mediante fotossíntese, troca com a atmosfera e degradação de matéria orgânica), variação da concentração de nutrientes (sedimentação, retirada de nutrientes por zooplanctons) e 
redução de microrganismos patogênicos (decaimento celular, radiação, temperatura, competição biológica e sedimentação).

A utilização de bacias de detenção para reserva ecológica também é comum. Nesta função os reservatórios são instalados para que não ocorram mudanças bruscas nas características das águas dos corpos hídricos. Estas bacias reduzem o risco de desestabilização ecológica do local de instalação, sendo comum o recebimento e assimilação de esgotos domésticos ou industriais nas bacias destinadas a funcionarem como reserva ecológica (BERQUE \& RUPERD, 2000).

Diversas são as atividades de lazer que podem ser realizadas em reservatórios de detenção de água. Na falta de locais para práticas de esportes aquáticos as bacias, devidamente monitoradas e avaliadas as condições qualitativas da água, funcionariam como polo recreativo (BERQUE \& RUPERD, 2000).

Os reservatórios de contenção também podem ser utilizados para aspectos estéticos - com a criação de espelhos d'águas - para recarga de aquíferos subterrâneos, onde se fariam necessários estudos a despeito de possível poluição do aquífero, para melhoria da qualidade da água, para evitar o redimensionamento de galerias de águas pluviais ou para reserva de água para rega.

\subsubsection{Tipos de bacias de detenção}

As bacias de detenção/retenção podem ser caracterizadas de acordo com o aspecto como bacias a céu aberto e enterradas. A depender da configuração entre bacias e o canal de drenagem principal pode-se caracterizá-las como sendo ligadas em série ou em paralelo.

\subsubsection{Bacias a céu aberto}

As bacias a céu aberto podem ser classificadas em bacias secas ou com nível d'água permanente. As bacias secas são construídas para permanecerem cheias pequenas partes do tempo, no máximo na ordem de alguns dias, sendo todo o seu volume usado para armazenamento da água. As bacias com nível d'água permanente são concebidas de forma a terem água mesmo nos períodos de estiagem (BERQUE \& RUPERD, 2000).

Matias (2006) afirmou que para construção de bacias secas o nível mais alto do lençol freático, da região, não deve exceder a cota de fundo do reservatório podendo, em caso contrário, haver o surgimento de zonas pantanosas. 
Para Matias (2006) a concepção de bacias com nível de água permanente deve ser realizada de maneira cautelosa, pois o balanço entre as afluências e efluências pode gerar problemas. A autora enfatiza que este balanço deve ser bem realizado, de outro modo níveis quali-quantitativos indesejáveis serão alcançados. Harrell \& Ranjithan (2003) enfatizaram que bacias com nível d'água permanente apresentam maior redução nas concentrações de poluentes.

\subsubsection{Bacias enterradas}

As bacias enterradas são utilizadas em zonas densamente urbanizadas, e nestes casos é quase indispensável o uso de bombas para drenagem da água presente na bacia após os eventos chuvosos (BERQUE \& RUPERD, 2000; MATIAS, 2006).

A grande vantagem deste tipo de bacia é a não ocupação de área superficial, apesar de necessitar em geral de grandes obras civis. Nestes tipos de bacias há também a possibilidade da utilização da água presente na bacia em períodos de seca (BERQUE \& RUPERD, 2000). Canholi (2005) citou os túneis subterrâneos da cidade de Tóquio como exemplo clássico deste tipo de bacias.

\subsubsection{Estruturas hidráulicas}

\subsubsection{Estruturas de entrada}

- Vertedores laterais

O vertedor lateral é o tipo de estrutura mais utilizado como dispositivo de entrada em reservatórios locados fora da linha principal de drenagem (off-line), este proporciona a derivação do escoamento por meio de uma abertura no canal ou na galeria de drenagem. Canholi (2005) destacou três aspectos no dimensionamento dessas estruturas: perturbações do escoamento nas extremidades do vertedor, a vazão específica da soleira - podendo ser expressa pelo seu coeficiente de descarga - e o regime hidráulico da estrutura aliviada, em geral canais ou galerias. A Equação 2.1 apresenta a formulação que rege a vazão neste dispositivo.

$$
\mathrm{Q}=\mathrm{m} * \sqrt{2 * \mathrm{~g}} * \mathrm{~h}^{3 / 2} * \mathrm{~L}_{\mathrm{u}}
$$

Em que: $Q$ - vazão descarregada pelo vertedor $\left(\mathrm{m}^{3} / \mathrm{s}\right)$;

$m$ - coeficiente de descarga adimensional do vertedor;

$h$ - carga sobre o vertedor em metros;

$L_{u}$ - largura útil em metros, admitida: $\mathrm{L}_{\mathrm{u}}=\mathrm{L}-0,2 * \mathrm{~h}$; 
$L$ - largura do vertedor em metros.

\subsubsection{Estruturas de saída}

As vazões descarregadas por bacias de detenção dependem do tipo, das dimensões e do controle de saída. Os tipos usualmente empregados para as bacias de detenção são: orifícios, soleiras vertentes e tomadas perfuradas. As tomadas perfuradas são bastante difundidas nos EUA. A combinação de dois tipos destas estruturas gera estruturas de controle mistas, que alteram as características do hidrograma efluente (CANHOLI, 2005).

Em geral ocorre a adoção de orifícios no fundo dos reservatórios sendo complementado por outros orifícios ou soleiras livres em cotas superiores. O nível máximo d'água deve ser garantido com o uso de vertedores de soleiras livres (CANHOLI, 2005).

As bacias off-line apresentam dois tipos de saída. A primeira por gravidade saída que pode ser controlada por comportas, assemelhando-se aos casos de bacias online, ou saída por orifício até que se atinja o nível do vertedor de soleira - o outro tipo de saída ocorre por meio de bombeamento ao passo que o nível d'água situa-se abaixo do nível da canalização. Para verificações das vazões efluentes a jusante visto que as vazões são muito pequenas, só interessa a curva de vazões no estado inicial (CANHOLI, 2005).

- Orifícios extravasores

São regidos pela lei de descarga dada na Equação 2.2, válida para condições de entrada afogada, situações ocorridas quando a altura d'água supera em pelo menos $20 \%$ a altura do orifício.

$$
Q=k_{0} * a_{0} * \sqrt{2 * g * h}
$$

Equação 2.2

Na qual: $Q$ - vazão descarregada pelo orifício $\left(\mathrm{m}^{3} / \mathrm{s}\right)$;

$k_{0}$ - coeficiente de descarga adimensional do orifício;

$a_{0}$ - área da seção do orifício $\left(\mathrm{m}^{2}\right)$;

$g$ - aceleração da gravidade assumida como $9,81 \mathrm{~m} / \mathrm{s}^{2}$;

$h$ - altura da lâmina d'água, medida a partir do eixo central do orifício, ou ainda diferença de nível d'água para situações na qual a saída está afogada (m).

Tomaz (2002) apresentou valores para determinação dos valores do coeficiente de descarga de orifícios variando de acordo com a dimensão predominante do orifício e a carga hidráulica. 
- Galerias de fundo

O escoamento em galerias de fundo pode ocorrer em seção plena ou não. Três são as condições básicas do escoamento nestas estruturas: o escoamento se dará em seção plena caso o controle do escoamento esteja à jusante - a saída do dispositivo encontre-se afogada - ou em casos que a tubulação possua comprimento suficientemente longo. $\mathrm{O}$ dispositivo possuirá escoamento em seção não plena caso a entrada do bueiro não se encontre afogada e a tubulação seja considerada curta. O limite estipulado por Chow (1959) para a entrada se encontrar não afogada é da lâmina d'água não ultrapassar 1,5 da altura útil do dispositivo. Em casos nos quais a declividade da tubulação seja menor que a declividade crítica do escoamento e o comprimento seja suficientemente longo este escoamento se dará em seção plena. Chow (1959) apresenta as condições pormenorizadas de escoamento em seus estudos.

- Vertedores de soleira livre

Apesar de usualmente serem retangulares, podem assumir formas trapezoidais, triangulares, circulares e parabólicas. Podem possuir soleiras delgadas ou espessas, sendo esta definição atribuída de acordo com a lâmina vertente e a espessura do vertedor (PORTO, 2004). A lei de descarga de vertedores de soleira livre é dada pela Equação 2.3.

$Q=c_{v} * l_{u} * \sqrt{2 * g} * H^{3 / 2}$

Equação 2.3

Em que: $Q$ - vazão descarregada pelo vertedor $\left(\mathrm{m}^{3} / \mathrm{s}\right)$;

$c_{v}$ - coeficiente de vazão adimensional da soleira;

$l_{u}$ - comprimento útil da soleira em metros;

$g$ - aceleração da gravidade assumida como $9,81 \mathrm{~m} / \mathrm{s}^{2}$;

$H$ - carga total acima da soleira - carga cinética e carga estática - medida em metros

O coeficiente de escoamento das soleiras depende do tipo de soleira, das condições de aproximação lateral e da relação entre a carga total - carga estática e cinética - e a altura da soleira em relação ao nível de fundo do reservatório.

Os vertedores são tidos como de soleira delgada sempre que a área de contato do escoamento é pouco significativa se comparada à carga estática, em geral estabelece-se que para espessuras de parede inferior a 2/3 da carga. Já os vertedores de parede espessa, cuja espessura da parede é maior que $2 / 3$ da carga, possuem aderência entre o escoamento e o plano horizontal da soleira. Para soleiras que possuam espessura maior 
que o dobro da carga estática a montante o vertedor é considerado francamente espessa. Os vertedores de soleira espessa são mais comuns em bacias de detenção — tanto como estruturas de entrada e de saída - e são empregados para vazões sensivelmente maiores que estruturas com soleira delgada (TOMAZ, 2002; PORTO, 2004; CANHOLI, 2005).

- Vertedores de emergência

São em geral vertedores de parede espessa com borda livre acima da cota máxima de projeto - Tucci et al. (1995) recomendaram borda livre destas estruturas variando entre 30 e $60 \mathrm{~cm}$.

- Tomada vertical perfurada

São estruturas bastante comuns em bacias de detenção nos EUA. A tomada é constituída normalmente por um tubo perfurado, que pode ou não possuir orifício regulador de vazão - disposto no fundo do tubo. McEnroe et al. (1988), apud Canholi (2005), mostraram que a lei de descarga é da forma apresentada na Equação 2.4 (para valores nos quais a altura d'água é maior que a altura do trecho perfurado):

$$
Q=c_{s} * \frac{2 * A_{s}}{3 * h_{s}} * \sqrt{2 * g} * h^{3 / 2}
$$

Equação 2.4

Em que: $Q$ - vazão descarregada pela tomada vertical $\left(\mathrm{m}^{3} / \mathrm{s}\right)$;

$c_{s}$ - coeficiente adimensional de vazão dos furos laterais;

$A_{s}$ - área total dos furos na coluna $\left(\mathrm{m}^{2}\right)$;

$g$ - aceleração da gravidade assumida como $9,81 \mathrm{~m} / \mathrm{s}^{2}$;

$h_{s}$ - altura do trecho perfurado (m);

$h$ - altura da lâmina d'água (m).

- Reguladores de controle

Estruturas mecânicas ou autorreguláveis que baseadas no nível d'água do sistema controlam as vazões efluentes. Dentre os dispositivos Tucci et al. (1995) listaram: comportas móveis com controle de nível, válvulas controladas por flutuadores, escoamento regulados por bombas e sistemas de comportas controlados por sensores de nível ou controles remotos.

\subsubsection{Operação e manutenção}

A eficiência e vida útil dos reservatórios estão intimamente ligadas à operação e manutenção. Desde a fase de planejamento deve-se pensar em custos e facilidades de operação e manutenção de todas as estruturas presentes em bacias de detenção. 
ASCE (1992), apud Canholi (2005), citou que dentre os critérios de projetos de bacias de detenção devem estar: garantir o funcionamento hidráulico e a integridade física das estruturas por toda vida útil da obra; evitar a infestação por insetos; garantir a segurança e o conforto dos visitantes; preservar o aspecto visual agradável; permitir a utilização múltipla.

Os aspectos operacionais das bacias de detenção devem levar em conta ainda o controle da qualidade da água. Apesar do Brasil ainda apresentar outros problemas sanitários, espera-se que num futuro estas estruturas sirvam para o controle da qualidade das águas que afluem a corpos receptores. Os dispositivos implantados nas bacias de detenção devem facilitar a remoção de diversos poluentes e/ou contaminantes.

No que diz respeito à manutenção da qualidade das águas escoadas para reservatórios, Canholi (2005) afirmou que no processo de gerenciamento destas estruturas, nos países desenvolvidos, medidas complementares que permitam melhorias da qualidade da água estão sendo adotadas.

Dentre as medidas de projeto que auxiliam a manutenção das bacias de detenção Canholi (2005) destacou:

- Previsão de acessos ao fundo do reservatório e seus dispositivos de entrada e saída - estes acessos devem permitir a entrada de caminhões pesados e escavadeiras;

- Instalação de dispositivos que permitam a drenagem total de bacias com espelho d'água permanente, permitindo remoção de sedimentos desta;

- Em bacias com espelho d'água permanente devem-se restringir lâminas que auxiliem a proliferação de plantas aquáticas;

- Introdução de patamares em bacias destinadas a diversos usos, de maneira que apenas eventos menos frequentes inundem áreas destinadas à recreação;

- Em reservatórios destinados a usos múltiplos devem ser implantadas medidas que alertem os frequentadores das áreas de lazer sempre que forem previstos eventos chuvosos intensos;

- Devem ser previstos sistemas de ventilação e iluminação em reservatórios subterrâneos;

Tomaz (2002) citou normas, tomadas como padrão, no Estado de New Jersey nos Estados Unidos como boas medidas de manutenção de reservatórios de detenção. Dentre estas se listam: inspeção e remoção de detritos com periodicidade máxima de 6 meses aos dispositivos que compõe o sistema e aparo de vegetação com periodicidade máxima de 1 ano. 
Dentre os critérios operacionais de reservatórios de detenção deve-se atentar para proliferação de insetos e possíveis vetores, garantir segurança e conforto a visitantes e transeuntes e apresentar aspecto visual agradável (TOMAZ, 2002).

A vida útil e o bom funcionamento de bacias de detenção estão intimamente ligados aos critérios operacionais e às medidas de manutenção adotadas. Desta forma é imprescindível que um projeto desta natureza apresente critérios condizentes com a realidade enfrentada na localidade protegida e um programa de manutenção adequado à realidade financeira do órgão gestor.

\subsection{MODELOS DE CÁLCULO}

Diversos são os métodos empregados para cálculo dos volumes de detenção, neste escopo, segundo Porto (2002), as diferenças nos métodos de cálculo e os critérios hidráulico-hidrológicos aparecem como problemas básicos. Diversos são os trabalhos que abordam estas discussões, apresentando aplicações específicas ou generalistas, estabelecendo relações diretas entre o volume reservado e as principais variáveis hidrológicas.

O cálculo de volumes detidos em bacias de detenção pode ser realizado com auxílio de metodologias puramente hidrológicas ou métodos hidráulico-hidrológicos. As proposições hidrológicas são baseadas em métodos chuva-vazão, e levam em consideração o uso do solo em condições anterior e posterior à urbanização, enquanto que métodos hidráulico-hidrológicos levam em consideração as condições de controle das estruturas de saída.

Porto (2002) afirmou que os métodos para determinação dos volumes detidos são, geralmente, baseados em alguns parâmetros como: a razão entre a vazão de pico antes e após a urbanização, a razão entre os tempos de pico das vazões efluentes e afluentes e o volume escoado após a urbanização da área drenada.

McCuen (1989) citou que em diversos Estados norte-americanos é comum determinar o volume reservado de forma que a máxima vazão efluente seja igual à vazão local nas condições anteriores à urbanização.

É importante ressaltar que tanto o modelo estudado, quanto os métodos para cálculo do volume de detenção dos métodos apresentados nas próximas seções se enquadram, a não ser que seja indicado, na categoria de métodos reservatórios locados in-line à linha de drenagem principal. 


\subsubsection{Métodos hidrológicos}

\section{Método generalizado}

Recomendado para fase de planejamento das ações, levando em consideração hidrograma afluente com forma triangular, com tempo de pico igual ao tempo de concentração e com tempo de base numericamente igual a duas vezes o tempo de concentração (MCCUEN, 1989).

Este método utiliza como parâmetros as relações mostradas na Equação 2.5 e na Equação 2.6.

$$
\begin{gathered}
\alpha=\frac{Q_{p b}}{Q_{p a}} \\
\gamma=\frac{T_{p b}}{T_{p a}}=\frac{T_{c b}}{T_{c a}}
\end{gathered}
$$

Nas quais: $Q_{p b}$ - pico de vazão anterior à urbanização;

$Q_{p a}-$ pico de vazão posterior á urbanização;

$T_{p b}$ - tempo de pico anterior à urbanização;

$T_{p a}$ - tempo de pico posterior à urbanização;

$T_{c b}$ - tempo de concentração anterior à urbanização;

$T_{c a}$ - tempo de concentração posterior à urbanização.

A razão entre os volumes armazenado $\left(V_{s}\right)$ e volume escoado após a urbanização $\left(V_{a}\right)$ pode ser escrita na forma da Equação 2.7 e da Equação 2.8. As variáveis $V_{s}$ e $V_{a}$ devem estar em unidades compatíveis de volume.

Para situações nas quais $\alpha<2-\gamma$ :

$$
\frac{V_{s}}{V_{a}}=\frac{\gamma+\alpha+\alpha * \gamma *(\alpha+\gamma+4)}{\gamma-\alpha}
$$

Equação 2.7

Para casos onde $\alpha \geq 2-\gamma$ :

$$
\frac{V_{s}}{V_{a}}=\frac{\gamma-\alpha}{\gamma+\alpha}
$$

Equação 2.8

A apresentação gráfica do método generalizado é apresentada na Figura 2.1. 


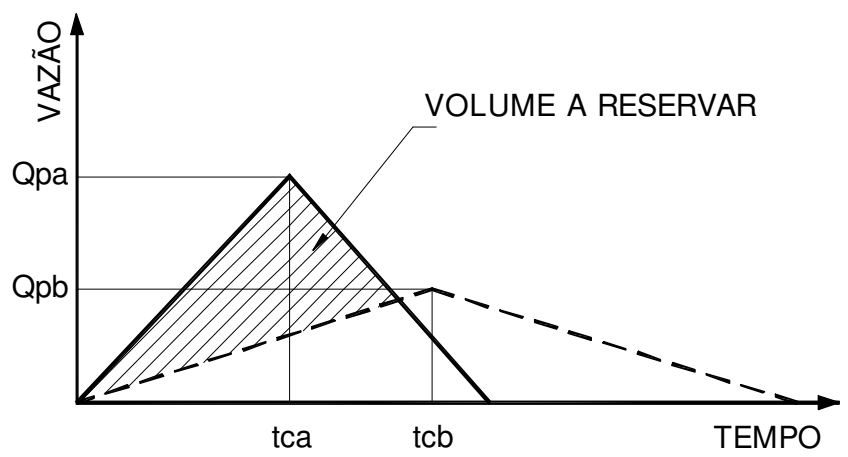

Figura 2.1: representação gráfica da aplicação do método generalizado para estimativa do volume retido (Fonte: MCCUEN, 1989).

Para a Equação 2.8 o pico de vazão do hidrograma efluente ocorre após o tempo em que os dois hidrogramas se interceptam, enquanto que para a Equação 2.7 ocorre antes do tempo em que os dois hidrogramas se cruzam. No caso em que $\alpha=2-\gamma$, o tempo de pico do hidrograma efluente ocorre na intersecção dos dois gráficos, e a Equação 2.8 resume-se a Equação 2.9.

$$
\frac{V_{s}}{V_{a}}=\gamma-1=1-\alpha
$$

Equação 2.9

\section{Método do hidrograma da fórmula racional}

Possui como principal vantagem a facilidade e popularidade do método racional. Possui como limitações as mesmas observadas na aplicação da fórmula racional para cálculo de vazões. O volume armazenado é representado graficamente na Figura 2.2.

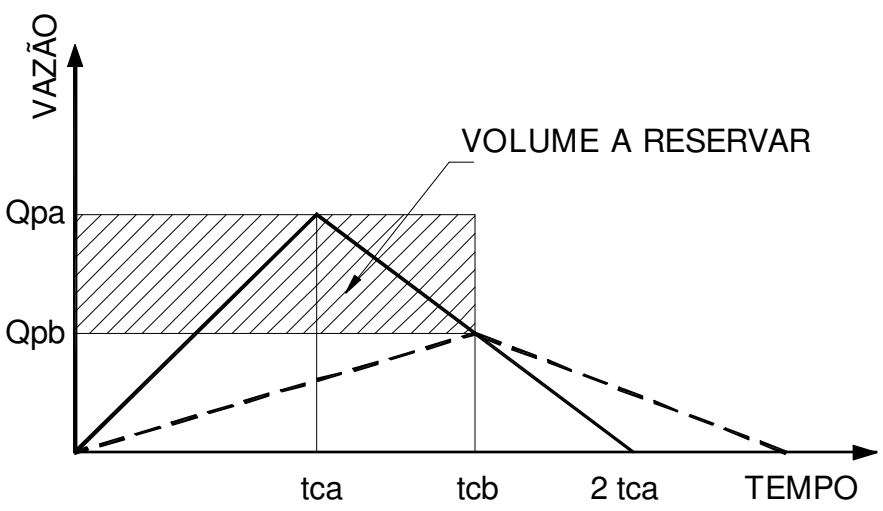

Figura 2.2: representação gráfica da estimativa do volume detido resultante do emprego do método da fórmula racional (Fonte: PORTO, 2002).

O volume de detenção, que pode ser deduzido da Figura 2.2, é exibido na Equação 2.10. 


$$
V_{s}=\left(Q_{p a}-Q_{p b}\right) * t_{c b}
$$

Em que: $V_{s}$ - volume de denteção;

$Q_{p b}$ - pico de vazão anterior à urbanização;

$Q_{p a}-$ pico de vazão posterior á urbanização;

$t_{c b}$ - tempo de concentração anterior à urbanização;

\section{Metodologia de Baker (1979)}

Nesta proposta o tempo onde ocorre a máxima vazão efluente é o ponto de cruzamento das hidrógrafas afluente e efluente. Apresenta resultados aceitáveis quando aplicado a pequenas áreas de drenagem - áreas menores que 200 acres (PORTO, 2002). É, portanto, um caso particular do método generalizado. A formulação deste método pode ser observada na Equação 2.9 e a Figura 2.3 representa graficamente a metodologia.

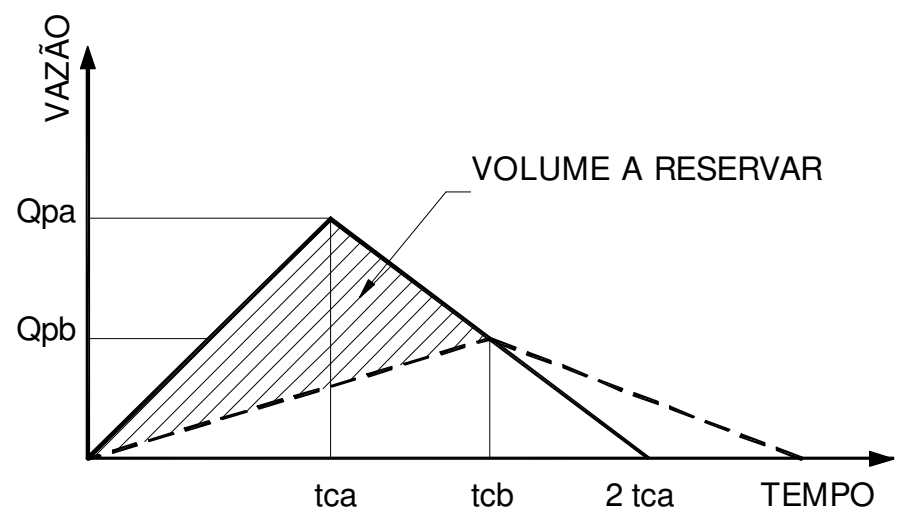

Figura 2.3: representação gráfica da utilização do método de Baker (1979) para estimativa do volume detido (Fonte: PORTO, 2002).

\section{Método de Abt e Grigg (1978)}

Este método assume que o hidrograma de vazão afluente é triangular, possuindo apenas um pico de vazão, sendo a hidrógrafa efluente assumida como trapezoidal (Figura 2.4). Os ramos iniciais dos hidrogramas são assumidos coincidentes até que se atinja o ponto de vazão de pico anterior à urbanização. Para cálculo do volume de detenção pode-se fazer uso da Equação 2.11 e da Equação 2.12, nas quais é necessário definir a relação entre a máxima vazão afluente e a vazão de pico $(\alpha)$.

$$
V_{s}=\left(\frac{1+m}{2}\right) * Q_{p a} * t_{c a} *(1-\alpha)^{2}
$$

Ou ainda: 
$\frac{V_{s}}{V_{a}}=(1-\alpha)^{2}=\left(1-\frac{Q_{p b}}{Q_{p a}}\right)^{2}$

Equação 2.12

Em que: $V_{s}$ - volume a ser detido;

$V_{a}$ - volume afluente ao dispositivo de detenção;

$m$ - a razão entre o tramo de recessão do hidrograma afluente e o seu tempo de pico;

$\alpha$ - relação entre as vazões anterior e posterior à urbanização;

$Q_{p b}$ - pico de vazão anterior à urbanização;

$Q_{p a}-$ pico de vazão posterior á urbanização;

$t_{c a}$ - tempo de concentração posterior à urbanização;

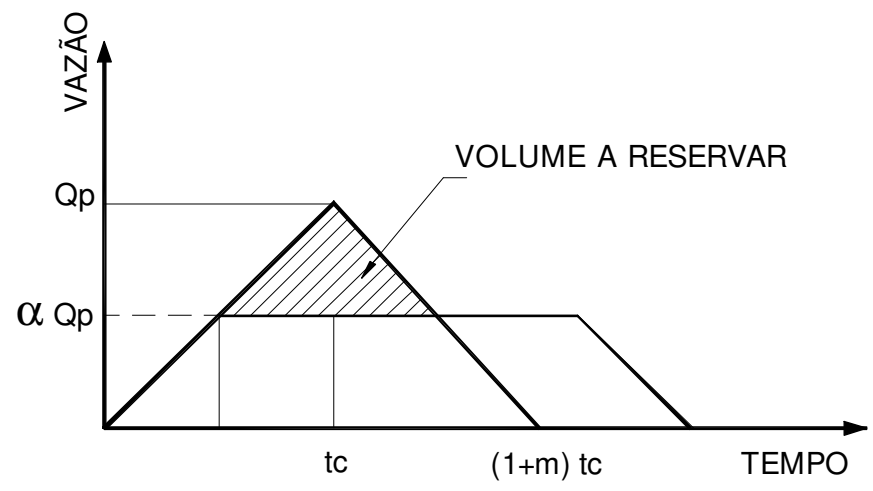

Figura 2.4: representação gráfica para estimativa do volume de detenção proposto por Abt e Grigg (adaptado de: ABT E GRIGG, 1978).

\section{Formulação de Wycoff e Singh (1976)}

Desenvolvido por análise de regressão múltipla de 50 experimentos computacionais do trânsito de hidrogramas de cheias em pequenas bacias de detenção o cálculo do volume de detenção desenvolvido por Wycoff e Singh (1976) dá-se conforme a Equação 2.13.

$$
\frac{V_{s}}{V_{a}}=\frac{1,291 *(1-\alpha)^{0,753}}{\left(T_{b} / T_{p}\right)^{0,411}}
$$

Na qual: $V_{s}$ - volume a ser detido;

$V_{a}$ - volume afluente ao dispositivo de detenção;

$\alpha$ - relação entre as vazões anterior e posterior à urbanização;

$T_{b}$ - tempo de base do hidrograma afluente;

$T_{p}$ - tempo de pico do hidrograma afluente; 


\section{Fórmula de Wilken (1978)}

Baseada na metodologia de Müller - Neuhaus, a formulação proposta apresenta como característica principal a presença de um fator de volume, definido através da relação entre a vazão de entrada e a vazão de saída. O fator de volume é apresentado na Equação 2.14, enquanto que o volume de detenção calculado de acordo com Wilken (1978) pode ser avaliado na Equação 2.15.

$$
K=\log \frac{1}{\xi}
$$

Em que: $\xi$ - é definido como a relação entre a vazão efluente máxima e a vazão afluente máxima à bacia.

$$
V=K * Q_{a} * t_{d}
$$

Na qual: $Q_{a}$ - vazão máxima afluente ao dispositivo de detenção de águas pluviais $\left(\mathrm{m}^{3} / \mathrm{s}\right)$;

$t_{a}$ - é o tempo de duração da chuva (s).

\section{Método de Tsuchiya (1978)}

A formulação de Tsuchiya (1978), citada por Franco (2004), desenvolvida para bacias com área de drenagem entre 0,001 e 0,2 $\mathrm{km}^{2}$, a partir de dados de bacias japonesas, pode ser vista na Equação 2.16.

$$
V=0,0028 *\left(i_{i}-\frac{i_{0}}{2}\right) * t_{d} * C * A
$$

Em que: $i_{i}$ - intensidade da precipitação em $\mathrm{mm} / \mathrm{h}$;

$i_{0}$ - intensidade da chuva que gera a máxima vazão efluente à bacia $(\mathrm{mm} / \mathrm{h})$;

$t_{d}$ - é o tempo de duração da chuva em minutos;

$C$ - coeficiente adimensional de escoamento do método racional;

$A$ - área de drenagem contribuinte ao dispositivo de detenção.

\section{Formulação de Maidment (1992)}

Maidment (1992) definiu um modelo de cálculo de volumes de detenção baseado no método racional, partindo do princípio que para pequenas áreas não se justifica a aplicação de modelos complexos para cálculo dos volumes retidos. Os parâmetros utilizados nesta formulação são de simples obtenção. 
Nesta metodologia o volume armazenado é estimado através da subtração do volume efluente à bacia do volume afluente à mesma. Sendo os volumes afluentes e efluentes calculados de acordo com a Equação 2.17 e a Equação 2.18 respectivamente.

$$
\begin{gathered}
V_{a}=\frac{C * i * A * t}{3,6} \\
V_{e}=k * Q_{e} * t
\end{gathered}
$$

Equação 2.18

Em que: $V_{a}$ - volume afluente ao reservatório $\left(\mathrm{m}^{3}\right)$;

$C$ - coeficiente adimensional de escoamento do método racional;

$A$ - área de drenagem contribuinte ao dispositivo de detenção;

$t$ - é o tempo de duração da chuva em unidades de hora;

$i$ - intensidade da chuva de projeto $(\mathrm{mm} / \mathrm{h})$;

$V_{e}$ - volume efluente à bacia de detenção $\left(\mathrm{m}^{3}\right)$;

$k$ - fator de ajuste, dependente da relação entre a vazão efluente e a máxima vazão afluente;

$Q_{e}$ - vazão efluente ao reservatório de detenção $\left(\mathrm{m}^{3} / \mathrm{h}\right)$.

\section{Equação de Tucci (1998)}

Tucci (1998) desenvolveu um método baseado na diferença entre os volumes afluentes e efluentes. Para áreas pequenas o volume de detenção é dado pela Equação 2.19 .

$$
V_{s}=Q_{d} * t_{d} *\left(1-\frac{Q_{a}}{Q_{d}}\right)
$$

$V_{s}$ - volume de detenção $\left(\mathrm{m}^{3}\right)$;

$Q_{d}$ - vazão de pós-urbanização da área drenada $\left(\mathrm{m}^{3} / \mathrm{s}\right)$;

$T_{d}$ - duração do evento crítico em segundos;

$Q_{a}$ - vazão efluente máxima à bacia de detenção $\left(\mathrm{m}^{3} / \mathrm{s}\right)$.

\section{Formulação de Tucci (2002)}

Esta formulação foi desenvolvida com base nos estudos de Tucci (2000), estudos que abordam a duração crítica da chuva, com hidrogramas retangulares. A formulação proposta por Tucci (2002) foi desenvolvida para a cidade de Curitiba. O volume específico esperado para uma bacia é dada pela Equação 2.20.

$$
v=2,456 * T_{r}^{0,332} * A_{i}
$$


Na qual: $v$ - volume específico $\left(\mathrm{m}^{3} / \mathrm{min} . h a\right)$;

$T_{r}$ - é o tempo de retorn em anos, para o qual é dimensionado o dispositivo; $A_{i}$ - é a parcela da área impermeabilizada.

\section{Método de Matias (2006)}

O método de Matias (2006) é baseado no esvaziamento da bacia após o evento chuvoso. O método pressupõe que o volume máximo de armazenamento ocorre após o término do evento chuvoso e que o tempo que resultará o máximo volume armazenado pelo reservatório será, portanto, maior que o tempo de duração da chuva. Para tanto se utilizam sucessivas aproximações do tempo de máximo armazenamento da bacia de detenção.

O volume inicial do método proposto por Matias (2006) é o volume a ser armazenado no momento em que a chuva cessa, e a partir de então sendo realizadas sucessivas aproximações no tempo e no volume máximo de reserva. O volume máximo, obtido quando o volume $V_{n+1}$ é menor que o volume $V_{n}$, e $V_{n}$ é definido como o volume a ser reservado. A estimativa inicial do tempo de chuva é dada pela Equação 2.21, enquanto que a estimativa do volume é realizada com auxílio da Equação 2.22.

$$
\begin{gathered}
t=\frac{\left(Q_{p a}-Q_{p d}\right) * t_{c}}{Q_{p a}}+t_{d} \\
V=\left(Q_{p a} * t_{d}\right)-\left(\frac{Q_{p a} * t_{c}}{2}\right)+Q_{p a} * \frac{\left[\left(-t^{2}\right)+2 *\left(t_{c}+t_{d}\right) * t-t_{d} *\left(2 * t_{c}+t_{d}\right)\right]}{2}-Q_{p b} * t
\end{gathered}
$$

Equação 2.22

Nas quais: $t$ - duração da precipitação que gera o maior volume de detenção em segundos;

$Q_{p a}$ - vazão de pós-urbanização da área de drenagem $\left(\mathrm{m}^{3} / \mathrm{s}\right)$;

$Q_{p b}$ - vazão de pico das condições anteriores à urbanização $\left(\mathrm{m}^{3} / \mathrm{s}\right)$;

$t_{c}$ - tempo de concentração da bacia hidrográfica (s);

$t_{d}$ - tempo de duração do evento chuvoso (s).

\section{Método Holandês (MATIAS, 2006)}

Método baseado em curvas IDF, que permite calcular o máximo volume a ser armazenado numa bacia resultante de uma chuva crítica, garantindo a passagem da máxima vazão efluente do reservatório. A formulação foi desenvolvida para curvas IDF do tipo apresentado na Equação 2.23.

$$
I=\frac{a}{60} * t^{b}
$$


Para a qual: $I$ - é a intensidade de precipitação em $\mathrm{mm} / \mathrm{min}$;

$a$ e $b$ - são constantes dependentes do local e do tempo de retorno;

$t$ - é o tempo da precipitação em minutos.

O tempo da chuva crítica para o método holandês é obtido através da igualdade da derivada da lâmina precipitada em relação ao tempo. A Equação 2.24 permite calcular o tempo da chuva crítica (em minutos) em função da máxima vazão afluente (1/min), da área de drenagem $\left(\mathrm{m}^{2}\right)$ e das constantes da curva IDF adotada para o cálculo.

$$
t_{M}=\left[\frac{60 * q}{a *(b+1) * A * C}\right]^{1 / b}
$$

Equação 2.24

$q$ - vazão efluente ao dispositivo de drenagem ( $\mathrm{mm} / \mathrm{min})$;

$C$ - coeficiente adimensional de escoamento do método racional;

$A$ - área de drenagem contribuinte ao dispositivo de detenção;

O volume de armazenamento pode ser estimado através, utilizando o método holandês, da Equação 2.25.

$$
V_{a}=-\frac{b * q}{1+b} *\left[\frac{60 * q}{a *(b+1) * A * C}\right]^{1 / b}
$$

Equação 2.25

Para a qual: $V_{a}$ - volume estimado para armazenamento das águas pluviais (l);

\section{Método Numérico}

O método numérico para estimativa do volume de detenção utilizado é baseado no método das diferenças finitas. A teoria utilizada para determinação do volume armazenado foi a do balanço de massa, com auxílio da equação da continuidade. A Equação 2.26 reflete a equação do balanço de massa envolvido no processo. Para tal foram desconsideradas perdas por infiltração, evaporação ou qualquer forma de retirada de água do sistema que não seja a vazão efluente.

$$
\Delta V_{t}=Q_{a_{t}}-Q_{e_{t}}
$$

Equação 2.26

Na qual: $\Delta V$ - variação do volume para um tempo qualquer $\left(\mathrm{m}^{3}\right)$;

$Q_{a t}$ - vazão afluente ao reservatório num instante qualquer $\left(\mathrm{m}^{3}\right)$;

$Q_{e t}$ - vazão efluente à bacia num tempo qualquer $\left(\mathrm{m}^{3}\right)$.

Para cálculo do volume reservado no dispositivo de detenção procedeu-se a um algoritmo simplificado de integração numérica. Cada espaço de tempo $\Delta t$ possui uma 
variação $\Delta V$ correspondente, procedendo-se iterativamente a soma de cada variação de volume sofrida estima-se o tamanho do reservatório. $\mathrm{O}$ volume estimado para o reservatório é numericamente igual ao máximo valor encontrado na soma de cada variação de volume. A Equação 2.27 apresenta a rotina implementada para cálculo do volume.

$$
V_{n}=V_{n-1}+\Delta V_{n}
$$

Para a qual: $V_{n}$ - é o volume total da aproximação $n$;

$V_{n-1}$ - volume total da aproximação $n-1$;

$\Delta V_{n}-$ variação do volume da aproximação $n$.

\section{Método da Federal Aviation Administration - FAA}

Método baseado na fórmula racional e recomendado para áreas pequenas. Desenvolvida em 1970 pela Federal Aviation Administration estima o volume de detenção pelo balanço de massa entre o volume de entrada e o efluente ao reservatório de detenção. Guo (1999) citou como locais onde se recomenda a utilização desta formulação os estacionamentos e as bacias de detenção/retenção com pequenas áreas de drenagem.

Neste método o hidrograma afluente é representado por um trapézio isósceles, com tramos de ascensão e recessão iguais ao tempo de concentração da bacia. $\mathrm{O}$ hidrograma efluente é considerado triangular. A Equação 2.28 mostra como é estimado o volume de detenção por esta metodologia.

$$
V=\left[\alpha * \frac{C * I_{d} * A * t_{d}}{N_{1}}-\frac{Q_{a}}{2} *\left(t_{d}+t_{c}\right)\right]
$$

Para a qual: $V$ - volume estimado para detenção do escoamento $\left(\mathrm{m}^{3}\right)$;

$\alpha$ - é o fator de atenuação entre a máxima vazão afluente e efluente;

$C$ - coeficiente adimensional de escoamento do método racional;

$A$ - área de drenagem contribuinte ao dispositivo de detenção;

$I_{d}$ - é a intensidade de precipitação de projeto $(\mathrm{mm} / \mathrm{h})$;

$t_{d}$ - tempo de duração da precipitação (s);

$N_{l}$ - coeficiente de conversão de unidades, que para $I_{s}$ em $\mathrm{mm} / \mathrm{h}, Q_{a} \mathrm{em} \mathrm{m} 3 / \mathrm{s}$ e $A$ em $\mathrm{km}^{2}$ vale 3,6;

$Q_{a}$ - vazão efluente ao reservatório de detenção $\left(\mathrm{m}^{3} / \mathrm{s}\right)$;

$t_{c}$ - tempo de concentração da área drenada (s). 


\section{Método Soil Conservation Service (1986)}

Método bastante difundido entre projetistas utiliza o método do hidrograma unitário do SCS para estimar o volume de detenção. Esta metodologia utiliza ábacos para cálculos das vazões e dos volumes a serem armazenados. Como é comum nos Estados Unidos a vazão máxima efluente é determinada pelas condições de préurbanização da área de drenagem.

Este procedimento correlaciona a capacidade de armazenamento de uma bacia hidrográfica a um valor denominado "Curve Number" - CN. O CN de uma bacia depende de variáveis como: tipo de solo, condições de uso e ocupação do solo, condições antecedentes de umidade do solo. A capacidade máxima de retenção do solo é mostrada na Equação 2.29.

$$
S=\frac{25400}{C N}-254
$$

Equação 2.29

Em que: $S$ - é o armazenamento potencial de água no solo da bacia ( $\mathrm{mm})$;

$C N$ - é o coeficiente adimensional que agrega as características da bacia, variando entre 0 e 100 .

Para cálculo do valor do "Curve Number" recorre-se à classificação hidrológica dos solos. Os solos podem ser classificados, de acordo com suas características, em 4 grupos hidrológicos. Sartori et al. (2005) classificaram hidrologicamente os solos do modo que segue:

Grupo hidrológico A: solos com profundidade maiores que 2 metros, podendo possuir profundidades entre 1 e 2 metros, com altas taxas de infiltração, alto grau de resistência e tolerantes à erosão. Estes são solos de textura argilosa ou muito argilosa — com estrutura que proporciona alta macroporosidade - possuem baixo gradiente textural, apresentando textura média. São de bem a excessivamente drenados. Enquadram-se neste grupo: Latossolo Amarelo, Latossolo Vermelho amarelo, Latossolo Vermelho com textura argilosa ou muito argilosa e com alta porosidade; Latossolo Amarelo e Latossolo Vermelho Amarelo com textura média com horizonte superficial não arenoso (SARTORI et al., 2005).

Grupo hidrológico B: solos com profundidades entre 1 e 2 metros, com moderada taxa de infiltração, com resistência moderada e tolerantes à erosão. Podem possuir textura arenosa ao longo do perfil ou de textura média com horizonte superficial arenoso, de textura argilosa ou muito argilosa desde que com boa macroporosidade. 
Classificam-se neste tipo de solo: Latossolo Amarelo, Latossolo Vermelho amarelo que possuem textura média, mas com horizonte superficial de textura arenosa; Latossolo Bruno, Nitossolo Vermelho, Neossolo Quartzarênico, Argilossolo Vermelho ou Vemelho-Amarelo todos com textura arenosa/média, média/argilosa, argilosa/argilosa ou argilosa/muito argilosa que não apresentem mudança textural abrupta (SARTORI et al., 2005).

Grupo hidrológico C: solos com profundidade variando entre 0,5 e 2 metros, com baixa taxa de infiltração, baixa resistência e tolerância à erosão. Possuem gradiente textural maior que 1,5 fazendo parte deste grupo hidrológico: Argilossolo pouco profundo, sem mudança textural abrupta; Argilossolo Vermelho, Argilossolo Vermelho Amarelo e Argilossolo Amarelo todos profundos e com mudança textural abrupta; Cambissolo de textura média e Cambissolo Háplico ou Húmico com características físicas semelhantes aos latossolos; Espodossolo Ferrocárbico; Neossolo Flúvico (SARTORI et al., 2005).

Grupo hidrológico D: solos com taxa de infiltração muito baixa, com pouquíssima resistência e tolerância a erosão, em geral com profundidades menores que 0,5 metro, associados à mudanças textural abrupta aliada à argila de alta atividade. Solos orgânicos também fazem parte deste grupo. Enquadram-se neste grupo hidrológico de solo: Neossolo Litólico; Organossolo; Gleissolo; Chernossolo; Planossolo; Vertissolo, Alissolo; Luvissolo; Plintossolo; Solos de Mangue; Afloramentos de Rocha; Cambissolos não classificados no grupo C; Argilossolo Vermelho Amarelo e Argilossolo Amarelo pouco profundos (SARTORI et al., 2005).

Diversos autores já estudaram as influências das condições do solo e sua ocupação na definição do "Curve Number", para tanto o Quadro 2.1 apresenta alguns valores de "Curve Number" para bacias rurais enquanto que o Quadro 2.2 para regiões urbanas. 
Quadro 2.1: valores de "Curve Number" para regiões rurais (FONTE: TUCCI, 2001).

\begin{tabular}{|c|c|c|c|c|c|}
\hline \multirow{2}{*}{$\begin{array}{l}\text { Utilização ou } \\
\text { cobertura } \\
\text { do solo }\end{array}$} & \multirow{2}{*}{ Condições de superfície } & \multicolumn{4}{|c|}{ Tipo de solo } \\
\hline & & A & B & C & $\mathrm{D}$ \\
\hline \multicolumn{2}{|c|}{ Solo lavrado com sulcos retilíneos } & 77 & 86 & 91 & 94 \\
\hline \multicolumn{2}{|c|}{ Solo lavrado em fileiras retas } & 70 & 80 & 87 & 90 \\
\hline \multirow{3}{*}{ Culturas regulares } & Em curvas de nível & 67 & 77 & 83 & 87 \\
\hline & Terraceado em nível & 64 & 76 & 84 & 88 \\
\hline & Em fileiras retas & 64 & 76 & 84 & 88 \\
\hline \multirow{3}{*}{$\begin{array}{c}\text { Plantações de } \\
\text { cereais }\end{array}$} & Em curvas de nível & 62 & 74 & 82 & 85 \\
\hline & Terraceado em nível & 60 & 71 & 79 & 82 \\
\hline & Em fileiras retas & 62 & 75 & 83 & 82 \\
\hline \multirow{3}{*}{$\begin{array}{l}\text { Plantações de } \\
\text { legumes ou } \\
\text { cultivados }\end{array}$} & Em curvas de nível & 60 & 72 & 81 & 84 \\
\hline & Terraceado em nível & 57 & 70 & 78 & 89 \\
\hline & Pobres & 68 & 79 & 86 & 89 \\
\hline \multirow{3}{*}{ Pastagens } & Pobre, segundo as curvas de nível & 47 & 67 & 81 & 88 \\
\hline & $\begin{array}{c}\text { Normal, segundo as curvas de } \\
\text { nível }\end{array}$ & 25 & 59 & 75 & 83 \\
\hline & Boa, segundo as curvas de nível & 6 & 35 & 70 & 79 \\
\hline Prado permanente & Normal & 30 & 58 & 71 & 78 \\
\hline $\begin{array}{c}\text { Zonas sociais } \\
\text { rurais }\end{array}$ & Normal & 59 & 74 & 82 & 86 \\
\hline \multirow{2}{*}{ Estradas } & Pavimento permeável & 72 & 82 & 87 & 89 \\
\hline & Pavimento impermeável & 74 & 84 & 90 & 92 \\
\hline \multirow{5}{*}{ Florestas } & $\begin{array}{l}\text { Muito abertas ou de baixa } \\
\text { transpiração }\end{array}$ & 56 & 75 & 86 & 91 \\
\hline & Abertas ou de baixa transpiração & 46 & 68 & 78 & 84 \\
\hline & Normal & 36 & 60 & 70 & 76 \\
\hline & Densas ou de alta transpiração & 26 & 51 & 62 & 69 \\
\hline & $\begin{array}{l}\text { Muito densas ou de alta } \\
\text { transpiração }\end{array}$ & 15 & 44 & 54 & 61 \\
\hline \multicolumn{2}{|c|}{ Superfície impermeável } & 100 & 100 & 100 & 100 \\
\hline
\end{tabular}


Quadro 2.2: valores de “Curve Number” para áreas urbanas (FONTE: TUCCI, 2001).

\begin{tabular}{|c|c|c|c|c|c|}
\hline \multirow{2}{*}{\multicolumn{2}{|c|}{ Utilização ou cobertura do solo }} & \multicolumn{4}{|c|}{ Tipo de solo } \\
\hline & & A & $\mathrm{B}$ & $\mathrm{C}$ & $\mathrm{d}$ \\
\hline \multicolumn{6}{|l|}{ Zonas cultivadas } \\
\hline \multicolumn{2}{|c|}{ Sem medidas de conservação do solo } & 72 & 81 & 88 & 91 \\
\hline \multicolumn{2}{|c|}{ Com medidas de conservação do solo } & 62 & 71 & 78 & 81 \\
\hline \multicolumn{6}{|c|}{ Pastagem ou baldios } \\
\hline \multicolumn{2}{|c|}{ Em más condições } & 68 & 79 & 86 & 89 \\
\hline \multicolumn{2}{|c|}{ Em boas condições } & 39 & 61 & 74 & 80 \\
\hline \multicolumn{2}{|c|}{ Prado em boas condições } & 30 & 58 & 71 & 78 \\
\hline \multicolumn{6}{|c|}{ Bosques ou zonas florestais } \\
\hline \multicolumn{2}{|c|}{ Cobertura má, sem "Mulch" } & 45 & 66 & 77 & 83 \\
\hline \multicolumn{2}{|c|}{ Boa cobertura } & 25 & 55 & 70 & 77 \\
\hline \multicolumn{6}{|c|}{ Espaços abertos, relvados, parques, campos de golfe, cemitérios, etc. } \\
\hline \multicolumn{2}{|c|}{ Boas condições, relva cobrindo mais de $75 \%$ da área } & 39 & 61 & 74 & 80 \\
\hline \multicolumn{2}{|c|}{$\begin{array}{l}\text { Condições razoáveis, relva cobrindo de } 50 \text { a } 75 \% \text { da } \\
\text { área }\end{array}$} & 49 & 69 & 79 & 84 \\
\hline \multicolumn{2}{|c|}{$\begin{array}{c}\text { Zonas comerciais e de escritórios (85 \% de área } \\
\text { impermeável) }\end{array}$} & 89 & 92 & 94 & 95 \\
\hline \multicolumn{2}{|c|}{ Zonas industriais (72 \% de área impermeável) } & 81 & 88 & 91 & 93 \\
\hline \multicolumn{6}{|c|}{ Zonas residenciais } \\
\hline \multicolumn{2}{|l|}{ Áreas médias dos } & & & & \\
\hline$<500 \mathrm{~m}^{2}$ & $65 \%$ & 77 & 85 & 90 & 92 \\
\hline $1000 \mathrm{~m}^{2}$ & $38 \%$ & 61 & 75 & 83 & 87 \\
\hline $1300 \mathrm{~m}^{2}$ & $30 \%$ & 57 & 72 & 81 & 86 \\
\hline $2000 \mathrm{~m}^{2}$ & $25 \%$ & 54 & 70 & 80 & 85 \\
\hline $4000 \mathrm{~m}^{2}$ & $20 \%$ & 51 & 68 & 79 & 84 \\
\hline \multicolumn{2}{|c|}{ Parques de estacionamento, telhados, viadutos, etc. } & 98 & 98 & 98 & 98 \\
\hline \multicolumn{6}{|c|}{ Arruamentos e estradas } \\
\hline \multicolumn{2}{|c|}{ Asfaltadas e com drenagem de águas pluviais } & 98 & 98 & 98 & 98 \\
\hline \multicolumn{2}{|c|}{ Gravilha } & 76 & 85 & 89 & 91 \\
\hline \multicolumn{2}{|c|}{ Terra } & 72 & 82 & 87 & 89 \\
\hline
\end{tabular}

A definição dos valores do "Curve Number" dependem das condições de umidade antecedente do solo - Antecedent Moisture Conditions, AMC. Três são as condições antecedentes de umidade do solo utilizadas em projetos. Os valores de CN apresentados no Quadro 2.1 e no Quadro 2.2 são para condições antecedentes de umidade do solo normais, considerado AMC II. O Quadro 2.3 define cada condição, enquanto que o Quadro 2.4 apresenta os valores para cada condição. 
Quadro 2.3: definição das condições antecedente de umidade do solo.

\begin{tabular}{|c|l|}
\hline Condição antecedente de umidade & \multicolumn{1}{|c|}{ Definição } \\
\hline AMC I & $\begin{array}{l}\text { Condição em que o solo se encontra seco. } \\
\text { Recomendação não indicada para casos de estudos de } \\
\text { cheias. }\end{array}$ \\
\hline AMC II & $\begin{array}{l}\text { Situação média, na qual a umidade do solo corresponde } \\
\text { aproximadamente à capacidade de campo. Situação } \\
\text { considerada como provável em cheias de pequenas } \\
\text { dimensões. }\end{array}$ \\
\hline AMC III & $\begin{array}{l}\text { Situação na qual o solo local encontra-se quase saturado. } \\
\text { Esta situação propicia a formação de maiores cheias, } \\
\text { sendo a mais crítica em projetos de contenção de cheias. }\end{array}$ \\
\hline
\end{tabular}

Quadro 2.4: valores de CN para as condições antecedentes de umidade do solo (FONTE: SETZER e PORTO, 1979).

\begin{tabular}{|c|c|c|}
\hline \multirow{2}{*}{$\begin{array}{c}\text { CN para } \\
\text { AMCII }\end{array}$} & \multicolumn{2}{|c|}{ Valor corrigido de CN } \\
\hline & $\mathrm{AMCl}$ & AMCIII \\
\hline 100 & 100 & 100 \\
\hline 95 & 87 & 99 \\
\hline 90 & 78 & 98 \\
\hline 85 & 70 & 97 \\
\hline 80 & 63 & 94 \\
\hline 75 & 57 & 91 \\
\hline 70 & 51 & 87 \\
\hline 65 & 45 & 83 \\
\hline 60 & 40 & 79 \\
\hline 55 & 35 & 75 \\
\hline 50 & 31 & 70 \\
\hline 45 & 27 & 65 \\
\hline 40 & 23 & 60 \\
\hline 35 & 19 & 55 \\
\hline 30 & 15 & 50 \\
\hline 25 & 12 & 45 \\
\hline 20 & 9 & 39 \\
\hline 15 & 7 & 33 \\
\hline 10 & 4 & 26 \\
\hline 5 & 2 & 17 \\
\hline 0 & 0 & 0 \\
\hline
\end{tabular}

Setzer e Porto (1979) fizeram a seguinte definição para as condições antecedentes de umidade do solo: 
Condição I: solos relativamente secos — não prejudicam a vida da vegetação — possuindo quantidade considerável de áreas que permitam a infiltração rápida das águas pluviais.

Condição II: condição de solo mais comum, considerada intermediária entre a condição I e a II. Esta condição é normalmente verificada na estação úmida do ano.

Condição III: solo praticamente saturado, condição na qual ocorreram precipitações pesadas nos últimos 5 dias, havendo baixa evapotranspiração — condição que ocorre em geral em períodos com muita chuva ou com baixas temperaturas. Nesta condição são maiores as possibilidades de inundação nas partes mais baixas da bacia.

Chow et al. (1988) desenvolveram formulações que relacionam as condições antecedentes do solo extremas - AMC I e AMC III — com a condição normal AMC II. A Equação 2.30 relaciona as condições AMC I e AMC II, enquanto que a Equação 2.31 relaciona as condições AMC III e AMC II.

$$
\begin{aligned}
& C N(I)=\frac{4,2 * C N(I I)}{10-0,058 * C N(I I)} \\
& C N(I I I)=\frac{23 * C N(I I)}{10+0,13 * C N(I I)}
\end{aligned}
$$

Equação 2.30

Equação 2.31

A formulação que rege a vazão escoada superficialmente para o método do SCS possui um termo que leva em consideração as retenções iniciais no solo. A Equação 2.32 e a Equação 2.33 mostram respectivamente a abstração inicial e a vazão escoada calculadas a partir da metodologia do hidrograma unitário do SCS.

$$
\begin{gathered}
I_{a}=0,2 * S \\
Q=\frac{\left(P-I_{a}\right)^{2}}{\left(P-I_{a}\right)+S}
\end{gathered}
$$

Equação 2.32

Equação 2.33

Para a qual: $I_{a}$ - representa as perdas iniciais de escoamento $(\mathrm{mm})$;

$S$ - é o armazenamento potencial de água no solo da bacia (mm);

$Q$ - é o volume escoado superficialmente ( $\mathrm{mm}$ ) para uma precipitação $P(\mathrm{~mm})$.

Com os valores de $P$ e $I_{a}$ utilizando-se o método gráfico estima-se o volume de detenção para bacias de detenção. $\mathrm{O}$ volume de detenção como retro citado é estimado considerando-se a máxima vazão efluente igual à vazão de pré-urbanização.

\subsubsection{Métodos hidráulico-hidrológicos}

Estes métodos são assim conhecidos por levar em consideração não apenas características hidrológicas na estimativa do volume retido. Estes métodos tendem a ser 
mais preciso por considerarem, para cálculo do volume necessário, características dos dispositivos de saída das bacias de detenção.

Alguns métodos que possuem esta característica possuem como inconveniente a necessidade de definição de diversas características dos dispositivos hidráulicos, tal quais altura e largura de vertedores, quantidade e diâmetros de orifícios.

\section{Método de Akan (1989a)}

O processo de cálculo sugerido por Akan (1989a) para estimativa do volume de detenção é baseado num processo adimensional fundamentado na técnica do "routing" pelo reservatório e utiliza equações de armazenamento hidrológico e de escoamento em estruturas de saídas. Os resultados são apresentados em forma gráfica, sendo fruto de escolha de combinações entre os vários parâmetros dimensionais. Porto (2002) apresentou em seus estudos um procedimento melhorado desta metodologia.

\section{Método de Porto (2002)}

Porto (2002) desenvolveu uma metodologia adimensional que permite estimar o volume detido em bacias de detenção duais baseado nas características do hidrograma afluente, características do reservatório e dispositivos de saída. O autor desenvolveu alguns parâmetros adimensionais que permitem estimar com boa precisão o volume de detenção de uma bacia. Os adimensionais desenvolvidos pelo autor são mostrados na Equação 2.34, Equação 2.35 e Equação 2.36.

$$
\begin{gathered}
P=\frac{k}{i_{p}} *\left(\frac{i_{p} * t_{p}}{b}\right)^{0,5 / c} *\left(\sqrt{\frac{2 * \pi}{n}}\right)^{(0,5 / c)-1} * V^{0,5 / c} \\
B=\frac{\left(\sqrt{\frac{2 * \pi}{n} * i_{p} * t_{p}}\right)^{1 / c}}{b^{1 / c} * h_{v}} \\
E=\frac{J^{2 / 3} * h_{v}}{i_{p}{ }^{2 / 3} *\left(\sqrt{\frac{2 * \pi}{n}}\right)^{2 / 3}}
\end{gathered}
$$

Equação 2.34

Equação 2.35

Equação 2.36

Nas quais: $P$ - é um adimensional que relaciona as características de descarga do orifício, do hidrograma afluente e das características da bacia;

$B$ - é um valor adimensional função do hidrograma afluente, da topografia do reservatório e da diferença de altura entre o centro do orifício e a soleira da bacia de detenção; 
$E$ - é um adimensional que leva em conta as características do vertedor e do hidrograma efluente.

$n$ - é um parâmetro adimensional que reflete a forma do hidrograma de entrada;

$k$ - coeficiente dependente do aspecto e do tamanho da estrutura de descarga;

$i_{p}$ - vazão de pico afluente ao reservatório de detenção;

$t_{p}$ - tempo de pico do hidrograma afluente;

$b$ - coeficiente da curva cota - volume do reservatório $\left(\mathrm{m}^{3^{-c}}\right)$;

$c$ - coeficiente da curva cota - volume do reservatório - este valor varia de 1 , para paredes verticais à 2,5 em topografias urbanas;

$J$ - coeficiente que representa as constantes que permitem o cálculo da vazão num vertedor;

$h_{v}$ - altura da soleira do vertedor, medida a partir do centro geométrico do orifício.

A partir dos adimensionais definidos na Equação 2.34, na Equação 2.35 e na Equação 2.36 Porto (2002) definiu relações funcionais para o volume máximo armazenado, a máxima vazão descarregada pelo dispositivo de saída e a altura máxima da lâmina d'água no reservatório de detenção - todas em função dos parâmetros $P, B$, $E, \mathrm{n}$ e c - gerando gráficos adimensionais, para valores de $n$ variando de 4 a 10 e valores de $c$ de 1,0,1,25 e 1,5, que permitem estimar os volumes retidos.

\section{Método de Horn (1987)}

Método desenvolvido em função da estimativa de vazão de saída do reservatório, do hidrograma de entrada e das características dos dispositivos de saída. Horn (1987) desenvolveu um adimensional $N_{r}$ denominado "número de routing" para dois tipos dispositivos de saída: vertedor e orifício, que podem ser observados respectivamente na Equação 2.37 e na Equação 2.38.

$$
\begin{gathered}
N_{r}=\frac{a * Q_{a}{ }^{\left(\frac{2 * m}{3}-1\right)}}{t_{p} *\left(C_{w} * L_{w}\right)^{2 * m / 3}} \\
N_{r}=\frac{a * Q_{a}^{(2 * m-1)}}{t_{p} * D^{4 * m} *\left(1,1107 * g * C_{d}\right)^{2 * m}}
\end{gathered}
$$

Para as quais: $a$ e $m$ - são parâmetros que relacionam a cota $\mathrm{x}$ volume do reservatório de detenção;

$Q_{a}$ - máxima vazão afluente ao dispositivo;

$t_{p}$ - tempo de pico do hidrograma afluente; 
$C_{w}$ e $C_{d}$ - são respectivamente os coeficientes de descarga do vertedor e do orifício;

$L_{w}$ - largura do vertedor (m);

$D$ - diâmetro do orifício (m);

$g$ - é a aceleração da gravidade, assumida como $9,81 \mathrm{~m} / \mathrm{s}^{2} ;$

Os volumes de detenção são calculados de acordo com a Equação 2.39.

$$
V=N_{r} * R^{\alpha} * t_{p} * Q_{a}
$$

Equação 2.39

Sendo: $R$ - a relação entre a máxima vazão efluente e a máxima vazão afluente ao reservatório;

$\alpha$ - expoente que relaciona o volume armazenado à descarga efluente do reservatório.

Para tanto uma análise detalhada da formulação de Horn (1987) considerando os fatores $a$ e $m$, da curva cota volume, como sendo respectivamente a área da bacia de detenção e 1, leva a definição da Equação 2.40 e da Equação 2.41 para cálculo do número de "routing" para os casos do dispositivo de saída ser um vertedor soleira e um orifício, na respectiva ordem.

$$
\begin{gathered}
N_{r}=\frac{A * Q_{s}{ }^{2 / 3}}{\left(C_{w} * L_{w}\right)^{2 / 3}} \\
N_{r}=\frac{0,8106 * A * Q_{s}{ }^{2}}{C_{d}{ }^{2} * D^{4} * g}
\end{gathered}
$$

Nestas equações tem-se: $N_{r}$ - número de "routing" para passagem da cheia no reservatório;

$Q_{s}$ - vazão efluente à bacia;

$A$ - Área da lâmina d'água do reservatório de detenção.

A Equação 2.42 e a Equação 2.43 apresentam, respectivamente, como é realizada a estimativa do volume de detenção para os casos do dispositivo de saída ser um vertedor soleira e um orifício.

$$
\begin{gathered}
V=N_{r} * R^{2} * A * t_{p} \\
V=N_{r} * R^{2 / 3} * A * t_{p}
\end{gathered}
$$

O Quadro 2.5 apresenta as principais características dos métodos para estimativa do volume de detenção estudados. 
Quadro 2.5: características dos métodos para estimativa do volume de detenção estudados.

\begin{tabular}{|c|c|}
\hline MÉTODO & CARACTERÍSTICAS \\
\hline Proposto & $\begin{array}{l}\text { Embasado no método racional para cálculo de vazões, sendo } \\
\text { recomendado para bacias com áreas não superiores a } 2 \mathrm{~km}^{2} \text {. Possui } \\
\text { como principal característica a consideração de variações no } \\
\text { hidrograma efluente em sua formulação e parâmetros IDF. }\end{array}$ \\
\hline $\begin{array}{c}\text { Generalizado } \\
\text { (MCCUEN, 1989) }\end{array}$ & $\begin{array}{l}\text { Baseado nos fatores de atenuação da vazão e do tempo de } \\
\text { concentração. }\end{array}$ \\
\hline Fórmula racional & $\begin{array}{l}\text { Possui as limitações impostas à aplicação do método racional } \\
\text { para cálculo de vazões. Utiliza como parâmetros as vazões de } \\
\text { pico (anterior e posterior à urbanização) e o tempo de } \\
\text { concentração da bacia nas condições pré-urbanização. }\end{array}$ \\
\hline Baker (1979) & Caso particular de aplicação do método generalizado. \\
\hline Abt e Grigg (1978) & $\begin{array}{c}\text { Assume como hipóteses hidrógrafa afluente triangular e } \\
\text { efluente trapezoidal. Caracterizado como método para } \\
\text { estimativa de volume de detenção em bacias "off line", } \\
\text { utilizando para cálculo do volume a razão de atenuação da } \\
\text { vazão. }\end{array}$ \\
\hline $\begin{array}{l}\text { Wycoff e Singh } \\
\text { (1978) }\end{array}$ & $\begin{array}{l}\text { Determinado através de regressão numérica, utiliza como } \\
\text { parâmetros a razão de atenuação da vazão e a relação entre o } \\
\text { tempo de base e de pico do hidrograma de afluente. }\end{array}$ \\
\hline Wilken (1978) & $\begin{array}{l}\text { Possui como característica a presença de um fator de volume, } \\
\text { baseado na relação entre as vazões máximas afluente e efluente, } \\
\text { e utiliza a vazão afluente máxima e o tempo de duração do } \\
\text { evento chuvoso. }\end{array}$ \\
\hline Tsuchiya (1978) & $\begin{array}{c}\text { Desenvolvida a partir de dados de bacias japonesas com área de } \\
\text { drenagem máxima de } 0,2 \mathrm{~km}^{2} \text {. }\end{array}$ \\
\hline Maidment (1992) & $\begin{array}{l}\text { Caracterizado por possuir um fator de ajuste do volume de } \\
\text { detenção, sendo a metodologia baseada no método racional. }\end{array}$ \\
\hline Tucci (1998) & $\begin{array}{l}\text { Metodologia baseada nas diferenças entre volumes afluentes e } \\
\text { efluentes ao dispositivo de detenção. }\end{array}$ \\
\hline Tucci (2002) & $\begin{array}{c}\text { Desenvolvida para a cidade de Curitiba, levando em } \\
\text { consideração o tempo de retorno e a parcela impermeabilizada } \\
\text { da área. }\end{array}$ \\
\hline Holandês & $\begin{array}{l}\text { Baseado em relações IDF, leva em consideração o coeficiente } \\
\text { de escoamento do método racional, a área de drenagem e a } \\
\text { máxima vazão efluente. }\end{array}$ \\
\hline Matias (2006) & $\begin{array}{l}\text { Embasado no método holandês, considera o esvaziamento da } \\
\text { bacia após o evento chuvoso, e que o máximo volume a ser } \\
\text { armazenado ocorre após o término do evento. }\end{array}$ \\
\hline $\begin{array}{l}\text { Federal Aviation } \\
\text { Administration }\end{array}$ & $\begin{array}{l}\text { Desenvolvido para drenagem de aeroportos, com utilização } \\
\text { aconselhada a pequenas áreas e altas taxas de } \\
\text { impermeabilização. Para estimativa do volume leva em conta o } \\
\text { fator de atenuação da vazão, a intensidade da chuva de projeto, } \\
\text { o tempo de duração do evento e o tempo de concentração da } \\
\text { bacia. }\end{array}$ \\
\hline $\begin{array}{l}\text { Soil Conservation } \\
\text { Service (1986) }\end{array}$ & $\begin{array}{c}\text { Bastante difundido entre projetistas, desenvolvido } \\
\text { originalmente para bacias rurais norte americanas. Para } \\
\text { estimativa do volume utiliza ábacos e gráficos baseados na } \\
\text { precipitação, volume escoado e infiltrado. }\end{array}$ \\
\hline
\end{tabular}


Quadro 2.5: (cont.) características dos métodos para estimativa do volume de detenção estudados.

\begin{tabular}{|c|c|}
\hline Akan $\left(1989^{\mathrm{a}}\right)$ & $\begin{array}{c}\text { Fundamentado num processo adimensional do routing do } \\
\text { hidrograma pelo reservatório. Leva em consideração } \\
\text { parâmetros de armazenamento hidrológico e das estruturas de } \\
\text { entrada. Para utilização do método há a necessidade de } \\
\text { utilização de gráficos. }\end{array}$ \\
\hline Porto (2002) & $\begin{array}{c}\text { Metodologia adimensional gráfica, apresenta os mesmos } \\
\text { parâmetros da metodologia de Akan (1989a). Apresentou } \\
\text { excelentes resultados, quando testado, na estimativa do volume } \\
\text { detido de reservatórios já implantados. }\end{array}$ \\
\hline Horn (1987) & $\begin{array}{c}\text { Desenvolvido a partir da determinação de um adimensional } \\
\text { denominado número de routing. Possui como inconveniente a } \\
\text { determinação de diversas variáveis não disponíveis na fase de } \\
\text { pré-dimensionamento dos reservatórios. }\end{array}$ \\
\hline
\end{tabular}

\subsection{Relações Intensidade - Duração - Frequência}

A previsão das precipitações é realizada com antecedência de poucos dias. A sua previsão, para fins de projetos, é realizada com bases estatísticas, que se tornaram a base da determinação da frequência nas quais precipitações de certas magnitudes ocorrem (TUCCI, 2001).

As intensidades máximas são retratadas pelas curvas Intensidade - Duração Frequência (IDF). Estas curvas relacionam a duração, a intensidade e o risco da precipitação ser igualada ou superada. A correlação feita entre as intensidades e durações das chuvas informa que quanto maior for a intensidade da precipitação, menor será a sua duração (TUCCI, 2001). A determinação de chuvas intensas assume grande importância em projetos de drenagem ao passo que as vazões são obtidas indiretamente por modelos chuva-deflúvio (TUCCI et al., 1995).

As equações IDF podem auxiliar no planejamento de ocupações urbanas, na determinação de vazões em situações futuras, uma vez que não há como determiná-las por séries históricas (MORUZZI e OLIVEIRA, 2009).

Tucci et al. (1995) afirmam que para que haja melhor caracterização da distribuição espacial das precipitações em bacias hidrográficas de maiores dimensões deve haver integração de informações obtidas de redes telemétricas, redes básicas, radares e satélites meteorológicos.

$\mathrm{Na}$ falta de séries históricas disponíveis de dados pluviográficos, onde se verifica a necessidade da determinação das relações Intensidade - Duração - Frequência, é 
comum utilizar para tal atividade as chuvas de 1 dia. Para tanto, neste trabalho, foi utilizada a metodologia exibida em Carvalho et al. (1972) e ESA (2006).

A determinação das curvas IDF pode ser realizada com a utilização de séries parciais - aconselhada para séries de dados pequenas — séries anuais ou séries completas.

Para a determinação de relações IDF de uma localidade, com quantidade de dados relevante, devem-se primeiramente formar as séries anuais. Podem-se obter séries anuais - formadas pelas maiores intensidades anuais para cada duração — séries de duração parcial, onde é selecionado um determinado número de maiores valores de intensidade para cada duração, ou ainda séries completas - formadas por todos os valores disponíveis para cada duração (CARVALHO et al., 1972).

As curvas IDF são determinadas para cada região, e são postas em geral em função do tempo de retorno e a duração da chuva crítica arbitrados para o projeto.

O ajuste matemático das curvas IDF é geralmente feito na forma da Equação 2.44. A transformação logarítmica das variáveis envolvidas faz com que numa escala bilogarítmica os valores de intensidade e duração agrupem-se em torno de uma variação linear (CARVALHO et al., 1972; ESA, 2006).

$$
\bar{I}_{(t)}=\frac{k * T^{m}}{(t+b)^{n}}
$$

Equação 2.44

A determinação dos coeficientes da Equação 2.44 é simples e pode ser vista nos trabalhos de Carvalho (1972) e ESA (2006) que utilizam o método de Gumbel - Chow.

A forma da curva IDF apresentada na Equação 2.44 é comumente chamada de fórmula IDF clássica. Existem outras formas de representar relações IDF como a exponencial e a hiperbólica, representadas — na ordem mencionada — na Equação 2.45 e Equação 2.46.

$$
\begin{aligned}
& I=a * t^{b} \\
& I=\frac{a}{t+b}
\end{aligned}
$$

Equação 2.45

Equação 2.46

Nestas equações - $a$ e $b$ - são parâmetros definidos para cada bacia e para cada tempo de retorno.

\subsubsection{Tempo de retorno}

A escolha do tempo de retorno de obras de drenagem está intimamente ligada à natureza do projeto e aos riscos envolvidos. Em obras de engenharia este está ligado à 
segurança e estabilidade (BRASIL, 2005). Cada projeto possui nuances que o caracterizam, apresentando maior ou menor importância, de acordo com os riscos envolvidos. Tucci et al. (1995) trataram a escolha do tempo de retorno de uma obra como a escolha do risco aceitável para o projeto.

Dentre os fatores que contribuem para a determinação do tempo de retorno dos projetos lista-se: custos envolvidos na execução da obra, custos relacionados a perdas materiais, perdas de vidas, bem estar da população protegida e outros.

Intrínsecos ao conceito de período de retorno estão os conceitos de frequência e de risco. As relações destes com o tempo de recorrência são apresentadas, respectivamente, na Equação 2.47 e na Equação 2.48.

$$
\begin{gathered}
F=100 * \frac{1}{T} \\
R=100 *\left[1-\left(1-\frac{1}{T}\right)^{N}\right]
\end{gathered}
$$

Nas quais: $T$ - é o tempo de retorno em anos;

$F$ - é a frequência, probabilidade de ocorrência do evento por ano (\%);

$N$ - vida útil da obra em anos;

$R$ - risco de falha da obra (\%). 


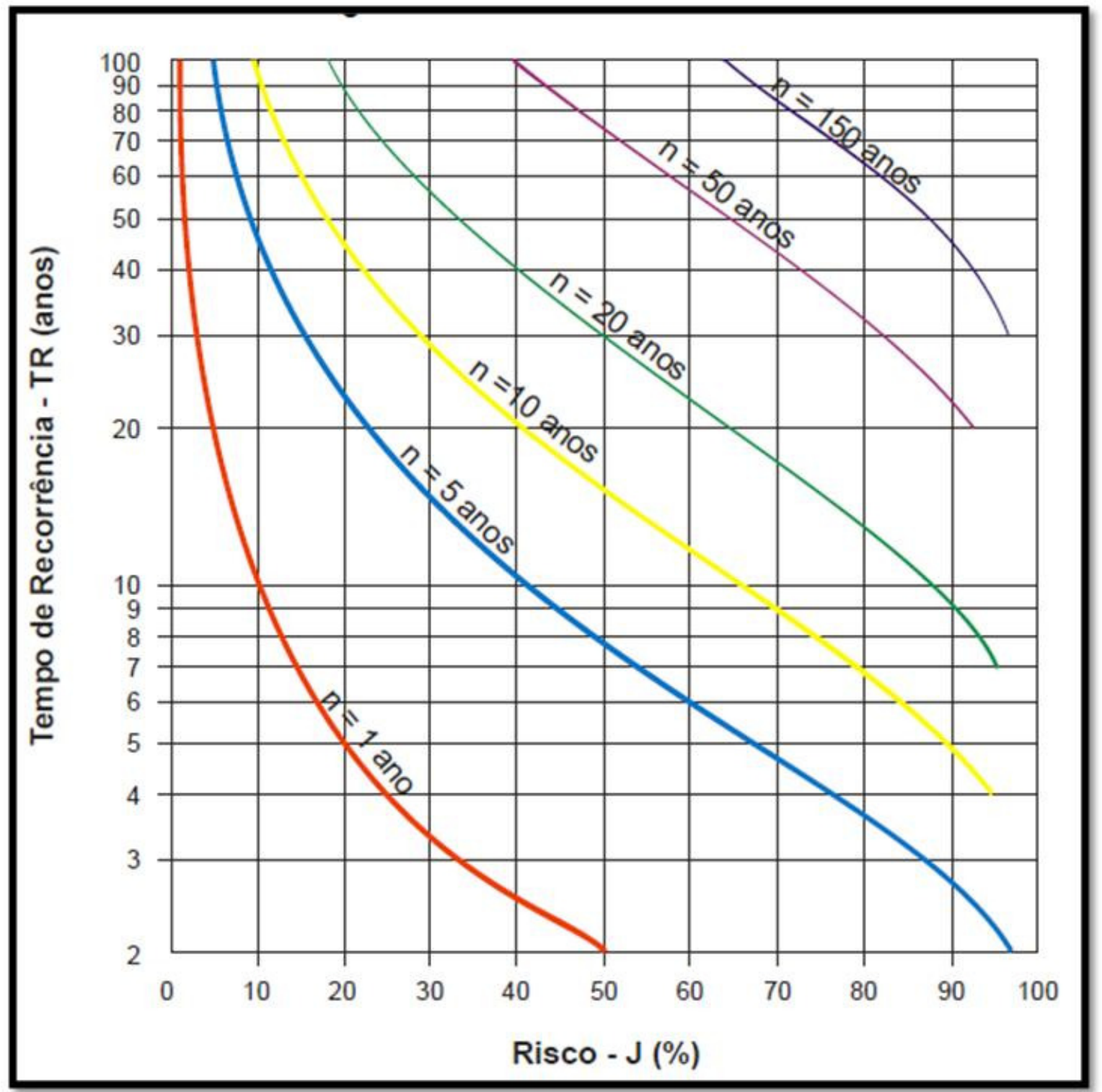

Figura 2.5: relações entre risco, tempo de recorrência e vida útil de obras de drenagem urbana (Fonte: BRASIL, 2005).

A Figura 2.5 retrata as relações entre probabilidade de risco, tempo de recorrência e vida útil de obras de arte.

Ao que trata de estudos econômicos para orientar a escolha do período de recorrência de uma obra, Tucci et al. (1995) frisaram a dificuldade na consideração de custos e benefícios uma vez que a quantificação destes é uma tarefa árdua e que nem todos os aspectos podem ser expressos em valores monetários. Em função da dificuldade, e por vezes subjetividade, da definição do tempo de recorrência os autores, supracitados, fixaram valores considerados aceitáveis para definição de tal. Estes valores podem ser avaliados no Quadro 2.6. 
Quadro 2.6: períodos de retorno utilizados em projetos de drenagem para diversas ocupações de áreas (Fonte: TUCCI et al. 1995).

\begin{tabular}{|c|c|c|}
\hline Tipo de obra & Tipo de ocupação da área & Tempo de Retorno (anos) \\
\hline Microdrenagem & Residencial & 2 \\
\hline Microdrenagem & Comercial & 5 \\
\hline Microdrenagem & Áreas com edif. de serviços ao público & 5 \\
\hline Microdrenagem & Aeroportos & $2-5$ \\
\hline Microdrenagem & Áreas comerciais e artérias de tráfego & $5-10$ \\
\hline Macrodrenagem & Áreas comerciais e residenciais & $50-100$ \\
\hline Macrodrenagem & Áreas de importância específica & 500 ou mais \\
\hline
\end{tabular}

\subsubsection{Duração da chuva crítica}

A definição da duração da chuva de projeto influencia significativamente na determinação de vazões máximas e volumes armazenados em projetos de macrodrenagem. A escolha deste parâmetro deve ser realizada de maneira criteriosa, uma vez que este se correlaciona diretamente à intensidade de precipitação e deste modo à vazão máxima e aos volumes detidos.

É comum em projetos de drenagem para pequenas bacias hidrográficas adotar o tempo de duração da chuva crítica igual ao tempo de concentração da bacia. A utilização desta condição é válida para situações nas quais o hietograma da chuva excedente tenha intensidade constante, ocasionando escoamento superficial no exutório em regime permanente (TUCCI et al., 1995).

\subsection{Tempo de concentração}

Um dos principais problemas na determinação das chuvas de projeto e dos picos de vazões é a determinação do tempo de concentração. Diversas são as formulações desenvolvidas para estimativas deste parâmetro, algumas empíricas, determinadas para condições fixas e bem definidas, outras semiempíricas, desenvolvidas levando em consideração possíveis mudanças nas características do uso e ocupação do solo. Akan (1986) atentou ao fato de que apesar de ser reconhecidamente sensível na determinação de picos de vazão, o tempo de concentração é calculado de maneira muito subjetiva.

Mata-Lima et al. (2007) definiram tempo de concentração como sendo "o tempo de percurso da água precipitada desde o ponto cinematicamente mais afastado da bacia hidrográfica até a seção de referência”. De modo prático o tempo de concentração é tido como o tempo necessário para que toda a área da bacia hidrográfica passe a contribuir para o escoamento superficial no seu exutório (SILVEIRA, 2005; FARIAS JÚNIOR, 2010). 
A estimativa do tempo de concentração é muito importante na definição de chuvas críticas e vazões máximas para projetos de obras hidráulicas, e sua determinação influencia indiretamente na concepção de sistemas de alertas de cheias, que têm por intuito previsão de desastres naturais (FARIAS JÚNIOR, 2010). McCuen (1989) afirmou que cerca de $75 \%$ dos erros na estimativa de picos de descargas são resultantes de falhas na determinação de variáveis temporais.

A importância de uma estimativa coerente do tempo de concentração é corroborada por McCuen (1989) ao passo que o autor citou a intensidade de precipitação e o volume precipitado, bem como o grau de atenuação dos efeitos das chuvas, em pequenas bacias, como parâmetros afetados por variáveis temporais como tempo de concentração e duração da precipitação. O autor prosseguiu afirmando que para bacias hidrográficas de maior porte as variáveis temporais podem indicar retenção de água na própria bacia hidrográfica e seus efeitos no escoamento superficial — forma do hidrograma e tempo do pico de vazão.

Para Pinto et al. (1975), Mata-Lima et al. (2007) e Farias Júnior (2010), em geral, o tempo de concentração de uma bacia depende de fatores como: área da bacia, comprimento e declividade do canal principal, forma da bacia, declividade média do terreno, densidade de drenagem, declividade e comprimento dos afluentes, rugosidade da superfície da bacia e de seus canais, tipo de cobertura vegetal e uso do solo e ainda obras hidráulicas existentes.

Os dispositivos hidráulicos instalados podem interferir de maneiras distintas no tempo de concentração das bacias. Obras como dutos e canalizações têm o efeito de diminuição do tempo de concentração das bacias, enquanto que dispositivos como reservatórios e válvulas de controle de vazão ocasionam o aumento deste parâmetro.

Outro fator que influencia na estimativa do tempo de concentração é a característica do local no qual se desenvolve o escoamento. Os escoamentos podem ocorrer em três tipos de condições: escoamento sobre a superfície do solo, escoamento em canais abertos e escoamento em galerias e tubulações. A maioria dos métodos desenvolvidos são identificados como misturas destes tipos de escoamento (MCCUEN, 1989).

McCuen (1989) relacionou para cada tipo de regime predominante de escoamento quais as variáveis que descrevem de melhor maneira os escoamentos. $\mathrm{O}$ autor dividiu em 4 as variáveis de entrada para cada tipo de regime de escoamento, sendo elas: cobertura do solo — indicando forças de resistência ao escoamento - 
características do tamanho da bacia, declividade da bacia ou do talvegue e características relacionadas às entradas de água.

Duas são as formas de obtenção do tempo de concentração, uma forma direta e outra indireta. A forma direta de obtenção de tempos de concentração consiste na utilização de dados primários, já a indireta é obtida através de informações secundárias, em geral formulações matemáticas estabelecidas para determinada região.

O método direto apresenta maior segurança quando há disponibilidade de dados hidrometeorológicos com discretização temporal inferior ao tempo de concentração. Pelo método gráfico o tempo de concentração é obtido a partir da relação entre a precipitação e a variação da cota ou vazão no corpo hídrico (FARIAS JÚNIOR, 2010).

Os métodos indiretos são, em geral, métodos mais simples, utilizados na falta de informações hidrometeorológicas ou em estudos preliminares. Duas são as possíveis classificações para as metodologias que permitem o cálculo do tempo de concentração de maneira indireta, sendo elas: métodos semiempíricos ou empíricos.

É importante salientar que estes métodos para cálculo do tempo de concentração não são isentos de erros uma vez que se baseiam nas características da bacia hidrográfica. As características das bacias não são constantes em toda a sua extensão como exemplo cita-se o tipo de cobertura da bacia que varia de região para região e nas formulações, em geral, deve-se assumir apenas um coeficiente que represente toda esta gama de tipos de cobertura - outra variável que possui variabilidade semelhante é a declividade da bacia e/ou do talvegue (MCCUEN, 1989).

A avaliação das metodologias de cálculo do tempo de concentração se faz necessária visto que erros nesta fase dos projetos podem ocasionar subestimação ou superestimação dos picos de vazão e, consequentemente, dos volumes armazenados em estruturas de detenção de água.

\subsubsection{Formulações empíricas}

Os métodos empíricos são obtidos através de regressões múltiplas, e levam a resultados mais confiáveis em condições que as bacias não possuam suas características originais não alteradas.

Akan (1986), McCuen (1989) e Tucci (2001) enfatizaram que as formulações empíricas desenvolvidas para cálculo do tempo de concentração são originadas de estudos de campos ou ensaios laboratoriais e têm seus usos limitados para locais com condições específicas e semelhantes às condições para as quais foram desenvolvidas. 


\section{Fórmula de Kirpich}

Desenvolvida a partir de dados de 7 bacias rurais no Tenessee (EUA) com área variando entre 1 e 112 acres e com declividades entre 3 e 10\%, e áreas vegetadas de até $56 \%$ da total (Equação 2.49).

$$
t_{c}=0,39 *\left(\frac{L^{2}}{I}\right)^{0,385}
$$

Em que $t_{c}$ é encontrado em horas, $L$ é o comprimento do talvegue principal em $\mathrm{km}$ e $I$ é a declividade média equivalente em $\%$.

Tucci (2001) afirmou que para talvegues com comprimentos maiores que 10 quilômetros esta formulação tende a subestimar o valor do tempo de concentração.

Farias Júnior (2010), citando diversos autores, afirmou que para correção dos tempos de concentração encontrados com esta formulação aplicada em bacias urbanas utilizam-se em geral dois métodos: o primeiro é a redução para $40 \%$ do tempo de concentração estimado para áreas com superfície asfáltica ou concretada, e a outra, apresentada na Equação 2.50, é a correção do tempo estimado baseada no $\mathrm{CN}$, quando este apresenta valor inferior a 80.

$$
t_{c c}=t_{c} *[1+(80-C N) * 0,04]
$$

Equação 2.50

Em que: $t_{c c}$ - tempo de concentração corrigido;

$t_{c}$ - tempo de concentração estimado;

CN - Curve Number do método desenvolvido pelo SCS (1986).

McCuen (1989) citou que a redução do tempo de concentração para superfícies asfálticas pode chegar a $20 \%$ do tempo estimado pela formulação.

\section{Fórmula California Culverts Practice}

Adaptada da formulação de Kirpich para pequenas bacias da Califórnia, apresentando como condições restritivas — idênticas às restrições de aplicação do método de Kirpich, uma vez que dela deriva - a área inferior à $0,5 \mathrm{~km}^{2} \mathrm{e}$ a declividade entre 3 e 10\% (TOMAZ, 2002; FRANCO, 2004; FARIAS JÚNIOR, 2010). Segundo Tomaz (2002) a utilização desta formulação, apresentada na Equação 2.51, assim como a de Kirpich, é bastante difundida pela facilidade de obtenção de seus parâmetros.

$$
t_{c}=57 *\left(\frac{L^{3}}{\Delta H}\right)^{0,385}
$$

$\mathrm{Na}$ qual $t_{c}$ é estimado em minutos, $L$ é o comprimento do talvegue $(\mathrm{km})$ e $\Delta \mathrm{H}$ o desnível máximo da bacia (m). 
O Departamento Nacional de Infraestrutura de Transportes - DNIT (BRASIL, 2005) estudou a aplicação desta formulação e concluiu que esta apresenta bons resultados para bacias, de rurais a urbanas, nas quais a área de drenagem varia entre $0,03 \mathrm{~km}^{2}$ e $683 \mathrm{~km}^{2}$.

O Departamento de Estrada e Rodagem (DER) de São Paulo adaptou a fórmula da California Culverts Practice para áreas superiores a $1 \mathrm{~km}^{2}$ obtendo a Equação 2.52 (FRANCO, 2004; FARIAS JÚNIOR, 2010):

$$
t_{c}=85,2 *\left(\frac{L^{3}}{\Delta H}\right)^{0,385}
$$

Sendo o $t_{c}$ encontrado em minutos, $L$ o comprimento do talvegue em $\mathrm{km}$ e $\Delta H$ o desnível máximo da bacia (m).

\section{Fórmula de Ven Te Chow}

Para o DNIT, Brasil (2005), que realizou estudos com a formulação - Equação 2.53 - esta apresenta bons resultados para bacias com áreas de drenagem superior a 45 km². DGC (1987), apud FARIAS JÚNIOR (2010), afirmou que esta formulação não se adapta à bacias pequenas, apresenta valores altos para bacias com declividade suaves e baixas para bacias com declividades acentuadas.

$$
t_{c}=25,2 *\left(\frac{L^{2}}{I}\right)^{0,64}
$$

Equação 2.53

Para a formulação apresentada o tempo de concentração, $t_{c}$, é estimado em minutos, para valores do comprimento do talvegue, $L$, em $\mathrm{km}$ e para declividade, $I$, em valores percentuais.

\section{Fórmula de Picking}

O DNIT (BRASIL, 2005) estudou a aplicação desta formulação em 29 bacias, concluindo que os tempos de concentração estimados por esta fórmula, Equação 2.54, apresentam valores excessivamente baixos.

$$
t_{c}=5,3 *\left(\frac{L^{2}}{I}\right)^{1 / 3}
$$

Em que: $t_{c}$ é estimado em minutos para $L$, comprimento do talvegue principal, em quilômetros e $I$, declividade média do talvegue principal, em $\mathrm{m} / \mathrm{m}$. 


\section{Fórmula de Johnstone-Cross}

Desenvolvida a partir de dados de bacias do Estado americano de Ohio (rios Scioto e Sandusky) com área de drenagem variando entre 65 e 4200 km² $^{2}$ (FRANCO, 2004). A formulação é apresentada na Equação 2.55.

$$
t_{c}=3,258 *\left(\frac{L}{I}\right)^{0,5}
$$

Para a qual: $t_{c}$ é o tempo de concentração (min), $L$ é o comprimento do talvegue $(\mathrm{km})$ e $I$ é a declividade do talvegue $(\mathrm{m} / \mathrm{m})$.

\section{Fórmula de Giandotti}

Desenvolvida a partir de dados de bacias hidrográficas italianas (MATA-LIMA et al., 2007). Segundo estudos do DNIT (BRASIL, 2005) esta fórmula, Equação 2.56, não apresentou resultados satisfatórios para áreas de drenagem inferiores a 20,5 km².

$$
t_{c}=\frac{4 * \sqrt{A}+1,5 * L}{0,8 * \sqrt{H_{m}}}
$$

Para que o tempo de concentração nesta formulação seja encontrado em horas a área de drenagem $(A)$ deve estar em unidades de $\mathrm{km}^{2}$, o comprimento do talvegue $(L)$ em quilômetros e a altitude média do talvegue em metros.

\section{Fórmula de Pasini}

Outra formulação desenvolvida com informações de bacias hidrográficas italianas (MATA-LIMA et al., 2007), apresentando — segundo o DNIT (BRASIL, 2005) - bons resultados para as bacias com áreas entre 0,03 e $3476 \mathrm{~km}^{2}$ (Equação 2.57).

$$
t_{c}=0,108 * \frac{(A * L)^{1 / 3}}{I^{0,5}}
$$

Equação 2.57

Na qual $t_{c}$ - o tempo de concentração — é obtido em horas, a área de drenagem (A) deve estar em $\mathrm{km}^{2}, L$ é o comprimento do talvegue principal $(\mathrm{km})$ e $I$ a declividade média do talvegue principal em $\mathrm{m} / \mathrm{m}$.

\section{Fórmula de Bransby-Williams}

Desenvolvida para bacias rurais, em 1922, é apresentada na Equação 2.58. A formulação apresentada apresentou excelentes resultados para aplicação em bacia de 
médio porte, cerca de $30 \mathrm{~km}^{2}$, em regiões com declividade considerada alta (FARIAS JÚNIOR, 2010).

$$
t_{c}=\frac{14,6 * L}{I^{0,2} * A^{0,1}}
$$

Na qual $t_{c}$ é o tempo de concentração (min), $L$ o comprimento do talvegue $(\mathrm{km})$, $A$ a área de drenagem $\left(\mathrm{km}^{2}\right)$ e $I$ a declividade do talvegue $(\mathrm{m} / \mathrm{m})$.

\section{Fórmula de Ventura}

Desenvolvida, Equação 2.59, para bacias rurais italianas, apresentando erro médio da ordem de 25\% pelos estudos feitos por Silveira (2005) e Farias Júnior (2010).

$$
t_{c}=240 * \sqrt{\frac{A * L}{\Delta H}}
$$

Equação 2.59

Em que: $t_{c}$ - tempo de concentração em minutos; $A$ - área de drenagem em km²; $L$ - comprimento do talvegue em $\mathrm{km} ; \Delta \mathrm{H}$ - diferença de cota entre o ponto mais alto do talvegue e seu exutório.

\section{Fórmula de Dooge}

Proposta para bacias entre 140 e $930 \mathrm{~km}^{2}$, baseada em dados de 10 bacias rurais irlandesas (Equação 2.60). Tucci et al. (1995) observaram que seus parâmetros são aplicáveis para bacias com escoamento predominante em canais.

$$
t_{c}=21,88 * \frac{A^{0,41}}{I^{0,17}}
$$

Em que: $t_{c}$ é estimado em minutos, $A$ é a área de drenagem $\mathrm{em}^{2}{ }^{2}, I$ a declividade do talvegue em $\mathrm{m} / \mathrm{km}$.

\section{Fórmula de Temez}

Desenvolvida para áreas de até $3000 \mathrm{~km}^{2}$ (MATA-LIMA et al., 2007), foi estudada pelo DNIT (BRASIL, 2005) para bacias com áreas de drenagem que variavam

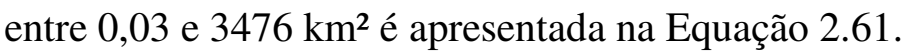

$$
t_{c}=0,3 *\left(\frac{L}{I^{0,25}}\right)^{0,76}
$$

Onde $t_{c}$ é encontrado em horas, $L$, o comprimento do curso d'água principal, em quilômetros e $I$ a declividade média equivalente em $\mathrm{m} / \mathrm{m}$. 


\section{Fórmula de Van Sickle}

Formulação desenvolvida com dados de bacias do município de Houston, para áreas de drenagem de no máximo 36 mi² $^{2}\left(93,2 \mathrm{~km}^{2}\right)$. A Formulação, Equação 2.62, pode ser utilizada para bacias com predominância de fluxos em canais e escoamento sobre superfícies (MCCUEN, 1989).

$$
t_{c}=0,49 *\left(\frac{L_{t} * L}{\sqrt{I}}\right)^{0,13}
$$

$\mathrm{Na}$ qual: $t_{c}$ é o tempo de concentração, determinado em minutos, $L_{t}$ é o comprimento total de cursos hídricos da bacia em quilômetros, $L$ é o comprimento do talvegue principal em quilômetros e $I$ é a declividade do talvegue principal em m/m.

\section{Fórmula de Tsuchiya}

Desenvolvida para projetos de bacias de detenção no Japão, formulada a partir da observação de informações de 235 bacias, rurais e urbanas, com área de drenagem entre 0,1 e 20 ha. Esta fórmula, Equação 2.63, leva em consideração as constantes C1 e C2 que variam de acordo com o uso e ocupação do solo (FARIAS JÚNIOR, 2010).

$$
t_{c}=\frac{C 1 * L}{I^{C 2}}
$$

Na qual $t_{c}$ é estimado em minutos, $L$ é o comprimento do talvegue $(\mathrm{km})$ e $I$ é a declividade do talvegue (m/m). As constantes C1 e C2 são apresentadas no Quadro 2.7.

Quadro 2.7: coeficientes de uso do solo para cálculo do tempo de concentração, pela formulação de Tsuchiya (Fonte: FRANCO, 2004; FARIAS JÚNIOR, 2010).

\begin{tabular}{|c|c|c|}
\hline Constante & Bacia Urbana & Bacia Rural \\
\hline $\mathrm{C} 1$ & 0,36 & 0,83 \\
\hline $\mathrm{C} 2$ & 0,50 & 0,60 \\
\hline
\end{tabular}

\section{Fórmula de Carter Lag Equation for Partially Sewered Watersheds}

Desenvolvida - Equação 2.64 - para bacias com área de drenagem inferior a 8 milhas quadradas, $20,7 \mathrm{~km}^{2}$, com comprimento do talvegue inferior a 7 milhas $(11,26$ $\mathrm{km}$ ), declividade inferior a $0,5 \%$ e coeficiente de Manning entre 0,013 e 0,025, todas inseridas no município de Washington, Estados Unidos (MCCUEN, 1989). 


$$
t_{c}=45,63 *\left(\frac{L^{0,6}}{I^{0,3}}\right)
$$

$\mathrm{Na}$ qual $t_{c}$ deve ser encontrado em minutos, $L$ é o comprimento do talvegue em quilômetros e $I$ a declividade do talvegue em metros por quilômetro.

\section{Fórmula da United States Army Corps of Engineers}

Formulação (Equação 2.65) desenvolvida para superfícies concretadas para precipitações com intensidade máxima igual a $254 \mathrm{~mm} / \mathrm{h}$ (WONG, 2005, apud FARIAS JÚNIOR, 2010).

$$
t_{c}=\frac{\left(10,57+\frac{0,12}{I}\right) *\left(\frac{L}{30,48}\right)^{0,55-\left(\frac{0,001}{I}\right)}}{i^{0,43}}
$$

Na qual $t_{c}$ é o tempo de concentração (min), $L$ é o comprimento do talvegue ou superfície de escoamento $(\mathrm{m}), i$ é a intensidade da chuva $(\mathrm{mm} / \mathrm{h})$ e $I$ é a declividade do talvegue ou superfície de escoamento $(\mathrm{m} / \mathrm{m})$.

\subsubsection{Formulações semiempíricas}

Os métodos semiempíricos por sua vez levam em consideração as mudanças ocorridas nas bacias de estudo, dentre os quais o mais conhecido e difundido é o método SCS (MATA-LIMA et al., 2007; FARIAS JÚNIOR, 2010).

\section{Método cinemático}

De fácil utilização e para aplicação em bacias com predominância de qualquer uso e ocupação do solo. Seu emprego consiste em subdividir a bacia hidrográfica em diversos trechos homogêneos, determinando para cada um deles o comprimento do talvegue e a velocidade do escoamento, sendo o tempo de concentração calculado conforme a Equação 2.66.

$$
t_{c}=\sum \frac{L}{V}
$$

Equação 2.66

$L$ e $V$ são o comprimento do talvegue e a velocidade de escoamento, e devem ser utilizados em unidades de metro, para comprimentos, e segundo, para unidades temporais, para resultarem em tempos de concentração, $t_{c}$, em segundos. 
A Velocidade de escoamento pode ser determinada, para superfícies ou calhas rasas (TUCCI et al., 1995; FRANCO, 2004), pela Equação 2.67.

$$
V=C_{v} * S^{0,5}
$$

Equação 2.67

Para a qual $S$ representa a declividade média do trecho (\%), $V$ é a velocidade $(\mathrm{m} / \mathrm{s})$ e $C_{v}$ é o coeficiente de escoamento em superfícies e calhas. Valores estimados para o coeficiente $C_{v}$ são apresentados ao Quadro 2.8.

Quadro 2.8: valores estimados para o coeficiente de escoamento (Fonte: TUCCI et al., 1995).

\begin{tabular}{|c|c|}
\hline Ocupação do solo & $C_{v}$ \\
\hline Florestas densas & 0,075 \\
\hline Campos naturais pouco cultivados & 0,135 \\
\hline Gramas ou pastos ralos & 0,210 \\
\hline Solos quase nus & 0,300 \\
\hline Canais gramados & 0,450 \\
\hline Escoamento em lâmina sobre pavimento ou sem sarjetas e \\
calhas rasas & 0,600 \\
\hline
\end{tabular}

Em bacias urbanas deve-se levar em consideração a presença de sistema de drenagem pluvial, e desta maneira o tempo de concentração será composto por duas parcelas, conforme apresentado na Equação 2.68. A primeira parcela refere-se ao tempo até que a lâmina d'água atinja a rede drenagem $\left(t_{i}\right)$ e a segunda parcela refere-se ao tempo necessário para que o escoamento nas galerias atinja o exutório $\left(t_{t}\right)$ (FRANCO, 2004).

$$
t_{c}=t_{i}+t_{t}
$$

O cálculo do tempo de translação $\left(t_{t}\right)$ pode ser realizado com o auxílio de fórmulas hidráulicas clássicas.

\section{Fórmula da Onda Cinemática}

Desenvolvida, de acordo com McCuen (1984) e Tucci (2001), para cálculo do tempo de concentração na superfície do solo das bacias hidrográficas. Segundo Franco (2004) esta fórmula deve ser aplicada para áreas de drenagem onde se pode aplicar o método racional — pequenas áreas drenagem, como exemplo clássico de aplicação citam-se os estacionamentos. Mata-Lima et al. (2007) afirmaram que esta fórmula, Equação 2.69, foi desenvolvida para áreas que possuam comprimento, na direção do escoamento inferior a 100 metros, enquanto McCuen (1989) e Franco (2004) 
recomendam sua utilização em superfícies para as quais o comprimento máximo de escoamento seja de 30 metros.

$$
t_{c}=447 * \frac{(n * L)^{0,6}}{I^{0,3} * i^{0,4}}
$$

Para tal formulação o tempo de concentração $\left(t_{c}\right)$ é estimado em minutos, $n$ é o coeficiente de Manning, apresentado no Quadro 2.9, o comprimento da superfície de escoamento $(L)$ é medido em quilômetros, a declividade da superfície é colocada em metro de desnível por metro linear de comprimento e a intensidade de precipitação (i) é colocada em milímetros por hora.

Para Tomaz (2002) o grande inconveniente desta formulação é a existência de duas incógnitas, o tempo de concentração e a intensidade — relacionadas nas equações e/ou curvas IDF. $\mathrm{O}$ autor sugere que a obtenção destes valores seja realizada por tentativas.

É importante ressaltar que esta formulação apesar de ter sido desenvolvida inicialmente para escoamento no solo da bacia pode ser facilmente adaptada para o escoamento em canais.

Quadro 2.9: coeficientes de escoamento determinado por Manning (Fonte: TUCCI et al., 1995)

\begin{tabular}{|c|c|}
\hline Cobertura da bacia & $n$ (Manning) \\
\hline Asfalto liso & 0,012 \\
\hline Asfalto ou concreto & 0,014 \\
\hline Argila compactada & 0,03 \\
\hline Pouca vegetação & 0,02 \\
\hline Vegetação densa & 0,35 \\
\hline Vegetação densa e floresta & 0,4 \\
\hline
\end{tabular}


Akan (1986, 1989b) em seus estudos associou ao método da onda cinemática o modelo de infiltração de Green-Ampt, desenvolvendo uma formulação com características constantes para sua superfície e subsuperfície, onde a infiltração foi considerada a única forma de perdas.

Akan (1989b) utilizando o método dos mínimos quadrados fez uma interpolação das curvas encontradas pelo autor em seus estudos em (1986), encontrando para o tempo de concentração a Equação 2.70:

$$
t_{c}=\left(\frac{L * n}{k * \sqrt{S}}\right)^{0,6} * \frac{1}{(i-K)^{0,4}}+3,10 * \frac{K^{1,33}}{i^{2,33}} * P_{f} * \Phi *\left(1-S_{i}\right)
$$

Equação 2.70

\section{Fórmula de Eagleson Lag Model}

É um método de cálculo misto, utilizado para cálculo de tempos de concentração que ocorram em canais e sistemas de drenagem, sendo sua metodologia original desenvolvida para bacias menores que $8 \mathrm{mi}^{2}\left(20,72 \mathrm{~km}^{2}\right)$, e as variáveis utilizadas na calibração foram computadas utilizando características do sistema de drenagem (Equação 2.71).

$$
t_{c}=0,99 * \frac{n * L}{{R_{h}}^{2 / 3} * I^{1 / 2}}
$$

Em que: $t_{c}$ - tempo de concentração (s); $L$ - comprimento do talvegue principal (m); $I$ - declividade média equivalente $(\mathrm{m} / \mathrm{m}) ; R_{h}$ - raio hidráulico $(\mathrm{m}) ; n$ - coeficiente de Manning.

Apesar de ser uma fórmula que permita a utilização para qualquer tipo de regime de escoamento (fluxo na superfície do solo, em canais ou em tubulações), McCuen (1989) destacou que o coeficiente de rugosidade, o comprimento e a declividade são variáveis atribuídas ao coletor de drenagem principal, enquanto que o raio hidráulico é do canal principal quando este estiver escoando sua capacidade máxima.

\section{Fórmula de Kerby-Hathaway}

Calibrada para áreas de drenagem pequenas e nas quais predomina o escoamento sobre a superfície do solo. A formulação, Equação 2.72, foi desenvolvida para bacias com menos de 10 acres $\left(0,04 \mathrm{~km}^{2}\right)$, com declividades menores que $1 \%$, coeficiente de 
escoamento de Manning de no máximo 0,8 e comprimento de escoamento menor que 365 metros (TOMAZ, 2002).

$$
t_{c}=0,606 * \frac{(L * n)^{0,467}}{I^{0,234}}
$$

Equação 2.72

Na qual: $t_{c}$ - tempo de concentração (h); $L$ - distância entre o exutório e o ponto mais distante da área drenada $(\mathrm{km}) ; I$ - declividade média $(\mathrm{m} / \mathrm{m}) ; n$ - coeficiente de rugosidade de Manning.

\section{Fórmula de Denver}

Também conhecida como método Colorado Urban Hydrograph Procedure foi desenvolvida inicialmente para cálculo do tempo de pico de vazões e adaptada para tempos de concentração (TOMAZ, 2002). Esta formulação, apresentada na Equação 2.73, é recomendada para bacias menores que $13 \mathrm{~km}^{2}$ e com declividades moderadas (FARIAS JÚNIOR, 2010).

$$
t_{c}=C_{t} *\left(\frac{0,386 * L * L_{c a}}{\sqrt{I}}\right)^{0,48}
$$

Para a qual: $t_{c}$ é o tempo de concentração medido em horas, $L$ é o comprimento do talvegue principal da bacia e $L_{c a}$ é o comprimento do talvegue a partir do centróide da bacia, ambos medidos em quilômetros, $I$ é a declividade média equivalente em metro por metro, $C_{t}$ é o coeficiente do tempo de pico - descrito em função da parcela impermeável da bacia $(A i)$, conforme mostrado na Equação 2.74, na Equação 2.75 e na Equação 2.76.

$$
\begin{array}{cc}
C_{t}=-0,00371 * A i+0,163 \text { para } 0 \leq A i \leq 10 & \text { Equação 2.74 } \\
C_{t}=0,000023 * A i^{2}-0,002241 * A i+0,146 \text { para } 10 \leq A i \leq 40 & \text { Equação 2.75 } \\
C_{t}=0,000033 * A i^{2}-0,000801 * A i+0,120 \text { para } 40 \leq A i \leq 100 & \text { Equação 2.76 }
\end{array}
$$

\section{Formulação de George-Ribeiro}

Para o DNIT (BRASIL, 2005) esta formulação, Equação 2.77, apresentou bons resultados para bacias com área de drenagem entre 0,03 e $1293 \mathrm{~km}^{2}$ e diversos tipos de cobertura de solo. 


$$
t_{c}=\frac{16 * L}{(1,05-0,2 * p) *(100 * I)^{0,04}}
$$

Para esta formulação $t_{c}$, tempo de concentração, é estimado em minutos, $L$, comprimento do talvegue, é medido em quilômetros, $p$ é a parcela de área vegetada da área de drenagem, em valores percentuais, $I$, a declividade do talvegue em metros de altura por metros lineares do talvegue.

\section{Fórmula do DNOS}

Desenvolvida para bacias rurais com área de drenagem menores que 0,45 km², declividades moderadas e comprimentos de talvegues não maiores que $1,2 \mathrm{~km}$ é representada pela Equação 2.78 (SILVEIRA, 2005).

$$
t_{c}=10 * \frac{A^{0,3} * L^{0,2}}{K * I^{0,4}}
$$

Na qual: $t_{c}$ é o tempo de concentração em minutos, $A$ a área de drenagem da bacia (ha), $L$ o comprimento do talvegue em metros, $I$ a declividade em valores percentuais e $K$ é a constante que considera as características do terreno, com valores apresentados no Quadro 2.10.

Quadro 2.10: relação entre características do terreno e seu coeficiente para cálculo de tempo de concentração por fórmula desenvolvida pelo DNOS (Fonte: FRANCO, 2004).

\begin{tabular}{|c|c|}
\hline Características do terreno & $K$ \\
\hline $\begin{array}{c}\text { Terreno areno-argiloso, coberto com vegetação intensa, elevada } \\
\text { absorção }\end{array}$ & 2,0 \\
\hline Terreno comum, coberto de vegetação, absorção apreciável & 3,0 \\
\hline Terreno argiloso, coberto com vegetação, absorção média & 4,0 \\
\hline Terreno argiloso, coberto com vegetação média, pouca absorção & 4,5 \\
\hline Terreno com rocha, escassa vegetação, baixa absorção & 5,0 \\
\hline Terreno rochoso, vegetação rala, reduzida absorção & 5,5 \\
\hline
\end{tabular}




\section{Fórmula Tulsa District}

Recomendada, Equação 2.79, para áreas de drenagem entre 1 e $1300 \mathrm{~km}^{2}$, declividade equivalente média entre 0,008 e $0,180 \mathrm{~m} / \mathrm{m}$, comprimento do talvegue entre 1,6 e 130 km e comprimento a partir do centróide da bacia variando entre 1,6 e 96 km. Possui uma constante que caracteriza numericamente o grau de urbanização da bacia.

$$
t_{c}=k *\left(\frac{0,053 * L * L_{c a}}{\sqrt{I}}\right)^{0,39}
$$

Em que: $t_{c}$ - tempo de concentração (h); $L$ - comprimento do talvegue principal $(\mathrm{km}) ; \mathrm{L}_{\mathrm{ca}}$ - comprimento do talvegue principal a partir do centróide da bacia $(\mathrm{km}) ; \mathrm{I}-$ declividade média equivalente $(\mathrm{m} / \mathrm{m}) ; k$ - constante que caracteriza o grau de urbanização da bacia, apresentado no Quadro 2.11.

Quadro 2.11: relação entre nível de urbanização e constante utilizada na fórmula Tulsa District (Fonte: FARIAS JÚNIOR, 2010).

\begin{tabular}{|c|c|}
\hline Nível de urbanização da bacia & $k$ \\
\hline Bacias naturais em área rural & 1,42 \\
\hline Bacias $50 \%$ urbanizadas & 0,92 \\
\hline Bacias totalmente urbanizadas & 0,59 \\
\hline
\end{tabular}

\section{Fórmula Soil Conservation Service Lag}

Desenvolvida para bacias rurais nas quais predomina o escoamento no solo. Recomendada, e apresentada na Equação 2.80, para áreas de drenagem não superiores a 2000 acres, equivalente a 8 km² (MCCUEN, 1989; TUCCI, 2001; TOMAZ, 2002).

$$
t_{c}=0,002269 * \frac{L^{0,8} *\left(\frac{1000}{C N}-9\right)^{0,7}}{\sqrt{I}}
$$

Para a qual: $t_{c}$ - tempo de concentração (h); $L$ - comprimento do talvegue (m); $I$ - declividade média equivalente (\%); CN - Curve Number do SCS. 
Existem fatores de correção para utilização da formulação em áreas urbanas. Tucci (2001) apresentou esses fatores, correlacionados com a porcentagem de área impermeabilizada. Para bacias urbanas a Equação 2.81 apresenta a formulação para correção do tempo de concentração:

$$
t_{c}=f_{1} * f_{2} * 0,002269 * \frac{L^{0,8} *\left(\frac{1000}{C N}-9\right)^{0,7}}{\sqrt{I}}
$$

Em que: $f_{1}$ e $f_{2}$ - fatores de correção do tempo de concentração determinado através de ábacos. Tucci (2001) apresenta os ábacos referentes a estes fatores de correção.

\section{Fórmula de Arnell}

Baseada em estudos realizados em 23 bacias urbanas japonesas com 14 rios, e comparados com outras bacias, parcialmente urbanizadas ou rurais, com áreas de drenagem entre 0,2 e $50 \mathrm{~km}^{2}$. Cada escoamento foi discretizado em tempos de 10 minutos. A formulação, apresentada na Equação 2.82 e na Equação 2.83 foi desenvolvida para qualquer tipo de bacia de drenagem (FRANCO, 2004).

$$
\begin{aligned}
& t_{c}=1,67 * 10^{-3} *\left(\frac{L}{I^{0,5}}\right)^{0,7} \text { para } 0,5<c<0,7 \\
& t_{c}=2,40 * 10^{-4} *\left(\frac{L}{I^{0,5}}\right)^{0,7} \text { para } 0,7<c<0,9
\end{aligned}
$$

Equação 2.82

Equação 2.83

Nas quais: $t_{c}$ é o tempo de concentração em horas, $L$ é o comprimento do talvegue em metros e $I$ é a declividade do talvegue em $\mathrm{m} / \mathrm{km}$.

\section{Fórmula da Federal Aviation Administration}

Desenvolvida para drenagem de aeroportos, sendo assim recomendada para pequenas bacias, com escoamento sobre o solo como predominante. As variáveis são todas relacionadas ao solo (MCCUEN, 1989; FRANCO, 2004). Para Tomaz (2002) a aplicação desta formulação, Equação 2.84, deve ser em áreas sem sistemas de drenagem ou canalizações. 


$$
\mathrm{t}_{\mathrm{c}}=\frac{22,73 *(1,1-\mathrm{c}) * \sqrt{\mathrm{L}}}{\mathrm{I}^{1 / 3}}
$$

Onde: $t_{c}$ - tempo de concentração estimado em minutos; $L$ - comprimento do talvegue, medido em quilômetros; $c$ - coeficiente de runoff do método racional, I declividade média equivalente da bacia em valores percentuais.

\section{Fórmula de Izzard}

Possui como características principais o fato da utilização da intensidade de precipitação, Equação 2.85, e coeficientes - Equação 2.86 - que variam de acordo com o uso e ocupação do solo (FARIAS JÚNIOR, 2010).

$$
\begin{aligned}
& t_{c}=\frac{526,4 * b * L^{0,333}}{(C * i)^{0,666}} \\
& b=\frac{0,0000276 * i+C_{r}}{I^{0,333}}
\end{aligned}
$$

Equação 2.85

Equação 2.86

Em que: $t_{c}$ - tempo de concentração em minutos; $L$ - comprimento do talvegue em quilômetros; $i$ - intensidade média da precipitação em milímetros por hora; $I$ declividade do talvegue em valores percentuais; $C_{r}$ - coeficiente de retardo, Quadro 2.12, varia de acordo com o tipo de superfície onde ocorre o escoamento (FARIAS JÚNIOR, 2010); $C$ - coeficiente de escoamento do método racional.

Quadro 2.12: relação entre cobertura superficial e coeficiente retardo (Fonte: FARIAS JÚNIOR, 2010).

\begin{tabular}{|l|c|}
\hline Características da superfície de escoamento & $C_{r}$ \\
\hline Superfície asfáltica lisa & 0,007 \\
\hline Pavimento de concreto & 0,012 \\
\hline Pavimento de brita-betume & 0,017 \\
\hline Gramado aparado & 0,046 \\
\hline Gramado denso & 0,060 \\
\hline
\end{tabular}


O Quadro 2.13 resume as características de aplicação das formulações apresentadas para estimativa do tempo de concentração.

Quadro 2.13: características das formulas utilizadas para estimativa do tempo de concentração.

\begin{tabular}{|c|c|c|c|c|}
\hline NOME & $\begin{array}{l}\text { USO DO } \\
\text { SOLO }\end{array}$ & $\begin{array}{c}\text { ÁREA DE } \\
\text { DRENAGEM }\end{array}$ & DECLIVIDADE & OBSERVAÇÕES \\
\hline Kirpich & Rural & $\begin{array}{l}\text { Menor que } \\
0,45 \mathrm{~km}^{2}\end{array}$ & Entre 3 e $10 \%$ & $\begin{array}{c}\text { Parcela da área } \\
\text { vegetada máxima de } \\
56 \%\end{array}$ \\
\hline Dooge & Rural & $\begin{array}{c}\text { Entre } 140 \mathrm{e} \\
930 \mathrm{~km}^{2}\end{array}$ & - & $\begin{array}{c}\text { Escoamento } \\
\text { predominante em } \\
\text { canais }\end{array}$ \\
\hline $\begin{array}{l}\text { Bransby - } \\
\text { Williams }\end{array}$ & Rural & $\begin{array}{c}\text { Menor que } 30 \\
\mathrm{~km}^{2}\end{array}$ & $\begin{array}{l}\text { Consideradas } \\
\text { altas }\end{array}$ & 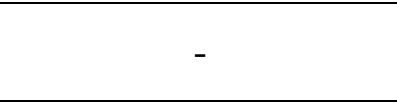 \\
\hline Ven te Chow & Rural & $\begin{array}{c}\text { Entre } 1,1 \text { e } 19 \\
\mathrm{~km}^{2}\end{array}$ & 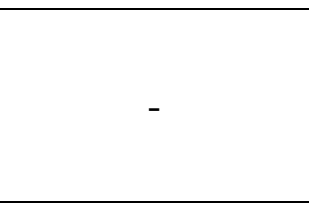 & $\begin{array}{l}\text { Apresentou bons } \\
\text { resultados para áreas } \\
\text { superiores a } 45 \mathrm{~km}^{2} \\
\text { (BRASIL, 2005) }\end{array}$ \\
\hline Picking & Rural & $\begin{array}{l}\text { Menor que } \\
0,45 \mathrm{~km}^{2}\end{array}$ & - & $\begin{array}{l}\text { Apresenta tendência } \\
\text { de Subestimar valores } \\
\text { (BRASIL, 2005) }\end{array}$ \\
\hline Giandotti & Rural & - & - & $\begin{array}{l}\text { Maiores que } 20,5 \mathrm{~km}^{2} \\
\text { (BRASIL,2005) }\end{array}$ \\
\hline Pasini & Rural & - & - & $\begin{array}{c}\text { Áreas entre } 0,03 \mathrm{e} \\
3476 \mathrm{~km}^{2} \text { (BRASIL } \\
2005)\end{array}$ \\
\hline $\begin{array}{l}\text { Johnstone - } \\
\text { Cross }\end{array}$ & Rural & - & - & $\begin{array}{l}\text { Áreas de drenagem } \\
\text { entre } 65 \text { e } 4200 \mathrm{~km}^{2} \\
\text { (FRANCO, 2004) }\end{array}$ \\
\hline Ventura & Rural & - & - & - \\
\hline DNOS & Rural & $\begin{array}{l}\text { Menor que } \\
0,45 \mathrm{~km}^{2}\end{array}$ & $\begin{array}{c}\text { Declividades } \\
\text { consideradas } \\
\text { moderadas } \\
\end{array}$ & $\begin{array}{c}\text { Comprimento de } \\
\text { talvegue não maior } \\
\text { que } 1,2 \mathrm{~km} \\
\end{array}$ \\
\hline $\begin{array}{l}\text { California } \\
\text { culverts } \\
\text { practice }\end{array}$ & - & $\begin{array}{l}\text { Menor que } \\
0,45 \mathrm{~km}^{2}\end{array}$ & Entre 3 e $10 \%$ & $\begin{array}{l}\text { Adaptada da } \\
\text { formulação de Kirpich }\end{array}$ \\
\hline DER - SP & - & $\begin{array}{c}\text { Maior que } 1 \\
\mathrm{~km}^{2}\end{array}$ & Entre 3 e $10 \%$ & $\begin{array}{c}\text { Adaptada da } \\
\text { formulação de Kirpich }\end{array}$ \\
\hline Temez & - & $\begin{array}{l}\text { Menor que } \\
3000 \mathrm{~km}^{2}\end{array}$ & - & $\begin{array}{c}\text { Áreas entre } 0,03 \mathrm{e} \\
3476 \mathrm{~km}^{2}(\mathrm{BRASIL}, \\
2005)\end{array}$ \\
\hline Van Sickle & - & $\begin{array}{c}\text { Menor que } 93 \\
\mathrm{~km}^{2}\end{array}$ & - & $\begin{array}{c}\text { Escoamento } \\
\text { predominante em } \\
\text { canais ou superfícies }\end{array}$ \\
\hline $\begin{array}{l}\text { Carter Lag Eq. } \\
\text { For Partially } \\
\text { Sewewred } \\
\text { Watersheds }\end{array}$ & Urbana & $\begin{array}{l}\text { Menor que } 21 \\
\mathrm{~km}^{2}\end{array}$ & Inferior a $0,5 \%$ & $\begin{array}{c}\text { Comprimentos } \\
\text { menores que } 11 \mathrm{~km}, \mathrm{e} \\
\text { coeficiente de } \\
\text { Manning entre } 0,013 \mathrm{e} \\
0,025\end{array}$ \\
\hline
\end{tabular}


Quadro 2.12: (cont.) características das fórmulas utilizadas para estimativa do tempo de concentração.

\begin{tabular}{|c|c|c|c|c|}
\hline $\begin{array}{l}\text { US Army Corps } \\
\text { of Engineers }\end{array}$ & Urbana & - & - & $\begin{array}{l}\text { Precipitações máximas de } \\
254 \mathrm{~mm} / \mathrm{h}\end{array}$ \\
\hline Tsuchiya & Qualquer & $\begin{array}{c}\text { Entre } 0,01 \mathrm{e} \\
0,2 \mathrm{~km}^{2}\end{array}$ & - & ( \\
\hline Arnell & Qualquer & $\begin{array}{c}\text { Entre } 0,2 \mathrm{e} \\
50 \mathrm{~km}^{2}\end{array}$ & - & - \\
\hline $\begin{array}{l}\text { Método } \\
\text { cinemático }\end{array}$ & Qualquer & $\begin{array}{c}\text { Sem } \\
\text { restrições }\end{array}$ & - & $\begin{array}{c}\text { Emprego em regiões } \\
\text { homogêneas }\end{array}$ \\
\hline $\begin{array}{l}\text { Federal Aviation } \\
\text { Administration }\end{array}$ & Qualquer & - & - & $\begin{array}{l}\text { Desenvolvida para } \\
\text { pequenas áreas }\end{array}$ \\
\hline $\begin{array}{l}\text { Eagleson Lag } \\
\text { Model }\end{array}$ & Qualquer & $\begin{array}{l}\text { Menor que } \\
21 \mathrm{~km}^{2}\end{array}$ & - & $\begin{array}{c}\text { Variáveis da fórmula } \\
\text { atribuído ao coletor de } \\
\text { drenagem }\end{array}$ \\
\hline SCS Lag & Qualquer & $\begin{array}{l}\text { Menor que } \\
8 \mathrm{~km}^{2}\end{array}$ & - & $\begin{array}{c}\text { Escoamento } \\
\text { predominante no solo }\end{array}$ \\
\hline Tulsa District & Qualquer & $\begin{array}{l}\text { Menor que } \\
1300 \mathrm{~km}^{2}\end{array}$ & $\begin{array}{c}\text { Entre } 0,008 \mathrm{e} \\
0,180 \mathrm{~m} / \mathrm{m}\end{array}$ & $\begin{array}{c}\text { Extensão do talvegue } \\
\text { entre } 1,6 \text { e } 130 \mathrm{~km}\end{array}$ \\
\hline Denver & Qualquer & $\begin{array}{c}\text { Menor que } \\
13 \mathrm{~km}^{2}\end{array}$ & $\begin{array}{c}\text { Declividades } \\
\text { moderadas }\end{array}$ & 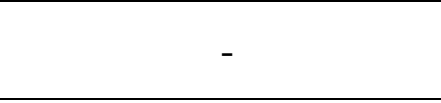 \\
\hline Onda cinemática & Qualquer & $\begin{array}{l}\text { Menor que } \\
2 \mathrm{~km}^{2}\end{array}$ & - & $\begin{array}{l}\text { Extensão do talvegue } \\
\text { menor que } 100 \mathrm{~m}\end{array}$ \\
\hline $\begin{array}{l}\text { George - } \\
\text { Ribeiro }\end{array}$ & Qualquer & - & - & $\begin{array}{c}\text { Áreas de drenagem entre } \\
0,03 \text { e } 1293 \mathrm{~km}^{2} \\
\text { (BRASIL, 2005) }\end{array}$ \\
\hline $\begin{array}{c}\text { Kerby - } \\
\text { Hathaway }\end{array}$ & Qualquer & $\begin{array}{l}\text { Menor que } \\
0,04 \mathrm{~km}^{2}\end{array}$ & $\begin{array}{c}\text { Menor que } \\
1 \%\end{array}$ & $\begin{array}{l}\text { Extensão máxima de } \\
\text { escoamento de } 365 \text { m }\end{array}$ \\
\hline Izzard & Qualquer & - & - & - \\
\hline
\end{tabular}




\section{METODOLOGIA}

\subsection{Chuva crítica}

Chuva crítica é aquela que no âmbito das restrições do método racional gera o máximo volume de detenção e corresponde a uma duração igual ao tempo em que as vazões afluentes e efluentes se igualam. A chuva crítica é ilustrada na Figura 3.1.

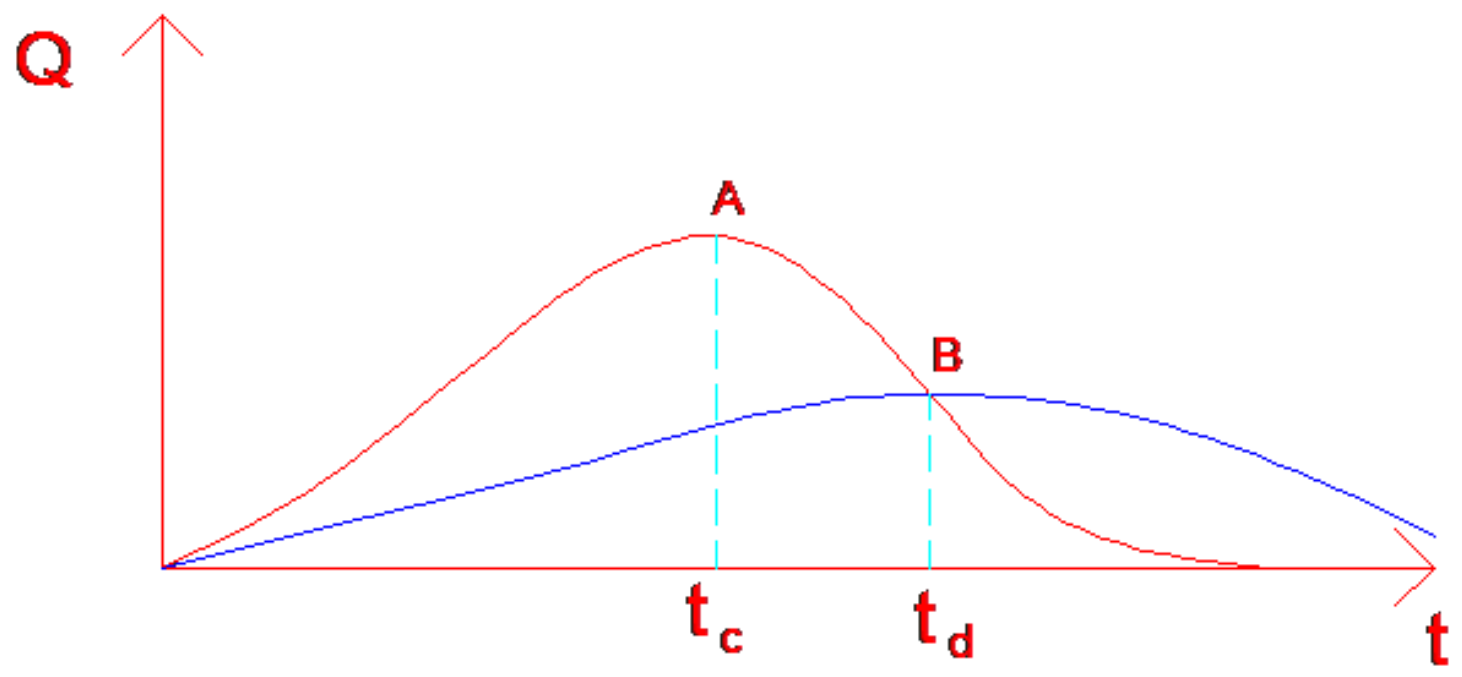

Figura 3.1: representação gráfica dos hidrogramas afluente e efluente durante um evento chuvoso crítico.

Neste ponto a intensidade instantânea da chuva deverá igualar-se a vazão efluente máxima, $\mathrm{Q}_{\mathrm{s}}$, dividida pelo produto do coeficiente de escoamento superficial pela área, como ilustrado na Equação 3.1.

$$
I_{s}=\frac{Q_{s} * N_{1}}{C * A}
$$

Em que: $I_{s}$ - intensidade efluente equivalente, em $\mathrm{mm} / \mathrm{h}$.

$N_{l^{-}}$coeficiente de conversão de unidades, que para $I_{s} \mathrm{em} \mathrm{mm} / \mathrm{h}, Q_{s}$, vazão efluente máxima, em m³/s e $A$, área de drenagem, em $\mathrm{km}^{2}$ vale 3,6.

As relações Intensidade - duração - Frequência, discutidas anteriormente possuem forma clássica apresentada na Equação 3.2, enquanto que a definição de intensidade média pode ser posta na forma da Equação 3.3.

$$
\begin{gathered}
\bar{I}_{(t)}=\frac{k * T^{m}}{(t+b)^{n}} \\
\bar{I}_{(t)}=\frac{1}{t} * \int_{0}^{t} I_{(t)} * d t
\end{gathered}
$$


Em que: $I_{(t)}$ é a intensidade instantânea para um tempo $t$ qualquer.

Igualando-se a Equação 3.2 à Equação 3.3 e fazendo a derivada de ambos os termos em função do tempo, $t$, e organizando seus termos chega-se à Equação 3.4.

$$
I_{(t)}=\frac{k * T^{m}}{(t+b)^{n}} *\left(1-\frac{n * t}{t+b}\right)
$$

Igualando-se a Equação 3.4 à Equação 3.1, chega-se à Equação 3.5 que representa a intensidade efluente equivalente, na qual o tempo $t$ define a duração da chuva crítica para o dimensionamento da bacia de detenção.

$$
I_{s(t)}=\frac{k * T^{m}}{(t+b)^{n}} *\left(1-\frac{n * t}{t+b}\right)
$$

\subsection{Volume de Detenção}

O modelo de cálculo proposto está baseado na metodologia de estimação do volume desenvolvida por Franco (2004) e Matias (2006) que leva em consideração o esvaziamento da bacia hidrográfica após o término do evento chuvoso. O modelo proposto assume que o reservatório de detenção encontra-se situado em série (in line) ao sistema de drenagem.

A forma utilizada para avaliar a aplicabilidade da metodologia proposta é a comparação desta com diversos métodos de pré-dimensionamento de volumes de detenção usualmente empregados. Adotou-se o método de Porto (2002) como processo que fornece valor padrão para o montante detido em bacias de detenção. O método de Porto (2002) foi escolhido como padrão por ter apresentado resultados satisfatórios em sua aplicação para estimativa do volume de detenção na bacia de drenagem da Praça Charles Miller, na cidade de São Paulo.

As hipóteses assumidas foram:

a. Hidrograma afluente triangular em $\mathrm{Q}_{\text {máx }}$ em $\mathrm{t}_{\mathrm{c}}$;

b. Hidrograma efluente linear variando de 0 (zero) a $t_{d}$; com valor máximo $Q_{s}$ no tempo $\mathrm{t}=\mathrm{t}_{\mathrm{d}}$.

c. Hidrograma efluente exponencial com $Q_{s}$ numericamente igual a $\alpha * t^{\beta}$. 


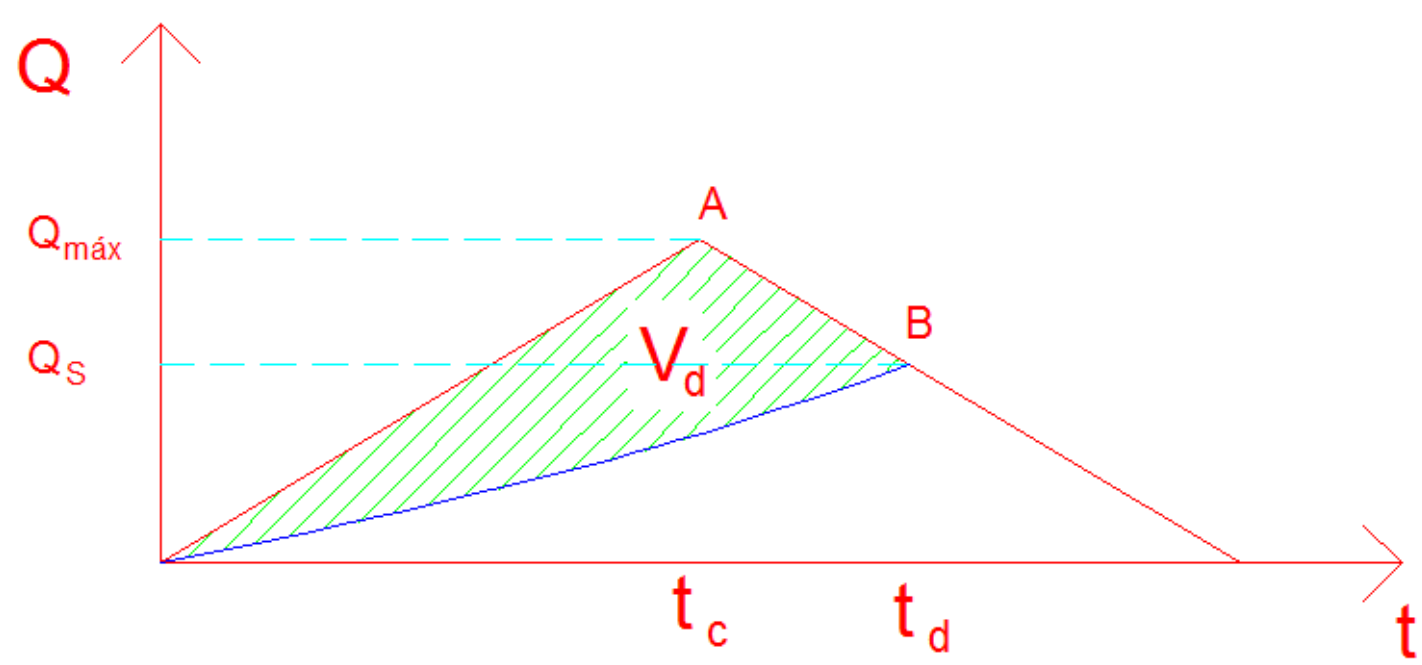

Figura 3.2: idealização gráfica da estimativa do volume de detenção pelo método proposto.

$\mathrm{O}$ volume afluente à bacia no intervalo $0<\mathrm{t}<\mathrm{t}_{\mathrm{d}}$, quando o volume retido é máximo pode ser visto na Equação 3.6.

$$
V_{a f}=\frac{C * A}{N_{1}} * \frac{k * T^{m} * t_{d}}{\left(t_{d}+b\right)^{n}} * N_{2}
$$

Em que $N_{l}$ e $N_{2}$ são coeficientes de conversão de unidades, sendo $N_{l}=3,6$ para área em unidades de $\mathrm{km}^{2}, \bar{I}(t)$ em mm/h e $V_{a f}$ em $\mathrm{m}^{3}$, e $N_{2}=60$ para $t_{d}$ em minutos.

\subsubsection{Volume de detenção para Hipótese b}

Para a hipótese assumida no item b do Capítulo 3.2, na qual o hidrograma efluente, dado na Figura 3.2, apresenta variação linear, o volume efluente à bacia de detenção pode ser calculado conforme Equação 3.7 e o volume de detenção que pode ser calculado conforme a Equação 3.8.

$$
\begin{gathered}
V_{e f}=\frac{Q_{s} * t_{d}}{2} \\
V_{d}=V_{a f}-\frac{Q_{s} * t_{d}}{2}
\end{gathered}
$$

Equação 3.7

Equação 3.8

Associando a Equação 3.6 a Equação 3.8 o volume de detenção $V_{d}$ assume a forma apresentada na Equação 3.9.

$$
V_{d}=\frac{C * A}{N_{1}} * \frac{k * T^{m} * t_{d}}{\left(t_{d}+b\right)^{n}} * N_{2}-\frac{\mathrm{Q}_{\mathrm{s}} * \mathrm{t}_{\mathrm{d}}}{2}
$$




\subsubsection{Volume de detenção para hipótese c}

Pelo hidrograma de saída exponencial o volume efluente ao reservatório de detenção é dado pela Equação 3.10.

$$
V_{e f}=\frac{C * A * I_{s}}{N_{1}} * \frac{t_{d}}{\beta+1}
$$

Em que o valor de $\beta$ depende do tipo do regime de variação da vazão efluente, que por sua vez varia de acordo com o dispositivo de extravasão da bacia de detenção. Desta forma o volume detido no reservatório é dado pela Equação 3.11.

$$
V_{d}=\frac{C * A}{N_{1}} * N_{2} * t_{d} *\left[\frac{k * T^{n}}{\left(t_{d}+b\right)^{m}}-\frac{I_{s}}{\beta+1}\right]
$$

\subsubsection{Análise comparativa}

A avaliação da metodologia proposta será realizada segundo a comparação da aplicação desta com métodos de pré-dimensionamento de volumes de detenção usualmente empregados. Desta forma adotou-se o método de Porto (2002) como processo que fornece valor padrão para o montante detido em bacias de detenção.

De forma a possibilitar esta avaliação fez-se dois tipos de validação dos volumes de detenção estimados pelas diversas fórmulas confrontadas. A primeira faz menção ao erro médio percentual e a segunda ao erro médio padrão. A primeira forma de avaliação possui formulação que pode ser observada na Equação 3.12. A segunda forma de julgamento das metodologias possui formulação que pode ser vista na Equação 3.13.

$$
\begin{aligned}
& E M=\frac{100}{n} * \sum_{i=1}^{n} \frac{V_{C}-V_{P}}{V_{P}} \\
& E P=\frac{1}{n-1} * \sum_{i=1}^{n}\left(100 * \frac{V_{C}-V_{P}}{V_{P}}-E M\right)^{2} \\
& \text { Para conferir validade ao processo, diversas foram as condições locais } \\
& \text { estudadas, permitindo análise confiável dos valores obtidos. Estas condições serão } \\
& \text { apresentadas no capítulo referente a resultados e discussões. }
\end{aligned}
$$

\subsection{Determinação das relações IDF}

A determinação de curvas Intensidade - Duração - Frequência depende de informações pluviográficas, que permitem determinar, com maior precisão, a intensidade de eventos chuvosos. Na ausência destes dados procede-se inicialmente à 
transformação de alturas pluviométricas máximas de 1 dia — obtidas por meio de pluviômetros - em intensidades médias dos eventos.

ESA (2006) apresentou relações obtidas pelo Instituto Astronômico e Geofísico de São Paulo em 1966 para transformação de chuvas de 1 dia em chuvas de 24 horas. Estas relações podem ser observadas no Quadro 3.1, na qual os valores apresentados foram determinados para a cidade de São Paulo, considerando eventos ocorridos no período de 1928 a 1965.

Quadro 3.1: relação entre alturas pluviométricas máximas de 24 horas e 1 dia determinadas para a cidade de São Paulo (FONTE: ESA, 2006).

\begin{tabular}{|c|c|c|c|c|c|}
\hline \multicolumn{7}{|c|}{$\begin{array}{c}\text { Relação entre alturas pluviométricas das chuvas } \\
\text { máximas de } 24 \text { horas e 1 dia }\end{array}$} \\
\hline 5 & 10 & 25 & 50 & 75 & 100 \\
\hline 1,13 & 1,13 & 1,14 & 1,15 & 1,14 & 1,15 \\
\hline
\end{tabular}

As relações entre as chuvas de diferentes durações também tem grande importância, e neste âmbito ESA (2006) apresentou valores estabelecidos pelo antigo Departamento Nacional de Obras e Saneamento - DNOS - que associam diferentes durações e períodos de retorno variando de 2 a 100 anos. Estas relações podem ser vistas no Quadro 3.2.

Quadro 3.2: relações entre alturas pluviométricas para diversas durações de eventos.

\begin{tabular}{|c|c|}
\hline $\begin{array}{c}\text { Relação entre as durações } \\
\text { das precipitações }\end{array}$ & $\begin{array}{c}\text { Relação entre as } \\
\text { alturas pluviométricas }\end{array}$ \\
\hline 5 minutos/ 30 minutos & 0,34 \\
\hline 10 minutos/30 minutos & 0,54 \\
\hline 15 minutos/ 30 minutos & 0,70 \\
\hline 20 minutos/ 30 minutos & 0,81 \\
\hline 25 minutos/ 30 minutos & 0,91 \\
\hline 30 minutos/ 1 hora & 0,74 \\
\hline 1 hora/ 24 horas & 0,42 \\
\hline 6 horas/ 24 horas & 0,72 \\
\hline 8 horas/ 24 horas & 0,78 \\
\hline 10 horas/ 24 horas & 0,82 \\
\hline 12 horas/ 24 horas & 0,85 \\
\hline
\end{tabular}




\subsubsection{Dados de chuvas utilizados}

Para determinação da relação Intensidade - Duração - Frequência há a necessidade de se determinar a série histórica de alturas pluviométricas mais confiável. $\mathrm{Na}$ região da cidade de Pirassununga, São Paulo, foram listadas as estações pluviométricas presentes no Quadro 3.3, todos obtidos na base de dados da Agência Nacional de Águas - ANA.

Quadro 3.3: estações pluviométricas localizadas nas proximidades da cidade de Pirassununga, SP (FONTE: ANA, 2012).

\begin{tabular}{|c|c|c|c|c|}
\hline Código & Nome & Rio & Responsável & Operadora \\
\hline 2147036 & USINA SÃO LUÍS & - & FCTH/DAEE-SP & DESATIVADA \\
\hline 2147041 & PIRASSUNUNGA & - & FCTH/DAEE-SP & DESATIVADA \\
\hline 2147042 & $\begin{array}{l}\text { GOVERNADOR } \\
\text { FERNANDO COSTA }\end{array}$ & - & FCTH/DAEE-SP & FCTH/DAEE-SP \\
\hline 2147052 & PIRASSUNUNGA & - & INMET & INMET \\
\hline 2147053 & $\begin{array}{l}\text { PIRASSUNUNGA (CPO } \\
\text { FONTENELLE) }\end{array}$ & - & INMET & INMET \\
\hline 2147081 & USINA EMAS & - & FCTH/DAEE-SP & DESATIVADA \\
\hline 2147084 & $\begin{array}{l}\text { FAZENDA SANTA } \\
\text { CATARINA }\end{array}$ & - & FCTH/DAEE-SP & DESATIVADA \\
\hline 2147085 & BAGUAÇU & - & FCTH/DAEE-SP & FCTH/DAEE-SP \\
\hline 2147087 & $\begin{array}{l}\text { FAZENDA SANTA } \\
\text { MARIA DA ROCHA }\end{array}$ & - & FCTH/DAEE-SP & DESATIVADA \\
\hline 2147096 & $\begin{array}{l}\text { PIRASSUNUNGA } \\
\text { (CPEF) }\end{array}$ & - & FCTH/DAEE-SP & DESATIVADA \\
\hline 2147117 & PIRASSUNUNGA & - & FCTH/DAEE-SP & FCTH/DAEE-SP \\
\hline 2147120 & BAGUACU (CPEF) & - & FCTH/DAEE-SP & DESATIVADA \\
\hline 2147168 & $\begin{array}{l}\text { FAZENDA SANTA } \\
\text { CATARINA }\end{array}$ & - & ELEKTRO & ELEKTRO \\
\hline 2147169 & SÍTIO AGROCERES & - & ELEKTRO & ELEKTRO \\
\hline 2247217 & $\begin{array}{l}\text { FAZENDA SANTA } \\
\text { TEREZA (ELEKTRO) }\end{array}$ & - & ELEKTRO & ELEKTRO \\
\hline
\end{tabular}


Foi utilizado o posto pluviométrico número 02147117, denominado Pirassununga possuindo como operador e responsável a Fundação Centro Tecnológico de Hidráulica - FCTH - e o Departamento de Águas e Energia Elétrica - DAEE pelo cadastro da ANA. O posto pluviométrico possui série histórica de 68 anos, de 1940 a 2007. As máximas alturas pluviométricas anuais são mostradas no Quadro 3.4, estas precipitações foram retiradas da série bruta da base de dados.

Quadro 3.4: máximas precipitações de 1 dia para o posto 02147117 da base de dados da ANA, Pirassununga, SP.

\begin{tabular}{|c|c|c|c|c|c|c|c|}
\hline Ano & $\mathrm{P}(\mathrm{mm})$ & Ano & $\mathrm{P}(\mathrm{mm})$ & Ano & $\mathrm{P}(\mathrm{mm})$ & Ano & $\mathrm{P}(\mathrm{mm})$ \\
\hline 1940 & 64,2 & 1957 & 62,7 & 1974 & 84,3 & 1991 & 87,0 \\
\hline 1941 & 56,4 & 1958 & 70,0 & 1975 & 76,8 & 1992 & 57,0 \\
\hline 1942 & 91,5 & 1959 & 70,8 & 1976 & 91,7 & 1993 & 52,2 \\
\hline 1943 & 140,2 & 1960 & 78,5 & 1977 & 77,9 & 1994 & 80,0 \\
\hline 1944 & 68,0 & 1961 & 88,6 & 1978 & 88,7 & 1995 & 91,4 \\
\hline 1945 & 90,5 & 1962 & 84,5 & 1979 & 63,5 & 1996 & 85,2 \\
\hline 1946 & 68,0 & 1963 & 100,6 & 1980 & 90,9 & 1997 & 53,6 \\
\hline 1947 & 81,0 & 1964 & 89,0 & 1981 & 103,9 & 1998 & 96,5 \\
\hline 1948 & 64,0 & 1965 & 78,5 & 1982 & 82,9 & 1999 & 130,0 \\
\hline 1949 & 68,0 & 1966 & 122,2 & 1983 & 105,7 & 2000 & 114,0 \\
\hline 1950 & 56,0 & 1967 & 62,8 & 1984 & 71,7 & 2001 & 64,0 \\
\hline 1951 & 63,7 & 1968 & 68,0 & 1985 & 71,2 & 2002 & 90,2 \\
\hline 1952 & 48,1 & 1969 & 72,5 & 1986 & 70,3 & 2003 & 99,9 \\
\hline 1953 & 100,2 & 1970 & 111,1 & 1987 & 101,9 & 2004 & 102,0 \\
\hline 1954 & 69,0 & 1971 & 54,6 & 1988 & 68,1 & 2005 & 77,0 \\
\hline 1955 & 65,0 & 1972 & 88,8 & 1989 & 74,0 & 2006 & 53,7 \\
\hline 1956 & 106,6 & 1973 & 57,5 & 1990 & 110,5 & 2007 & 113,0 \\
\hline
\end{tabular}

Os dados foram ordenados em ordem decrescente, calculou-se a frequência e o período de retorno, Quadro 3.5 Para esta série foram calculados ainda a média aritmética, o desvio padrão e o coeficiente de assimetria, sendo seus respectivos valores $81,50 \mathrm{~mm}, 20,06 \mathrm{~mm}$, e 0,61 . 
Quadro 3.5: análise de frequência da série histórica do posto 02147117 da base de dados da ANA, Pirassununga, SP.

\begin{tabular}{|c|c|c|c|c|c|c|c|}
\hline \multicolumn{8}{|c|}{ Série ordenada } \\
\hline Ordem & Freq. (\%) & P. Retorno & Altura & Ordem & Freq. (\%) & P. Retorno & Altura \\
\hline 1 & 1,45 & 69,00 & 140,2 & 35 & 50,72 & 1,97 & 78,5 \\
\hline 2 & 2,90 & 34,50 & 130,0 & 36 & 52,17 & 1,92 & 77,9 \\
\hline 3 & 4,35 & 23,00 & 122,2 & 37 & 53,62 & 1,86 & 77,0 \\
\hline 4 & 5,80 & 17,25 & 114,0 & 38 & 55,07 & 1,82 & 76,8 \\
\hline 5 & 7,25 & 13,80 & 113,0 & 39 & 56,52 & 1,77 & 74,0 \\
\hline 6 & 8,70 & 11,50 & 111,1 & 40 & 57,97 & 1,73 & 72,5 \\
\hline 7 & 10,14 & 9,86 & 110,5 & 41 & 59,42 & 1,68 & 71,7 \\
\hline 8 & 11,59 & 8,63 & 106,6 & 42 & 60,87 & 1,64 & 71,2 \\
\hline 9 & 13,04 & 7,67 & 105,7 & 43 & 62,32 & 1,60 & 70,8 \\
\hline 10 & 14,49 & 6,90 & 103,9 & 44 & 63,77 & 1,57 & 70,3 \\
\hline 11 & 15,94 & 6,27 & 102,0 & 45 & 65,22 & 1,53 & 70,0 \\
\hline 12 & 17,39 & 5,75 & 101,9 & 46 & 66,67 & 1,50 & 69,0 \\
\hline 13 & 18,84 & 5,31 & 100,6 & 47 & 68,12 & 1,47 & 68,1 \\
\hline 14 & 20,29 & 4,93 & 100,2 & 48 & 69,57 & 1,44 & 68,0 \\
\hline 15 & 21,74 & 4,60 & 99,9 & 49 & 71,01 & 1,41 & 68,0 \\
\hline 16 & 23,19 & 4,31 & 96,5 & 50 & 72,46 & 1,38 & 68,0 \\
\hline 17 & 24,64 & 4,06 & 91,7 & 51 & 73,91 & 1,35 & 68,0 \\
\hline 18 & 26,09 & 3,83 & 91,5 & 52 & 75,36 & 1,33 & 65,0 \\
\hline 19 & 27,54 & 3,63 & 91,4 & 53 & 76,81 & 1,30 & 64,2 \\
\hline 20 & 28,99 & 3,45 & 90,9 & 54 & 78,26 & 1,28 & 64,0 \\
\hline 21 & 30,43 & 3,29 & 90,5 & 55 & 79,71 & 1,25 & 64,0 \\
\hline 22 & 31,88 & 3,14 & 90,2 & 56 & 81,16 & 1,23 & 63,7 \\
\hline 23 & 33,33 & 3,00 & 89,0 & 57 & 82,61 & 1,21 & 63,5 \\
\hline 24 & 34,78 & 2,88 & 88,8 & 58 & 84,06 & 1,19 & 62,8 \\
\hline 25 & 36,23 & 2,76 & 88,7 & 59 & 85,51 & 1,17 & 62,7 \\
\hline 26 & 37,68 & 2,65 & 88,6 & 60 & 86,96 & 1,15 & 57,5 \\
\hline 27 & 39,13 & 2,56 & 87,0 & 61 & 88,41 & 1,13 & 57,0 \\
\hline 28 & 40,58 & 2,46 & 85,2 & 62 & 89,86 & 1,11 & 56,4 \\
\hline 29 & 42,03 & 2,38 & 84,5 & 63 & 91,30 & 1,10 & 56,0 \\
\hline 30 & 43,48 & 2,30 & 84,3 & 64 & 92,75 & 1,08 & 54,6 \\
\hline 31 & 44,93 & 2,23 & 82,9 & 65 & 94,20 & 1,06 & 53,7 \\
\hline 32 & 46,38 & 2,16 & 81,0 & 66 & 95,65 & 1,05 & 53,6 \\
\hline 33 & 47,83 & 2,09 & 80,0 & 67 & 97,10 & 1,03 & 52,2 \\
\hline 34 & 49,28 & 2,03 & 78,5 & 68 & 98,55 & 1,01 & 48,1 \\
\hline
\end{tabular}




\subsubsection{Método de Gumbel-Chow}

O método de Gumbel-Chow é recomendado para determinação de relações baseadas em eventos anuais extremos. A metodologia permite a determinação de intensidades máximas de precipitação para diversos tempos de recorrência. A distribuição pode ser representada segundo a forma apresentada na Equação 3.14.

$$
P_{T}=P_{\text {med }}+k * \sigma_{P}
$$

Equação 3.14

Na qual: $P_{T}$ - representa a precipitação total máxima diária utilizada na distribuição;

$P_{m e d}$ - é a média das precipitações máximas da série histórica;

$k$ - fator de frequência - dependente do tamanho da amostra, do tempo de retorno e do tipo de distribuição, apresentado no Quadro 3.6.

$\sigma_{P}-$ desvio padrão da amostra utilizada.

Quadro 3.6: valores do valor de frequência estabelecidos de acordo com o tempo de retorno.

\begin{tabular}{|c|c|}
\hline Período de retorno (anos) & Fator de Frequência \\
\hline 2 & $-0,158$ \\
\hline 5 & 0,809 \\
\hline 10 & 1,449 \\
\hline 15 & 1,811 \\
\hline 20 & 2,064 \\
\hline 25 & 2,258 \\
\hline 50 & 2,858 \\
\hline 75 & 3,207 \\
\hline 100 & 3,454 \\
\hline
\end{tabular}

Partindo dos valores de precipitação total diários, obtidos a partir da aplicação da metodologia de Gumbel-Chow, recorre-se à transformação destes valores para cada tempo de duração de evento chuvoso - utilizando as relações presentes no Quadro 3.1 e no Quadro 3.2 - transformando-os posteriormente em valores de intensidade de chuva. O Quadro 3.7 e o Quadro 3.8 apresentam, respectivamente, as alturas máximas precipitadas e suas intensidades de precipitação. 
Quadro 3.7: relação entre alturas precipitadas máximas, duração do evento e período de retorno para dados do posto pluviométrico 02147117 da base de dados da ANA, Pirassununga, SP.

\begin{tabular}{|c|c|c|c|c|c|c|c|c|c|}
\hline \multirow[b]{2}{*}{ Duração } & \multicolumn{9}{|c|}{ PERÍODO DE RETORNO (ANOS) } \\
\hline & 2 & 5 & 10 & 15 & 20 & 25 & 50 & 75 & 100 \\
\hline $5 \mathrm{~min}$ & 9,4 & 11,8 & 13,3 & 14,2 & 14,8 & 15,3 & 16,7 & 17,6 & 18,2 \\
\hline $10 \min$ & 15,0 & 18,7 & 21,2 & 22,5 & 23,5 & 24,3 & 26,6 & 27,9 & 28,8 \\
\hline $15 \mathrm{~min}$ & 19,4 & 24,2 & 27,4 & 29,2 & 30,5 & 31,4 & 34,4 & 36,2 & 37,4 \\
\hline $20 \min$ & 22,5 & 28,0 & 31,7 & 33,8 & 35,3 & 36,4 & 39,8 & 41,9 & 43,3 \\
\hline $25 \mathrm{~min}$ & 25,3 & 31,5 & 35,6 & 38,0 & 39,6 & 40,9 & 44,8 & 47,0 & 48,6 \\
\hline $30 \mathrm{~min}$ & 27,8 & 34,6 & 39,2 & 41,7 & 43,5 & 44,9 & 49,2 & 51,7 & 53,4 \\
\hline $1 \mathrm{~h}$ & 37,5 & 46,8 & 52,9 & 56,4 & 58,8 & 60,7 & 66,5 & 69,8 & 72,2 \\
\hline $6 \mathrm{~h}$ & 64,3 & 80,2 & 90,8 & 96,7 & 100,9 & 104,1 & 113,9 & 119,7 & 123,8 \\
\hline $8 \mathrm{~h}$ & 69,6 & 86,9 & 98,3 & 104,8 & 109,3 & 112,7 & 123,4 & 129,7 & 134,1 \\
\hline $10 \mathrm{~h}$ & 73,2 & 91,4 & 103,4 & 110,1 & 114,9 & 118,5 & 129,8 & 136,3 & 141,0 \\
\hline $12 \mathrm{~h}$ & 75,9 & 94,7 & 107,1 & 114,2 & 119,1 & 122,9 & 134,5 & 141,3 & 146,1 \\
\hline $24 \mathrm{~h}$ & 89,3 & 111,4 & 126,0 & 134,3 & 140,1 & 144,5 & 158,3 & 166,2 & 171,9 \\
\hline $1 \mathrm{dia}$ & 78,3 & 97,7 & 110,6 & 117,8 & 122,9 & 126,8 & 138,8 & 145,8 & 150,8 \\
\hline
\end{tabular}

Quadro 3.8: Relação entre intensidades de precipitação máximas, duração do evento e período de retorno para dados do posto pluviométrico 02147117 da base de dados da ANA, Pirassununga, SP.

\begin{tabular}{|c|c|c|c|c|c|c|c|c|c|}
\hline \multirow{2}{*}{ Duração } & \multicolumn{10}{|c|}{ PERÍODO DE RETORNO (ANOS) } \\
\cline { 2 - 10 } & 2 & 5 & 10 & 15 & 20 & 25 & 50 & 75 & 100 \\
\cline { 2 - 10 } & \multicolumn{10}{|c|}{ (1, 5 min } & 1,887 & 2,355 & 2,664 & 2,839 & 2,961 & 3,055 & 3,345 & 3,513 & 3,633 \\
\hline $10 \mathrm{~min}$ & 1,499 & 1,870 & 2,115 & 2,254 & 2,351 & 2,426 & 2,656 & 2,790 & 2,885 \\
\hline $15 \mathrm{~min}$ & 1,295 & 1,616 & 1,828 & 1,948 & 2,032 & 2,096 & 2,295 & 2,411 & 2,493 \\
\hline $20 \mathrm{~min}$ & 1,124 & 1,402 & 1,587 & 1,691 & 1,764 & 1,819 & 1,992 & 2,093 & 2,164 \\
\hline $25 \mathrm{~min}$ & 1,010 & 1,260 & 1,426 & 1,520 & 1,585 & 1,635 & 1,790 & 1,881 & 1,945 \\
\hline $30 \mathrm{~min}$ & 0,925 & 1,154 & 1,306 & 1,392 & 1,451 & 1,497 & 1,640 & 1,722 & 1,781 \\
\hline $1 \mathrm{~h}$ & 0,625 & 0,780 & 0,882 & 0,940 & 0,981 & 1,012 & 1,108 & 1,164 & 1,203 \\
\hline $6 \mathrm{~h}$ & 0,179 & 0,223 & 0,252 & 0,269 & 0,280 & 0,289 & 0,317 & 0,332 & 0,344 \\
\hline $8 \mathrm{~h}$ & 0,145 & 0,181 & 0,205 & 0,218 & 0,228 & 0,235 & 0,257 & 0,270 & 0,279 \\
\hline $10 \mathrm{~h}$ & 0,122 & 0,152 & 0,172 & 0,184 & 0,191 & 0,198 & 0,216 & 0,227 & 0,235 \\
\hline $12 \mathrm{~h}$ & 0,105 & 0,132 & 0,149 & 0,159 & 0,165 & 0,171 & 0,187 & 0,196 & 0,203 \\
\hline $24 \mathrm{~h}$ & 0,062 & 0,077 & 0,088 & 0,093 & 0,097 & 0,100 & 0,110 & 0,115 & 0,119 \\
\hline
\end{tabular}

Para determinação dos coeficientes da relação Intensidade - Duração Frequência procede-se primeiramente à relação entre os logaritmos naturais das intensidades de precipitação com o termo relativo ao tempo de duração do evento chuvoso. A escolha do termo $t_{0}$ das relações é realizada pelo valor que melhor ajuste as retas. Após realização dos ajustes chegou-se a conclusão de que o tempo inicial de 13 
minutos melhor ajustou as relações. O Quadro 3.9 mostra os valores obtidos para os logaritmos naturais da duração e das intensidades de precipitação, enquanto a Figura 3.3 apresenta os ajustes realizados para estas relações.

Quadro 3.9: relação entre os logaritmos naturais da duração do evento chuvoso e suas intensidades, em função do tempo de retorno para a cidade de Pirassununga, SP.

\begin{tabular}{|c|c|c|c|c|c|c|c|c|c|}
\hline \multirow{2}{*}{$\operatorname{In}(\mathrm{t}+\mathrm{t} 0)$} & \multicolumn{7}{|c|}{ PERÍODO DE RETORNO (ANOS) } \\
\cline { 2 - 10 } & 2 & 5 & 10 & 15 & 20 & 25 & 50 & 75 & 100 \\
\hline 2,89037 & 0,635 & 0,856 & 0,980 & 1,043 & 1,086 & 1,117 & 1,207 & 1,257 & 1,290 \\
\hline 3,13549 & 0,405 & 0,626 & 0,749 & 0,813 & 0,855 & 0,886 & 0,977 & 1,026 & 1,059 \\
\hline 3,3322 & 0,259 & 0,480 & 0,603 & 0,667 & 0,709 & 0,740 & 0,831 & 0,880 & 0,914 \\
\hline 3,49651 & 0,117 & 0,338 & 0,462 & 0,525 & 0,567 & 0,599 & 0,689 & 0,738 & 0,772 \\
\hline 3,63759 & 0,010 & 0,231 & 0,355 & 0,418 & 0,461 & 0,492 & 0,582 & 0,632 & 0,665 \\
\hline 3,7612 & $-0,078$ & 0,143 & 0,267 & 0,330 & 0,373 & 0,404 & 0,494 & 0,544 & 0,577 \\
\hline 4,29046 & $-0,470$ & $-0,249$ & $-0,125$ & $-0,062$ & $-0,019$ & 0,012 & 0,102 & 0,152 & 0,185 \\
\hline 5,92158 & $-1,723$ & $-1,501$ & $-1,378$ & $-1,314$ & $-1,272$ & $-1,241$ & $-1,150$ & $-1,101$ & $-1,068$ \\
\hline 6,20051 & $-1,930$ & $-1,709$ & $-1,586$ & $-1,522$ & $-1,480$ & $-1,449$ & $-1,358$ & $-1,309$ & $-1,275$ \\
\hline 6,41836 & $-2,103$ & $-1,882$ & $-1,759$ & $-1,695$ & $-1,653$ & $-1,622$ & $-1,531$ & $-1,482$ & $-1,449$ \\
\hline 6,59715 & $-2,250$ & $-2,029$ & $-1,905$ & $-1,842$ & $-1,799$ & $-1,768$ & $-1,678$ & $-1,628$ & $-1,595$ \\
\hline 7,28139 & $-2,780$ & $-2,559$ & $-2,436$ & $-2,372$ & $-2,330$ & $-2,299$ & $-2,208$ & $-2,159$ & $-2,126$ \\
\hline
\end{tabular}




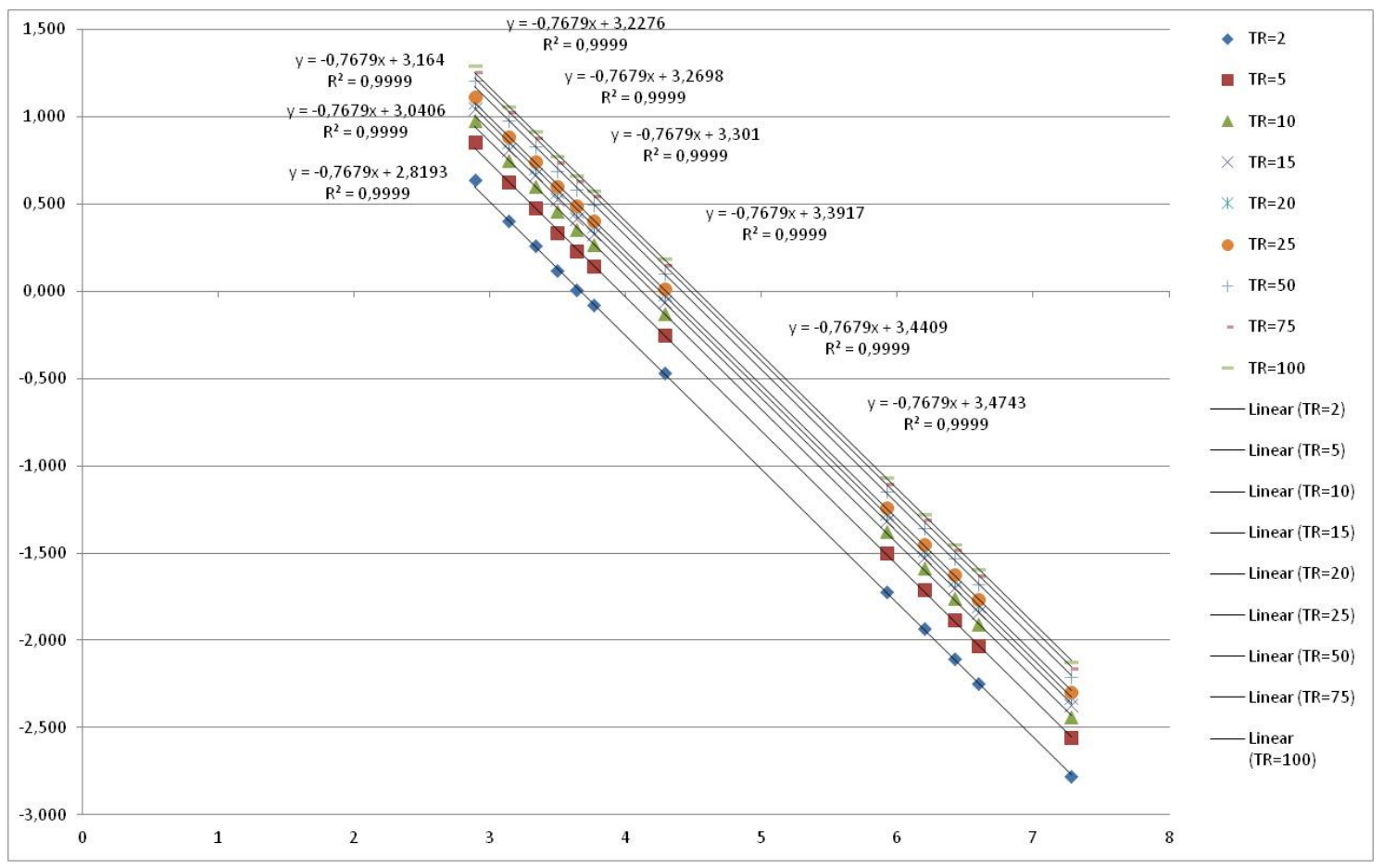

Figura 3.3: relação entre os logaritmos da intensidade $(\mathrm{mm} / \mathrm{min})$ e da duração das precipitações (min).

Na Figura 3.3 observa-se que o valor de 13 minutos escolhido para valor de $t_{0}$ apresenta um bom ajuste — o valor de $\mathrm{R}^{2}$ é de 0,9999 - e a partir desta também se define o valor do coeficiente $n$ da relação IDF como sendo igual ao coeficiente angular das retas, que numericamente é 0,7679 .

As constantes das retas encontradas no ajuste presente na Figura 3.3 são numericamente ao logaritmo natural do termo $k^{*} T^{m}$. Sendo assim um ajuste dos valores da constante com o logaritmo natural do tempo de retorno permite encontrar os valores dos termos $k$ e $m$ da relação IDF. Tal procedimento pode ser visto na Tabela 3.1 e na Figura 3.4.

Tabela 3.1: relação entre os valores do tempo de retorno, e do termo $k^{*} T^{m}$.

\begin{tabular}{|c|c|c|c|}
\hline TR & LN( TR ) & LN $\left(k^{*} T^{m}\right)$ & $k^{*} T^{m}$ \\
\hline 100 & 4,605 & 3,4743 & 32,275 \\
\hline 75 & 4,317 & 3,4409 & 31,215 \\
\hline 50 & 3,912 & 3,3917 & 29,716 \\
\hline 25 & 3,219 & 3,301 & 27,140 \\
\hline 20 & 2,996 & 3,2698 & 26,306 \\
\hline 15 & 2,708 & 3,2276 & 25,219 \\
\hline 10 & 2,303 & 3,164 & 23,665 \\
\hline 5 & 1,609 & 3,0406 & 20,918 \\
\hline 2 & 0,693 & 2,8193 & 16,765 \\
\hline
\end{tabular}




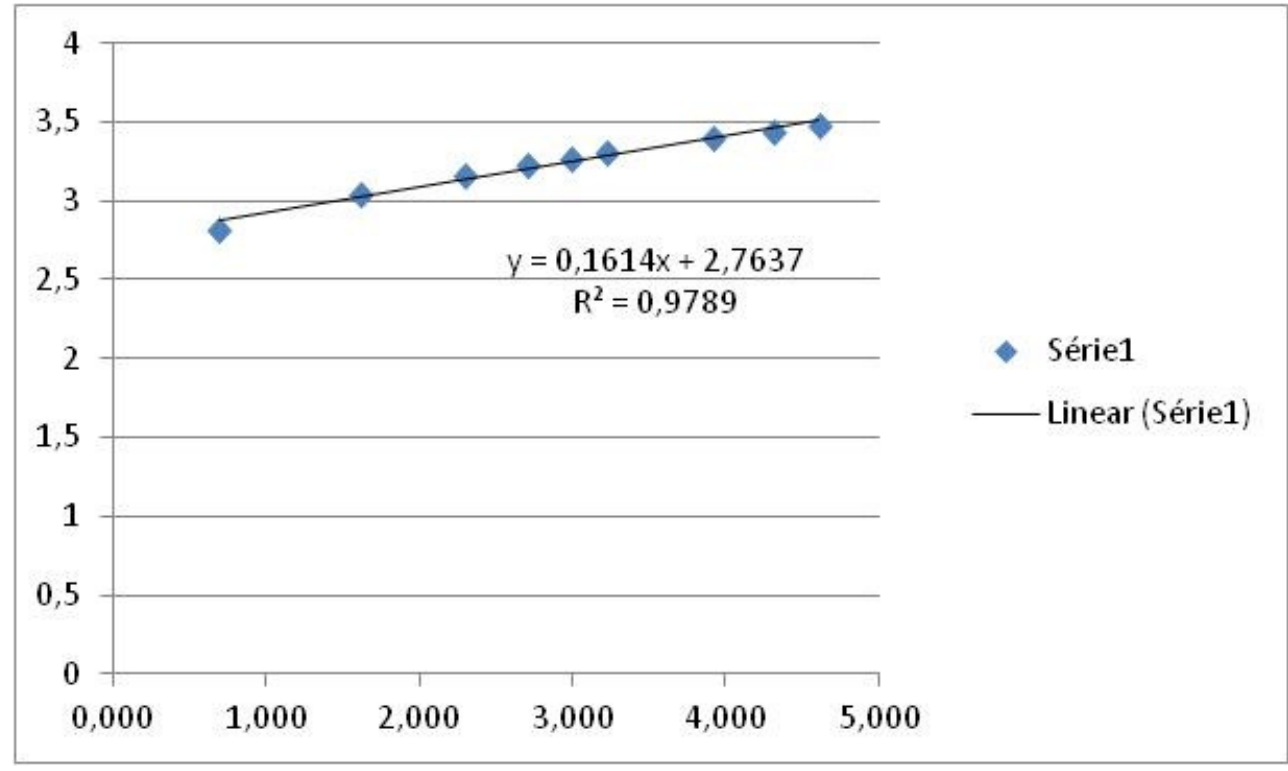

Figura 3.4: ajuste dos valores dos logaritmos naturais de $T$ e $k^{*} T^{m}$.

A partir da análise do gráfico da Figura 3.4 constata-se que o valor da constante $m$ da relação IDF corresponde ao valor numérico 0,1614 , enquanto que o logaritmo natural da constante $k$ vale 2,7637 , e portanto $k$ vale 15,8584 para intensidades de precipitação em mm/min e 951,504 para intensidades de precipitação em mm/h.

Desta forma a relação Intensidade - Duração - Frequência para a cidade de Pirassununga, São Paulo, para o posto número 02147117 da base de dados da ANA é dada na Equação 3.15 para intensidade em mm/min e na Equação 3.16 para intensidade $\mathrm{em} \mathrm{mm} / \mathrm{h}$.

$$
\begin{gathered}
I(\mathrm{~mm} / \mathrm{min})=\frac{15,8584 * T_{r}^{0,1614}}{(t+13)^{0,7679}} \\
I(\mathrm{~mm} / \mathrm{h})=\frac{951,504 * T_{r}^{0,1614}}{(t+13)^{0,7679}}
\end{gathered}
$$

Para as quais $T_{r}$ é o tempo de retorno em anos para a obra em estudo e $t$ é a duração do evento chuvoso em minutos.

\subsection{Tempo de concentração}

A maioria das fórmulas utilizadas para estimativas do tempo de concentração apresentam caráter empírico e são essencialmente obtidas através de regressão numérica (SILVEIRA, 2005).

É consenso que a determinação do tempo de concentração de uma bacia hidrográfica tem influência direta na estimativa das vazões de pico. Neste âmbito há a 
necessidade de estudar quais metodologias, de cálculo indireto, melhor se adaptam às características físicas de cada área.

A ausência de dados hidrometeorológicos que subsidiem o cálculo direto do tempo de concentração faz com que projetistas lancem mão de formulações que permitam estimar este parâmetro. Neste trabalho foi avaliada a aplicação de 28 fórmulas de tempo de concentração, sendo 16 empíricas e 12 semiempíricas. As características destas formulações são apresentadas no Quadro 3.10.

Quadro 3.10: características das formulações para cálculo do tempo de concentração avaliadas.

\begin{tabular}{|c|c|c|}
\hline NOME & USO DO SOLO & OBSERVAÇÕES \\
\hline Kirpich & Rural & Áreas menores que $0,45 \mathrm{~km}^{2}$ \\
\hline Dooge & Rural & Áreas entre 140 e $930 \mathrm{~km}^{2}$ \\
\hline California culverts practice & - & Adaptação da formulação de Kirpich \\
\hline DER - SP & - & $\begin{array}{l}\text { Adaptação da formulação de kirpich para } \\
\text { Áreas maiores que } 1 \mathrm{~km}^{2}\end{array}$ \\
\hline Tsuchiya & Qualquer & Áreas entre 0,01 e $0,2 \mathrm{~km}^{2}$ \\
\hline Bransby - Williams & Rural & - \\
\hline Ven te Chow & Rural & Áreas entre $1,1 \mathrm{e} 19 \mathrm{~km}^{2}$ \\
\hline Picking & Rural & Método equivalente ao de Kirpich \\
\hline Giandotti & Rural & - \\
\hline Pasini & Rural & \\
\hline Temez & - & Áreas de até $3000 \mathrm{~km}^{2}$ \\
\hline $\begin{array}{l}\text { Carter Lag Eq. For Partially } \\
\text { Sewewred Watersheds }\end{array}$ & Urbana & Areas menores que $21 \mathrm{~km}^{2}$ \\
\hline US Army Corps of Engineers & Urbana & - \\
\hline Johnstone - Cross & Rural & Áreas de drenagem entre 65 e $4200 \mathrm{~km}^{2}$ \\
\hline Ventura & Rural & - \\
\hline Van Sickle & - & Áreas de drenagem máximas de 93 km² \\
\hline DNOS & Rural & Áreas de drenagem menores que $0,45 \mathrm{~km}^{2}$ \\
\hline Arnell & Qualquer & Áreas de drenagem entre 0,2 e $50 \mathrm{~km}^{2}$ \\
\hline Método cinemático & Qualquer & Sem restrições \\
\hline Eagleson Lag Model & Qualquer & Áreas contribuintes menores que $21 \mathrm{~km}^{2}$ \\
\hline $\begin{array}{l}\text { Federal Aviation } \\
\text { Administration }\end{array}$ & Qualquer & Desenvolvida a partir do método racional \\
\hline SCS Lag & Qualquer & Áreas menores que $8,1 \mathrm{~km}^{2}$ \\
\hline Tulsa District & Qualquer & Áreas drenantes menores que $1300 \mathrm{~km}^{2}$ \\
\hline Denver & Qualquer & Áreas não superiores à 13 km² \\
\hline Onda cinemática & Qualquer & Desenvolvida a partir do método racional \\
\hline George - Ribeiro & Qualquer & - \\
\hline Kerby - Hathaway & Qualquer & Áreas menores que $0,04 \mathrm{~km}^{2}$ \\
\hline Izzard & Qualquer & - \\
\hline
\end{tabular}

A avaliação das estimativas do tempo de concentração de cada formulação proposta foi realizada de maneira semelhante à metodologia de Silveira (2005). A 
metodologia de comparação proposta por Silveira (2005) se baseia na definição dos erros percentuais de cada fórmula. A formulação utilizada para determinação dos erros percentuais pode ser vista na Equação 3.17.

$$
E M=100 * \frac{T_{C C}-T_{C O}}{T_{C O}}
$$

Na Equação 3.17 o termo $E M$ corresponde ao erro em unidades percentuais, $T_{C C}$ ao tempo de concentração calculado e $T_{C O}$ o tempo de concentração assumido como ideal para a bacia.

\section{5.Área de estudo}

A validação do método proposto será realizada na bacia do córrego Andrezinho, localizado no bairro Cidade Jardim, Pirassununga, Estado de São Paulo. A região onde se localiza o canal tem apresentado problemas na drenagem das águas pluviais, ocorrendo diversos pontos de inundação durante chuvas críticas.

A bacia que drena para o início do canal - local avaliado como adequado para implantação de uma bacia de detenção - possui área de contribuição de aproximadamente $1,4 \mathrm{~km}^{2}$, sendo em sua totalidade provida de rede de drenagem. A cabeceira da bacia do córrego do Andrezinho localiza-se numa região em que o uso predominante do solo é residencial. O córrego tem início nas proximidades da Alameda das Açucenas, proximidades da Praça dos Ipês, sendo um dos formadores do ribeirão da Laranja Azeda.

\subsubsection{Situação física do canal}

Foi realizado levantamento da situação atual do canal, no qual se percebeu a presença de obras para confinamento de seu trecho inicial, entre a Alameda das Açucenas e a Rua Pedro Verona (Figura 3.5). À jusante da Rua Pedro Verona verificouse total obstrução do canal, que já possui margens totalmente ocupadas por residências (Figura 3.6). É importante salientar que no ano de 2006, segundo estudos da ESA, o canal possuía diversos trechos com excesso de vegetação. 


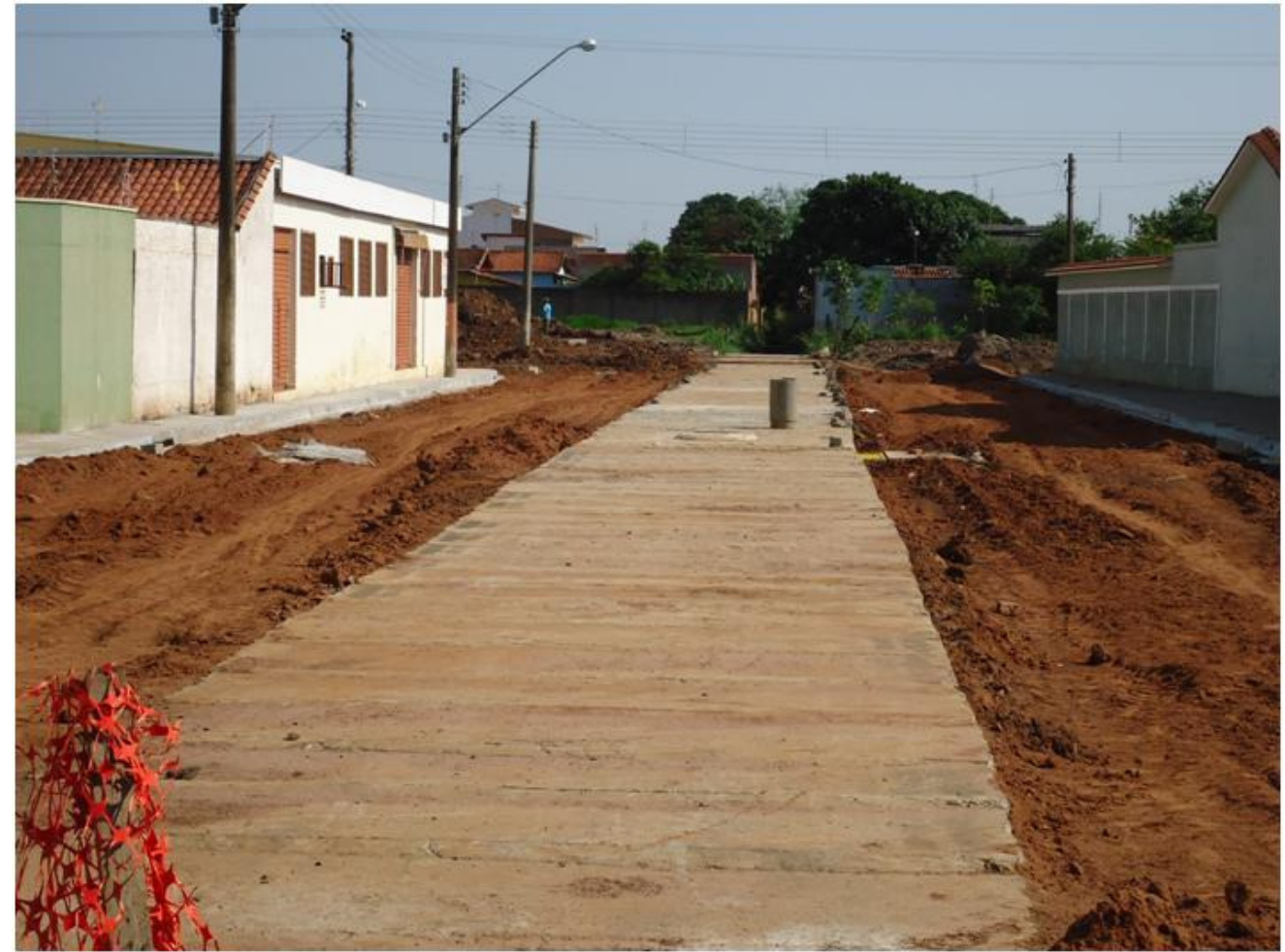

Figura 3.5: obras de retificação no trecho inicial do canal do Andrezinho, à jusante da Alameda das Açucenas.

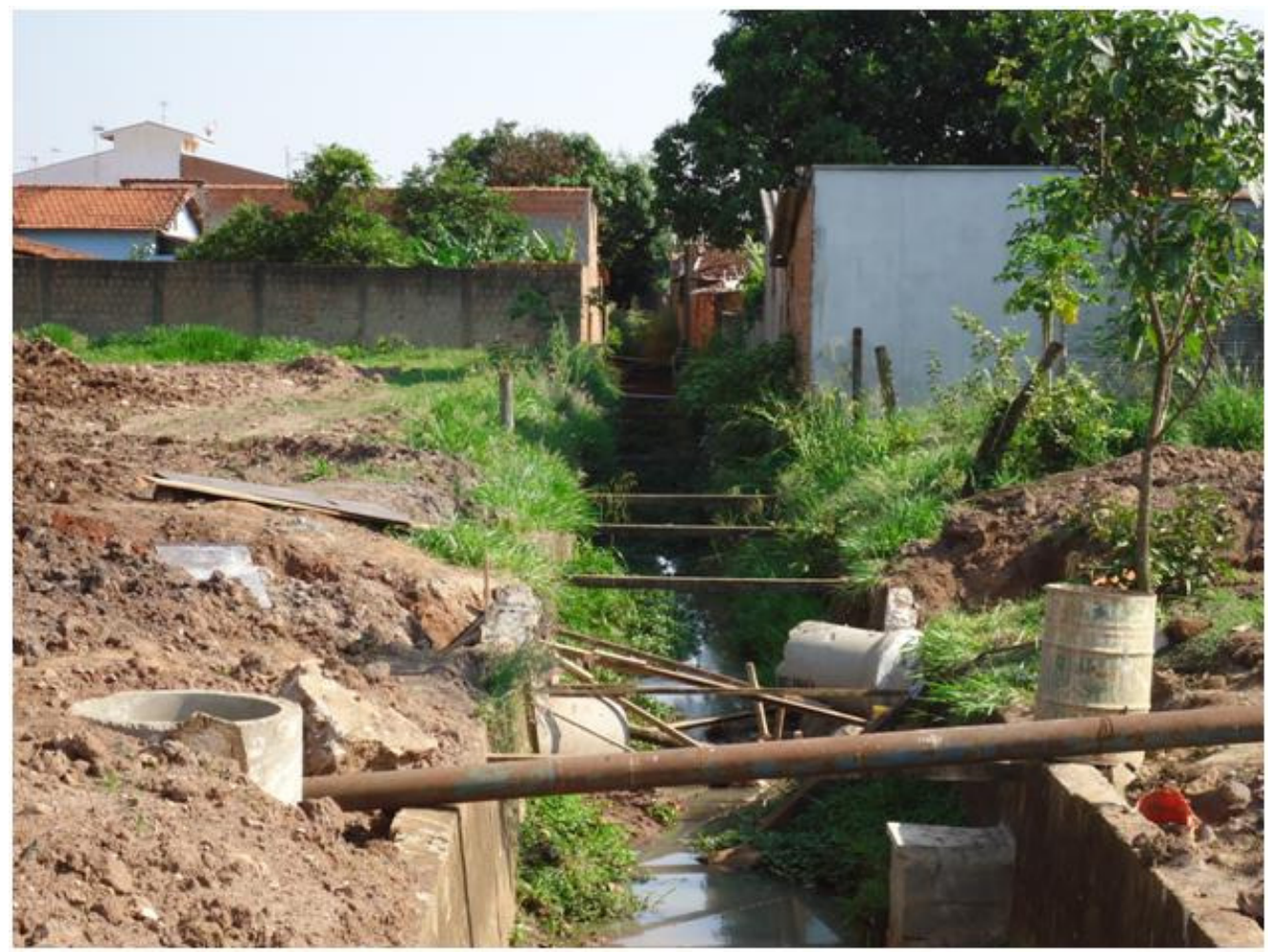

Figura 3.6: obstrução do canal, por entulhos e vegetação, e ocupação das margens por residências.

O canal possui um coletor tronco de esgotos que recebe contribuições das moradias próximas. Na Figura 3.7 observam-se algumas destas ligações, assim como a 
presença de vegetação no leito do canal. Essas ligações prejudicam o desempenho hidráulico do canal, uma vez que funcionam como obstáculos — ocasionando acúmulo de detritos carreados com os deflúvios.

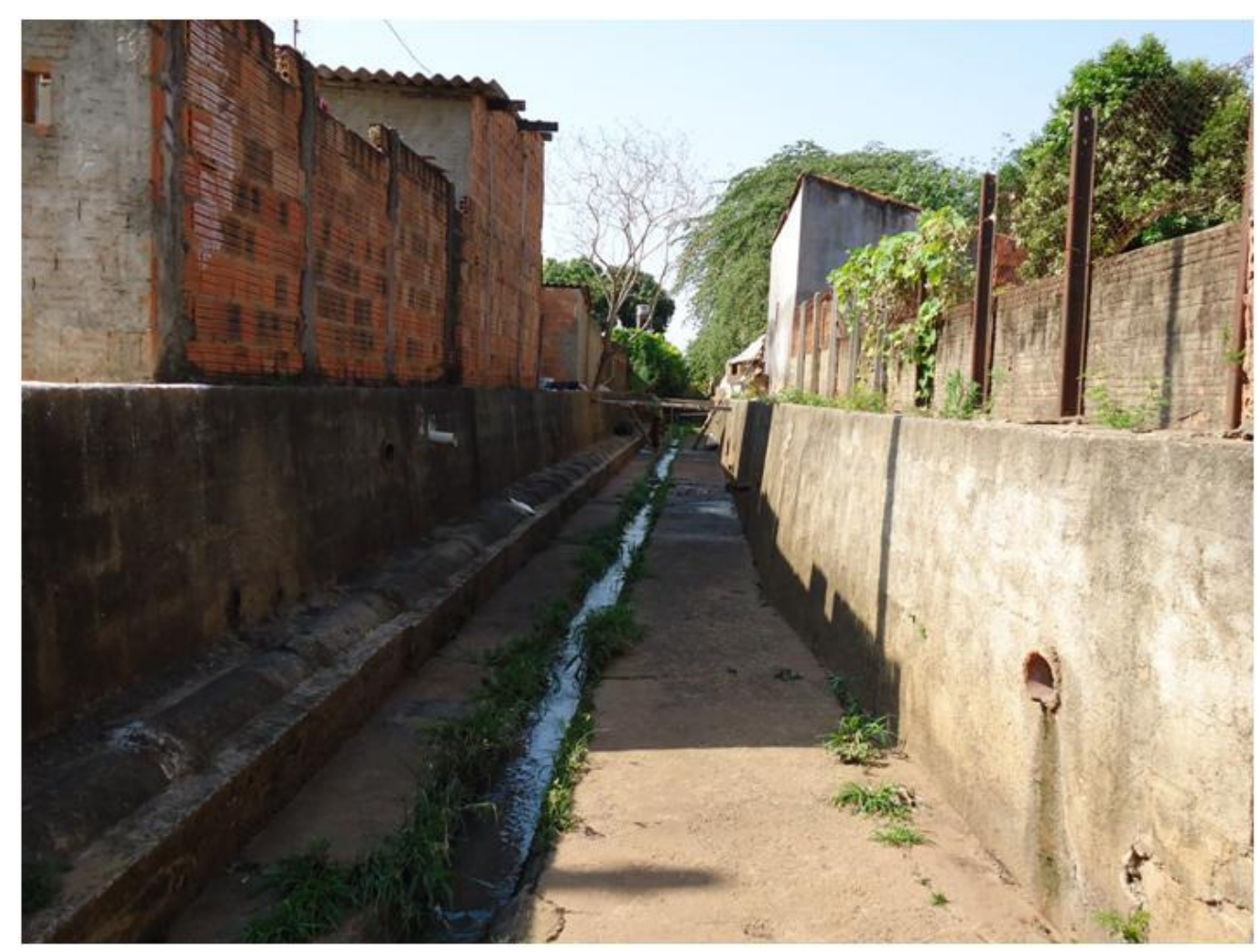

Figura 3.7: destaca-se a presença de coletor tronco, com efluentes sanitários, e algumas de suas ligações.

\subsubsection{Capacidade de escoamento do canal}

ESA (2006) realizou levantamentos sobre as características hidráulicas do canal. Neste trabalho o canal foi dividido em trechos, sendo levantadas as dimensões das seções de escoamento. A capacidade de escoamento foi determinada através da fórmula de Manning, sendo o coeficiente de rugosidade assumido como 0,023 — característico de canais de terra e/ou canais com paredes irregulares e presença de vegetação.

Para o trecho crítico do canal a capacidade de escoamento determinada por ESA (2006) foi de $2,8 \mathrm{~m} 3 / \mathrm{s}$, com declividade média do canal de $0,001 \mathrm{~m} / \mathrm{m}$, largura média de 2,8 e profundidade média de 1,4 metros.

\subsubsection{Uso e ocupação do solo}

A definição de uso e ocupação do solo para estudos hidrológicos está voltada para estimativas de coeficientes de escoamento e infiltração das regiões. Desta forma esta etapa do processo assume vital importância nestes tipos de estudo. 
A bacia hidrográfica, na qual está inserido o canal do Andrezinho, está localizada numa região na qual o uso predominante do solo é residencial. De acordo com Setzer e Porto (1979) a cidade de Pirassununga se encontra na Zona Ecológica Depressão Paleozóica.

\subsubsection{Determinação do Curve Number}

Por definição o Curve Number retrata numericamente as condições superficiais do solo - tipo de solo, cobertura e uso do solo, umidade. A definição deste passa inicialmente pela identificação do tipo de solo do local, para o qual o SCS (1986) define quatro tipos básicos de acordo com suas condições de infiltração. Após a determinação do tipo de solo da bacia, resta caracterizar o uso dado ao solo local e sua condição antecedente de umidade.

A região em estudo é caracterizada por ser uma região destinada a uso residencial. A condição de umidade antecedente do solo usualmente empregada em estudos hidrológicos é a condição de umidade antecedente II (AMC II). Esta condição de umidade apresenta valores intermediários aos demais.

De acordo com os estudos de Setzer e Porto (1979) os tipos de solos predominantes na cidade são o tipo hidrológico "A" e "B". Para modelo de cálculo neste trabalho foi considerado o tipo hidrológico "B", por resultar em escoamentos mais representativos que o tipo hidrológico "A".

\subsubsection{Correlação entre "Curve Number" e coeficiente de escoamento do método racional}

Uma vez que o método proposto se apoia nas premissas do método racional, e a metodologia para definição do coeficiente de escoamento deste método não é tão detalhado e difundido quanto à definição do "Curve number" do método do Soil Conservation Service (SCS, 1986), Porto (1987) propôs o uso conjunto dos métodos para determinação de vazões de projeto em bacias urbanas.

Uma vez definidas as formulações para cálculo das vazões pelo método racional e pelo método do SCS (1986) - apresentadas respectivamente na Equação 3.18 e Equação 3.19 - Porto (1987) desenvolveu a relação presente na Equação 3.20 para relacionar os coeficientes.

$$
Q=C * I * A
$$




$$
\begin{gathered}
R_{e}=\frac{\left(R-\frac{5080}{C N}+C N\right)^{2}}{R+\frac{20320}{C N}-203,2} \\
C=\frac{\left(R-\frac{5080}{C N}+C N\right)^{2}}{R+\frac{20320}{C N}-203,2} * \frac{1}{R}
\end{gathered}
$$

Nas quais: $Q$ - é a vazão calculada com auxílio do método racional;

$C$ - coeficiente de escoamento adimensional da fórmula racional;

$I$ - intensidade de precipitação;

$A$ - área de drenagem da bacia hidrográfica;

CN - Curve Number do método desenvolvido pelo SCS (1986);

$R_{e}$ - corresponde à lâmina excedente de chuva em mm;

$R$ - lâmina precipitada em mm.

Para correlacionar os valores do coeficiente de escoamento da fórmula racional com os valores de "Curve Number" foi realizada a combinação do último com a duração da precipitação e tempo de recorrência do evento chuvoso, fatores que influenciam na lâmina precipitada e por consequência no volume escoado. 


\section{RESULTADOS E DISCUSSÃO}

\subsection{Uso e ocupação do solo}

Para determinação de variáveis como tempo de concentração e volume de detenção é necessário primeiramente determinar as características de uso e ocupação do solo, uma vez que estas variáveis dependem diretamente das condições do terreno. Para determinação destes parâmetros utilizou-se como referência o método do Soil Conservation Service (1986) por apresentar maior difusão de sua metodologia.

Os valores estimados para o "Curve Number" são condizentes com os valores obtidos por ESA (2006) que apresenta valores para este de 85. Uma análise pouco precisa feita de acordo com as diretrizes de Setzer e Porto (1979), que definiram a região da cidade de Pirassununga como apresentando predominância de solos dos grupos hidrológicos "A" e "B", sendo o uso predominante do solo na região estudada residencial, considerando área impermeável de $65 \%$ e umidade do solo como AMC II o valor do "Curve Number" se encontraria entre 77 e 85, respectivamente para os tipos de solos hidrologicamente classificados como "A" e "B".

Definido o valor do "Curve Number" como sendo de 85 na situação atual da bacia de drenagem do córrego Andrezinho, procede-se à relação entre este e o coeficiente de escoamento do coeficiente da fórmula racional. Os valores obtidos para o coeficiente de escoamento do método racional, para valores de "Curve Number" de 85 , podem ser observados na Tabela 4.1.

Tabela 4.1: relação entre valores do coeficiente de escoamento da fórmula racional, tempo de retorno e duração do evento chuvoso para $\mathbf{C N}=\mathbf{8 5}$.

\begin{tabular}{|c|c|c|c|}
\hline \multirow{2}{*}{$\begin{array}{c}\text { Tempo } \\
\text { retorno }\end{array}$} & \multicolumn{3}{|c|}{ Duração da precipitação } \\
\cline { 3 - 4 } 10 anos & 0,30 & 0,40 & 0,45 \\
\hline & & & \\
20 anos & 0,34 & 0,44 & 0,48 \\
\hline & 0,35 & 0,45 & 0,49 \\
\hline 25 anos & 0,39 & 0,49 & 0,53 \\
\hline 50 anos & 0,39 & \\
\hline & & & \\
100 anos & 0,43 & 0,52 & 0,56 \\
\hline
\end{tabular}

Para motivos de comparação das metodologias de estimativas do volume de detenção foi considerado a situação hipotética de toda a região estar impermeabilizada, 
ocasião que geraria o maior volume escoado pela bacia hidrográfica. Para este caso o "Curve Number" estimado seria de 98 e na Tabela 4.2 encontram-se os valores do coeficiente de escoamento da fórmula racional.

Tabela 4.2: relação entre valores do coeficiente de escoamento da fórmula racional, tempo de retorno e duração do evento chuvoso para $\mathrm{CN}=98$.

\begin{tabular}{|c|c|c|c|}
\hline \multirow{2}{*}{$\begin{array}{c}\text { Tempo } \\
\text { retorno }\end{array}$} & \multicolumn{3}{|c|}{ Duração da precipitação } \\
\cline { 3 - 4 } 10 anos & 0,85 & 60 min & 90 min \\
\hline 20 anos & 0,87 & 0,90 & 0,90 \\
\hline 25 anos & 0,87 & 0,90 & 0,91 \\
\hline & & & \\
\hline 50 anos & 0,89 & 0,91 & 0,92 \\
\hline 100 anos & 0,90 & 0,92 & 0,93 \\
\hline
\end{tabular}

Com base nas informações apresentadas na Tabela 4.1 e na Tabela 4.2 os valores do coeficiente de escoamento aumentam, como esperado, ao passo que se aumentam o volume precipitado, seja este aumento devido à redução na frequência - com aumento do período de retorno - ou com acréscimos na duração da precipitação.

As variações decorrentes do acréscimo na duração da precipitação apresentam maior sensibilidade para menores intensidades, e consequentemente volume precipitado, uma vez que a variação sofrida para tempos de retorno menores são mais sensíveis que para eventos com menor recorrência.

A variação sofrida pelo coeficiente de escoamento da fórmula racional apresenta menor sensibilidade para áreas com maiores taxas de impermeabilização. Para tempos de retorno idênticos, bacias menos urbanizadas apresentam maiores diferenças relativas ao passo que se aumentam as durações dos eventos chuvosos. Situação semelhante é observada ao se fixar as durações dos eventos e alterar suas recorrências.

\subsection{Tempo de Concentração}

Do total de 24 equações verificadas neste trabalho - sendo 14 empíricas e 10 semiempíricas, selecionadas de acordo com as características dos dados disponíveis na bacia hidrográfica do córrego do Andrezinho. As características fisiográficas da área de drenagem em estudo, utilizadas para estimativa do tempo de concentração, são apresentadas no Quadro 4.1. 
Quadro 4.1: características fisiográficas da bacia do córrego do Andrezinho, Pirassununga, SP.

\begin{tabular}{|l|l|}
\hline Característica & Valor observado \\
\hline Área de drenagem & $1,40 \mathrm{~km}^{2}$ \\
\hline Comprimento do talvegue & $1,75 \mathrm{~km}$ \\
\hline Cota máxima & $681 \mathrm{~m}$ \\
\hline Cota mínima & $648 \mathrm{~m}$ \\
\hline Declividade média & $0,019 \mathrm{~m} / \mathrm{m}$ \\
\hline Perímetro & $4,87 \mathrm{~km}$ \\
\hline Coeficiente de compacidade & 1,15 \\
\hline
\end{tabular}

As estimativas do tempo de concentração foram realizadas em duas etapas, a primeira considerando a situação atual do uso do solo e a condição hipotética de toda a bacia hidrográfica se encontrar impermeabilizada. Foi realizada análise comparativa dos tempos de concentração obtidos, sendo descartados os valores que se apresentaram excessivamente altos ou baixos.

As informações adicionais utilizadas na estimativa do tempo de concentração, em cada etapa, são apresentadas no Quadro 4.2.

Quadro 4.2: parâmetros utilizados para estimativa do tempo de concentração na bacia do córrego do Andrezinho, Pirassununga, SP.

\begin{tabular}{|c|c|c|c|}
\hline Metodologia & Parâmetro & Valor para CN $=85$ & Valor para CN =98 \\
\hline DNOS & $\mathrm{K}$ & 5 & 5,5 \\
\hline Arnell & $\mathrm{C}$ & 0,45 & 0,90 \\
\hline Eagleson Lag Model & $n$ & 0,030 & 0,020 \\
\hline $\begin{array}{c}\text { Federal Aviation } \\
\text { Administration }\end{array}$ & $\mathrm{C}$ & 0,45 & 0,90 \\
\hline SCS Lag & Curve Number & 85 & 98 \\
\hline Tulsa District & $\mathrm{k}$ & 0,59 & 0,59 \\
\hline Denver & $\mathrm{C}_{\mathrm{t}}$ & 0,119 & 0,119 \\
\hline George-Ribeiro & $\mathrm{p}$ & 0,79 & 1,00 \\
\hline Kerby-Hathaway & $n$ & 0,030 & 0,020 \\
\hline Izzard & $\mathrm{C}_{\mathrm{r}}$ & 0,017 & 0,012 \\
\hline
\end{tabular}

Após análise inicial das estimativas do tempo de concentração na área de estudo, para o uso do solo com "Curve Number" estimado em 85, as formulações de Van Sickle, Tsuchiya e Izzard apresentaram valores muito inferiores à realidade para a bacia, enquanto que a metodologia de Giandotti proporcionou valor excessivamente alto para as características da região estudada. Desta forma estes métodos não foram levados em consideração nesta fase da avaliação.

Para as condições de uso do solo futuras considerada hipoteticamente como sendo toda a área impermeabilizada, na qual o valor atribuído ao "Curve Number" foi de 98, como apenas as formulações semiempíricas são passíveis de alterações em seus 
valores apenas estas serão avaliadas. Para esta segunda etapa as formulações de Arnell e de Izzard apresentaram valores incompatíveis com as características da região avaliada, sendo desconsideradas nesta fase das análises.

As análises relativas às estimativas do tempo de concentração para a bacia do córrego do Andrezinho tiveram como referência o cálculo deste pelo método de GeorgeRibeiro. Esta consideração foi realizada com base nos estudos de ESA (2006) e Farias Júnior (2010) que concluíram que a formulação de George-Ribeiro apresenta valores consistentes para áreas de drenagem do porte estudado.

\subsubsection{Estudo das formulações empíricas}

As formulações empíricas avaliadas foram Ven Te Chow, Kirpich, Dooge, Bransby-Williams, Pasini, Temez, Carter Lag Equation for Partially Sewered Watersheds, United States Army Corps of Engineers - USACE, Johnstone-Cross, California Culverts Practice, Picking, Ventura e DER - SP, todas descritas no capítulo 2. A Tabela 4.3 apresenta os tempos de concentração obtidos para as fórmulas supracitadas e seus erros percentuais para valores de "Curve Number" de 85 e 98 (comparadas com o método de George-Ribeiro). Na Figura 4.1 pode-se observar graficamente a comparação entre os tempos de concentração estimados.

Tabela 4.3: erros percentuais das formulações empíricas para estimativas do tempo de concentração da área estudada.

\begin{tabular}{|c|c|c|c|c|}
\hline Métodos & $\begin{array}{c}\mathrm{t}_{\mathrm{c}}(\mathrm{min} .) \\
\mathrm{CN}=85\end{array}$ & $\begin{array}{c}\mathrm{t}_{\mathrm{c}}(\mathrm{min} .) \\
\mathrm{CN}=98\end{array}$ & $\begin{array}{c}\mathrm{EP} \% \\
(\mathrm{CN}=85)\end{array}$ & $\begin{array}{c}\mathrm{EP} \% \\
(\mathrm{CN}=98)\end{array}$ \\
\hline George-Ribeiro & 26,30 & 25,25 & - & - \\
\hline Ven Te Chow & 28,81 & 28,81 & 9,55 & 14,11 \\
\hline Kirpich & 27,50 & 27,50 & 4,56 & 8,91 \\
\hline Dooge & 15,23 & 15,23 & $-42,11$ & $-39,70$ \\
\hline Bransby-Williams & 53,02 & 53,02 & 101,60 & 109,98 \\
\hline Pasini & 62,77 & 62,77 & 138,65 & 148,58 \\
\hline Temez & 57,21 & 57,21 & 117,52 & 126,56 \\
\hline $\begin{array}{c}\text { Carter Lag Equation For } \\
\text { Partially Sewered } \\
\text { Watersheds }\end{array}$ & 25,94 & 25,94 & $-1,38$ & 2,72 \\
\hline USACE & 28,55 & 28,55 & 8,55 & 13,06 \\
\hline Johnstone-Cross & 30,82 & 30,82 & 17,18 & 22,05 \\
\hline $\begin{array}{c}\text { California culverts } \\
\text { Practice }\end{array}$ & 27,61 & 27,61 & 4,96 & 9,33 \\
\hline Picking & 28,29 & 28,29 & 7,57 & 12,05 \\
\hline Ventura & 65,15 & 65,15 & 147,71 & 158,01 \\
\hline DER - SP & 41,26 & 41,26 & 56,89 & 63,42 \\
\hline
\end{tabular}




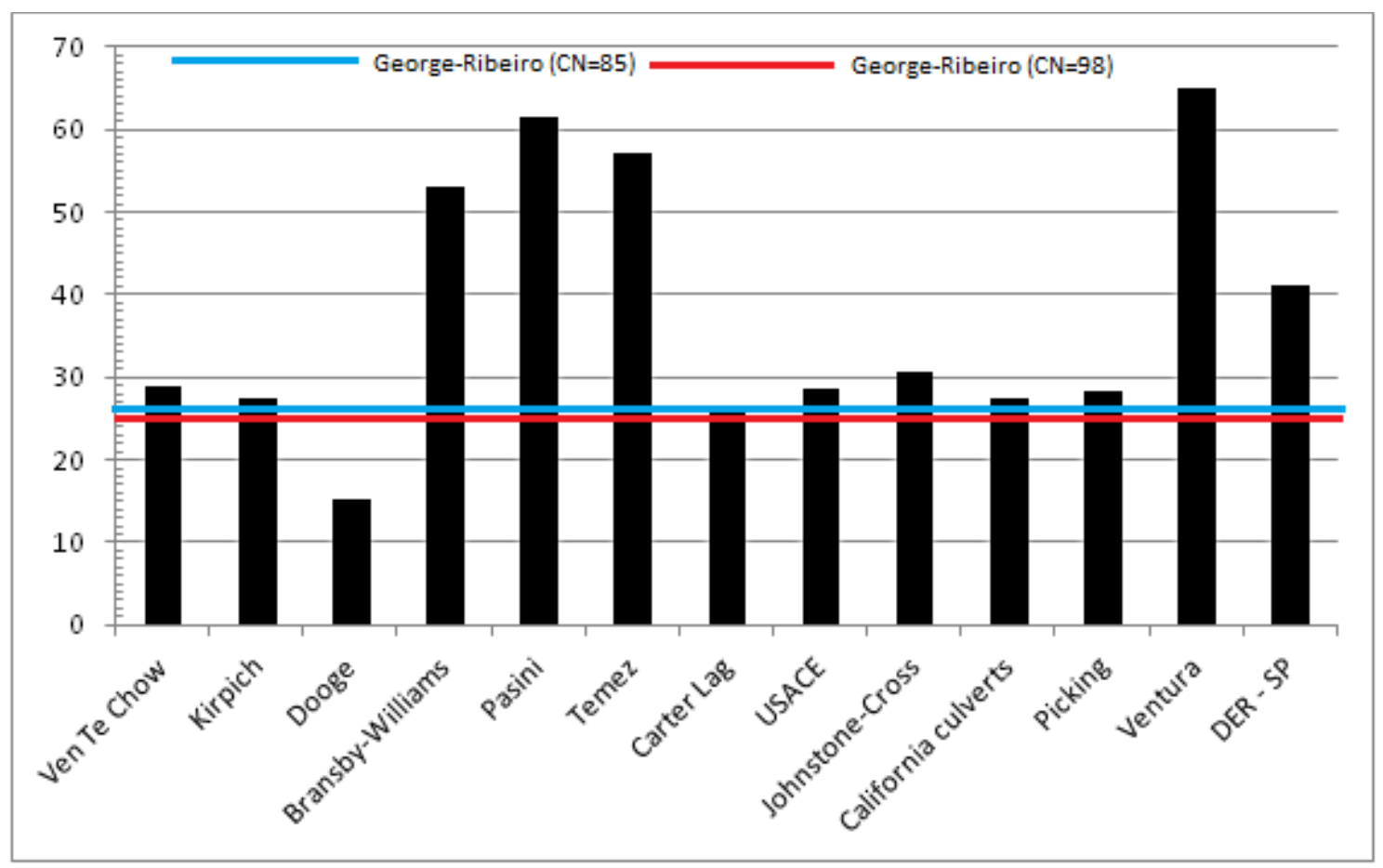

Figura 4.1: comparação entre o tempo de concentração estimado por fórmulas empíricas e o calculado pela formulação de George-Ribeiro, para a área estudada.

Dentre as formulações avaliadas a que melhor ajustou-se a área de estudo tanto para as condições atuais quanto para condição hipotética futura - foi à formulação Carter Lag Equation for Partially Sewered Watersheds. O fato de esta formulação ter sido desenvolvida para regiões servidas de microdrenagem, com áreas não superiores à $20,7 \mathrm{~km}^{2}$, com declividade menor $0,5 \%$ explica o valor de erro médio de apenas 1,38\% para as condições atuais e 2,72\% para condição futura. Silveira (2005) encontrou resultados médios parecidos na aplicação desta formulação em 32 bacias urbanas, é importante ressaltar que o erro padrão encontrado pelo autor neste estudo foi de aproximadamente $40 \%$.

As formulações desenvolvidas por Ven Te Chow, Kirpich, USACE, California Culverts Practice e Picking apresentaram erro médio próximo de $10 \%$ maiores que o estimado pela proposta de George-Ribeiro. O fato da formulação de Ven Te Chow apresentar valores considerados razoáveis para a bacia em estudo vai contra as afirmações de DGC (1987), apud Farias Júnior (2010), de que esta formulação não se adapta a bacias pequenas, porém como esperado a formulação apresentou resultados superiores ao estimado como ideal, uma vez que a bacia apresenta declividade suave. 
As metodologias de Kirpich e California Culverts Practice responderam de forma semelhante, fato explicado ao passo que a última foi desenvolvida segundo diretrizes da primeira. $\mathrm{O}$ fato de estes métodos apresentarem valores maiores que o estimado está relacionado ao fato da bacia estudada possuir declividade sensivelmente menor que a declividade para a qual estas formulações foram desenvolvidas.

A formulação desenvolvida pelo United States Army Corps of Engineer apresentou resultados superiores ao esperado, uma vez que foi desenvolvido para regiões concretadas. Já a metodologia de Picking apresentou resultados diferentes dos relatados pelo DNIT (BRASIL, 2005), que em seus estudos constatou que a proposta de Picking resultava valores excessivamente baixos.

A proposição de Johnstone-Cross apresentou erro médio na estimativa do tempo de concentração de cerca de $20 \%$. Uma vez que esta formulação foi desenvolvida para bacias maiores que $65 \mathrm{~km}^{2}$ este resultado mostra adaptabilidade razoável da formulação para bacias de pequeno porte com declividades suaves.

Era de se esperar que a metodologia proposta por Dooge apresentasse valores superiores ao de George-Ribeiro, já que esta formulação foi desenvolvida para bacias rurais irlandesas, porém a estimativa de tempo de concentração feita com a fórmula de Dooge apresentou valor cerca de 50\% menor. Este resultado vai de encontro à informação apresentada por Silveira (2005) que em seus estudos constatou que formulações que usam a área de drenagem como variável básica tendem a superestimar os valores do tempo de concentração.

As formulações de Ventura, Temez, Pasini e Bransby-Williams apresentaram valores maiores que duas vezes o estimado pela formulação de George-Ribeiro. Em se tratando o desenvolvimento destas metodologias para áreas rurais era esperado que os valores por elas apresentadas fossem superiores ao estimado com auxílio da metodologia de George-Ribeiro.

\subsubsection{Estudo das formulações semiempíricas}

O estudo das formulações semiempíricas para cálculo do tempo de concentração foi realizado com auxílio das formulações da Federal Aviation Administration, de Arnell, do DNOS, Eagleson Lag Model, do SCS Lag, de Kerby-Hathaway, de Tulsa District e de Denver. Para cada metodologia estudada foram determinados dois tempos de concentração - para a situação atual da bacia, "Curve Number" igual a 85, e para um valor futuro de 98 - que foram comparados com o valor estimado através da 
aplicação da formulação de George-Ribeiro para a bacia hidrográfica do córrego do Andrezinho.

Os valores obtidos da aplicação das metodologias de cálculo do tempo de concentração podem ser observados na Tabela 4.4, que apresenta os valores estimados e os erros percentuais, e na Figura 4.2 que apresenta graficamente as diferenças nos valores avaliados.

Tabela 4.4: erros percentuais das formulações semiempíricas para estimativas do tempo de concentração da área estudada.

\begin{tabular}{|c|c|c|c|c|}
\hline Métodos & $\mathrm{CN}=85$ & $\mathrm{CN}=98$ & $\begin{array}{c}\mathrm{EM} \\
(\mathrm{CN}=85)\end{array}$ & $\begin{array}{c}\mathrm{EM} \\
(\mathrm{CN}=98)\end{array}$ \\
\hline George-Ribeiro & 26,30 & 25,25 & - & - \\
\hline FAA & 70,55 & 21,71 & 168,27 & $-14,02$ \\
\hline Arnell & 12,11 & 1,74 & $-53,95$ & $-93,11$ \\
\hline DNOS & 30,16 & 27,42 & 14,68 & 8,59 \\
\hline $\begin{array}{c}\text { Eagleson Lag } \\
\text { Model }\end{array}$ & 17,11 & 11,41 & $-34,95$ & $-54,83$ \\
\hline SCS lag & 77,29 & 43,19 & 193,88 & 71,07 \\
\hline Kerby-Hathaway & 22,85 & 18,91 & $-13,10$ & $-25,10$ \\
\hline Tulsa District & 28,15 & 28,15 & 7,03 & 11,48 \\
\hline Denver & 36,23 & 36,25 & 37,75 & 43,56 \\
\hline
\end{tabular}

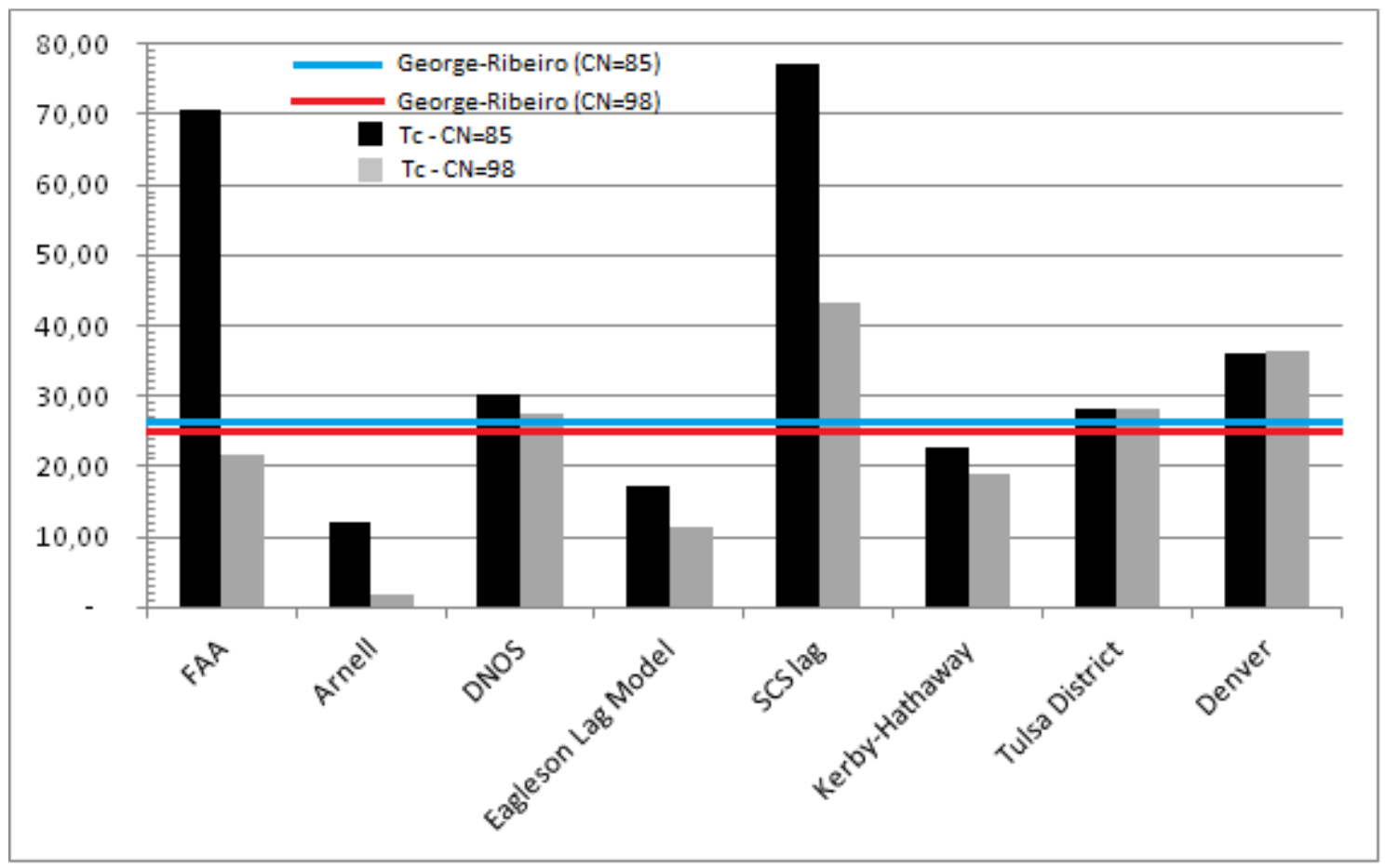

Figura 4.2: comparação entre o tempo de concentração estimado por metodologias semiempíricas e o calculado pela formulação de George-Ribeiro. 
O valor estimado para a metodologia de Arnell quando o "Curve Number" assume valor de 98 foi desconsiderado das avaliações.

Das formulações semiempíricas avaliadas a proposta pela Federal Aviation Administration mostrou-se mais sensível às alterações de cobertura do solo consideradas. Este comportamento é atribuído ao fato do desenvolvimento desta bacia estar associado a pequenas áreas de drenagem e quase que totalmente impermeabilizadas.

As formulações de Arnell e Eagleson Lag Model resultaram em valores subestimados do tempo de concentração. $\mathrm{O}$ fato da formulação de Arnell considerar faixas de variações para o coeficiente de escoamento da fórmula racional é o principal motivo para a diferença de valores apresentados. Já a formulação Eagleson Lag Model foi desenvolvida para escoamentos predominantes em sistemas de drenagem, o que justifica estimativa abaixo do considerado ideal para áreas de drenagem.

Os métodos de cálculo do DNOS e de Tulsa District apresentaram valores cerca de $10 \%$ maiores que os valores estimados pela formulação de George-Ribeiro. Este valor pode ser considerado satisfatório uma vez que a formulação do DNOS foi desenvolvida para áreas de drenagem menores que $0,5 \mathrm{~km}^{2}$ e talvegues menores que 1,2 km, características diferentes da bacia estudada. A formulação de Tulsa District apresenta como principal característica levar em consideração na sua formulação apenas o grau de urbanização da bacia, que pode levar a erros de estimativa.

A formulação de Kerby-Hathaway apresentou valores da ordem de 15 e $25 \%$ menores que a estimativa considerada ideal para a bacia, George-Ribeiro. A equação de Kerby-Hathaway foi desenvolvida para bacias muito pequenas, máximo de 10 acres, que explica os valores baixos nas estimativas do tempo de concentração.

A proposta desenvolvida na cidade de Denver resultou em superestimação do tempo de concentração da bacia. A fórmula apresenta como principal característica a definição de um coeficiente que leva em consideração a parcela de área impermeabilizada para ajuste do tempo de concentração. Como o ajuste deste coeficiente é realizado por faixas de variação da área impermeabilizada este erro pode estar associado a esta variação.

A proposta do SCS Lag Time apresentou valores bastante superiores aos demais. Estes resultados podem ser atribuídos ao fato da formulação ter sido desenvolvida inicialmente para bacias rurais. 


\subsubsection{Considerações sobre as estimativas de tempo de concentração}

Tendo como formulação base para estimativa do tempo de concentração a proposta por George-Ribeiro foram definidos valores referências para cálculo dos volumes de detenção. Foram assumidos alguns valores para estimativas dos volumes armazenados. A Tabela 4.5 apresenta um resumo de todos os valores de tempo de concentração estimados.

Tabela 4.5: resumo dos valores estimados para tempo de concentração em minutos e seus erros percentuais quando comparados à fórmula desenvolvida por George-Ribeiro.

\begin{tabular}{|c|c|c|c|c|}
\hline Método & $\begin{array}{l}\mathrm{t}_{\mathrm{c}}(\min .) \\
\mathrm{CN}=85\end{array}$ & $\begin{array}{c}t_{c}(\min .) \\
C N=98\end{array}$ & $\begin{array}{c}E P(\%) \\
(C N=85)\end{array}$ & $\begin{array}{c}\mathrm{EP}(\%) \\
(\mathrm{CN}=98)\end{array}$ \\
\hline George-Ribeiro & 26,30 & 25,25 & - & - \\
\hline Ven Te Chow & 28,81 & 28,81 & 9,55 & 14,11 \\
\hline Kirpich & 27,50 & 27,50 & 4,56 & 8,91 \\
\hline Dooge & 15,23 & 15,23 & $-42,11$ & $-39,70$ \\
\hline Bransby-Williams & 53,02 & 53,02 & 101,60 & 109,98 \\
\hline Pasini & 62,77 & 62,77 & 138,65 & 148,58 \\
\hline Temez & 57,21 & 57,21 & 117,52 & 126,56 \\
\hline Carter Lag & 25,94 & 25,94 & $-1,38$ & 2,72 \\
\hline USACE & 28,55 & 28,55 & 8,55 & 13,06 \\
\hline Johnstone-Cross & 30,82 & 30,82 & 17,18 & 22,05 \\
\hline California culverts & 27,61 & 27,61 & 4,96 & 9,33 \\
\hline Picking & 28,29 & 28,29 & 7,57 & 12,05 \\
\hline Ventura & 65,15 & 65,15 & 147,71 & 158,01 \\
\hline DER - SP & 41,26 & 41,26 & 56,89 & 63,42 \\
\hline FAA & 70,55 & 21,71 & 168,27 & $-14,02$ \\
\hline Arnell & \multicolumn{2}{|c|}{12,11} & \multicolumn{2}{|c|}{$-53,95$} \\
\hline DNOS & 30,16 & 27,42 & 14,68 & 8,59 \\
\hline $\begin{array}{c}\text { Eagleson Lag } \\
\text { Model }\end{array}$ & 17,11 & 11,41 & $-34,95$ & $-54,83$ \\
\hline SCS lag & 77,29 & 43,19 & 193,88 & 71,07 \\
\hline Kerby-Hathaway & 22,85 & 18,91 & $-13,10$ & $-25,10$ \\
\hline Tulsa District & 28,15 & 28,15 & 7,03 & 11,48 \\
\hline Denver & 36,23 & 36,25 & 37,75 & 43,56 \\
\hline Média & 36,95 & 33,54 & 40,49 & 32,85 \\
\hline Mínimo & 12,11 & 11,41 & $-53,95$ & $-54,83$ \\
\hline Máximo & 77,29 & 65,15 & 193,88 & 158,01 \\
\hline
\end{tabular}

Para estimativa dos volumes de detenção foram utilizados os valores de tempo de concentração encontrado com a utilização da formulação de George-Ribeiro (considerado como sendo 26 minutos), o valor considerado médio da situação atual (37 minutos), o máximo valor estimado para o tempo de concentração (considerado 75 minutos) e o tempo de 15 minutos. 


\subsection{Volume de detenção}

O diagnóstico relativo à aplicação do método proposto para estimativa volume de detenção na área de drenagem do córrego do Andrezinho foi feito em duas etapas. A primeira etapa avalia a escolha do valor do parâmetro $\beta$ e suas implicações na estimativa do volume reservado. A segunda julga a aplicação de diversos métodos de cálculo - hidrológicos e hidráulico-hidrológicos — para três durações de precipitação. Nesta última etapa estuda-se a influência do tempo de concentração nos volumes armazenados.

Para avaliação das propostas de cálculo de volumes de detenção foi escolhido como método padrão o de Porto (2002), que apresentou resultados satisfatórios em sua aplicação na bacia de drenagem da Praça Charles Miller, na cidade de São Paulo.

\subsubsection{Volume de detenção em função do parâmetro $\beta$}

Nesta fase dos estudos foi avaliada a escolha do parâmetro $\beta$ do método proposto na determinação dos volumes detidos na área de estudo. Para tanto foram utilizados como tempo de recorrência do projeto os valores de 10, 20, 25, 50 e 100 anos, para durações de precipitações de 30, 60 e 90 minutos e condições do solo atual ("Curve Number" de 85) e condições futuras extremas ("Curve Number" de 98). Os valores de $\beta$ variaram de 0 a 2, permitindo fazer uma avaliação da curva de vazão efluente do reservatório.

Respectivamente para tempo de retorno de 25 e 100 anos a Figura 4.3 e a Figura 4.4 apresentam graficamente as diferenças nos volumes obtidos da variação do parâmetro $\beta$ quando relacionados com a proposta de Porto (2002) para "Curve Number" de 85 e duração da precipitação de 30 minutos. A Figura 4.5 e a Figura 4.6 mostram, para a duração e recorrências citadas, estes valores para condições de uso do solo futura - $\mathrm{CN}$ igual a 98. 


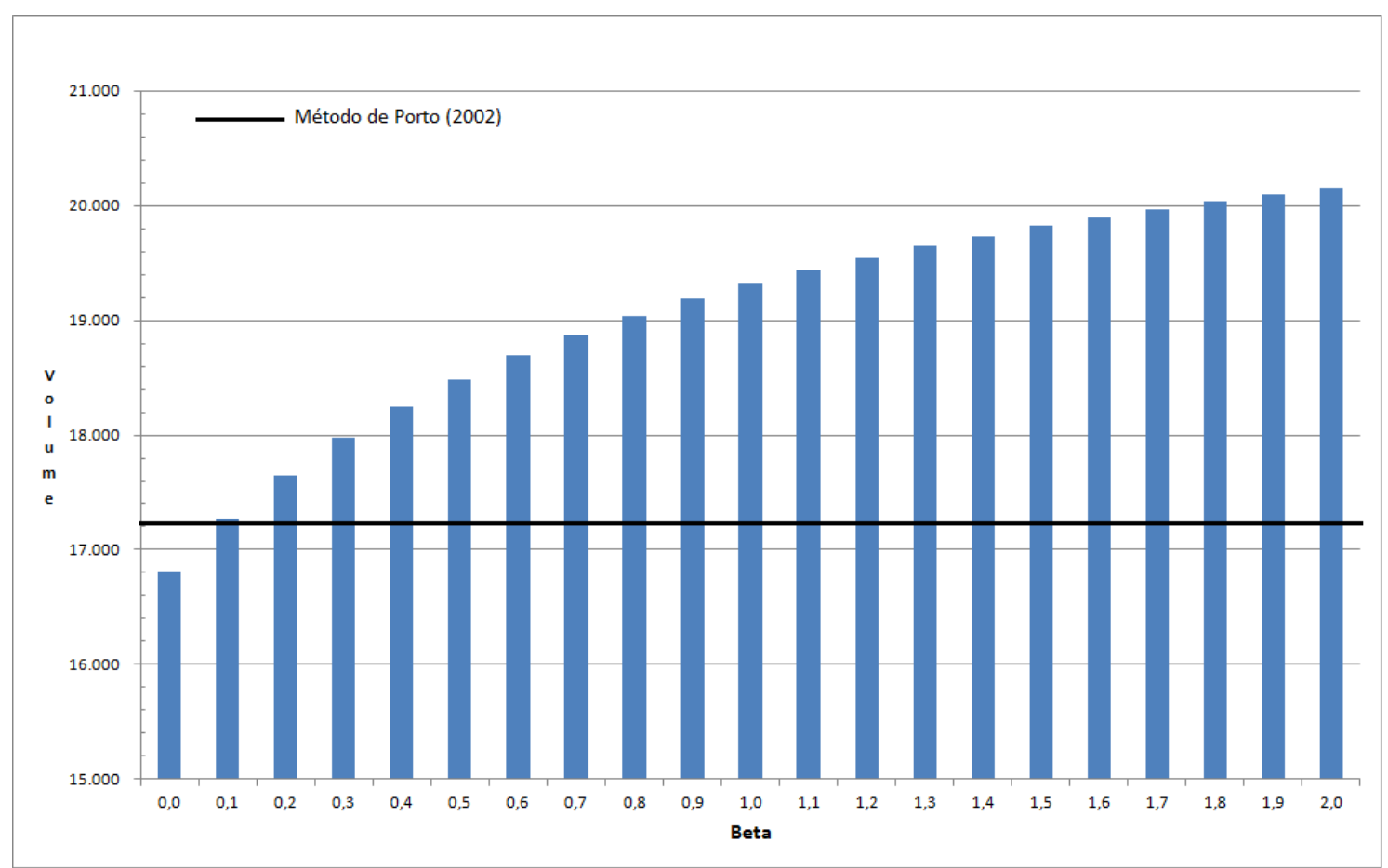

Figura 4.3: comparação entre volumes detido pela metodologia proposta e o método de Porto (2002) para tempo de retorno de 25 anos, duração de precipitação de 30 minutos e CN de 85.

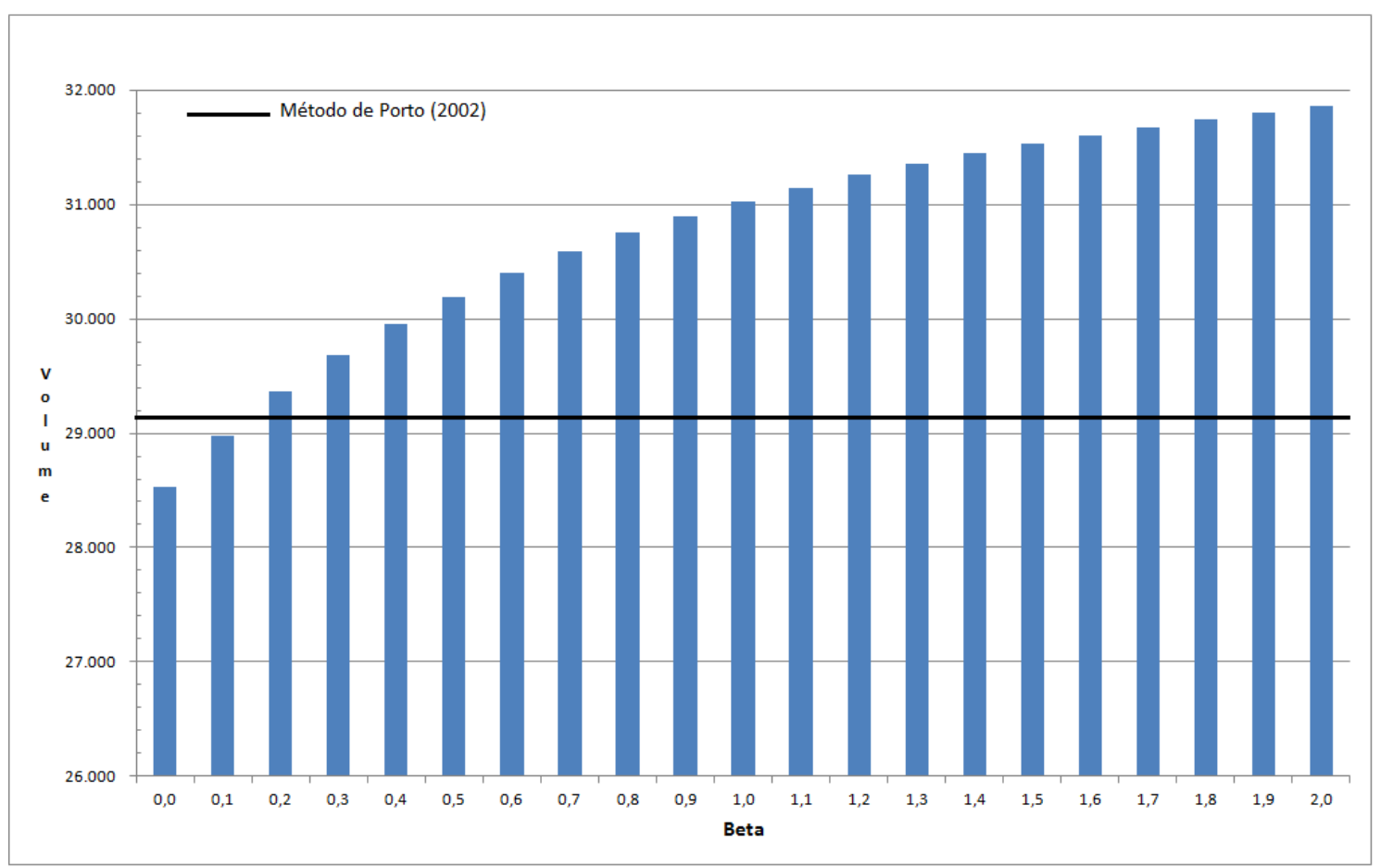

Figura 4.4: comparação entre volumes detido pela metodologia proposta e o método de Porto (2002) para tempo de retorno de 100 anos, duração de precipitação de 30 minutos e CN de 85. 


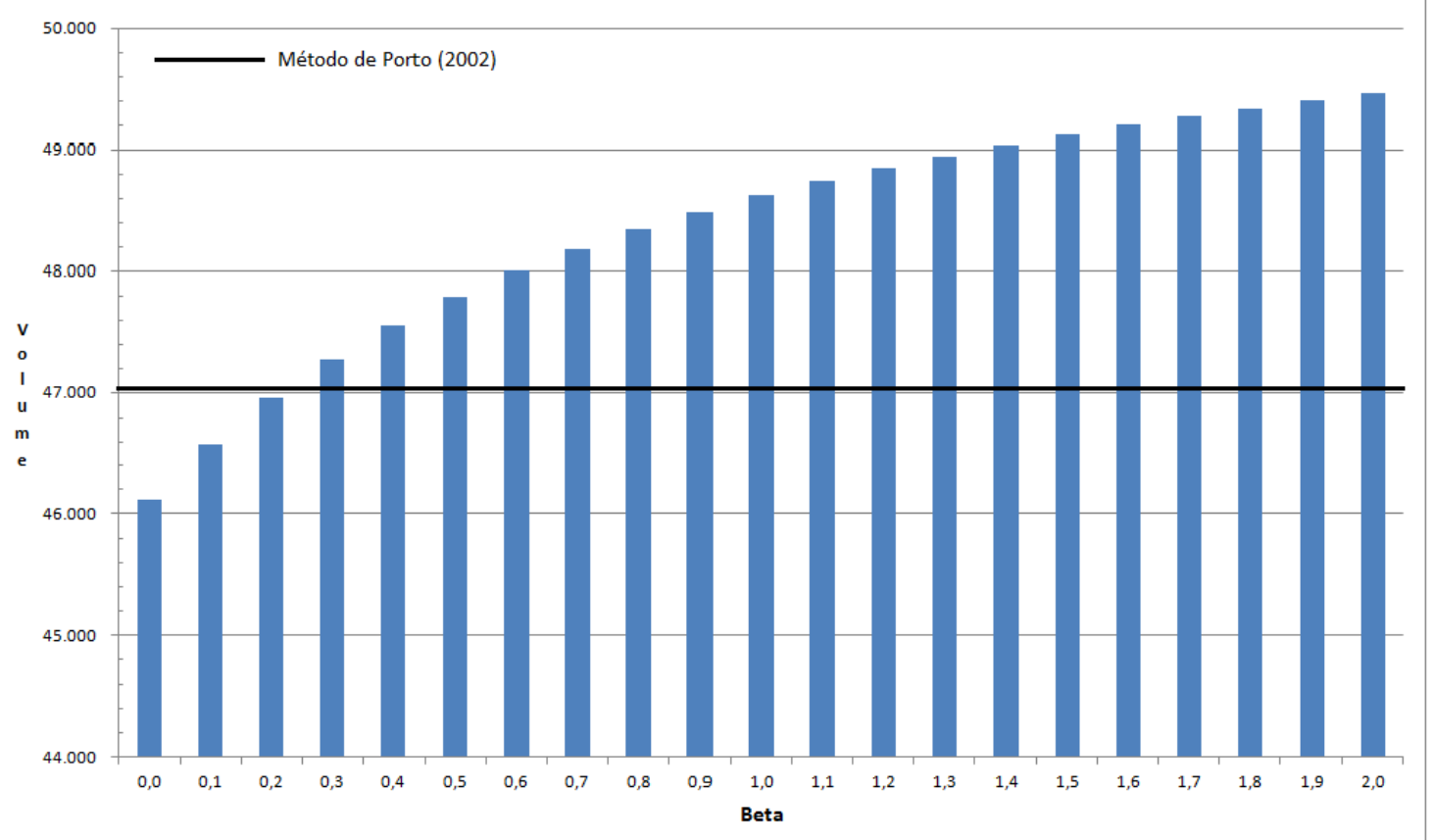

Figura 4.5: comparação entre volumes detido pela metodologia proposta e o método de Porto (2002) para tempo de retorno de 25 anos, duração de precipitação de 30 minutos e $\mathrm{CN}$ de 98.

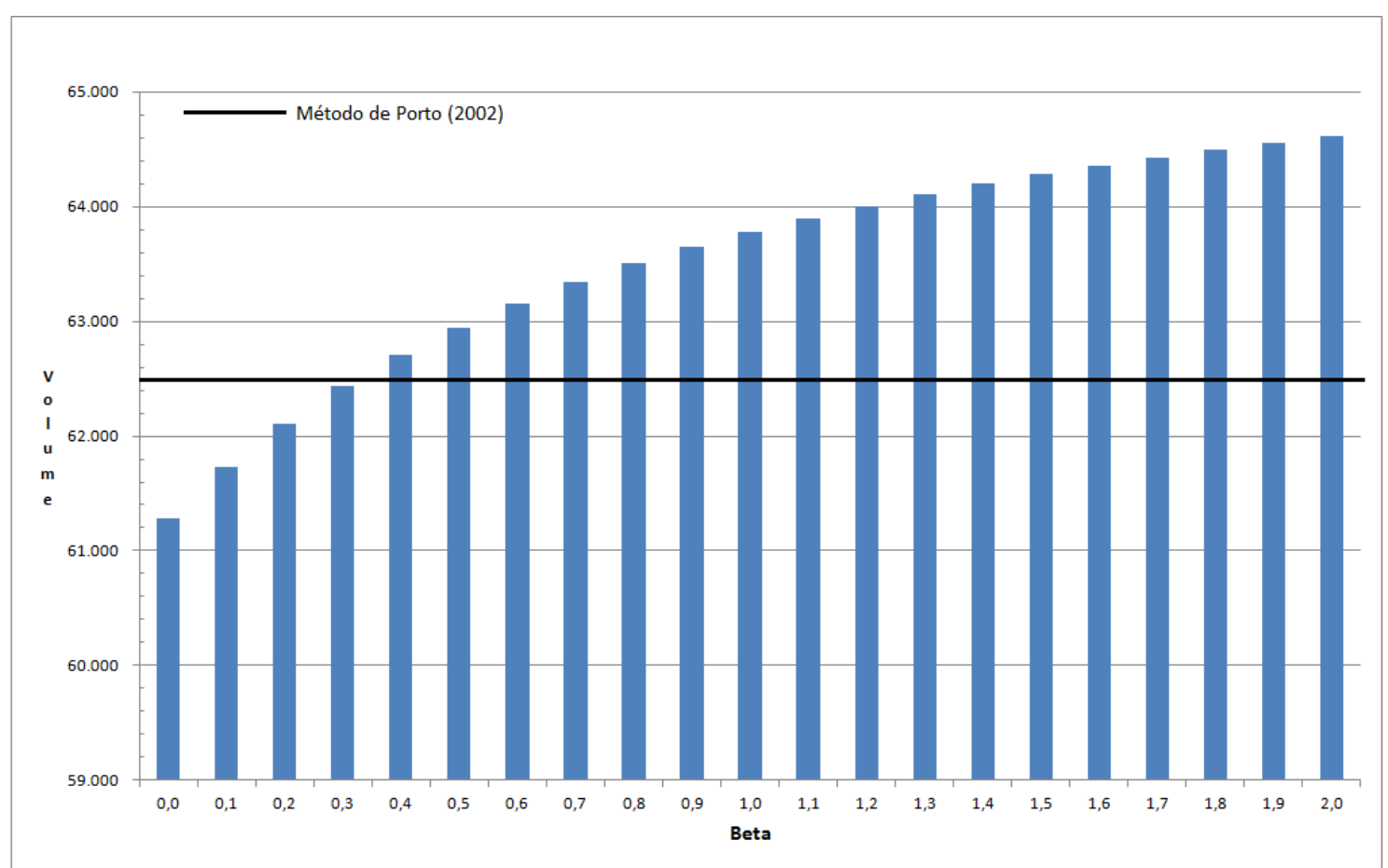

Figura 4.6: comparação entre volumes detido pela metodologia proposta e o método de Porto (2002) para tempo de retorno de 100 anos, duração de precipitação de 30 minutos e CN de 98. 
Para duração de evento chuvoso de 30, 60 e 90 minutos a Tabela 4.6 e a Tabela 4.7 apresentam as diferenças percentuais para condições de solo atual e futuras, com respectivos valores "Curve Number's" de 85 e 98, para os tempos de retorno de 25 e 100 anos.

Tabela 4.6: avaliação percentual dos volumes obtidos pelo método proposto e pela metodologia de Porto (2002) para CN 85, para diversas durações de chuvas e tempo de retorno de 25 e 100 anos.

\begin{tabular}{|c|c|c|c|c|c|c|}
\hline \multicolumn{7}{|c|}{ Volume de detenção diferença percentual } \\
\hline \multirow{2}{*}{$\begin{array}{c}\text { Duração do evento } \\
\text { Tempo de recorrência } \\
\text { (anos) }\end{array}$} & \multicolumn{2}{|c|}{30 minutos } & \multicolumn{2}{|c|}{60 minutos } & \multicolumn{2}{|c|}{90 minutos } \\
\hline & 25 & 100 & 25 & 100 & 25 & 100 \\
\hline Volume Porto (2002) & 17.235 & 29.152 & 27.397 & 43.930 & 32.771 & 53.251 \\
\hline Beta $=0,0$ & $-2,4 \%$ & $-2,1 \%$ & $-0,1 \%$ & $0,2 \%$ & $-2,8 \%$ & $-2,4 \%$ \\
\hline Beta $=0,1$ & $0,2 \%$ & $-0,6 \%$ & $3,2 \%$ & $2,2 \%$ & $1,3 \%$ & $0,2 \%$ \\
\hline Beta $=0,2$ & $2,4 \%$ & $0,7 \%$ & $6,0 \%$ & $4,0 \%$ & $4,8 \%$ & $2,3 \%$ \\
\hline Beta $=0,3$ & $4,3 \%$ & $1,8 \%$ & $8,3 \%$ & $5,4 \%$ & $7,8 \%$ & $4,1 \%$ \\
\hline Beta $=0,4$ & $5,9 \%$ & $2,8 \%$ & $10,3 \%$ & $6,7 \%$ & $10,3 \%$ & $5,6 \%$ \\
\hline Beta $=0,5$ & $7,3 \%$ & $3,6 \%$ & $12,1 \%$ & $7,8 \%$ & $12,5 \%$ & $7,0 \%$ \\
\hline Beta $=0,6$ & $8,5 \%$ & $4,3 \%$ & $13,6 \%$ & $8,7 \%$ & $14,4 \%$ & $8,2 \%$ \\
\hline Beta $=0,7$ & $9,5 \%$ & $4,9 \%$ & $14,9 \%$ & $9,6 \%$ & $16,0 \%$ & $9,2 \%$ \\
\hline Beta $=0,8$ & $10,5 \%$ & $5,5 \%$ & $16,1 \%$ & $10,3 \%$ & $17,5 \%$ & $10,1 \%$ \\
\hline Beta $=0,9$ & $11,3 \%$ & $6,0 \%$ & $17,2 \%$ & $11,0 \%$ & $18,9 \%$ & $10,9 \%$ \\
\hline Beta $=1,0$ & $12,1 \%$ & $6,4 \%$ & $18,1 \%$ & $11,6 \%$ & $20,1 \%$ & $11,7 \%$ \\
\hline Beta $=1,1$ & $12,8 \%$ & $6,8 \%$ & $19,0 \%$ & $12,1 \%$ & $21,2 \%$ & $12,4 \%$ \\
\hline Beta $=1,2$ & $13,4 \%$ & $7,2 \%$ & $19,8 \%$ & $12,6 \%$ & $22,2 \%$ & $13,0 \%$ \\
\hline Beta $=1,3$ & $14,0 \%$ & $7,6 \%$ & $20,5 \%$ & $13,0 \%$ & $23,1 \%$ & $13,5 \%$ \\
\hline Beta $=1,4$ & $14,5 \%$ & $7,9 \%$ & $21,2 \%$ & $13,5 \%$ & $23,9 \%$ & $14,0 \%$ \\
\hline Beta $=1,5$ & $15,0 \%$ & $8,2 \%$ & $21,8 \%$ & $13,8 \%$ & $24,7 \%$ & $14,5 \%$ \\
\hline Beta $=1,6$ & $15,4 \%$ & $8,4 \%$ & $22,4 \%$ & $14,2 \%$ & $25,4 \%$ & $14,9 \%$ \\
\hline Beta $=1,7$ & $15,9 \%$ & $8,7 \%$ & $22,9 \%$ & $14,5 \%$ & $26,0 \%$ & $15,3 \%$ \\
\hline Beta $=1,8$ & $16,2 \%$ & $8,9 \%$ & $23,4 \%$ & $14,8 \%$ & $26,6 \%$ & $15,7 \%$ \\
\hline Beta $=1,9$ & $16,6 \%$ & $9,1 \%$ & $23,8 \%$ & $15,1 \%$ & $27,2 \%$ & $16,1 \%$ \\
\hline Beta $=2,0$ & $16,9 \%$ & $9,3 \%$ & $24,2 \%$ & $15,4 \%$ & $27,7 \%$ & $16,4 \%$ \\
\hline
\end{tabular}


Tabela 4.7: avaliação percentual dos volumes obtidos pelo método proposto e pela metodologia de Porto (2002) para CN 98, para diversas durações de chuvas e tempo de retorno de 25 e 100 anos.

\begin{tabular}{|c|c|c|c|c|c|c|}
\hline \multicolumn{7}{|c|}{ Volume de denção diferença percentual } \\
\hline $\begin{array}{c}\text { Duração do evento } \\
\begin{array}{c}\text { Tempo de recorrência } \\
\text { (anos) }\end{array}\end{array}$ & 25 & 100 & 25 & 100 & 25 & 100 \\
\hline Volume Porto (2002) & 47.056 & 62.484 & 61.223 & 81.078 & 69.756 & 94.641 \\
\hline Beta $=0,0$ & $-2,0 \%$ & $-1,9 \%$ & $0,3 \%$ & $0,4 \%$ & $-2,2 \%$ & $-2,1 \%$ \\
\hline Beta $=0,1$ & $-1,0 \%$ & $-1,2 \%$ & $1,8 \%$ & $1,5 \%$ & $-0,3 \%$ & $-0,7 \%$ \\
\hline Beta $=0,2$ & $-0,2 \%$ & $-0,6 \%$ & $3,0 \%$ & $2,5 \%$ & $1,3 \%$ & $0,5 \%$ \\
\hline Beta $=0,3$ & $0,5 \%$ & $-0,1 \%$ & $4,1 \%$ & $3,2 \%$ & $2,7 \%$ & $1,5 \%$ \\
\hline Beta $=0,4$ & $1,0 \%$ & $0,4 \%$ & $5,0 \%$ & $3,9 \%$ & $3,9 \%$ & $2,4 \%$ \\
\hline Beta $=0,5$ & $1,6 \%$ & $0,7 \%$ & $5,8 \%$ & $4,5 \%$ & $4,9 \%$ & $3,2 \%$ \\
\hline Beta $=0,6$ & $2,0 \%$ & $1,1 \%$ & $6,4 \%$ & $5,0 \%$ & $5,8 \%$ & $3,8 \%$ \\
\hline Beta $=0,7$ & $2,4 \%$ & $1,4 \%$ & $7,0 \%$ & $5,5 \%$ & $6,6 \%$ & $4,4 \%$ \\
\hline Beta $=0,8$ & $2,7 \%$ & $1,6 \%$ & $7,6 \%$ & $5,9 \%$ & $7,3 \%$ & $4,9 \%$ \\
\hline Beta $=0,9$ & $3,0 \%$ & $1,9 \%$ & $8,1 \%$ & $6,2 \%$ & $7,9 \%$ & $5,4 \%$ \\
\hline Beta $=1,0$ & $3,3 \%$ & $2,1 \%$ & $8,5 \%$ & $6,6 \%$ & $8,5 \%$ & $5,8 \%$ \\
\hline Beta $=1,1$ & $3,6 \%$ & $2,3 \%$ & $8,9 \%$ & $6,9 \%$ & $9,0 \%$ & $6,2 \%$ \\
\hline Beta $=1,2$ & $3,8 \%$ & $2,4 \%$ & $9,2 \%$ & $7,1 \%$ & $9,5 \%$ & $6,5 \%$ \\
\hline Beta $=1,3$ & $4,0 \%$ & $2,6 \%$ & $9,5 \%$ & $7,4 \%$ & $9,9 \%$ & $6,8 \%$ \\
\hline Beta $=1,4$ & $4,2 \%$ & $2,7 \%$ & $9,8 \%$ & $7,6 \%$ & $10,3 \%$ & $7,1 \%$ \\
\hline Beta $=1,5$ & $4,4 \%$ & $2,9 \%$ & $10,1 \%$ & $7,8 \%$ & $10,7 \%$ & $7,4 \%$ \\
\hline Beta $=1,6$ & $4,6 \%$ & $3,0 \%$ & $10,4 \%$ & $8,0 \%$ & $11,0 \%$ & $7,6 \%$ \\
\hline Beta $=1,7$ & $4,7 \%$ & $3,1 \%$ & $10,6 \%$ & $8,2 \%$ & $11,3 \%$ & $7,9 \%$ \\
\hline Beta $=1,8$ & $4,8 \%$ & $3,2 \%$ & $10,8 \%$ & $8,3 \%$ & $11,6 \%$ & $8,1 \%$ \\
\hline Beta $=1,9$ & $5,0 \%$ & $3,3 \%$ & $11,0 \%$ & $8,5 \%$ & $11,9 \%$ & $8,3 \%$ \\
\hline 2,0 & $5,1 \%$ & $3,4 \%$ & $11,2 \%$ & $8,6 \%$ & $12,1 \%$ & $8,5 \%$ \\
\hline
\end{tabular}

A Avaliação da Tabela 4.6 e da Tabela 4.7, bem como da Figura 4.3 à Figura 4.6, retrata que os valores de $\beta$ que melhor estimam os volumes a serem reservados estão entre 0 e 0,5. Observa-se que eventos de projeto com duração menor apresentam resultados mais consistentes e próximos do estimado ideal e para projetos com recorrência maior o processo de cálculo proposto apresenta valores menos discrepantes dos considerados volumes ideais.

Foi realizada análise semelhante para a bacia do córrego do Andrezinho para as condições supracitadas, as tabelas e figuras relativas a estes estudos podem ser observadas no Apêndice A, bem como os resultados gráficos obtidos para as recorrências de 10, 20 e 50 anos, não apresentados nesta seção. 
Como modo de checar a faixa de $\beta$ que retorna os melhores resultados foi feita uma análise estatística baseada no erro médio e no erro padrão dos dados obtidos nesta fase dos estudos. A Tabela 4.8 apresenta os valores deste diagnóstico.

Tabela 4.8: erro médio e erro padrão obtidos da comparação dos volumes detidos calculados pelo método proposto e do método de Porto (2002).

\begin{tabular}{|c|c|c|}
\hline Beta & $\begin{array}{c}\text { Erro Médio } \\
(\%)\end{array}$ & $\begin{array}{c}\text { Erro Padrão } \\
(\%)\end{array}$ \\
\hline 0,0 & 1,9 & 0,9 \\
\hline 0,1 & 1,0 & 0,8 \\
\hline 0,2 & 2,5 & 1,7 \\
\hline 0,3 & 4,0 & 2,5 \\
\hline 0,4 & 5,4 & 3,1 \\
\hline 0,5 & 6,6 & 3,6 \\
\hline 0,6 & 7,7 & 4,0 \\
\hline 0,7 & 8,6 & 4,4 \\
\hline 0,8 & 9,4 & 4,8 \\
\hline 0,9 & 10,2 & 5,1 \\
\hline 1,0 & 10,8 & 5,4 \\
\hline 1,1 & 11,5 & 5,7 \\
\hline 1,2 & 12,0 & 5,9 \\
\hline 1,3 & 12,5 & 6,1 \\
\hline 1,4 & 13,0 & 6,3 \\
\hline 1,5 & 13,4 & 6,5 \\
\hline 1,6 & 13,8 & 6,7 \\
\hline 1,7 & 14,1 & 6,9 \\
\hline 1,8 & 14,5 & 7,0 \\
\hline 1,9 & 14,8 & 7,1 \\
\hline 2,0 & 15,1 & 7,3 \\
\hline & & \\
\hline
\end{tabular}

Os valores de $\beta$ que apresentaram resultados satisfatórios vão de 0 a 0,5 , com erro médio máximo da ordem de $7 \%$ e desvio padrão de $4 \%$. Da gama de valores de $\beta$ avaliados para cálculo de volumes detidos o que apresentou melhores resultados foi o valor de 0,1 que apresentou erro médio e desvio padrão da ordem de $1 \%$.

À medida que os valores de $\beta$ ultrapassaram o valor unitário os erros médios passaram a se distanciar demasiadamente do valor neutro, que representa que ao passo que foram atribuídos valores maiores que 1 para $\beta$ os valores de volume de detenção calculados pelo método proposto apresentaram valores discrepantes do procedimento de Porto (2002). É importante salientar que os volumes de detidos obtidos da aplicação da metodologia proposta, quando atribuído a $\beta$ valor maior que 1 , apresentaram valores 
superestimados quando relacionados ao procedimento de Porto (2002). Neste caso o erro médio máximo chegou a aproximadamente $15 \%$.

\subsubsection{Volume de detenção: comparação de procedimentos}

Nesta fase de avaliação do método proposto foram comparados os volumes de detenção estimados por diversas metodologias hidrológicas e hidráulico-hidrológicas. Os processos comparados foram: método generalizado (MCCUEN, 1989), hidrograma do método racional, Abt e Grigg (1979), Wycoff e Singh (1976), Tsuchiya (1978), Maidment (1992), Tucci (1998) e Tucci (2002), Matias (2006), método Holandês (MATIAS, 2006), método numérico das diferenças finitas, Federal Aviation Administration, Soil Conservation Service (1986) e o método de Akan (1989a). Para o procedimento proposto foi utilizado o melhor e o pior ajuste de $\beta$ e a média dos ajustes para comparação com as metodologias supracitadas. Como já mencionado o método de Porto (2002) por apresentar resultados satisfatórios foi escolhido como processo de referência.

Para esta parte dos estudos foi avaliada a sensibilidade nos volumes de detenção sujeitas a alterações no tempo de concentração da bacia, duração dos eventos chuvosos e alterações na dinâmica do uso e ocupação do solo. Os tempos de concentração utilizados foram de 15, 26, 37 e 75 minutos, a duração das precipitações foi admitida como sendo 30, 60 e 90 minutos, enquanto que para as condições de cobertura do solo foram considerados a situação do "Curve Number" valendo 85, condição atual, e o cenário crítico de toda a área está impermeabilizada com CN igual a 98.

A Tabela 4.9, a Tabela 4.10, a Figura 4.7 e a Figura 4.8 apresentam os volumes detidos estimados para a consideração do tempo de concentração da bacia de 15 minutos, para os tempos de recorrência de 25 e 100 anos.

Tabela 4.9: diferenças percentuais entre os processos de cálculo de volume de detenção, para tempo de concentração de 15 minutos, tempo de duração da chuva de 30, 60 e 90 minutos e $\mathrm{CN}=85$.

\begin{tabular}{|c|c|c|c|c|c|c|}
\hline \multicolumn{7}{|c|}{ Volume de detenção diferença percentual } \\
\hline $\begin{array}{c}\text { Duração do evento } \\
\begin{array}{c}\text { Tempo de recorrência } \\
\text { (anos) }\end{array}\end{array}$ & 25 & 100 & 25 & 100 & 25 & 100 \\
\hline $\begin{array}{c}\text { Volume Porto (2002) } \\
\text { Mét. Proposto (valor } \\
\text { médio) }\end{array}$ & 17.235 & 29.152 & 27.397 & 43.930 & 32.771 & 53.251 \\
\hline Mét. Proposto (melhor aj.) & $4,3 \%$ & $2,8 \%$ & $-0,1 \%$ & $0,2 \%$ & $1,3 \%$ & $2,3 \%$ \\
\hline Mét. Proposto (pior aj.) & $16,9 \%$ & $9,3 \%$ & $24,2 \%$ & $15,4 \%$ & $27,7 \%$ & $16,4 \%$ \\
\hline Método SCS (1986) & $-60,4 \%$ & $-55,3 \%$ & $-42,8 \%$ & $-39,6 \%$ & $-33,6 \%$ & $-34,1 \%$ \\
\hline Método da FAA & $4,8 \%$ & $2,1 \%$ & $13,6 \%$ & $8,7 \%$ & $16,3 \%$ & $9,3 \%$ \\
\hline
\end{tabular}


Tabela 4.9: (cont.) diferenças percentuais entre os processos de cálculo de volume de detenção, para tempo de concentração de 15 minutos, tempo de duração da chuva de 30, 60 e 90 minutos e CN=85.

\begin{tabular}{|c|c|c|c|c|c|c|}
\hline Método de Wycoff e Singh & $-14,5 \%$ & $-16,3 \%$ & $-28,1 \%$ & $-29,8 \%$ & $-38,0 \%$ & $-39,7 \%$ \\
\hline Mét. generalizado & $1,0 \%$ & $-0,6 \%$ & $4,4 \%$ & $2,4 \%$ & $3,5 \%$ & $0,6 \%$ \\
\hline Método Racional & $-0,6 \%$ & $0,0 \%$ & $-49,6 \%$ & $-49,2 \%$ & $-67,6 \%$ & $-67,2 \%$ \\
\hline Método de Abt \& Grigg & $-24,8 \%$ & $-16,8 \%$ & $-26,9 \%$ & $-18,4 \%$ & $-34,0 \%$ & $-24,3 \%$ \\
\hline Tsuchiya (1978) & $13,0 \%$ & $7,3 \%$ & $19,1 \%$ & $12,5 \%$ & $21,0 \%$ & $12,6 \%$ \\
\hline Maidment (1992) & $-1,6 \%$ & $-1,8 \%$ & $1,7 \%$ & $1,1 \%$ & $0,4 \%$ & $-1,0 \%$ \\
\hline Tucci (1998) & $-2,4 \%$ & $-2,1 \%$ & $-0,1 \%$ & $0,2 \%$ & $-2,8 \%$ & $-2,4 \%$ \\
\hline Tucci (2002) & $22,0 \%$ & $40,4 \%$ & $-1,3 \%$ & $12,7 \%$ & $-10,2 \%$ & $0,1 \%$ \\
\hline Mét. Numérico & $-13,5 \%$ & $-9,4 \%$ & $-6,8 \%$ & $-4,4 \%$ & $-8,0 \%$ & $-6,0 \%$ \\
\hline Método Holandês & $-12,7 \%$ & $-5,4 \%$ & $-18,0 \%$ & $-15,0 \%$ & $-21,4 \%$ & $-21,1 \%$ \\
\hline Mét. de Matias (2006) & $-15,3 \%$ & $-10,1 \%$ & $-8,0 \%$ & $-5,0 \%$ & $-9,2 \%$ & $-6,6 \%$ \\
\hline Mét. de Akan (1989a) & $32,0 \%$ & $27,6 \%$ & $30,0 \%$ & $33,7 \%$ & $23,4 \%$ & $32,5 \%$ \\
\hline
\end{tabular}

Tabela 4.10: diferenças percentuais entre os processos de cálculo de volume de detenção, para tempo de concentração de 15 minutos, tempo de duração da chuva de 30, 60 e 90 minutos e $\mathrm{CN}=98$.

\begin{tabular}{|c|c|c|c|c|c|c|}
\hline \multicolumn{7}{|c|}{ Volume de detenção diferença percentual } \\
\hline \multirow{2}{*}{$\begin{array}{c}\text { Duração do evento } \\
\text { Tempo de recorrência } \\
\text { (anos) }\end{array}$} & \multicolumn{2}{|c|}{30 minutos } & \multicolumn{2}{|c|}{60 minutos } & \multicolumn{2}{|c|}{90 minutos } \\
\hline & 25 & 100 & 25 & 100 & 25 & 100 \\
\hline Volume Porto (2002) & 47.056 & 62.484 & 61.223 & 81.078 & 69.756 & 94.641 \\
\hline $\begin{array}{l}\text { Mét. Proposto (valor } \\
\text { médio) }\end{array}$ & $2,5 \%$ & $1,3 \%$ & $7,6 \%$ & $5,9 \%$ & $7,3 \%$ & $4,9 \%$ \\
\hline Mét. Proposto (melhor aj.) & $0,1 \%$ & $-0,1 \%$ & $0,3 \%$ & $0,4 \%$ & $-0,3 \%$ & $0,5 \%$ \\
\hline Mét. Proposto (pior aj.) & $5,0 \%$ & $3,2 \%$ & $11,2 \%$ & $8,6 \%$ & $12,1 \%$ & $8,5 \%$ \\
\hline Método SCS (1986) & $-47,1 \%$ & $-43,9 \%$ & $-38,4 \%$ & $-36,6 \%$ & $-34,1 \%$ & $-35,3 \%$ \\
\hline Método da FAA & $0,4 \%$ & $-0,4 \%$ & $6,4 \%$ & $5,0 \%$ & $6,7 \%$ & $4,5 \%$ \\
\hline Método de Wycoff e Singh & $-17,6 \%$ & $-18,2 \%$ & $-30,6 \%$ & $-31,2 \%$ & $-40,4 \%$ & $-41,1 \%$ \\
\hline Mét. generalizado & $-1,7 \%$ & $-2,1 \%$ & $1,5 \%$ & $1,2 \%$ & $-0,5 \%$ & $-1,0 \%$ \\
\hline Método Racional & $-0,7 \%$ & $-0,5 \%$ & $-49,4 \%$ & $-49,1 \%$ & $-67,4 \%$ & $-67,1 \%$ \\
\hline Método de Abt \& Grigg & $-12,3 \%$ & $-10,5 \%$ & $-13,7 \%$ & $-10,6 \%$ & $-19,9 \%$ & $-15,8 \%$ \\
\hline Tsuchiya (1978) & $3,9 \%$ & $2,6 \%$ & $9,4 \%$ & $7,4 \%$ & $9,4 \%$ & $6,7 \%$ \\
\hline Maidment (1992) & $-2,1 \%$ & $-2,4 \%$ & $1,1 \%$ & $0,9 \%$ & $-0,7 \%$ & $-1,3 \%$ \\
\hline Tucci (1998) & $-2,4 \%$ & $-2,6 \%$ & $0,3 \%$ & $0,4 \%$ & $-2,2 \%$ & $-2,1 \%$ \\
\hline Tucci (2002) & $4,7 \%$ & $29,5 \%$ & $-15,6 \%$ & $3,3 \%$ & $-25,1 \%$ & $-9,5 \%$ \\
\hline Mét. Numérico & $-6,7 \%$ & $-5,6 \%$ & $-3,2 \%$ & $-2,3 \%$ & $-5,2 \%$ & $-4,4 \%$ \\
\hline Método Holandês & $21,6 \%$ & $25,2 \%$ & $3,2 \%$ & $6,6 \%$ & $-7,7 \%$ & $-5,3 \%$ \\
\hline Mét. de Matias (2006) & $-7,7 \%$ & $-6,7 \%$ & $-3,5 \%$ & $-2,5 \%$ & $-5,5 \%$ & $-4,6 \%$ \\
\hline Mét. de Akan (1989a) & $20,6 \%$ & $17,7 \%$ & $29,5 \%$ & $25,1 \%$ & $29,7 \%$ & $26,2 \%$ \\
\hline
\end{tabular}




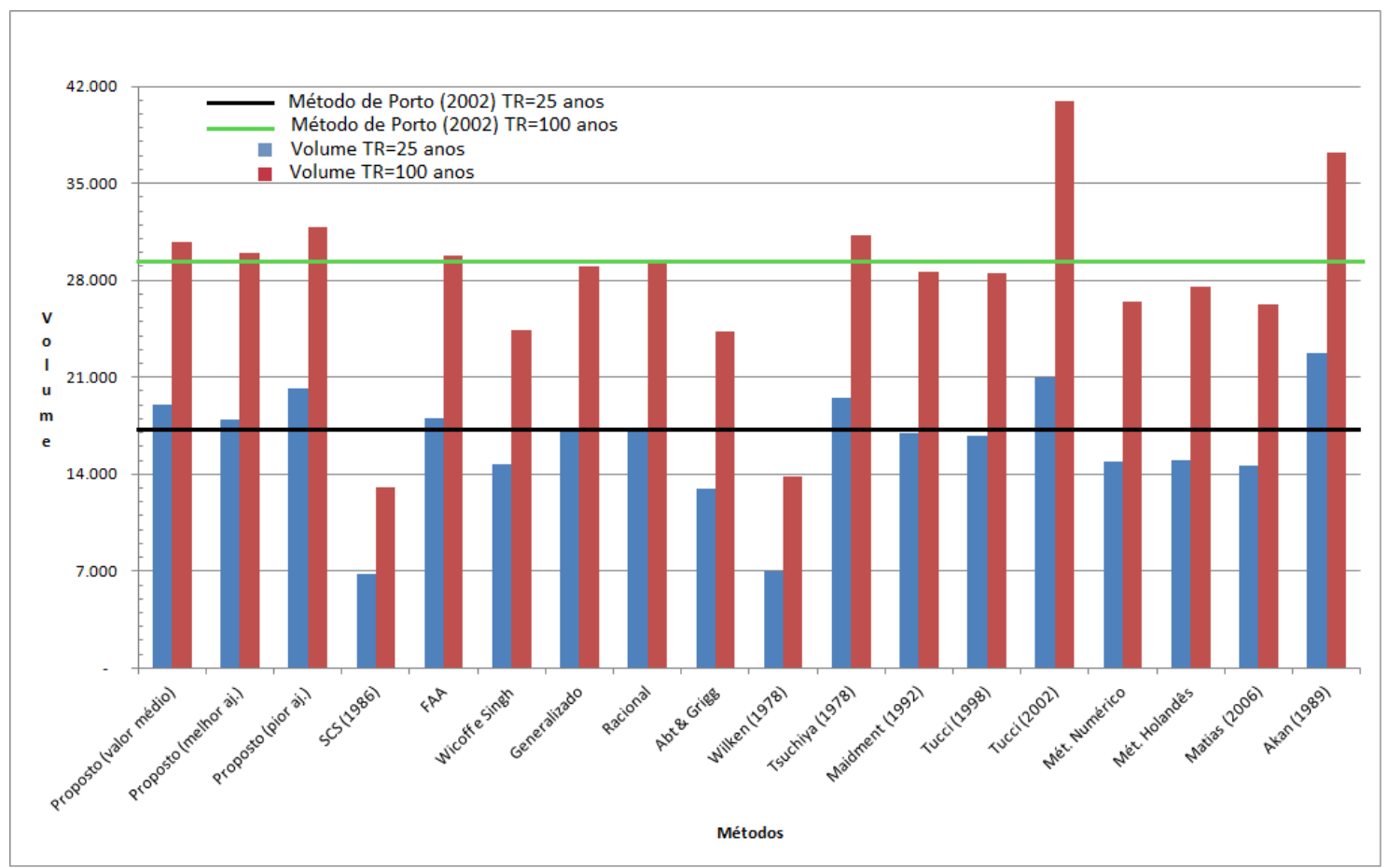

Figura 4.7: comparação gráfica de volumes de detenção para tempo de concentração de 15 minutos, duração da chuva de 30 minutos e CN de 85 .

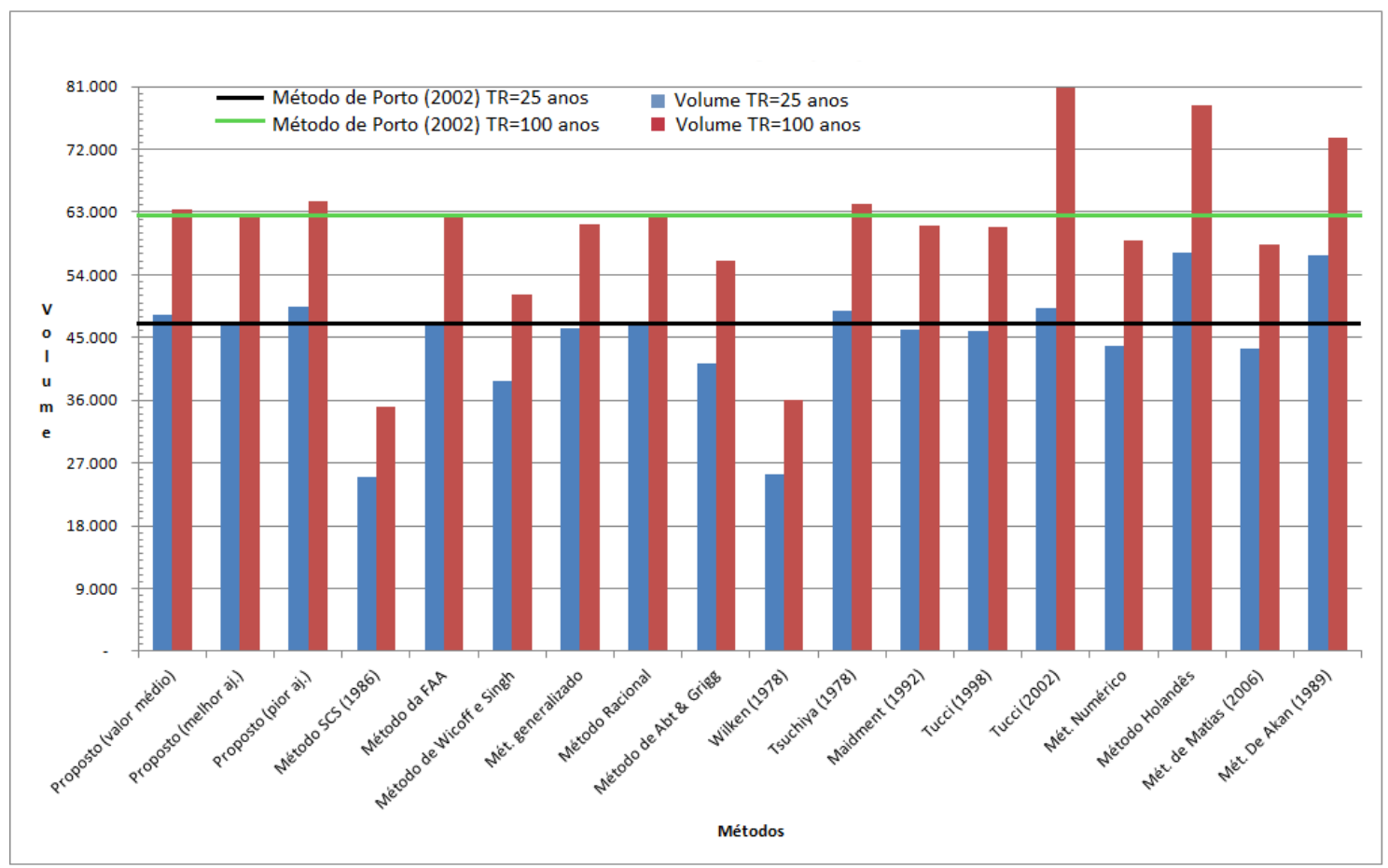

Figura 4.8: comparação gráfica de volumes de detenção para tempo de concentração de 15 minutos, duração da chuva de 30 minutos e CN de 98 .

A Tabela 4.11, a Tabela 4.12, a Figura 4.9 e a Figura 4.10 apresentam os volumes detidos estimados para a consideração do tempo de concentração da bacia de 26 minutos, para os tempos de recorrência de 25 e 100 anos. 
Tabela 4.11: diferenças percentuais entre os processos de cálculo de volume de detenção, para tempo de concentração de 26 minutos, duração da chuva de 30, 60 e 90 minutos e $\mathbf{C N}=85$.

\begin{tabular}{|c|c|c|c|c|c|c|}
\hline \multicolumn{7}{|c|}{ Volume de detenção diferença percentual } \\
\hline Duração do evento & 30 minutos & 60 minutos & \multicolumn{2}{c|}{90 minutos } \\
\hline Tempo de recorrência (anos) & 25 & 100 & 25 & 100 & 25 & 100 \\
\hline Volume Porto (2002) & 17.235 & 29.152 & 27.397 & 43.930 & 32.771 & 53.251 \\
\hline Mét. Proposto (valor médio) & $10,5 \%$ & $5,5 \%$ & $16,1 \%$ & $10,3 \%$ & $17,6 \%$ & $10,1 \%$ \\
\hline Mét. Proposto (melhor aj.) & $4,3 \%$ & $2,8 \%$ & $-0,1 \%$ & $0,2 \%$ & $1,3 \%$ & $2,3 \%$ \\
\hline Mét. Proposto (pior aj.) & $16,9 \%$ & $9,3 \%$ & $24,2 \%$ & $15,4 \%$ & $27,7 \%$ & $16,4 \%$ \\
\hline Método SCS (1986) & $-57,8 \%$ & $-54,2 \%$ & $-42,8 \%$ & $-39,6 \%$ & $-33,6 \%$ & $-34,1 \%$ \\
\hline Método da FAA & $-0,6 \%$ & $-1,1 \%$ & $10,1 \%$ & $6,6 \%$ & $13,4 \%$ & $7,6 \%$ \\
\hline Método de Wycoff e Singh & $-1,8 \%$ & $-3,9 \%$ & $-14,6 \%$ & $-16,6 \%$ & $-25,1 \%$ & $-27,2 \%$ \\
\hline Mét. generalizado & $-11,7 \%$ & $-2,3 \%$ & $-14,8 \%$ & $-4,8 \%$ & $-23,5 \%$ & $-12,1 \%$ \\
\hline Método Racional & $-0,6 \%$ & $0,0 \%$ & $-49,6 \%$ & $-49,2 \%$ & $-67,6 \%$ & $-67,2 \%$ \\
\hline Método de Abt \& Grigg & $-24,8 \%$ & $-16,8 \%$ & $-26,9 \%$ & $-18,4 \%$ & $-34,0 \%$ & $-24,3 \%$ \\
\hline Tsuchiya (1978) & $13,0 \%$ & $7,3 \%$ & $19,1 \%$ & $12,5 \%$ & $21,0 \%$ & $12,6 \%$ \\
\hline Maidment (1992) & $-1,6 \%$ & $-1,8 \%$ & $1,7 \%$ & $1,1 \%$ & $0,4 \%$ & $-1,0 \%$ \\
\hline Tucci (1998) & $-2,4 \%$ & $-2,1 \%$ & $-0,1 \%$ & $0,2 \%$ & $-2,8 \%$ & $-2,4 \%$ \\
\hline Tucci (2002) & $22,0 \%$ & $40,4 \%$ & $-1,3 \%$ & $12,7 \%$ & $-10,2 \%$ & $0,1 \%$ \\
\hline Mét. Numérico & $-21,8 \%$ & $-14,8 \%$ & $-11,7 \%$ & $-7,9 \%$ & $-11,8 \%$ & $-8,7 \%$ \\
\hline Método Holandês & $-12,7 \%$ & $-5,4 \%$ & $-18,0 \%$ & $-15,0 \%$ & $-21,4 \%$ & $-21,1 \%$ \\
\hline Mét. de Matias (2006) & $-24,9 \%$ & $-16,0 \%$ & $-14,0 \%$ & $-8,9 \%$ & $-14,0 \%$ & $-9,7 \%$ \\
\hline Mét. de Akan (1989a) & $32,0 \%$ & $27,6 \%$ & $30,0 \%$ & $33,7 \%$ & $23,4 \%$ & $32,5 \%$ \\
\hline
\end{tabular}

Tabela 4.12: diferenças percentuais entre os processos de cálculo de volume de detenção, para tempo de concentração de 26 minutos, duração da chuva de 30,60 e 90 minutos e $\mathrm{CN}=98$.

\begin{tabular}{|c|c|c|c|c|c|c|}
\hline \multicolumn{7}{|c|}{ Volume de detenção diferença percentual } \\
\hline Duração do evento & 30 minutos & 60 minutos & \multicolumn{2}{c|}{90 minutos } \\
\hline Tempo de recorrência (anos) & 25 & 100 & 25 & 100 & 25 & 100 \\
\hline Volume Porto (2002) & 47.056 & 62.484 & 61.223 & 81.078 & 69.756 & 94.641 \\
\hline Mét. Proposto (valor médio) & $2,7 \%$ & $1,6 \%$ & $7,6 \%$ & $5,9 \%$ & $7,3 \%$ & $4,9 \%$ \\
\hline Mét. Proposto (melhor aj.) & $0,5 \%$ & $0,4 \%$ & $0,3 \%$ & $0,4 \%$ & $-0,3 \%$ & $0,5 \%$ \\
\hline Mét. Proposto (pior aj.) & $5,1 \%$ & $3,4 \%$ & $11,2 \%$ & $8,6 \%$ & $12,1 \%$ & $8,5 \%$ \\
\hline Método SCS (1986) & $-47,1 \%$ & $-43,9 \%$ & $-38,4 \%$ & $-36,6 \%$ & $-34,1 \%$ & $-35,3 \%$ \\
\hline Método da FAA & $-1,3 \%$ & $-1,4 \%$ & $4,9 \%$ & $3,9 \%$ & $5,4 \%$ & $3,5 \%$ \\
\hline Método de Wycoff e Singh & $-5,1 \%$ & $-5,6 \%$ & $-17,6 \%$ & $-18,2 \%$ & $-28,1 \%$ & $-28,9 \%$ \\
\hline Mét. generalizado & $3,2 \%$ & $6,1 \%$ & $-0,2 \%$ & $4,0 \%$ & $-7,9 \%$ & $-2,6 \%$ \\
\hline Método Racional & $-0,2 \%$ & $0,2 \%$ & $-49,4 \%$ & $-49,1 \%$ & $-67,4 \%$ & $-67,1 \%$ \\
\hline Método de Abt \& Grigg & $-11,6 \%$ & $-9,3 \%$ & $-13,7 \%$ & $-10,6 \%$ & $-19,9 \%$ & $-15,8 \%$ \\
\hline Tsuchiya (1978) & $4,1 \%$ & $2,9 \%$ & $9,4 \%$ & $7,4 \%$ & $9,4 \%$ & $6,7 \%$ \\
\hline Maidment (1992) & $-1,7 \%$ & $-1,8 \%$ & $1,1 \%$ & $0,9 \%$ & $-0,7 \%$ & $-1,3 \%$ \\
\hline Tucci (1998) & $-2,0 \%$ & $-1,9 \%$ & $0,3 \%$ & $0,4 \%$ & $-2,2 \%$ & $-2,1 \%$ \\
\hline Tucci (2002) & $4,7 \%$ & $29,5 \%$ & $-15,6 \%$ & $3,3 \%$ & $-25,1 \%$ & $-9,5 \%$ \\
\hline
\end{tabular}


Tabela 4.12: (cont.) diferenças percentuais entre os processos de cálculo de volume de detenção, para tempo de concentração de 26 minutos, tempo de duração da chuva de 30, 60 e 90 minutos e $\mathbf{C N}=98$.

\begin{tabular}{|c|c|c|c|c|c|c|}
\hline Mét. Numérico & $-10,3 \%$ & $-8,3 \%$ & $-5,8 \%$ & $-4,4 \%$ & $-7,3 \%$ & $-6,0 \%$ \\
\hline Método Holandês & $24,5 \%$ & $30,9 \%$ & $3,2 \%$ & $6,6 \%$ & $-7,7 \%$ & $-5,3 \%$ \\
\hline Mét. de Matias (2006) & $-10,8 \%$ & $-8,7 \%$ & $-6,3 \%$ & $-4,7 \%$ & $-8,0 \%$ & $-6,4 \%$ \\
\hline Mét. de Akan (1989a) & $20,6 \%$ & $17,7 \%$ & $29,5 \%$ & $25,1 \%$ & $29,7 \%$ & $26,2 \%$ \\
\hline
\end{tabular}

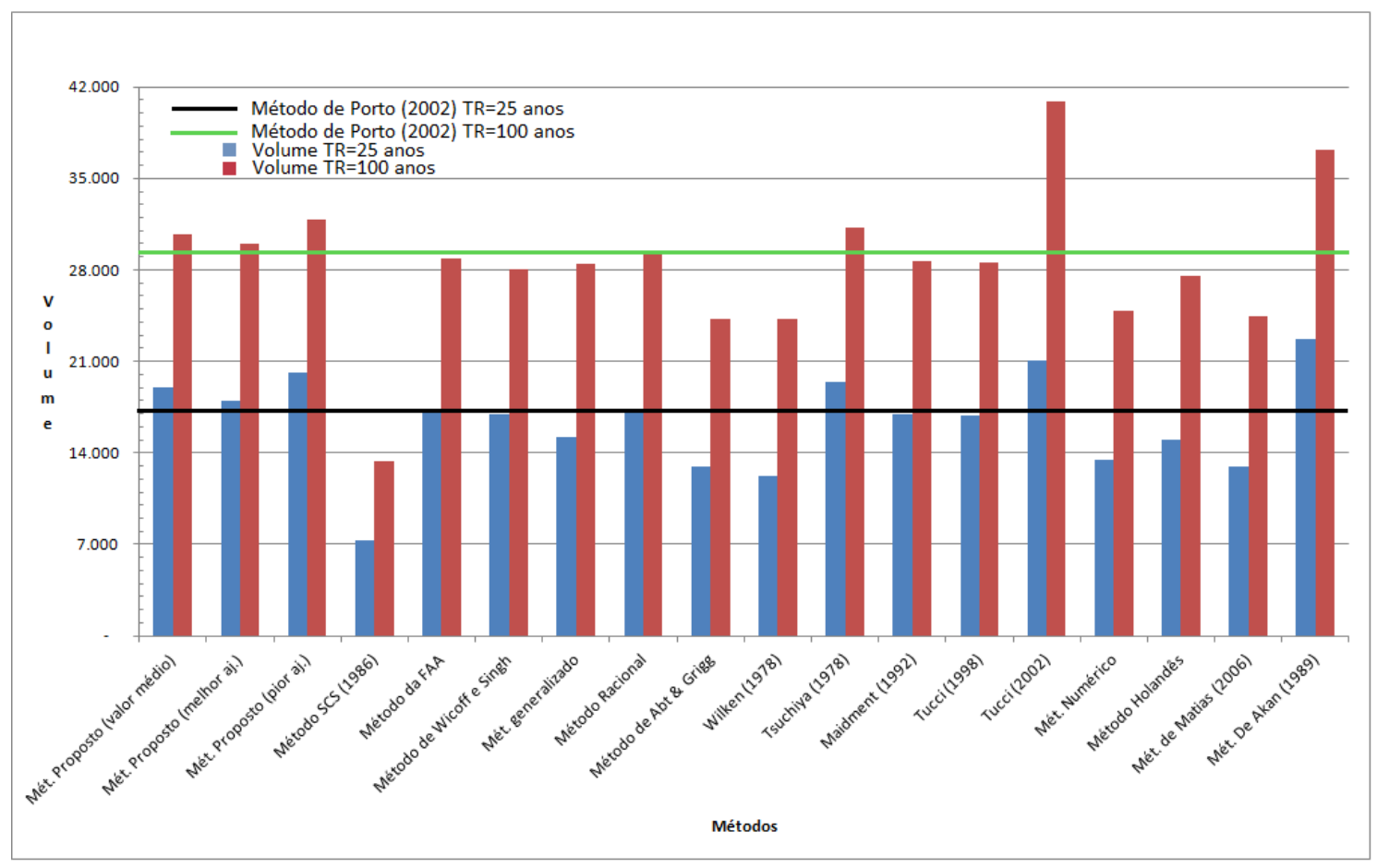

Figura 4.9: comparação gráfica de volumes de detenção para tempo de concentração de 26 minutos, duração da chuva de 30 minutos e CN de 85. 


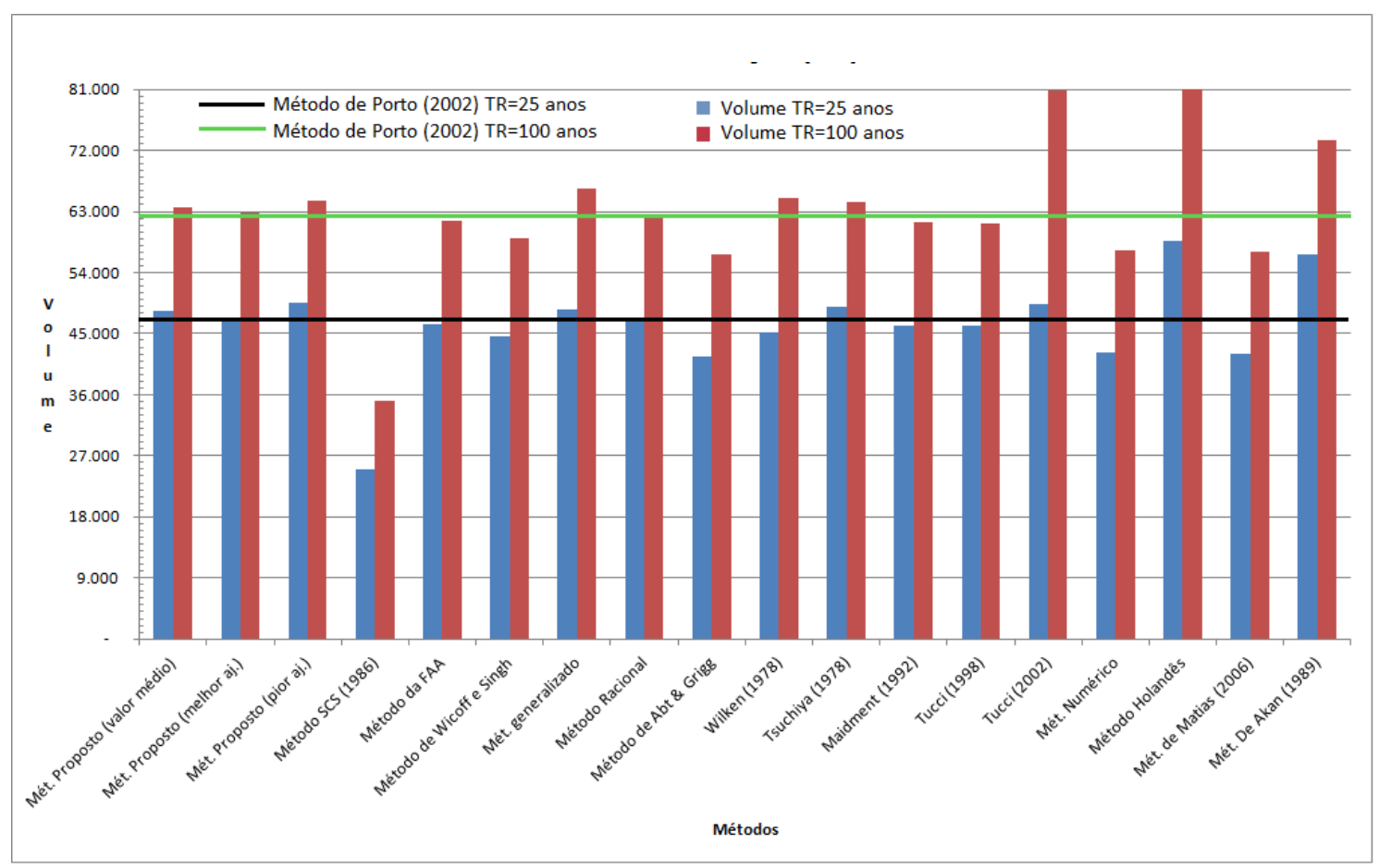

Figura 4.10: comparação gráfica de volumes de detenção para tempo de

concentração de 26 minutos, duração da chuva de 30 minutos e $\mathrm{CN}$ de 98.

Tabela 4.13: diferenças percentuais entre os processos de cálculo de volume de detenção, para tc de 37 minutos, duração da chuva de 30,60 e 90 minutos e $\mathrm{CN}=85$.

\begin{tabular}{|c|c|c|c|c|c|c|}
\hline \multicolumn{7}{|c|}{ Volume de detenção diferença percentual } \\
\hline \multirow{2}{*}{$\begin{array}{c}\text { Duração do evento } \\
\text { Tempo de recorrência } \\
\text { (anos) }\end{array}$} & \multicolumn{2}{|c|}{30 minutos } & \multicolumn{2}{|c|}{60 minutos } & \multicolumn{2}{|c|}{90 minutos } \\
\hline & 25 & 100 & 25 & 100 & 25 & 100 \\
\hline Volume Porto (2002) & 17.235 & 29.152 & 27.397 & 43.930 & 32.771 & 53.251 \\
\hline $\begin{array}{l}\text { Mét. Proposto (valor } \\
\text { médio) }\end{array}$ & $10,5 \%$ & $5,5 \%$ & $16,1 \%$ & $10,3 \%$ & $17,6 \%$ & $10,1 \%$ \\
\hline Mét. Proposto (melhor aj.) & $4,3 \%$ & $2,8 \%$ & $-0,1 \%$ & $0,2 \%$ & $1,3 \%$ & $2,3 \%$ \\
\hline Mét. Proposto (pior aj.) & $16,9 \%$ & $9,3 \%$ & $24,2 \%$ & $15,4 \%$ & $27,7 \%$ & $16,4 \%$ \\
\hline Método SCS (1986) & $-60,4 \%$ & $-54,2 \%$ & $-42,8 \%$ & $-39,6 \%$ & $-33,6 \%$ & $-34,1 \%$ \\
\hline Método da FAA & $-6,1 \%$ & $-4,3 \%$ & $6,7 \%$ & $4,4 \%$ & $10,5 \%$ & $5,8 \%$ \\
\hline Método de Wycoff e Singh & $5,5 \%$ & $3,3 \%$ & $-6,0 \%$ & $-8,1 \%$ & $-16,5 \%$ & $-18,9 \%$ \\
\hline Mét. generalizado & $-37,7 \%$ & $-31,4 \%$ & $-39,6 \%$ & $-33,0 \%$ & $-45,3 \%$ & $-37,9 \%$ \\
\hline Método Racional & $-0,6 \%$ & $0,0 \%$ & $-49,6 \%$ & $-49,2 \%$ & $-67,6 \%$ & $-67,2 \%$ \\
\hline Método de Abt \& Grigg & $-24,8 \%$ & $-16,8 \%$ & $-26,9 \%$ & $-18,4 \%$ & $-34,0 \%$ & $-24,3 \%$ \\
\hline Tsuchiya (1978) & $13,0 \%$ & $7,3 \%$ & $19,1 \%$ & $12,5 \%$ & $21,0 \%$ & $12,6 \%$ \\
\hline Maidment (1992) & $-1,6 \%$ & $-1,8 \%$ & $1,7 \%$ & $1,1 \%$ & $0,4 \%$ & $-1,0 \%$ \\
\hline Tucci (1998) & $-2,4 \%$ & $-2,1 \%$ & $-0,1 \%$ & $0,2 \%$ & $-2,8 \%$ & $-2,4 \%$ \\
\hline Tucci (2002) & $22,0 \%$ & $40,4 \%$ & $-1,3 \%$ & $12,7 \%$ & $-10,2 \%$ & $0,1 \%$ \\
\hline Mét. Numérico & $-27,2 \%$ & $-17,5 \%$ & $-16,8 \%$ & $-11,4 \%$ & $-15,8 \%$ & $-11,5 \%$ \\
\hline Método Holandês & $-12,7 \%$ & $-5,4 \%$ & $-18,0 \%$ & $-15,0 \%$ & $-21,4 \%$ & $-21,1 \%$ \\
\hline Mét. de Matias (2006) & $-34,6 \%$ & $-22,0 \%$ & $-19,9 \%$ & $-12,7 \%$ & $-18,8 \%$ & $-12,8 \%$ \\
\hline Mét. de Akan (1989a) & $32,0 \%$ & $27,6 \%$ & $30,0 \%$ & $33,7 \%$ & $23,4 \%$ & $32,5 \%$ \\
\hline
\end{tabular}


A Tabela 4.13, a Tabela 4.14, a Figura 4.11 e a Figura 4.12 apresentam os volumes detidos estimados para a consideração do tempo de concentração da bacia de 37 minutos, para os tempos de recorrência de 25 e 100 anos.

Tabela 4.14: diferenças percentuais entre os processos de cálculo de volume de detenção, para tc de 37 minutos, duração da chuva de 30,60 e 90 minutos e $\mathrm{CN}=98$.

\begin{tabular}{|c|c|c|c|c|c|c|}
\hline \multicolumn{7}{|c|}{ Volume de detenção diferença percentual } \\
\hline \multirow{2}{*}{$\begin{array}{c}\text { Duração do evento } \\
\begin{array}{c}\text { Tempo de recorrência } \\
\text { (anos) }\end{array}\end{array}$} & \multicolumn{2}{|c|}{30 minutos } & \multicolumn{2}{|c|}{60 minutos } & \multicolumn{2}{|c|}{90 minutos } \\
\hline & 25 & 100 & 25 & 100 & 25 & 100 \\
\hline Volume Porto (2002) & 47.056 & 62.484 & 61.223 & 81.078 & 69.756 & 94.641 \\
\hline $\begin{array}{l}\text { Mét. Proposto (valor } \\
\text { médio) }\end{array}$ & $2,5 \%$ & $1,3 \%$ & $7,6 \%$ & $5,9 \%$ & $7,3 \%$ & $4,9 \%$ \\
\hline Mét. Proposto (melhor aj.) & $0,1 \%$ & $-0,1 \%$ & $0,3 \%$ & $0,4 \%$ & $-0,3 \%$ & $0,5 \%$ \\
\hline Mét. Proposto (pior aj.) & $5,0 \%$ & $3,2 \%$ & $11,2 \%$ & $8,6 \%$ & $12,1 \%$ & $8,5 \%$ \\
\hline Método SCS (1986) & $-47,1 \%$ & $-43,9 \%$ & $-38,4 \%$ & $-36,6 \%$ & $-34,1 \%$ & $-35,3 \%$ \\
\hline Método da FAA & $-3,8 \%$ & $-3,6 \%$ & $3,4 \%$ & $2,7 \%$ & $4,0 \%$ & $2,5 \%$ \\
\hline Método de Wycoff e Singh & $1,6 \%$ & $0,9 \%$ & $-9,2 \%$ & $-9,9 \%$ & $-19,8 \%$ & $-20,7 \%$ \\
\hline Mét. generalizado & $-28,3 \%$ & $-26,6 \%$ & $-29,8 \%$ & $-27,0 \%$ & $-35,0 \%$ & $-31,5 \%$ \\
\hline Método Racional & $-0,7 \%$ & $-0,5 \%$ & $-49,4 \%$ & $-49,1 \%$ & $-67,4 \%$ & $-67,1 \%$ \\
\hline Método de Abt \& Grigg & $-12,3 \%$ & $-10,5 \%$ & $-13,7 \%$ & $-10,6 \%$ & $-19,9 \%$ & $-15,8 \%$ \\
\hline Tsuchiya (1978) & $3,9 \%$ & $2,6 \%$ & $9,4 \%$ & $7,4 \%$ & $9,4 \%$ & $6,7 \%$ \\
\hline Maidment (1992) & $-2,1 \%$ & $-2,4 \%$ & $1,1 \%$ & $0,9 \%$ & $-0,7 \%$ & $-1,3 \%$ \\
\hline Tucci (1998) & $-2,4 \%$ & $-2,6 \%$ & $0,3 \%$ & $0,4 \%$ & $-2,2 \%$ & $-2,1 \%$ \\
\hline Tucci (2002) & $4,7 \%$ & $29,5 \%$ & $-15,6 \%$ & $3,3 \%$ & $-25,1 \%$ & $-9,5 \%$ \\
\hline Mét. Numérico & $-11,3 \%$ & $-8,5 \%$ & $-8,5 \%$ & $-6,5 \%$ & $-9,6 \%$ & $-7,8 \%$ \\
\hline Método Holandês & $21,6 \%$ & $25,2 \%$ & $3,2 \%$ & $6,6 \%$ & $-7,7 \%$ & $-15,7 \%$ \\
\hline Mét. de Matias (2006) & $-15,5 \%$ & $-12,9 \%$ & $-9,2 \%$ & $-6,9 \%$ & $-10,4 \%$ & $-8,3 \%$ \\
\hline Mét. de Akan (1989a) & $20,6 \%$ & $17,7 \%$ & $29,5 \%$ & $25,1 \%$ & $29,7 \%$ & $26,2 \%$ \\
\hline
\end{tabular}




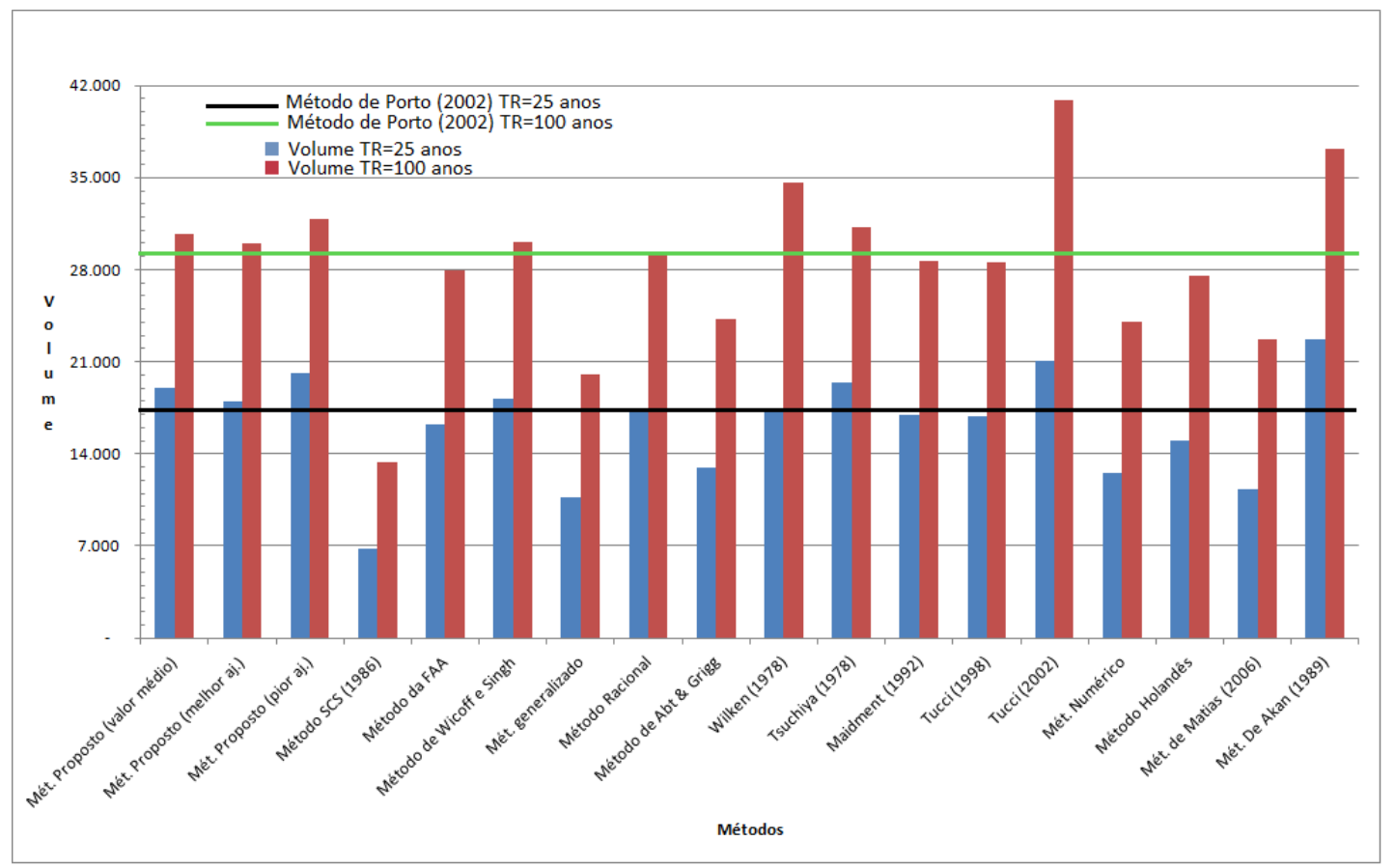

Figura 4.11: comparação gráfica de volumes de detenção para tempo de concentração de 37 minutos, duração da chuva de 30 minutos e CN de 85.

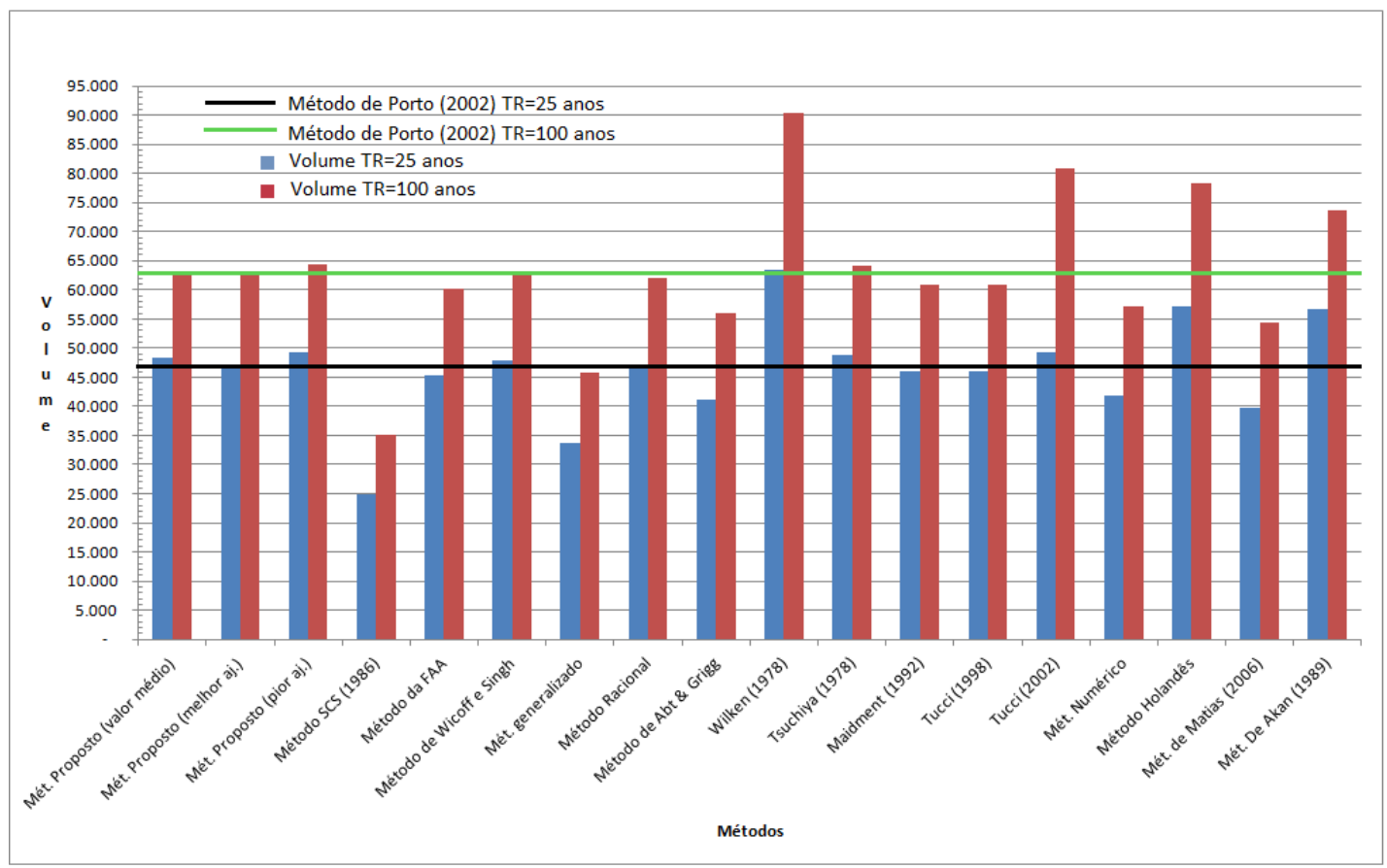

Figura 4.12: comparação gráfica de volumes de detenção para tempo de concentração de 37 minutos, duração da chuva de 30 minutos e CN de 98.

A Tabela 4.15, a Tabela 4.16, a Figura 4.13 e a Figura 4.14 apresentam os volumes detidos estimados para a consideração do tempo de concentração da bacia de 75 minutos, para os tempos de recorrência de 25 e 100 anos. 
Tabela 4.15: diferenças percentuais entre os processos de cálculo de volume de detenção, para tempo de concentração de 75 minutos, duração da chuva de 30, 60 e 90 minutos e $\mathbf{C N}=85$.

\begin{tabular}{|c|c|c|c|c|c|c|}
\hline \multicolumn{7}{|c|}{ Volume de detenção diferença percentual } \\
\hline $\begin{array}{c}\text { Duração do evento } \\
\text { Tempo de recorrência } \\
\text { (anos) }\end{array}$ & 25 & 100 & 25 & 100 & 25 & 100 \\
\hline $\begin{array}{c}\text { Volume Porto (2002) } \\
\text { Mét. Proposto (valor médio) }\end{array}$ & 17.235 & 29.152 & 27.397 & 43.930 & 32.771 & 53.251 \\
\hline Mét. Proposto (melhor aj.) & $4,3 \%$ & $5,5 \%$ & $16,1 \%$ & $10,3 \%$ & $17,6 \%$ & $10,1 \%$ \\
\hline Mét. Proposto (pior aj.) & $16,9 \%$ & $9,3 \%$ & $-0,1 \%$ & $0,2 \%$ & $1,3 \%$ & $2,3 \%$ \\
\hline Método SCS (1986) & $-60,4 \%$ & $-54,2 \%$ & $-42,8 \%$ & $-39,6 \%$ & $-33,6 \%$ & $-34,1 \%$ \\
\hline Método da FAA & $-24,2 \%$ & $-15,0 \%$ & $-4,7 \%$ & $-2,7 \%$ & $1,0 \%$ & $-0,1 \%$ \\
\hline Método de Wycoff e Singh & $17,0 \%$ & $14,5 \%$ & $9,4 \%$ & $6,8 \%$ & $-0,2 \%$ & $-3,0 \%$ \\
\hline Mét. generalizado & $-59,2 \%$ & $-60,0 \%$ & $-57,5 \%$ & $-58,8 \%$ & $-57,1 \%$ & $-59,4 \%$ \\
\hline Método Racional & $-0,6 \%$ & $0,0 \%$ & $-49,6 \%$ & $-49,2 \%$ & $-67,6 \%$ & $-67,2 \%$ \\
\hline Método de Abt \& Grigg & $-24,8 \%$ & $-16,8 \%$ & $-26,9 \%$ & $-18,4 \%$ & $-34,0 \%$ & $-24,3 \%$ \\
\hline Tsuchiya (1978) & $13,0 \%$ & $7,3 \%$ & $19,1 \%$ & $12,5 \%$ & $21,0 \%$ & $12,6 \%$ \\
\hline Maidment (1992) & $-1,6 \%$ & $-1,8 \%$ & $1,7 \%$ & $1,1 \%$ & $0,4 \%$ & $-1,0 \%$ \\
\hline Tucci (1998) & $-2,4 \%$ & $-2,1 \%$ & $-0,1 \%$ & $0,2 \%$ & $-2,8 \%$ & $-2,4 \%$ \\
\hline Tucci (2002) & $22,0 \%$ & $40,4 \%$ & $-1,3 \%$ & $12,7 \%$ & $-10,2 \%$ & $0,1 \%$ \\
\hline Mét. Numérico & $-2,6 \%$ & $12,0 \%$ & $-30,4 \%$ & $-20,2 \%$ & $-28,8 \%$ & $-20,6 \%$ \\
\hline Método Holandês & $-12,7 \%$ & $-5,4 \%$ & $-18,0 \%$ & $-15,0 \%$ & $-21,4 \%$ & $-21,0 \%$ \\
\hline Mét. de Matias (2006) & $-66,7 \%$ & $-41,9 \%$ & $-39,7 \%$ & $-25,7 \%$ & $-34,9 \%$ & $-23,3 \%$ \\
\hline Mét. de Akan (1989a) & $32,0 \%$ & $27,6 \%$ & $30,0 \%$ & $33,7 \%$ & $23,4 \%$ & $32,5 \%$ \\
\hline
\end{tabular}

Tabela 4.16: diferenças percentuais entre os processos de cálculo de volume de detenção, para tempo de concentração de 75 minutos, duração da chuva de 30, 60 e 90 minutos e $\mathbf{C N}=98$.

\begin{tabular}{|c|c|c|c|c|c|c|}
\hline \multicolumn{7}{|c|}{ Volume de detenção diferença percentual } \\
\hline \multirow{2}{*}{$\begin{array}{c}\text { Duração do evento } \\
\text { Tempo de recorrência } \\
\text { (anos) }\end{array}$} & \multicolumn{2}{|c|}{30 minutos } & \multicolumn{2}{|c|}{60 minutos } & \multicolumn{2}{|c|}{90 minutos } \\
\hline & 25 & 100 & 25 & 100 & 25 & 100 \\
\hline Volume Porto (2002) & 47.056 & 62.484 & 61.223 & 81.078 & 69.756 & 94.641 \\
\hline Mét. Proposto (valor médio) & $2,5 \%$ & $1,3 \%$ & $7,6 \%$ & $5,9 \%$ & $7,3 \%$ & $4,9 \%$ \\
\hline Mét. Proposto (melhor aj.) & $0,1 \%$ & $-0,1 \%$ & $0,3 \%$ & $0,4 \%$ & $-0,3 \%$ & $0,5 \%$ \\
\hline Mét. Proposto (pior aj.) & $5,0 \%$ & $3,2 \%$ & $11,2 \%$ & $8,6 \%$ & $12,1 \%$ & $8,5 \%$ \\
\hline Método SCS (1986) & $-47,1 \%$ & $-44,9 \%$ & $-38,4 \%$ & $-36,6 \%$ & $-34,1 \%$ & $-35,3 \%$ \\
\hline Método da FAA & $-10,7 \%$ & $-9,0 \%$ & $-1,7 \%$ & $2,7 \%$ & $-0,5 \%$ & $-0,8 \%$ \\
\hline Método de Wycoff e Singh & $12,7 \%$ & $11,9 \%$ & $5,6 \%$ & $-9,9 \%$ & $-4,1 \%$ & $-5,2 \%$ \\
\hline Mét. generalizado & $-60,4 \%$ & $-60,4 \%$ & $-59,4 \%$ & $-27,0 \%$ & $-60,2 \%$ & $-60,4 \%$ \\
\hline Método Racional & $-0,7 \%$ & $-0,5 \%$ & $-49,4 \%$ & $-49,1 \%$ & $-67,4 \%$ & $-67,1 \%$ \\
\hline Método de Abt \& Grigg & $-12,3 \%$ & $-10,5 \%$ & $-13,7 \%$ & $-10,6 \%$ & $-19,9 \%$ & $-15,8 \%$ \\
\hline Wilken (1978) & $169,6 \%$ & $189,0 \%$ & $24,5 \%$ & $-32,3 \%$ & $-26,1 \%$ & $-18,9 \%$ \\
\hline Tsuchiya (1978) & $3,9 \%$ & $2,6 \%$ & $9,4 \%$ & $7,4 \%$ & $9,4 \%$ & $6,7 \%$ \\
\hline Maidment (1992) & $-2,1 \%$ & $-2,4 \%$ & $1,1 \%$ & $0,9 \%$ & $-0,7 \%$ & $-1,3 \%$ \\
\hline Tucci (1998) & $-2,4 \%$ & $-2,6 \%$ & $0,3 \%$ & $0,4 \%$ & $-2,2 \%$ & $-2,1 \%$ \\
\hline
\end{tabular}


Tabela 4.16: (cont.) diferenças percentuais entre os processos de cálculo de volume de detenção, para tempo de concentração de 75 minutos, tempo de duração da chuva de 30, 60 e 90 minutos e $\mathbf{C N}=98$.

\begin{tabular}{|c|c|c|c|c|c|c|}
\hline Tucci (2002) & $4,7 \%$ & $29,5 \%$ & $-15,6 \%$ & $3,3 \%$ & $-25,1 \%$ & $-9,5 \%$ \\
\hline Mét. Numérico & $21,8 \%$ & $26,2 \%$ & $-14,5 \%$ & $-10,7 \%$ & $-16,9 \%$ & $-13,5 \%$ \\
\hline Método Holandês & $21,6 \%$ & $25,2 \%$ & $3,2 \%$ & $6,6 \%$ & $-7,7 \%$ & $-5,3 \%$ \\
\hline Mét. de Matias (2006) & $-28,6 \%$ & $-23,2 \%$ & $-18,7 \%$ & $-6,9 \%$ & $-18,6 \%$ & $-14,4 \%$ \\
\hline Mét. De Akan (1989a) & $20,6 \%$ & $17,7 \%$ & $29,5 \%$ & $25,1 \%$ & $29,7 \%$ & $26,2 \%$ \\
\hline
\end{tabular}

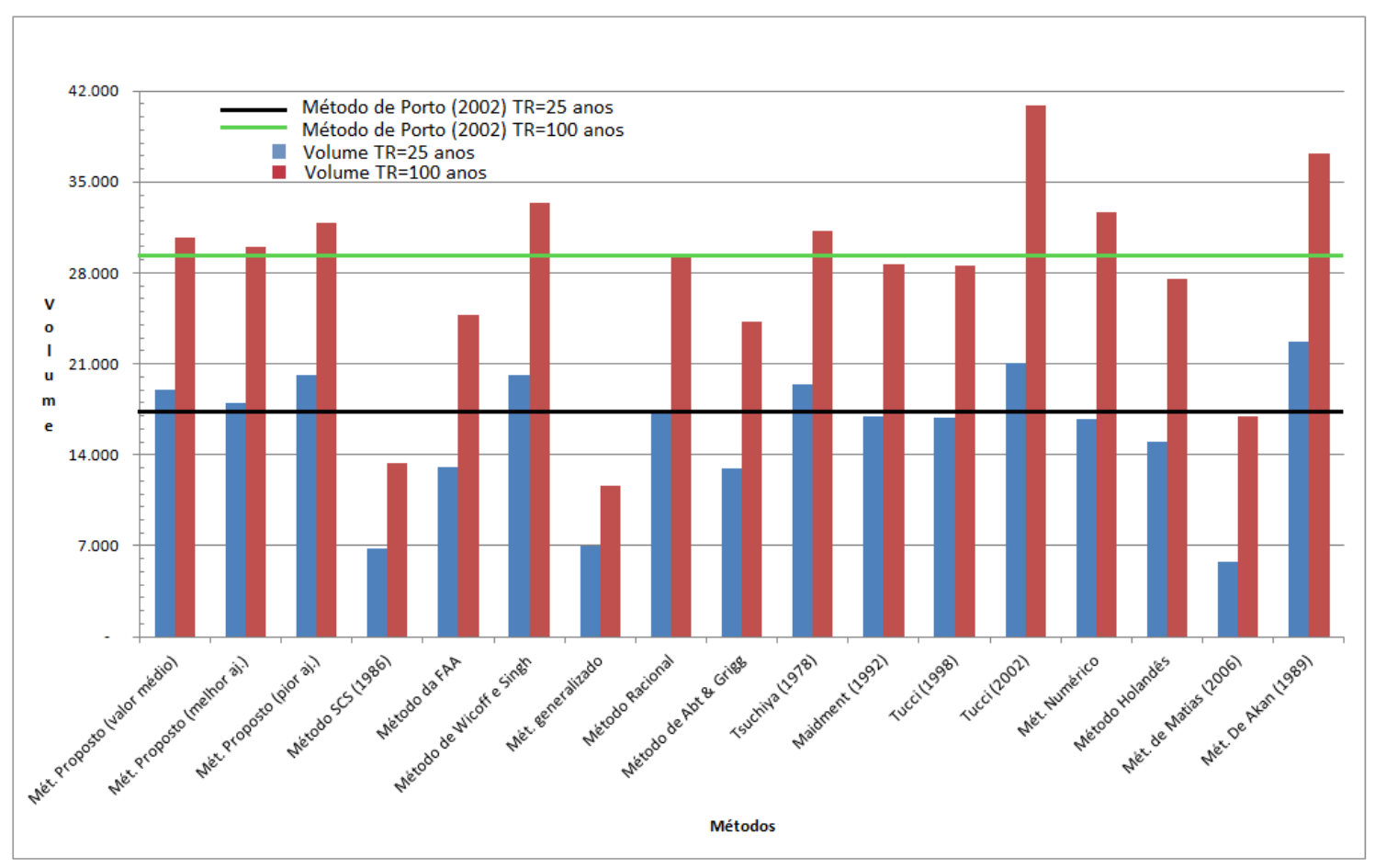

Figura 4.13: comparação gráfica de volumes de detenção para tempo de concentração de 75 minutos, duração da chuva de 30 minutos e CN de 85 . 


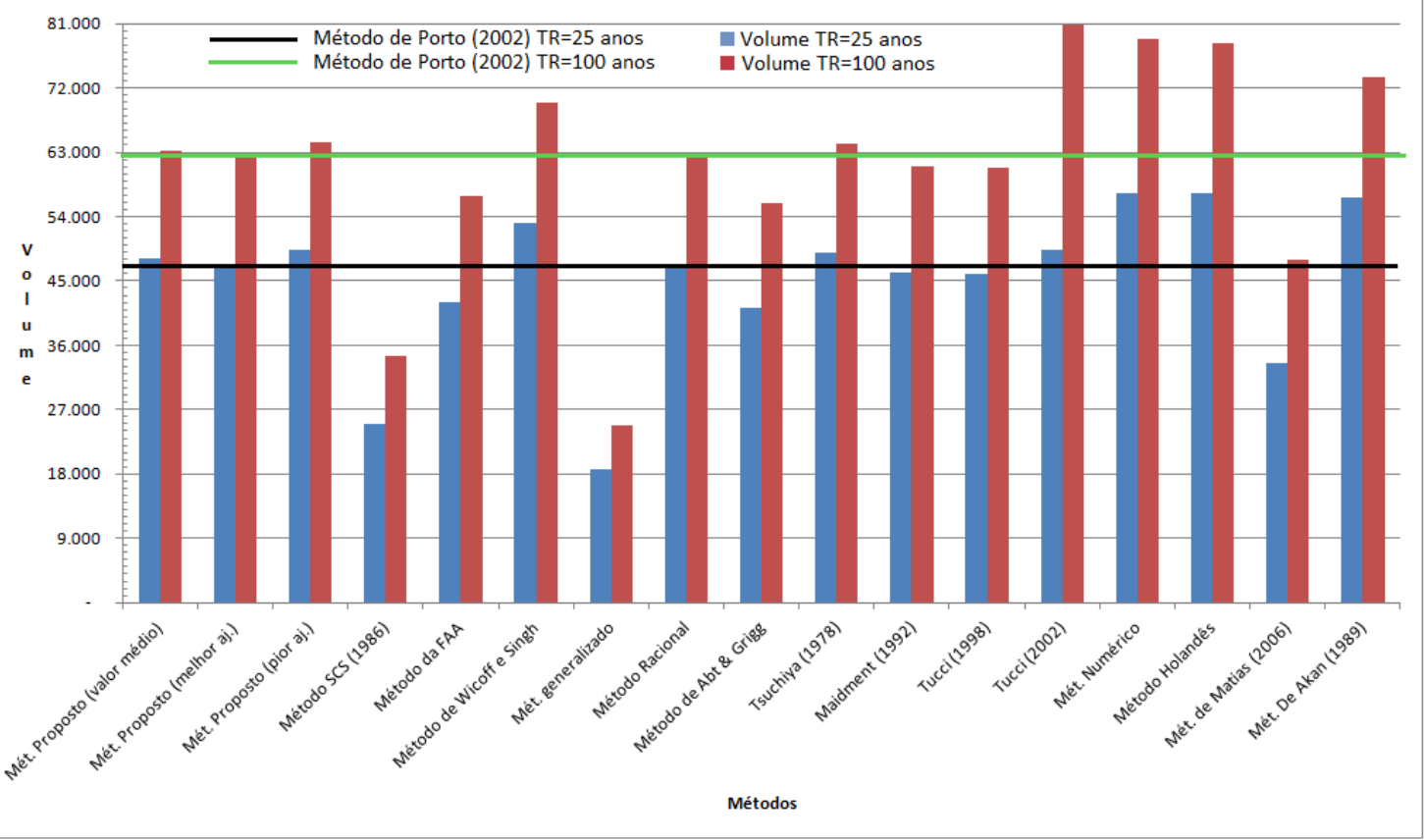

Figura 4.14: comparação gráfica de volumes de detenção para tempo de concentração de 75 minutos, duração da chuva de 30 minutos e CN de 98 .

A análise da Tabela 4.9 e Tabela 4.10, em conjunto com a Figura 4.7 e a Figura 4.8, revela que a aplicação dos métodos da Federal Aviation Administration, generalizado (MCCUEN, 1989) e de Matias (2006) apresentaram resultados bastante satisfatórios quando admitido tempo de concentração da bacia de 15 minutos para as durações de precipitação e tempos de retorno estudados.

Os procedimentos definidos por Maidment (1992) e Tucci (1998), conforme observado nos resultados apresentados entre a Tabela 4.11 e a Tabela 4.16, apresentaram excelentes resultados para todos os eventos estudados em todos os tempos de concentração admitidos.

A não dependência da estimativa do volume de detenção pelo método proposto do tempo de concentração faz com que a proposição torne-se menos susceptível a erros, uma vez que a determinação do tempo de concentração é comprovadamente uma etapa problemática.

O melhor ajuste do parâmetro $\beta$ do método proposto apresentou resultados excelentes de volumes de detenção. $\mathrm{O}$ valor mais discrepante revelado deste ajuste foi da ordem de $4 \%$ maior que o montante obtido através da aplicação da metodologia de Porto (2002). Os valores médios da formulação proposta diferenciaram cerca de $18 \%$ do estimado como ideal, enquanto que o pior ajuste, valor de $\beta$ igual a 2 , apresentou volume cerca de $28 \%$ maior para as condições impostas. A aplicação do modelo 
apresentou melhores resultados para durações menores de precipitação e maiores tempos de recorrência dos eventos. Com a diminuição na infiltração do solo, aumento do "Curve Number", o método proposto apresentou resultados mais próximos dos estimados com a proposta de Porto (2002).

O método do Soil Conservation Service (1986) apresentou resultados sempre subestimados do volume de detenção. Estes resultados apresentaram valores de 35 a $60 \%$ menores que o método de Porto (2002). À medida que se aumentam as durações das precipitações este método apresentou menores diferenças percentuais, de modo semelhante ao aumento do valor do "Curve Number". Estas diferenças se devem ao fato da metodologia do SCS (1986) ter sido desenvolvida inicialmente para bacias com características predominantemente rurais.

A proposta de cálculo da Federal Aviation Administration, modelo de fácil aplicação, apresentou resultados excelentes para aplicação na bacia do córrego do Andrezinho. O desvio máximo do valor resultante da aplicação desta metodologia foi de cerca de $24 \%$ para o tempo de concentração assumido na bacia como sendo de 75 minutos. A metodologia revelou melhores resultados para tempos de precipitações menores e para maiores períodos de retorno dos eventos. Com o aumento dos volumes escoados, resultante do aumento do $\mathrm{CN}$, os valores resultantes da aplicação do método foram mais precisos — fato esperado uma vez que a formulação foi desenvolvida para áreas com alto grau de impermeabilização.

A fórmula desenvolvida por Wycoff e Singh (1978) revelou melhores resultados, com exceção do tempo de concentração de 75 minutos, para a duração da precipitação de 30 minutos. O aumento da impermeabilização do solo e da duração dos eventos chuvosos proporcionaram, em geral, maiores diferenças entre os volumes considerados ideais, Porto (2002), e da formulação de Wycoff e Singh (1978).

O método generalizado (MCCUEN, 1989) apresentou resultados satisfatórios para a bacia quando considerado o tempo de concentração de 15 minutos. Ao passo que se aumentaram os valores admitidos para o tempo de concentração os volumes resultantes da aplicação desta metodologia passaram a ser subestimados. Para períodos de retorno maiores, em geral, esta formulação apresentou resultados mais consistentes.

A metodologia da fórmula racional apresentou excelentes resultados para evento chuvoso de 30 minutos e volumes detidos muito menores para as outras durações de eventos. Ao passo que se aumentou a duração das precipitações este modelo respondeu 
subestimando os volumes de detenção, chegando a uma diferença de cerca de $67 \%$ para durações de 90 minutos.

A aplicação da formulação de Abt e Grigg (1978) gerou valores da ordem média de $25 \%$ menores que os valores resultantes da aplicação do modelo de Porto (2002) para “Curve Number" adotado de 85 , e cerca de $15 \%$ para CN igual a 98. Esta formulação apresentou melhores resultados para eventos menos frequentes.

A formulação de Tsuchiya (1978) apresentou resultados excelentes para CN igual a 98, onde o desvio máximo foi da ordem de 10\%. A proposta de Tsuchiya (1978) proporcionou volumes mais próximos dos obtidos por Porto (2002) para maiores tempos de retorno. A aplicação deste método à bacia de estudo tendeu a superestimar os volumes detidos, principalmente para valores menores de $\mathrm{CN}$ e eventos mais frequentes, situação na qual chegou a apresentar valores da ordem de $20 \%$ maiores que o volume alcançado pela aplicação da metodologia de Porto (2002).

O procedimento de cálculo proposto por Maidment (1992) apresentou excelentes resultados para estimativa dos volumes detidos. O resultado mais discrepante, quando comparado ao volume determinado via método de Porto (2002), apresentou $2 \%$ de diferença. Esta metodologia apresentou resultados mais consistentes ao passo que se aumentou a duração dos eventos chuvosos.

Os procedimentos de Tucci (1998 e 2002) apresentaram melhores resultados para a duração de evento chuvoso de 60 minutos. O modelo proposto por Tucci (1998) apresentou resultados semelhantes, para ambos os "Curve Number's" admitidos, apresentando diferença percentual máxima do volume calculado pelo método de Porto (2002) de 3\%. A formulação proposta por Tucci (2002) tendeu a superestimar os volumes estimados para duração de 30 minutos e a subestimar para precipitações de projeto de 90 minutos.

A aplicação do método numérico, baseado no balanço de massa, tendeu a subestimar os montantes detidos, sem, no entanto apresentar valores demasiadamente díspares do considerado ideal. O método resultou em valores mais precisos para maiores períodos de recorrência, respondendo de maneira mais exata ao passo que se aumentou o CN da bacia.

A aplicação do método holandês à bacia de estudo revelou volumes subestimados para "Curve Number" de 85, mostrando melhores resultados para a duração do evento chuvoso de 30 minutos. Para CN igual a 98 a formulação apresentou melhores resultados para as durações maiores de precipitação. 
O cálculo do volume através do método de Matias (2006) revelou volumes de detenção subestimados. O incremento de escoamento superficial, obtido através do aumento do $\mathrm{CN}$, resultou em menores diferenças entre o volume estimado pelo método de Matias (2006) e o de Porto (2002). Eventos chuvosos menos frequentes e tempos de concentração reduzidos fizeram com que a formulação respondesse mais precisamente. A formulação apresentou resultados ligeiramente mais exatos para eventos chuvosos com duração de 60 minutos.

A proposta de Akan (1989a) resultou em montantes de detenção superestimados. Este procedimento apresentou resultados melhores para "Curve Number" de 98, quando seus valores foram cerca de $25 \%$ maiores que o da proposta por Porto (2002). Para CN de 85 esta diferença ficou em cerca de $30 \%$. 


\section{APLICAÇÃO DO MÉTODO PROPOSTO}

De forma a demonstrar a aplicação do método proposto foi dimensionado um reservatório de detenção para a bacia de drenagem do córrego do Andrezinho, Pirassununga, São Paulo. Para tanto se adotou o tempo de recorrência para o projeto de 25 anos e características atuais da área de drenagem. As características da bacia são demonstradas no Quadro 5.1.

Quadro 5.1: características atuais da bacia do córrego do Andrezinho, Pirassununga, SP
\begin{tabular}{|l|l|}
\hline Característica & Valor observado \\
\hline Área de drenagem & $1,40 \mathrm{~km}^{2}$ \\
\hline Comprimento do talvegue & $1,75 \mathrm{~km}$ \\
\hline Cota máxima & $681 \mathrm{~m}$ \\
\hline Cota mínima & $648 \mathrm{~m}$ \\
\hline Declividade média & $0,019 \mathrm{~m} / \mathrm{m}$ \\
\hline Parcela impermeável & $79 \%$ \\
\hline Curve Number & 85 \\
\hline Vazão máxima efluente & $2,78 \mathrm{~m}^{3} / \mathrm{s}$ \\
\hline
\end{tabular}

Para cálculo do tempo de concentração utilizou-se a fórmula desenvolvida por George-Ribeiro que é demonstrada na Equação 5.1.

$$
t_{c}=\frac{16 * L}{(1,05-0,2 * p) *(100 * I)^{0,04}}
$$

Equação 5.1

O tempo de concentração obtido para estas condições foi de aproximadamente 26 minutos, adotando-se a duração do evento chuvoso de 30 minutos, o que garante que toda a área de drenagem contribuirá para o escoamento no local estudado. Sendo a relação Intensidade - Duração - Frequência da cidade dada pela Equação 5.2.

$$
I(\mathrm{~mm} / \mathrm{h})=\frac{951,504 * T_{r}^{0,1614}}{(t+13)^{0,7679}}
$$

Equação 5.2

Da Equação 5.2 constata-se que $k, m, n$ e $b$ valem respectivamente 951,504, 0,1614, 0,7679 e 13 minutos. Calculando a intensidade média deste evento chuvoso, com tempo de retorno de 25 anos e duração da precipitação de 30 minutos, chega-se ao valor de $89,06 \mathrm{~mm} / \mathrm{h}$.

Para este valor de intensidade de precipitação, com auxílio da Tabela 4.1, que relaciona a duração da precipitação, o tempo de retorno e o "Curve Number" chega-se ao valor do coeficiente de escoamento do método racional de 0,35 .

Estimando-se a vazão afluente máxima ao dispositivo de detenção com auxílio do método racional, Equação 5.3, chega-se ao valor de 12,12 m³/s. O reservatório 
dimensionado deve garantir que a máxima vazão efluente seja de $2,78 \mathrm{~m}^{3} / \mathrm{s}$, uma vez que esta é a máxima capacidade de vazão do córrego do Andrezinho.

$$
Q=\frac{C * I * A}{3,6}
$$

Com o conhecimento da máxima vazão efluente, calcula-se a intensidade efluente equivalente através da Equação 5.4. O valor encontrado para a intensidade efluente equivalente é de $20,42 \mathrm{~mm} / \mathrm{h}$. É importante ressaltar que para casos nos quais não se tenha conhecimento da vazão efluente máxima - condição restritiva - a intensidade efluente equivalente pode ser calculada com auxílio da Equação 5.5.

$$
\begin{gathered}
I_{s}=\frac{Q_{s} * 3,6}{C * A} \\
I_{s(t)}=\frac{k * T^{m}}{(t+b)^{n}} *\left(1-\frac{n * t}{t+b}\right)
\end{gathered}
$$

Equação 5.4

Equação 5.5

O volume de detenção calculado pelo método proposto pode ser calculado pela Equação 5.6, que se resume a Equação 5.7 para valores de $\beta$ iguais à unidade.

$$
\begin{gathered}
V_{d}=\frac{C * A}{3,6} * 60 * t_{d} *\left[\frac{k * T^{n}}{\left(t_{d}+b\right)^{m}}-\frac{I_{s}}{\beta+1}\right] \\
V_{d}=\frac{C * A}{3,6} * \frac{k * T^{m} * t_{d}}{\left(t_{d}+b\right)^{n}} * 60-\frac{\mathrm{Q}_{\mathrm{s}} * \mathrm{t}_{\mathrm{d}}}{2}
\end{gathered}
$$

Equação 5.7

Por motivos didáticos escolheram-se dois valores de $\beta$ para cálculo dos volumes detidos. O valor unitário foi escolhido, por ser o valor usualmente mais utilizado e o valor de $\beta$ igual a 0,5 , que apresentou resultados satisfatórios para aplicação na bacia. Para o valor de $\beta$ igual a 1 o volume estimado foi de $19.318 \mathrm{~m}^{3}$ enquanto que para $\beta$ igual a 0,5 o montante encontrado foi de $18.484 \mathrm{~m}^{3}$.

O volume estimado pelo método de Porto (2002) para as condições definidas neste modelo de aplicação foi de $17.235 \mathrm{~m}^{3}$, o que corresponde a um erro da ordem de $12 \%$ para o valor de $\beta$ unitário e de $7 \%$ para o valor de $\beta$ igual a 0,5 . 


\section{CONCLUSÕES}

A atualização dos parâmetros da curva Intensidade - Duração - Frequência para a cidade de Pirassununga, São Paulo, revelou não haver grandes diferenças entre os coeficientes definidos por ESA (2006) e os valores atuais. ESA (2006) procedeu à determinação dos valores da equação com série histórica de dados de 58 anos (19401997). A atualização realizada neste trabalho foi realizada com série histórica de 68 anos (1940-2007) e não apresentou grandes distorções da curva ajustada por ESA (2006).

Os estudos relativos às formulações de tempo de concentração revelaram que das metodologias empíricas avaliadas, as que apresentaram melhores resultados, quando comparados com os valores obtidos pela proposta de George-Ribeiro, foram a Carter Lag Equation for Partially Sewered Watersheds apresentando diferenças de 1,38\% para "Curve Number" de 85 e 2,72\% para CN de 98. Silveira (2005) encontrou resultados semelhantes de erro médio na aplicação desta metodologia, porém o desvio padrão encontrado foi da ordem de $40 \%$. A utilização da formulação Carter Lag Equation for Partially Sewered Watersheds para estimativas do tempo de concentração deve ser sempre ponderado, pois apesar de apresentar pequenos desvios para algumas condições, como a do caso estudado, pode apresentar grandes discrepâncias como verificado por Silveira (2005).

As formulações de Kirpich e California Culverts Practice, a última desenvolvida a partir da primeira, também apresentaram resultados satisfatórios com desvios da ordem de 5\% para CN de 85 e próximo de 9\% para CN de 98. É importante ressaltar que o uso destas equações é bastante difundido devido à facilidade de obtenção de seus parâmetros de cálculo. Já a utilização da formulação do DER - SP, bastante utilizada e ajustada da formulação de Kirpich para bacias com áreas maiores que $1 \mathrm{~km}^{2}$, deve ser usada com cautela uma vez que não demonstrou resultados satisfatórios em sua aplicação para uma bacia com área contribuinte de $1,4 \mathrm{~km}^{2}$ - desvios superiores a $50 \%$.

A proposta de Dooge para cálculo do tempo de concentração apresentou valores abaixo dos estimados pela aplicação da formulação de George-Ribeiro (cerca de $50 \%$ menor), este fato comprova que a escolha das características da formulação empregada deve ser bastante fundamentada uma vez que era de se esperar que a metodologia de Dooge apresentasse valores superiores aos de George-Ribeiro já que foi desenvolvida a 
partir de bacias rurais. A provável causa desta discrepância está no fato da formulação ter sido desenvolvida para áreas de drenagem entre 140 e $930 \mathrm{~km}^{2}$ enquanto a área contribuinte do córrego do Andrezinho é de apenas 1,4 km².

Das formulações semiempíricas analisadas a que se mostrou mais sensível à variação do "Curve Number" foi a desenvolvida pela Federal Aviation Administration apresentando tempo de concentração de cerca de 70 minutos (168\% de desvio para o tempo obtido através da formulação de George-Ribeiro) para $\mathrm{CN}$ de 85 e de aproximadamente 22 minutos, desvio de 14\%) para $\mathrm{CN}$ de 98 . Este fato corrobora as constatações de diversos autores, Silveira (2005) e Farias Júnior (2010) dentre estes de que esta formulação deve ser aplicada em bacias com taxas de impermeabilização elevadas.

A formulação desenvolvida na cidade de Denver apresentou a menor variabilidade à mudança do "Curve Number", apresentando para o valor de $\mathrm{CN}=85$ tempo de concentração de 36,23 minutos e para CN de 98 tempo de 36,25 minutos. Esta baixa variabilidade da formulação desenvolvida para a cidade de Denver está associada ao ajuste do coeficiente de impermeabilização, que leva em consideração faixas de variação da área impermeável. A utilização desta formulação em bacias hidrográficas que apresentem elevada dinâmica de uso do solo deve ser condicionada a estudos que relacionem a variabilidade do coeficiente de impermeabilização do solo com a mudança de ocupação da bacia, definindo - se possível — faixas menores de variação entre a área impermeável e o coeficiente.

A formulação de Tulsa District e do antigo DNOS, dentre as formulações semiempíricas, apresentaram melhores ajustes aos tempos de concentração considerados ideais. A fórmula de Tulsa District apresentou desvios de 7 e 11,5\% para os CN's de 85 e 98, enquanto que a proposta do antigo DNOS apresentou desvios de 14,7 e 8,6\% para as respectivas condições. Apesar de apresentar resultados satisfatórios a utilização da formulação de Tulsa District deve ser cautelosa uma vez que esta leva em consideração apenas o grau de urbanização da bacia, o que pode levar a erros de estimativa.

A avaliação da influência do parâmetro $\beta$ ao ajuste do volume de detenção, calculado a partir do método proposto, ao volume calculado pelo procedimento de Porto (2002), revelou que os melhores ajustes ocorrem para valores de $\beta$ entre 0 e 0,5 . O melhor ajuste do coeficiente $\beta$ sempre se apresentou com diferenças inferiores a $1 \%$, resultado excelente para pré-dimensionamento de reservatórios de detenção. Para a gama de valores que vai de 0 a 0,5 o máximo erro médio foi pouco maior que $6 \% \mathrm{com}$ 
desvio padrão de 3,6\% que representa resultados satisfatórios para a fase de projeto ao qual se propõe o procedimento proposto.

$\mathrm{O}$ valor de $\beta$ mais aceito seria o unitário que representa hidrograma efluente à bacia linear. Este valor apresentou erro percentual da ordem de $15 \%$ para $\mathrm{CN}$ de 85 e TR de 25 anos, e cerca de 10\% para TR de 100 anos. Para CN de 98 estes desvios foram da ordem de $7 \%$ para o primeiro caso e de $5 \%$ para o último. O erro médio do valor de $\beta$ unitário para os diversos períodos de retorno estipulados (10, 20, 25, 50 e 100 anos) nas condições de uso do solo consideradas foi de 10,8\% com desvio padrão de cerca de 5\%, o que assegura, para fins de pré-dimensionamento, resultados confiáveis.

$O$ valor de $\beta$ que apresentou resultados mais díspares do considerado ideal foi de 2. O erro médio calculado para este valor de $\beta$ foi da ordem de $15 \%$ com desvio padrão da ordem de $7,3 \%$.

A formulação proposta para cálculo do volume detido apresentou bons resultados quando aplicada à bacia do córrego do Andrezinho. O erro médio máximo da comparação entre o volume calculado via processo proposto e o montante estimado pela metodologia de Porto (2002) foi da ordem de $20 \%$ para tempo de duração da chuva de 60 minutos e $\mathrm{CN}$ de 85 , porém o melhor ajuste da proposição sempre apresentou discrepâncias menores que 5\%, fato comprovado com a observação das Tabelas presentes no Apêndice A.

A não dependência do método proposto do tempo de concentração, considerada neste trabalho, refletiu de maneira positiva na utilização do método, uma vez que se eliminou uma das etapas mais controversas dos estudos hidrológicos.

O aumento da duração das precipitações afetou de maneira distinta as estimativas de volumes detidos pelo método proposto. Ao passo que os valores médios apresentaram maiores diferenças percentuais, quando relacionado ao procedimento de Porto (2002), o melhor ajuste dos valores de $\beta$, de 0 a 0,5 , apresentaram valores menos díspares para a duração de chuva de 60 minutos. Os maiores valores de $\beta$, que apresentaram piores ajustes, se comportaram de maneira semelhante aos valores médios.

O aumento do período de recorrência dos eventos chuvosos resultou em melhores ajustes, ao valor calculado pela metodologia de Porto (2002), por parte da formulação proposta.

O aumento dos volumes escoados superficialmente, obtido através do incremento do valor do "Curve Number", fez com que os montantes estimados, via 
metodologia proposta, resultassem em desvios menos significativos dos valores estimados pelo procedimento de Porto (2002).

O modelo proposto apresentou resultados semelhantes aos métodos que melhor estimaram os volumes reservados — Maidment (1992) e Tucci (1998) - quando utilizado o valor de $\beta$ que melhor ajusta aos valores do processo de Porto (2002). A utilização dos métodos de Maidment (1992) e Tucci (1998) por serem métodos generalistas é sempre recomendada para fins de pré-dimensionamento de estruturas de detenção, devendo-se, o projetista, atentar somente aos métodos empregados para cálculo das máximas vazões escoadas.

A metodologia do SCS (1986), amplamente difundida entre hidrólogos, apresentou resultados excessivamente baixos para o caso estudado. A provável diferença obtida é reflexo das origens da formulação, desenvolvida inicialmente para bacias rurais. Este resultado vai de encontro ao amplo uso feito desta formulação por projetistas, que a utilizam devido à facilidade de definição de seus parâmetros. A utilização desta formulação em bacias urbanas deve ser julgada cuidadosamente.

A metodologia da Federal Administration Aviation para estimativa do volume detido demonstrou facilidade de aplicação e obtenção de seus parâmetros e apresentou resultados satisfatórios para a bacia estudada. Para menores tempos de concentração e maior taxa de impermeabilização os valores obtidos foram mais próximos do ideal para tempo de concentração de 15 minutos e $\mathrm{CN}$ de 98 a máxima diferença fícou próxima de $7 \%$. Estes resultados levam à conclusão que para menores áreas contribuintes e maiores taxas de impermeabilização, caso observado em estacionamentos e áreas industriais, esta formulação é a mais indicada.

Desta forma a metodologia de cálculo para estimativas iniciais de volume de detenção proposta neste trabalho apresentou bons resultados para a bacia hidrográfica estudada. Salienta-se que seus melhores resultados ocorreram para situação de bacias com maior valor de "Curve Number", numericamente igual a 98, e que a escolha de valores do parâmetro $\beta$ maior que a unidade possui tendência a superestimar demasiadamente os montantes estimados.

Uma vez que o método proposto apresentou resultados significantes para estimativas de volume reservados para área de drenagem considerada pequena e urbana fica como sugestão para trabalhos posteriores a avaliação da aplicação do método em bacias com maior porte e menor índice de urbanização. 


\section{REFERÊNCIAS BIBLIOGRÁFICAS}

ABT, S. R.; GRIGG, N. S. An approximate method for sizing detention reservoirs. Water Resources Bulletin, American Water Resources Association. Vol. 14, $\mathrm{n}^{\mathrm{o}}$ 4, agosto, 1978. Pg. 956-965.

AKAN, A. O. Detention pond sizing for multiple return periods. Journal of Hydraulic Engineering, vol. 115, № 5, maio, 1989a.

AKAN, A. O. Single-outlet detention-pond analysis and design. Journal of Irrigation and Drainage Engineering, vol. 116, № 4, julho - agosto, 1990.

AKAN, A. O. Time of concentration formula for pervious catchments. Journal of Irrigation and Drainage Engineering, vol. 115, № 4, agosto, $1989 \mathrm{~b}$.

AKAN, A. O. Time of concentration of overland flow. Journal of Irrigation and Drainage Engineering, vol. 112, № 4, novembro, 1986.

ANMALA, J.; ZHANG, B.; GOVINDARAJU, R. S. Comparison of ANNs and empirical approahes for predicting watershed runoff. Journal of Water Resouces Planning and management, vol. 126, № 3, pg. 156-166, março - junho, 2000.

BARREIRO, C. H.; FELEX, J. B. Boca-de-lobo e drenagem superficial urbana. In: IX Congresso de Pesquisa e Ensino e Transportes, 1995, São Carlos. Anais... São Carlos: Anpet, 1995.

BERQUE, J. M.; RUPERD, Y. (coordenadores). Stormwater retention basins. Rotterdam: A. A. Balkema, 2000.

BRASIL, Agência Nacional de Águas - ANA. Base de dados. Disponível em http://hidroweb.ana.gov.br/HidroWeb.asp?TocItem=1080\&TipoReg=7\&MostraCon=fal se $\&$ CriaArq=false $\&$ TipoArq=1\&SerieHist=true, acesso às 19:15 de 27 de fevereiro de 2012. 
BRASIL, Departamento Nacional de Infra-Estrutura e Transporte — DNIT. Manual de hidrologia básica para estruturas de drenagem. 2a Ed. - Rio de Janeiro, 2005. Publicação $715 . \quad 133$ pag. Disponível em: http://ipr.dnit.gov.br/manuais/manual_de_hidrologia_basica.pdf. Acesso em 12 de janeiro de 2012.

CANHOLI, A. P.; Drenagem urbana e controle de enchentes. São Paulo: Oficina de Textos, 2005.

CARVAlHO, O. DE O.; GAZEN, A. F.; SILVA, A. Chuvas intensas de Porto Alegre. Porto Alegre, 1972.

CHOW, V. T. Open channel hydraulics. New York: McGraw-Hill, 1959.

CHOW, V. T.; MAIDMENT, D. R.; MAYS, L. W. Applied Hidrology. New York: McGraw-Hill. 1988.

ESA, ENGENHARIA SANITÁRIA E AMBIENTAL. Estudo básico, diagnóstico e proposta de soluções para os problemas de enchentes no bairro Cidade Jardim Pirassununga - São Paulo, Relatório final. Pirassununga, 2006.

FARIAS JÚNIOR, E. F. Análise do comportamento do tempo de concentração no rio Cônego, município de Nova Friburgo/RJ. Monografia (Escola Nacional de Ciências Estatísticas), agosto de 2010.

FONSECA, P. L.; NASCIMENTO, E. A. Routing de reservatório para amortecimento de cheias aplicado à Bacia Hidrográfica do Rio Guandu do Sena, Zona Oeste da cidade do Rio de Janeiro, Brasil. In: $24^{\circ}$ CONGRESSO BRASILEIRO DE ENGENHARIA SANITÁRIA E AMBIENTAL，2007, BELO HORIZONTE. Anais Eletrônicos...Belo Horizonte: ABES, 2007. CD-ROM. 
FRANCO, E. J. Dimensionamento de bacias de detenção das águas pluviais com base no método racional. Dissertação de mestrado apresentada na Universidade Federal do Paraná, 2004.

GOFF, K. M.; GENTRY, R. W. The influence of watershed and development characteristics on the cumulative impacts of stormwater detention pond. Water Resources Management, № 20, pg. 829-860. Springer, 2006.

GUO, JAMES C. Y. Detention storage volume for small urban catchments. Journal of Water resources planning and Management, Vol. 125, $\mathrm{n}^{\circ} .6$, novembro - dezembro, 1999.

HARRELL, J.; RANJITHAN, S. R. Detention pond design and land use planning for watershed management. Journal of Water Resources Planning and Management, vol. 129, No 2, pg. 98-106, Março/abril, 2003.

HORN, D. R. Graphic estimation of peak flow reduction in reservoirs. Journal of Hydraulic Engineering, ASCE. Vol. 113, nº 11, novembro, 1987. Pg. 1441-1450.

HOSSAIN, M. A.; ALAM, M.; YONGE, D. R.; DUTTA, P. Efficiency and flow regime of a highway stormwater detention pond in Washington, USA. Water, Air, and Soil Pollution. No 164, pg. 79-89. Springer, 2005.

MAIDMENT, D. R. (Ed. Chefe) Handbook of hydrology. Nova York, McGraw-Hill, 1992.

MATA-LIMA, H.; VARGAS, H.; CARVALHO, J.; GONÇALVES, M.; CAETANO, H.; MARQUES, A.; RAMINHOS, C. Comportamento hidrológico de bacias hidrográficas: integração de métodos e aplicação a um estudo de caso. Rem: Ver. Esc. Minas, Ouro Preto, vol. 60, $\mathrm{n}^{\circ}$ 3, set. 2007. Disponível em HTTP:// www.scielo.br/scielo.php?script=sci_arttext\&pid=S037044672007000300014\&lng=pt \&nrm=iso>. Acesso em 13 dez. 2010. 
MATIAS, M. G. B. Bacias de retenção: estudo de métodos de dimensionamento. Porto, 2006. Dissertação de mestrado apresentada à Universidade do Porto, 2006.

MCCUEN, R. H. Hydrlogic analysis and design. Nova Jersey, Prentice-Hall, 1989.

MORUZZI, R. B.; OLIVEIRA, S. C.; Relação entre intensidade, duração e frequência de chuvas em Rio Claro, SP: Métodos e aplicação. Teoria e Prática na Engenharia Civil, n. 13, pag. 59-68. Maio, 2009.

PINTO, N. L. DE S., HOLTZ, A. C. T., MASSUCCI, C. J. J. Vazão de dimensionamento de bueiros. Rio de Janeiro, IPR, reimp. 1975. 56p (Publ. 478).

PORTO, R. M. Análise de desempenho de bacias de detenção. In: BRAGA, B.; TUCCI, C. E. M.; TOZZI, M. (Organizadores). Drenagem urbana: gerenciamento simulação controle. Porto Alegre, Ed. da Universidade/UFRGS: ABRH, 1998.

PORTO, R. M. Hidráulica Básica. 3ª Ed. São Carlos: EESC - USP, 2004. 540 pag.

PORTO, R. M. Metodologia de cálculo para procedimentos preliminares em bacias de detenção. São Carlos: 2002. Tese de Livre-Docência, Universidade de São Paulo, 2002.

PORTO, R. M. Uso conjunto dos métodos racional e do "Soil Conservation Service" na determinação da vazão de projeto em bacias urbanas. Revista DAEE, vol. $47, \mathrm{n}^{\circ}$ 148, março, 1987. Pg. 37-39.

SANTOS, R. B.; FUCHS, L.; SOBRAL, M. C. M. Experiência alemã no controle de enchentes urbanas usando GIS e modelos de simulação de precipitação. In: $24^{\circ}$ CONGRESSO BRASILEIRO DE ENGENHARIA SANITÁRIA E AMBIENTAL, 2007, Belo Horizonte. Anais Eletrônicos... Belo Horizonte: ABES, 2007. CD-ROM.

SARTORI, A.; LOMBARDI NETO, F.; GENOVEZ, A. M. Classificação hidrológica de solos brasileiro para a estimativa da chuva excedente com o método do Serviço 
de Conservação do Solo dos Estados Unidos Parte 1: Classificação. RBRH - Revista Brasileira de Recursos Hídricos. Vol. 10, nº 4, outubro - dezembro, 2005. Pg. 5-18.

SETZER, J.; PORTO, R. LA L. Tentativa de avaliação de escoamento superficial de acordo com o solo e o seu recobrimento vegetal nas condições do Estado de São Paulo. Boletim Técnico DAEE, Vol. 2, nº 2, maio - agosto, 1979. Pg. 82-135.

SILVA R. T.; FOLEGATTI, M. V. Desenvolvimento de um programa computacional para cálculo do volume útil de armazenamento de reservatórios com regularização anual pelo método dos picos sequenciais. In: $24^{\circ}$ CONGRESSO BRASILEIRO DE ENGENHARIA SANITÁRIA E AMBIENTAL, 2007, BELO HORIZONTE. Anais Eletrônicos... Belo Horizonte: ABES, 2007. CD-ROM.

SILVEIRA, A. L. L. Desempenho de fórmulas de tempo de concentração em bacias urbanas e rurais. RBRH - Revista Brasileira de Recursos Hídricos, vol. 10, $\mathrm{n}^{\mathrm{o}} 1$ janeiro - março, 2005. Pg. 5-23.

SOIL CONSERVATION SERVICE. Technical Release 55. Urban Hydrology of Small Watersheds. USDA, NRCS, 1986.

STARZEC, P.; LIND, B. B.; LANNGREN, A.; LINDGREN, A.; SVENSON, T. Technical and environmental functioning of detention ponds for the treatment of highway and road runoff. Water, Air, and Soil Pollution. $\mathrm{N}^{\mathrm{o}} 165$, pg. 153-167. Springer, 2005.

TASSI, R. Comparação de duas metodologias para determinação do volume de detenção em pequenas bacias urbanas: o caso de Porto Alegre/RS Brasil. In: XX CONGRESSO NACIONAL DEL ÁGUA E III SIMPÓSIO DE RECURSOS HÍDRICOS DEL CONO SUR, 2005, Mendoza. Anais... Mendoza, 2005.

TOMAZ,P. Cálculos hidrológicos e hidráulicos para obras municipais. Maio, 2007. Versão digital. 
TUCCI, C. E. M. (organizador). Hidrologia: ciência e aplicação. $2^{\mathrm{a}}$ ed. Porto Alegre, Ed. Universidade/UFRGS: ABRH, 2001.

TUCCI, C. E. M. Coeficiente de escoamento e vazão máxima em bacias urbanas. In: RBRH - Revista Brasileira de Recursos Hídricos. Vol. 5, nº 1, janeiro - março, 2000. Pg. 61-68.

TUCCI, C. E. M. Modelos Hidrológicos. Universidade Federal do Rio Grande do Sul, 1998.

TUCCI, C. E. M.; PORTO, R. L.; BARROS, M. T. (Organizadores). Drenagem urbana. Porto Alegre, E. da Universidade/UFRGS: ABRH, 1995.

WYCOFF R. L.; SINGH, U. P. Preliminary hydrologic design of small flood detention reservoirs. Water Resources Bulletin, American Water Resources Association. Vol. 12, no 2, abril, 1976. Pg. 337-349. 


\section{Apêndice A}

Tabela 8.1: avaliação percentual dos volumes de detenção obtidos pelo método proposto e pela metodologia de Porto (2002) para $\mathbf{C N}=85$ e duração do evento de 30 minutos.

\begin{tabular}{|c|c|c|c|c|c|}
\hline \multirow{2}{*}{\begin{tabular}{c} 
Método \\
\cline { 2 - 5 }
\end{tabular}} & \multicolumn{5}{|c|}{ Diferenças percentuais no volume de detenção } \\
\cline { 2 - 6 } & 10 & 20 & 25 & 50 & 100 \\
\hline $\begin{array}{c}\text { Vol. Método de Porto (2002) } \\
\left(\mathbf{m}^{3}\right)\end{array}$ & 11.445 & 15.837 & 17.235 & 22.702 & 29.152 \\
\hline Beta $=0,0$ & $-2,8 \%$ & $-2,5 \%$ & $-2,4 \%$ & $-2,3 \%$ & $-2,1 \%$ \\
\hline Beta $=0,1$ & $1,2 \%$ & $0,4 \%$ & $0,2 \%$ & $-0,3 \%$ & $-0,6 \%$ \\
\hline Beta $=0,2$ & $4,5 \%$ & $2,8 \%$ & $2,4 \%$ & $1,4 \%$ & $0,7 \%$ \\
\hline Beta $=0,3$ & $7,3 \%$ & $4,8 \%$ & $4,3 \%$ & $2,8 \%$ & $1,8 \%$ \\
\hline Beta $=0,4$ & $9,7 \%$ & $6,5 \%$ & $5,9 \%$ & $4,0 \%$ & $2,8 \%$ \\
\hline Beta $=0,5$ & $11,8 \%$ & $8,0 \%$ & $7,3 \%$ & $5,1 \%$ & $3,6 \%$ \\
\hline Beta $=0,6$ & $13,6 \%$ & $9,4 \%$ & $8,5 \%$ & $6,0 \%$ & $4,3 \%$ \\
\hline Beta $=0,7$ & $15,2 \%$ & $10,5 \%$ & $9,5 \%$ & $6,8 \%$ & $4,9 \%$ \\
\hline Beta $=0,8$ & $16,7 \%$ & $11,6 \%$ & $10,5 \%$ & $7,5 \%$ & $5,5 \%$ \\
\hline Beta $=0,9$ & $17,9 \%$ & $12,5 \%$ & $11,3 \%$ & $8,2 \%$ & $6,0 \%$ \\
\hline Beta $=1,0$ & $19,1 \%$ & $13,3 \%$ & $12,1 \%$ & $8,8 \%$ & $6,4 \%$ \\
\hline Beta $=1,1$ & $20,1 \%$ & $14,1 \%$ & $12,8 \%$ & $9,3 \%$ & $6,8 \%$ \\
\hline Beta $=1,2$ & $21,1 \%$ & $14,7 \%$ & $13,4 \%$ & $9,8 \%$ & $7,2 \%$ \\
\hline Beta $=1,3$ & $21,9 \%$ & $15,4 \%$ & $14,0 \%$ & $10,2 \%$ & $7,6 \%$ \\
\hline Beta $=1,4$ & $22,7 \%$ & $15,9 \%$ & $14,5 \%$ & $10,6 \%$ & $7,9 \%$ \\
\hline Beta $=1,5$ & $23,5 \%$ & $16,5 \%$ & $15,0 \%$ & $11,0 \%$ & $8,2 \%$ \\
\hline Beta $=1,6$ & $24,1 \%$ & $17,0 \%$ & $15,4 \%$ & $11,3 \%$ & $8,4 \%$ \\
\hline Beta $=1,7$ & $24,8 \%$ & $17,4 \%$ & $15,9 \%$ & $11,6 \%$ & $8,7 \%$ \\
\hline Beta $=1,8$ & $25,3 \%$ & $17,8 \%$ & $16,2 \%$ & $11,9 \%$ & $8,9 \%$ \\
\hline Beta $=1,9$ & $25,9 \%$ & $18,2 \%$ & $16,6 \%$ & $12,2 \%$ & $9,1 \%$ \\
\hline Beta $=2,0$ & $26,4 \%$ & $18,6 \%$ & $16,9 \%$ & $12,4 \%$ & $9,3 \%$ \\
\hline
\end{tabular}




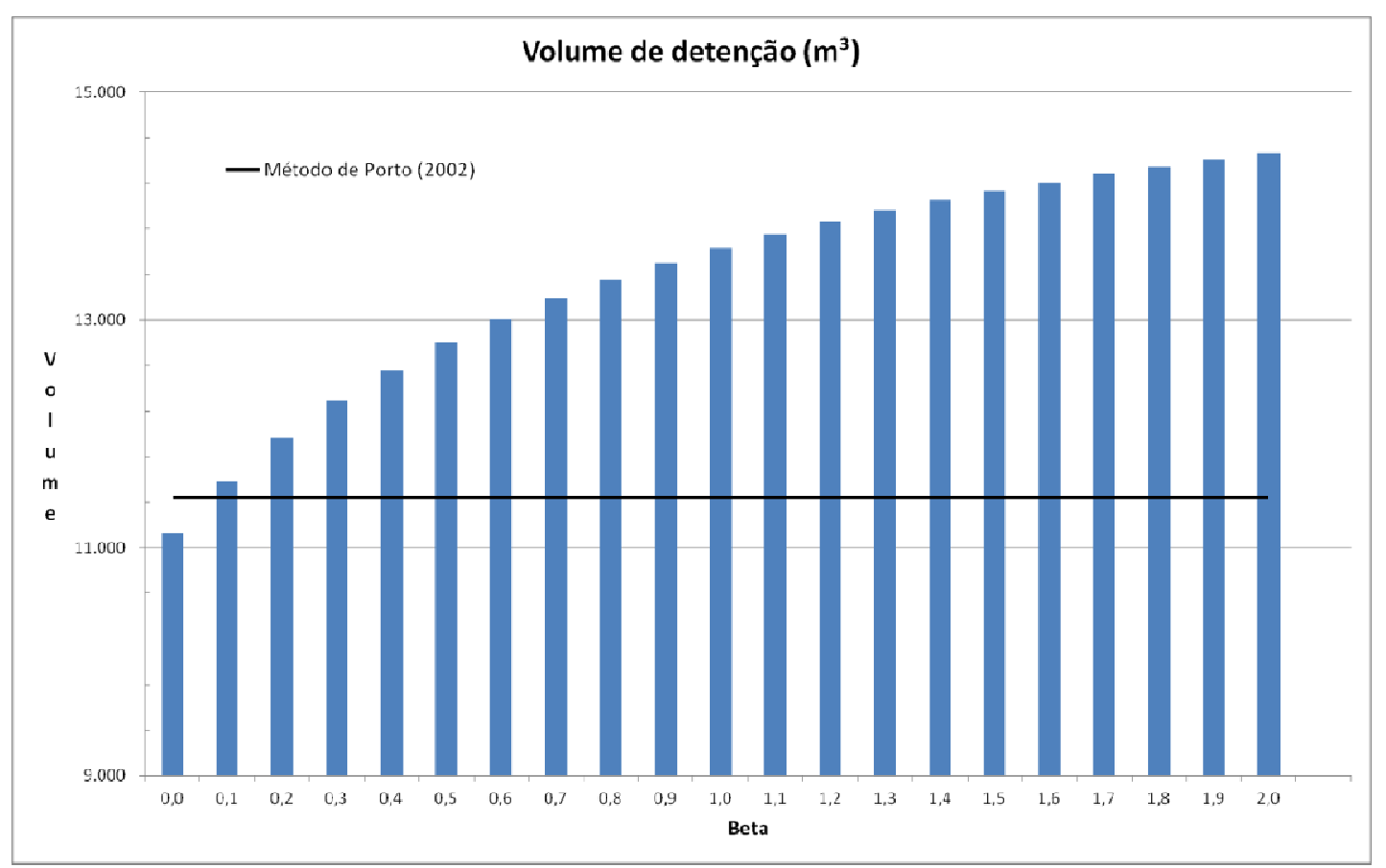

Figura 8.1: comparação entre volumes detido pela metodologia proposta e o método de Porto (2002) para tempo de retorno de 10 anos, duração de precipitação de 30 minutos e $\mathrm{CN}$ de 85.

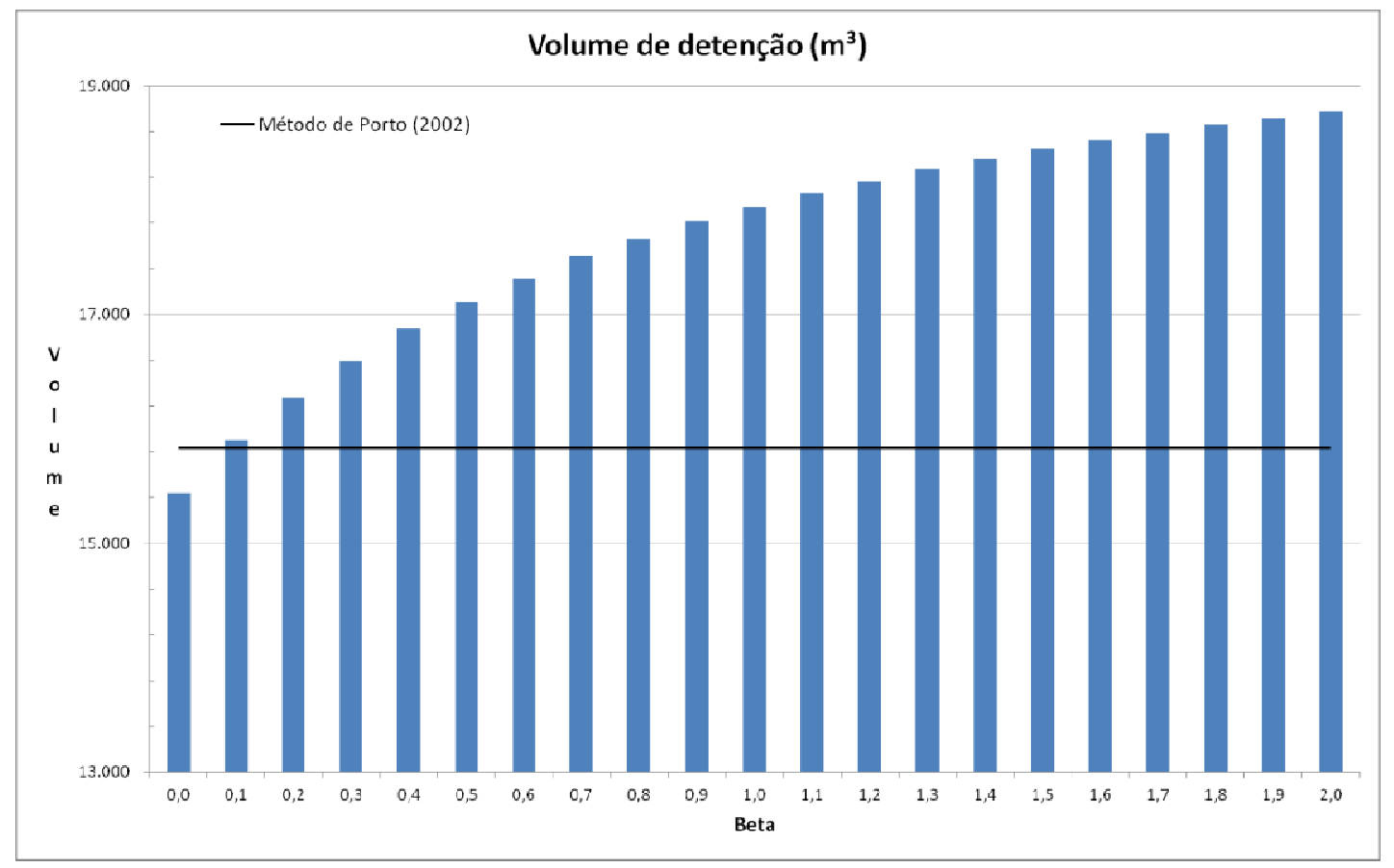

Figura 8.2: comparação entre volumes detido pela metodologia proposta e o método de Porto (2002) para tempo de retorno de 20 anos, duração de precipitação de 30 minutos e CN de 85. 


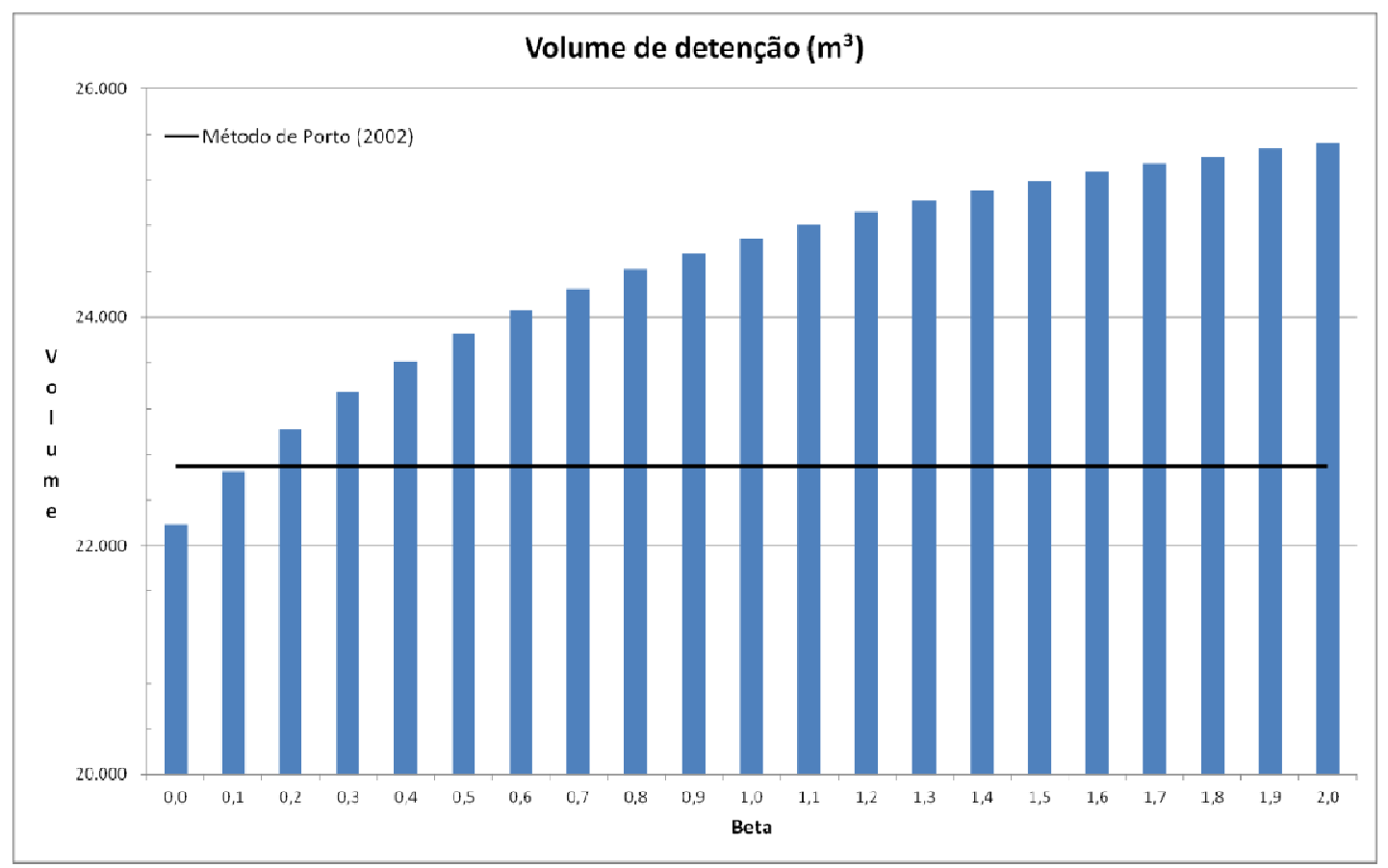

Figura 8.3: comparação entre volumes detido pela metodologia proposta e o método de Porto (2002) para tempo de retorno de 50 anos, duração de precipitação de 30 minutos e $\mathrm{CN}$ de 85.

Tabela 8.2: avaliação percentual dos volumes de detenção obtidos pelo método proposto e pela metodologia de Porto (2002) para $\mathrm{CN}=98$ e duração do evento de 30 minutos.

\begin{tabular}{|c|c|c|c|c|c|}
\hline \multirow{2}{*}{\begin{tabular}{c} 
Método \\
\cline { 2 - 5 }
\end{tabular}} & \multicolumn{5}{|c|}{ Diferenças percentuais no volume de detenção } \\
\cline { 2 - 6 } & 10 & 20 & 25 & 50 & 100 \\
\hline $\begin{array}{c}\text { Vol. Método de Porto (2002) } \\
\left(\mathrm{m}^{3}\right)\end{array}$ & 38.262 & 44.604 & 47.056 & 53.925 & 62.484 \\
\hline Beta $=0,0$ & $-2,1 \%$ & $-2,0 \%$ & $-2,0 \%$ & $-2,0 \%$ & $-1,9 \%$ \\
\hline Beta $=0,1$ & $-0,9 \%$ & $-1,0 \%$ & $-1,0 \%$ & $-1,1 \%$ & $-1,2 \%$ \\
\hline Beta $=0,2$ & $0,1 \%$ & $-0,1 \%$ & $-0,2 \%$ & $-0,4 \%$ & $-0,6 \%$ \\
\hline Beta $=0,3$ & $1,0 \%$ & $0,6 \%$ & $0,5 \%$ & $0,2 \%$ & $-0,1 \%$ \\
\hline Beta $=0,4$ & $1,7 \%$ & $1,2 \%$ & $1,0 \%$ & $0,7 \%$ & $0,4 \%$ \\
\hline Beta $=0,5$ & $2,3 \%$ & $1,7 \%$ & $1,6 \%$ & $1,1 \%$ & $0,7 \%$ \\
\hline Beta $=0,6$ & $2,9 \%$ & $2,2 \%$ & $2,0 \%$ & $1,5 \%$ & $1,1 \%$ \\
\hline Beta $=0,7$ & $3,3 \%$ & $2,6 \%$ & $2,4 \%$ & $1,9 \%$ & $1,4 \%$ \\
\hline Beta $=0,8$ & $3,8 \%$ & $3,0 \%$ & $2,7 \%$ & $2,2 \%$ & $1,6 \%$ \\
\hline Beta $=0,9$ & $4,1 \%$ & $3,3 \%$ & $3,0 \%$ & $2,4 \%$ & $1,9 \%$ \\
\hline Beta $=1,0$ & $4,5 \%$ & $3,6 \%$ & $3,3 \%$ & $2,7 \%$ & $2,1 \%$ \\
\hline Beta $=1,1$ & $4,8 \%$ & $3,9 \%$ & $3,6 \%$ & $2,9 \%$ & $2,3 \%$ \\
\hline Beta $=1,2$ & $5,1 \%$ & $4,1 \%$ & $3,8 \%$ & $3,1 \%$ & $2,4 \%$ \\
\hline Beta $=1,3$ & $5,3 \%$ & $4,3 \%$ & $4,0 \%$ & $3,3 \%$ & $2,6 \%$ \\
\hline Beta $=1,4$ & $5,6 \%$ & $4,5 \%$ & $4,2 \%$ & $3,5 \%$ & $2,7 \%$ \\
\hline Beta $=1,5$ & $5,8 \%$ & $4,7 \%$ & $4,4 \%$ & $3,6 \%$ & $2,9 \%$ \\
\hline Beta $=1,6$ & $6,0 \%$ & $4,9 \%$ & $4,6 \%$ & $3,7 \%$ & $3,0 \%$ \\
\hline
\end{tabular}


Tabela 7.2: (cont.) avaliação percentual dos volumes de detenção obtidos pelo método proposto e pela metodologia de Porto (2002) para $\mathrm{CN}=98$ e duração do evento de 30 minutos.

\begin{tabular}{|c|c|c|c|c|c|}
\hline Beta $=1,7$ & $6,2 \%$ & $5,1 \%$ & $4,7 \%$ & $3,9 \%$ & $3,1 \%$ \\
\hline Beta $=1,8$ & $6,4 \%$ & $5,2 \%$ & $4,8 \%$ & $4,0 \%$ & $3,2 \%$ \\
\hline Beta $=1,9$ & $6,5 \%$ & $5,3 \%$ & $5,0 \%$ & $4,1 \%$ & $3,3 \%$ \\
\hline Beta $=2,0$ & $6,7 \%$ & $5,5 \%$ & $5,1 \%$ & $4,2 \%$ & $3,4 \%$ \\
\hline
\end{tabular}

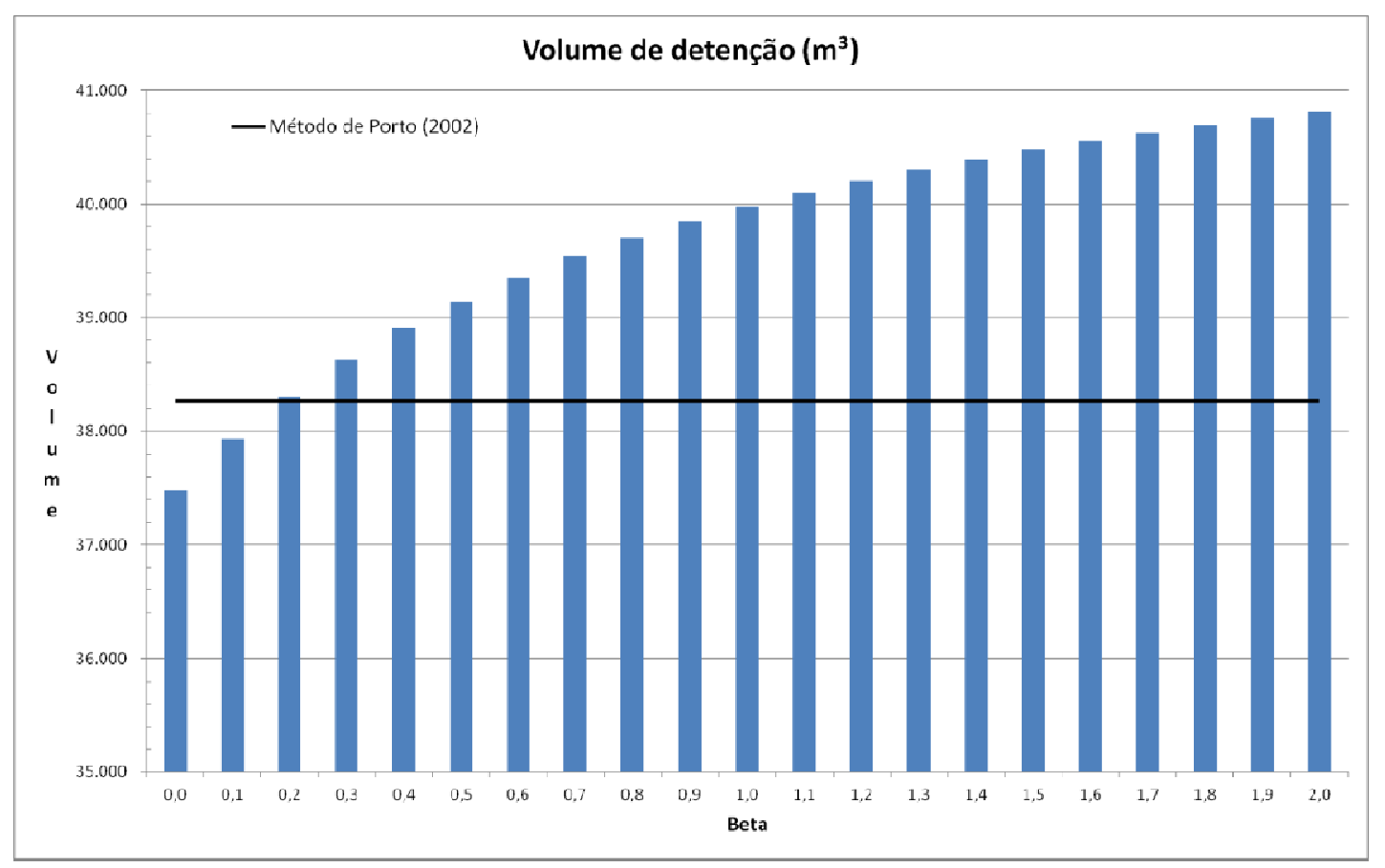

Figura 8.4: comparação entre volumes detido pela metodologia proposta e o método de Porto (2002) para tempo de retorno de 10 anos, duração de precipitação de 30 minutos e CN de 98. 


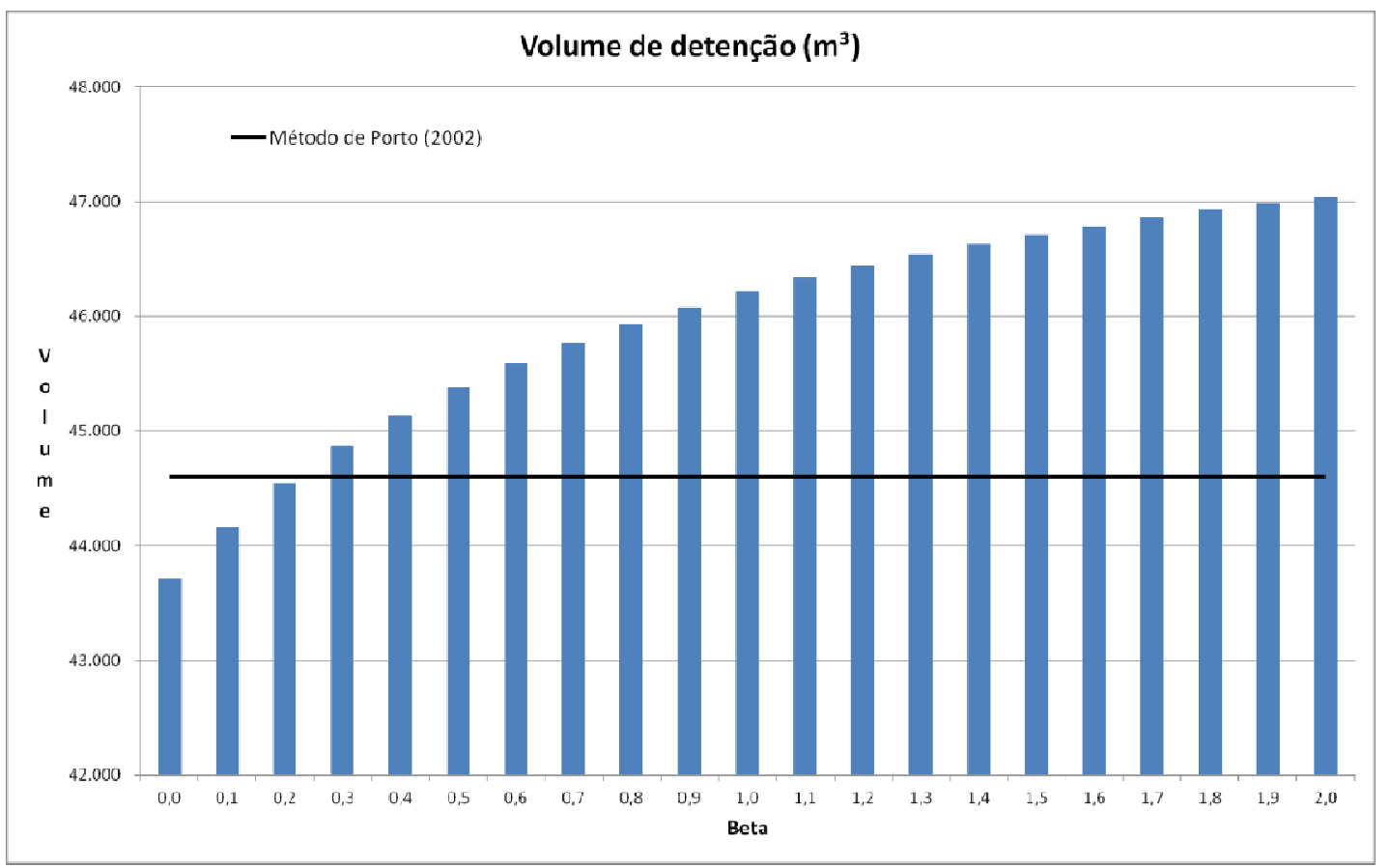

Figura 8.5: comparação entre volumes detido pela metodologia proposta e o método de Porto (2002) para tempo de retorno de 20 anos, duração de precipitação de 30 minutos e CN de 98.

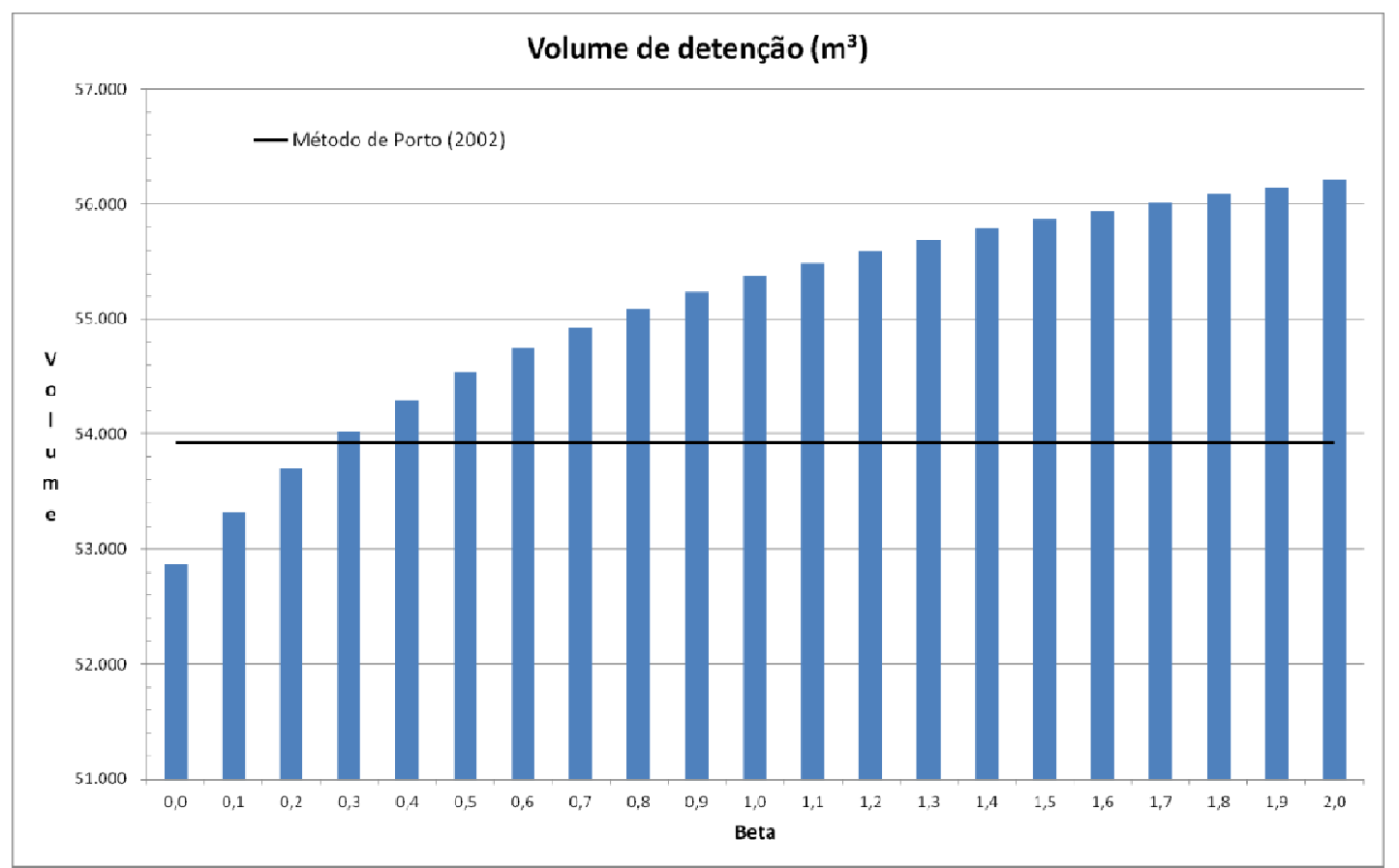

Figura 8.6: comparação entre volumes detido pela metodologia proposta e o método de Porto (2002) para tempo de retorno de 50 anos, duração de precipitação de 30 minutos e CN de 98. 
Tabela 8.3: avaliação percentual dos volumes de detenção obtidos pelo método proposto e pela metodologia de Porto (2002) para $\mathrm{CN}=85$ e duração do evento de 60 minutos.

\begin{tabular}{|c|c|c|c|c|c|}
\hline \multirow{2}{*}{ Método } & \multicolumn{5}{|c|}{ Diferença percentual no volume de detenção } \\
\cline { 2 - 6 } & \multicolumn{4}{|c|}{ Tempo de recorrência (anos) } \\
\cline { 2 - 6 } & 10 & 20 & 25 & 50 & 100 \\
\hline $\begin{array}{c}\text { Volume Porto } \\
(2002)\end{array}$ & 19.214 & 25.927 & 27.397 & 35.483 & 43.930 \\
\hline Beta $=0,0$ & $-3,0 \%$ & $-2,7 \%$ & $-0,1 \%$ & $0,1 \%$ & $0,2 \%$ \\
\hline Beta $=0,1$ & $1,8 \%$ & $0,9 \%$ & $3,2 \%$ & $2,6 \%$ & $2,2 \%$ \\
\hline Beta $=0,2$ & $5,7 \%$ & $3,8 \%$ & $6,0 \%$ & $4,8 \%$ & $4,0 \%$ \\
\hline Beta $=0,3$ & $9,1 \%$ & $6,3 \%$ & $8,3 \%$ & $6,6 \%$ & $5,4 \%$ \\
\hline Beta $=0,4$ & $11,9 \%$ & $8,4 \%$ & $10,3 \%$ & $8,1 \%$ & $6,7 \%$ \\
\hline Beta $=0,5$ & $14,4 \%$ & $10,2 \%$ & $12,1 \%$ & $9,5 \%$ & $7,8 \%$ \\
\hline Beta $=0,6$ & $16,6 \%$ & $11,8 \%$ & $13,6 \%$ & $10,6 \%$ & $8,7 \%$ \\
\hline Beta $=0,7$ & $18,5 \%$ & $13,2 \%$ & $14,9 \%$ & $11,7 \%$ & $9,6 \%$ \\
\hline Beta $=0,8$ & $20,2 \%$ & $14,5 \%$ & $16,1 \%$ & $12,6 \%$ & $10,3 \%$ \\
\hline Beta $=0,9$ & $21,7 \%$ & $15,6 \%$ & $17,2 \%$ & $13,4 \%$ & $11,0 \%$ \\
\hline Beta $=1,0$ & $23,1 \%$ & $16,7 \%$ & $18,1 \%$ & $14,2 \%$ & $11,6 \%$ \\
\hline Beta $=1,1$ & $24,3 \%$ & $17,6 \%$ & $19,0 \%$ & $14,8 \%$ & $12,1 \%$ \\
\hline Beta $=1,2$ & $25,4 \%$ & $18,4 \%$ & $19,8 \%$ & $15,4 \%$ & $12,6 \%$ \\
\hline Beta $=1,3$ & $26,5 \%$ & $19,2 \%$ & $20,5 \%$ & $16,0 \%$ & $13,0 \%$ \\
\hline Beta $=1,4$ & $27,4 \%$ & $19,9 \%$ & $21,2 \%$ & $16,5 \%$ & $13,5 \%$ \\
\hline Beta $=1,5$ & $28,3 \%$ & $20,5 \%$ & $21,8 \%$ & $17,0 \%$ & $13,8 \%$ \\
\hline Beta $=1,6$ & $29,1 \%$ & $21,1 \%$ & $22,4 \%$ & $17,4 \%$ & $14,2 \%$ \\
\hline Beta $=1,7$ & $29,8 \%$ & $21,7 \%$ & $22,9 \%$ & $17,8 \%$ & $14,5 \%$ \\
\hline Beta $=1,8$ & $30,5 \%$ & $22,2 \%$ & $23,4 \%$ & $18,2 \%$ & $14,8 \%$ \\
\hline Beta $=1,9$ & $31,2 \%$ & $22,6 \%$ & $23,8 \%$ & $18,5 \%$ & $15,1 \%$ \\
\hline Beta $=2,0$ & $31,8 \%$ & $23,1 \%$ & $24,2 \%$ & $18,9 \%$ & $15,4 \%$ \\
\hline
\end{tabular}




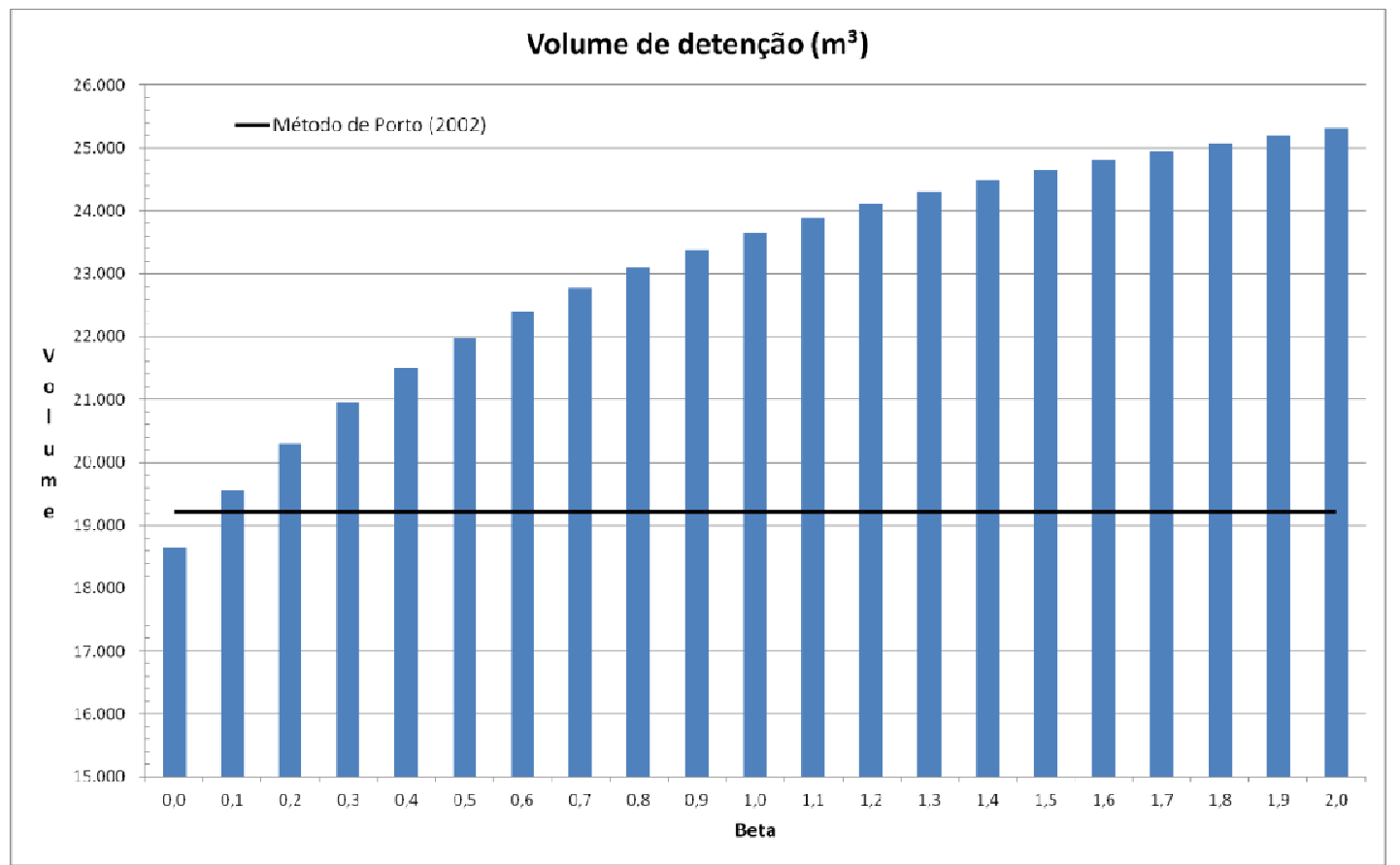

Figura 8.7: comparação entre volumes detido pela metodologia proposta e o método de Porto (2002) para tempo de retorno de 10 anos, duração de precipitação de 60 minutos e CN de 85.

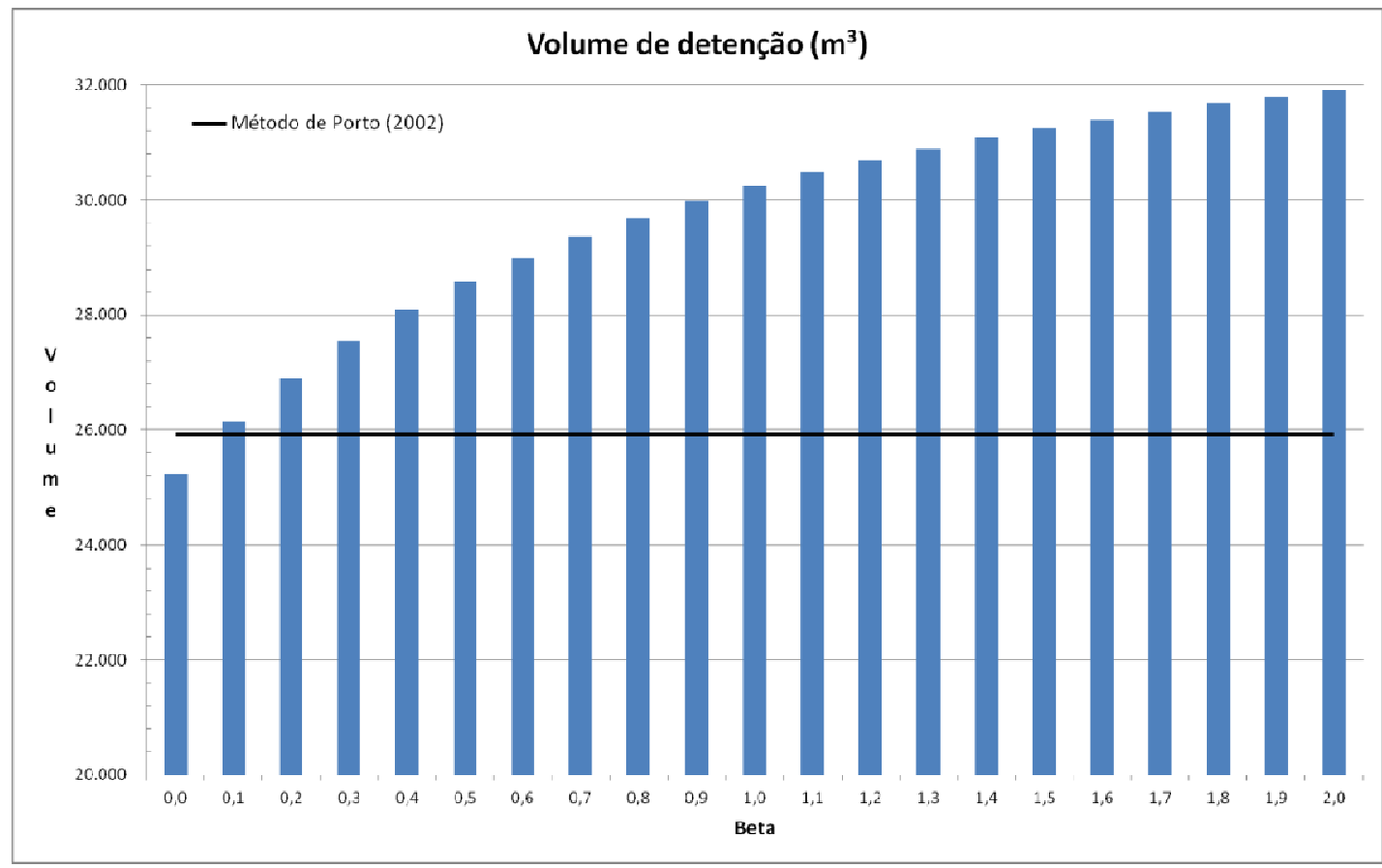

Figura 8.8: comparação entre volumes detido pela metodologia proposta e o método de Porto (2002) para tempo de retorno de 20 anos, duração de precipitação de 60 minutos e CN de 85. 


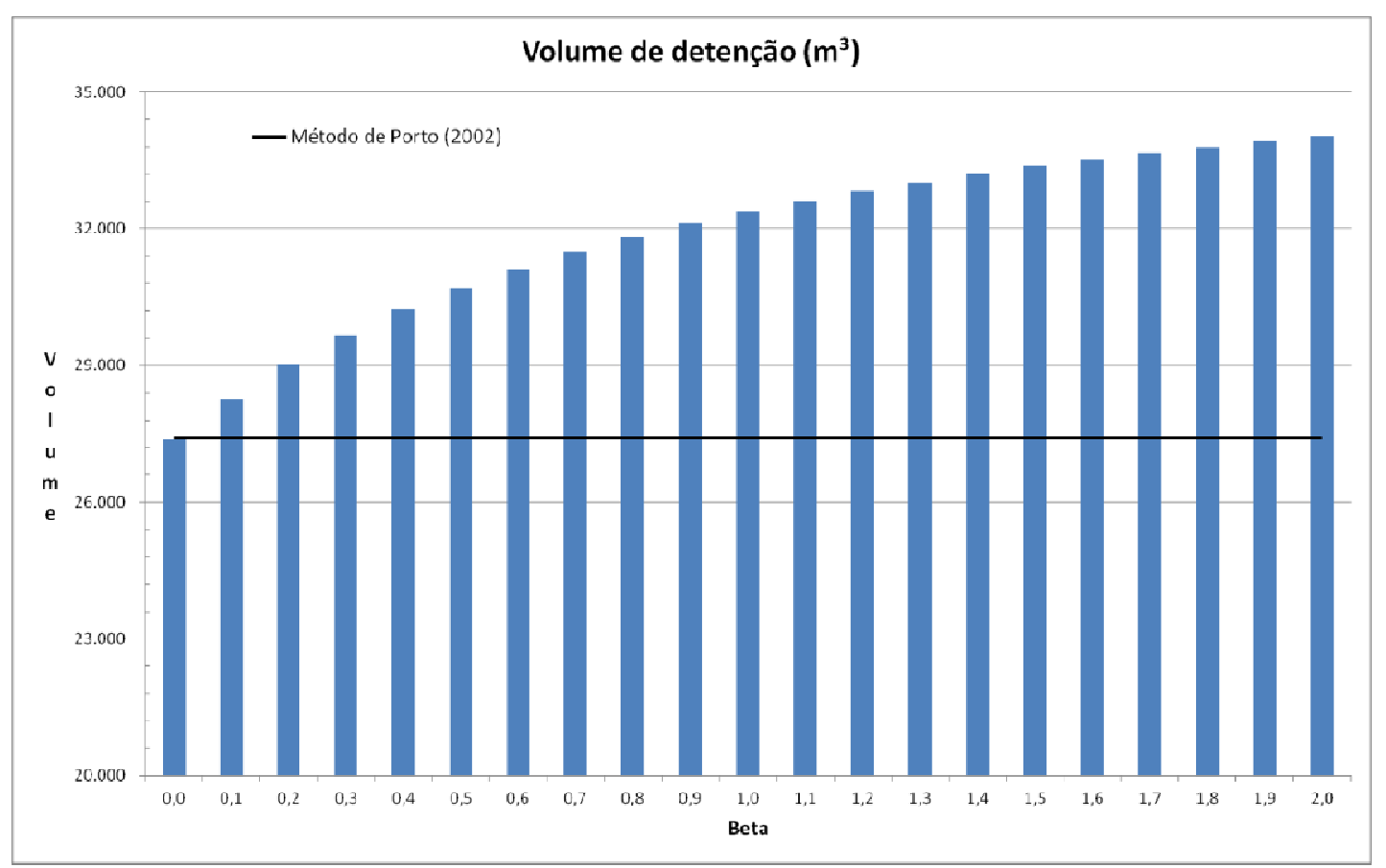

Figura 8.9: comparação entre volumes detido pela metodologia proposta e o método de Porto (2002) para tempo de retorno de 25 anos, duração de precipitação de 60 minutos e CN de 85.

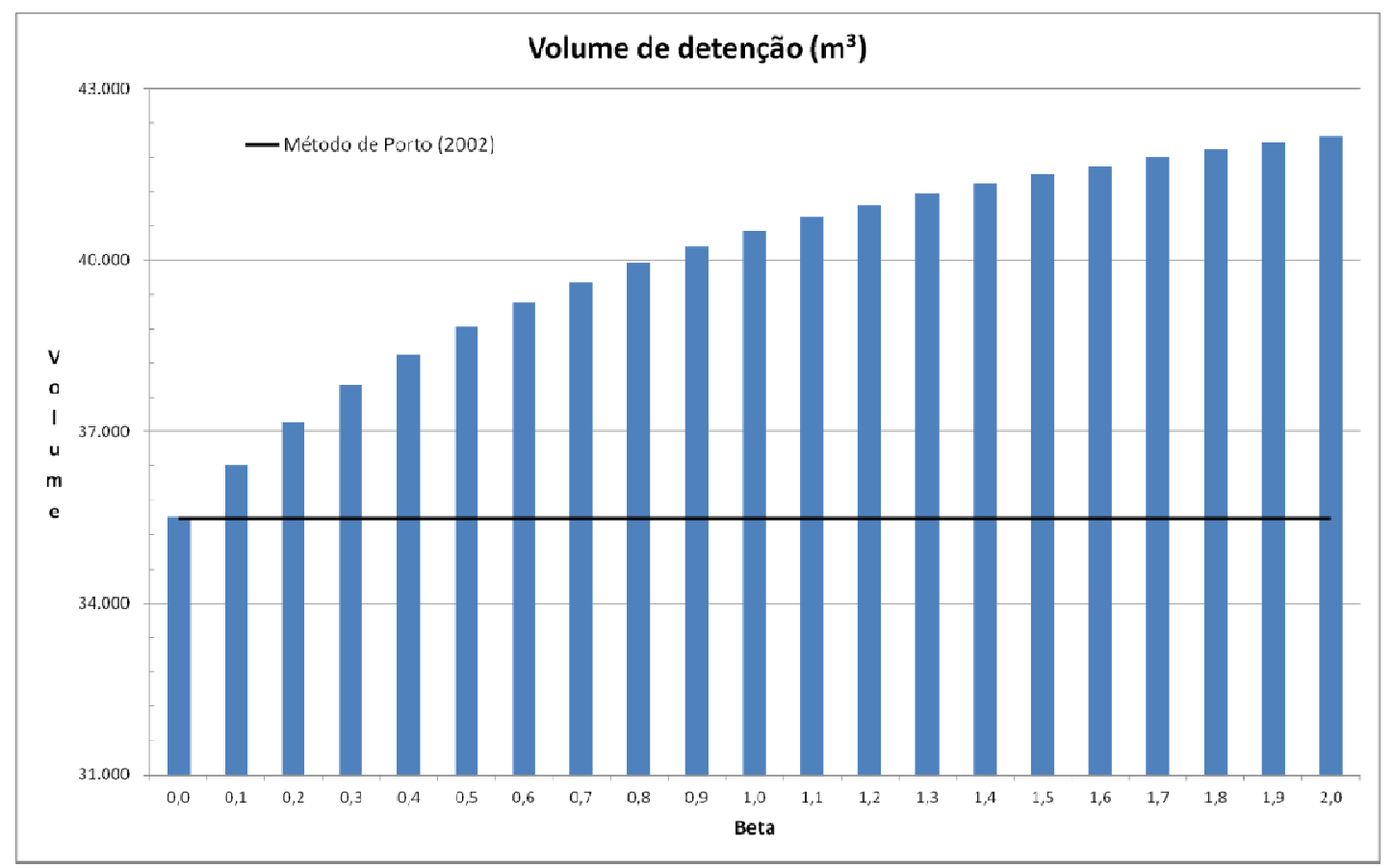

Figura 8.10: comparação entre volumes detido pela metodologia proposta e o método de Porto (2002) para tempo de retorno de 50 anos, duração de precipitação de 60 minutos e CN de 85. 


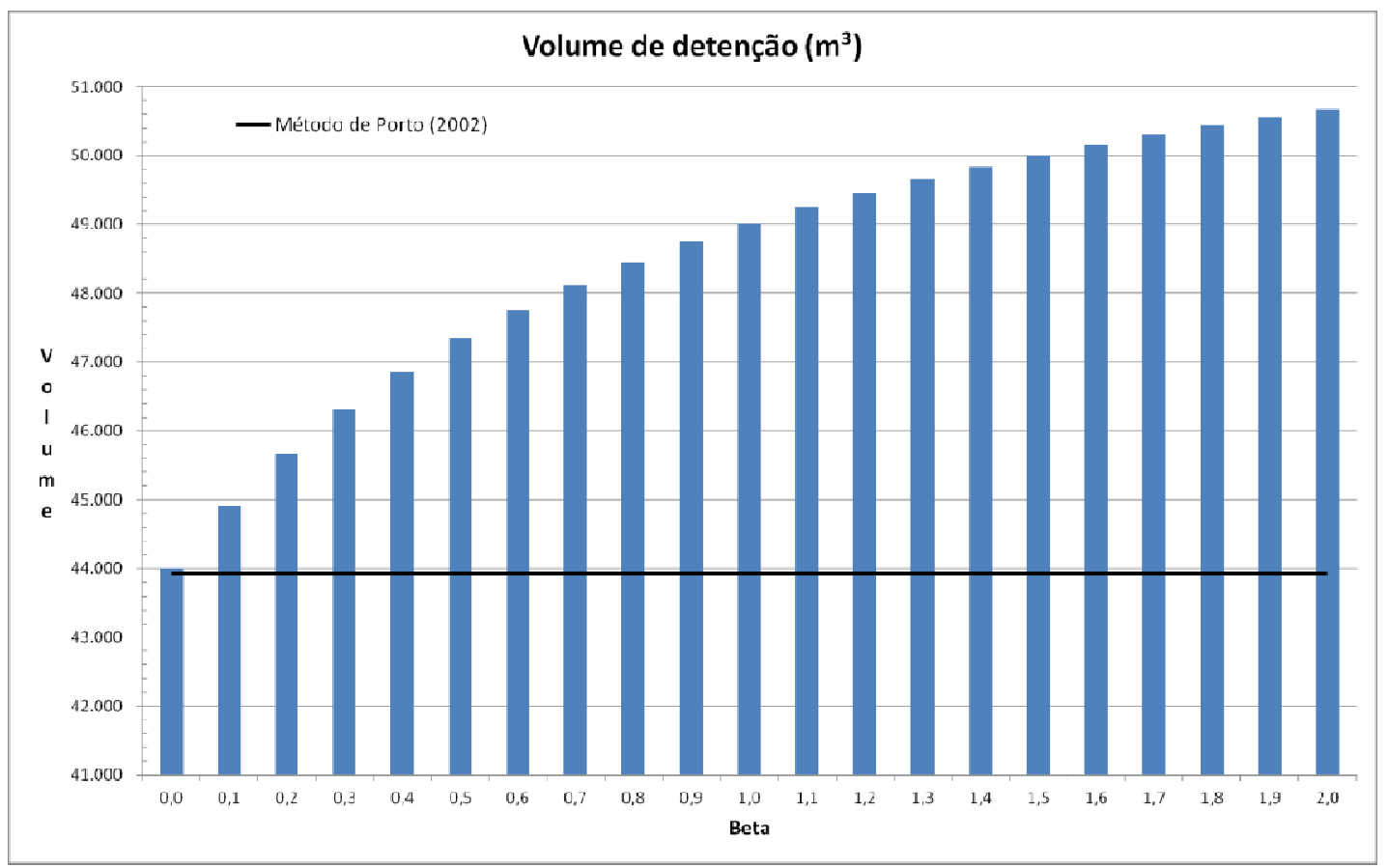

Figura 8.11: comparação entre volumes detido pela metodologia proposta e o método de Porto (2002) para tempo de retorno de 100 anos, duração de precipitação de 60 minutos e CN de 85.

Tabela 8.4: avaliação percentual dos volumes de detenção obtidos pelo método proposto e pela metodologia de Porto (2002) para $\mathrm{CN}=98$ e duração do evento de 60 minutos.

\begin{tabular}{|c|c|c|c|c|c|}
\hline \multirow{2}{*}{ Método } & \multicolumn{5}{|c|}{ Diferença percentual no volume de detenção } \\
\cline { 2 - 6 } & 10 & 20 & 25 & 50 & 100 \\
\hline $\begin{array}{c}\text { Volume Porto } \\
(2002)\end{array}$ & 51.290 & 59.355 & 61.223 & 70.544 & 81.078 \\
\hline Beta $=0,0$ & $-2,2 \%$ & $-2,1 \%$ & $0,3 \%$ & $0,4 \%$ & $0,4 \%$ \\
\hline Beta $=0,1$ & $-0,4 \%$ & $-0,6 \%$ & $1,8 \%$ & $1,6 \%$ & $1,5 \%$ \\
\hline Beta $=0,2$ & $1,0 \%$ & $0,7 \%$ & $3,0 \%$ & $2,7 \%$ & $2,5 \%$ \\
\hline Beta $=0,3$ & $2,3 \%$ & $1,8 \%$ & $4,1 \%$ & $3,6 \%$ & $3,2 \%$ \\
\hline Beta $=0,4$ & $3,4 \%$ & $2,7 \%$ & $5,0 \%$ & $4,4 \%$ & $3,9 \%$ \\
\hline Beta $=0,5$ & $4,3 \%$ & $3,5 \%$ & $5,8 \%$ & $5,1 \%$ & $4,5 \%$ \\
\hline Beta $=0,6$ & $5,1 \%$ & $4,2 \%$ & $6,4 \%$ & $5,7 \%$ & $5,0 \%$ \\
\hline Beta $=0,7$ & $5,8 \%$ & $4,8 \%$ & $7,0 \%$ & $6,2 \%$ & $5,5 \%$ \\
\hline Beta $=0,8$ & $6,5 \%$ & $5,4 \%$ & $7,6 \%$ & $6,7 \%$ & $5,9 \%$ \\
\hline Beta $=0,9$ & $7,0 \%$ & $5,8 \%$ & $8,1 \%$ & $7,1 \%$ & $6,2 \%$ \\
\hline Beta $=1,0$ & $7,6 \%$ & $6,3 \%$ & $8,5 \%$ & $7,4 \%$ & $6,6 \%$ \\
\hline Beta $=1,1$ & $8,0 \%$ & $6,7 \%$ & $8,9 \%$ & $7,8 \%$ & $6,9 \%$ \\
\hline Beta $=1,2$ & $8,4 \%$ & $7,1 \%$ & $9,2 \%$ & $8,1 \%$ & $7,1 \%$ \\
\hline Beta $=1,3$ & $8,8 \%$ & $7,4 \%$ & $9,5 \%$ & $8,4 \%$ & $7,4 \%$ \\
\hline Beta $=1,4$ & $9,2 \%$ & $7,7 \%$ & $9,8 \%$ & $8,6 \%$ & $7,6 \%$ \\
\hline Beta $=1,5$ & $9,5 \%$ & $8,0 \%$ & $10,1 \%$ & $8,9 \%$ & $7,8 \%$ \\
\hline Beta $=1,6$ & $9,8 \%$ & $8,2 \%$ & $10,4 \%$ & $9,1 \%$ & $8,0 \%$ \\
\hline Beta $=1,7$ & $10,1 \%$ & $8,5 \%$ & $10,6 \%$ & $9,3 \%$ & $8,2 \%$ \\
\hline
\end{tabular}


Tabela 7.4: (cont.) avaliação percentual dos volumes de detenção obtidos pelo método proposto e pela metodologia de Porto (2002) para $\mathbf{C N = 9 8}$ e duração do evento de 60 minutos.

\begin{tabular}{|c|c|c|c|c|c|}
\hline Beta $=1,8$ & $10,3 \%$ & $8,7 \%$ & $10,8 \%$ & $9,5 \%$ & $8,3 \%$ \\
\hline Beta $=1,9$ & $10,6 \%$ & $8,9 \%$ & $11,0 \%$ & $9,7 \%$ & $8,5 \%$ \\
\hline Beta $=2,0$ & $10,8 \%$ & $9,1 \%$ & $11,2 \%$ & $9,8 \%$ & $8,6 \%$ \\
\hline
\end{tabular}

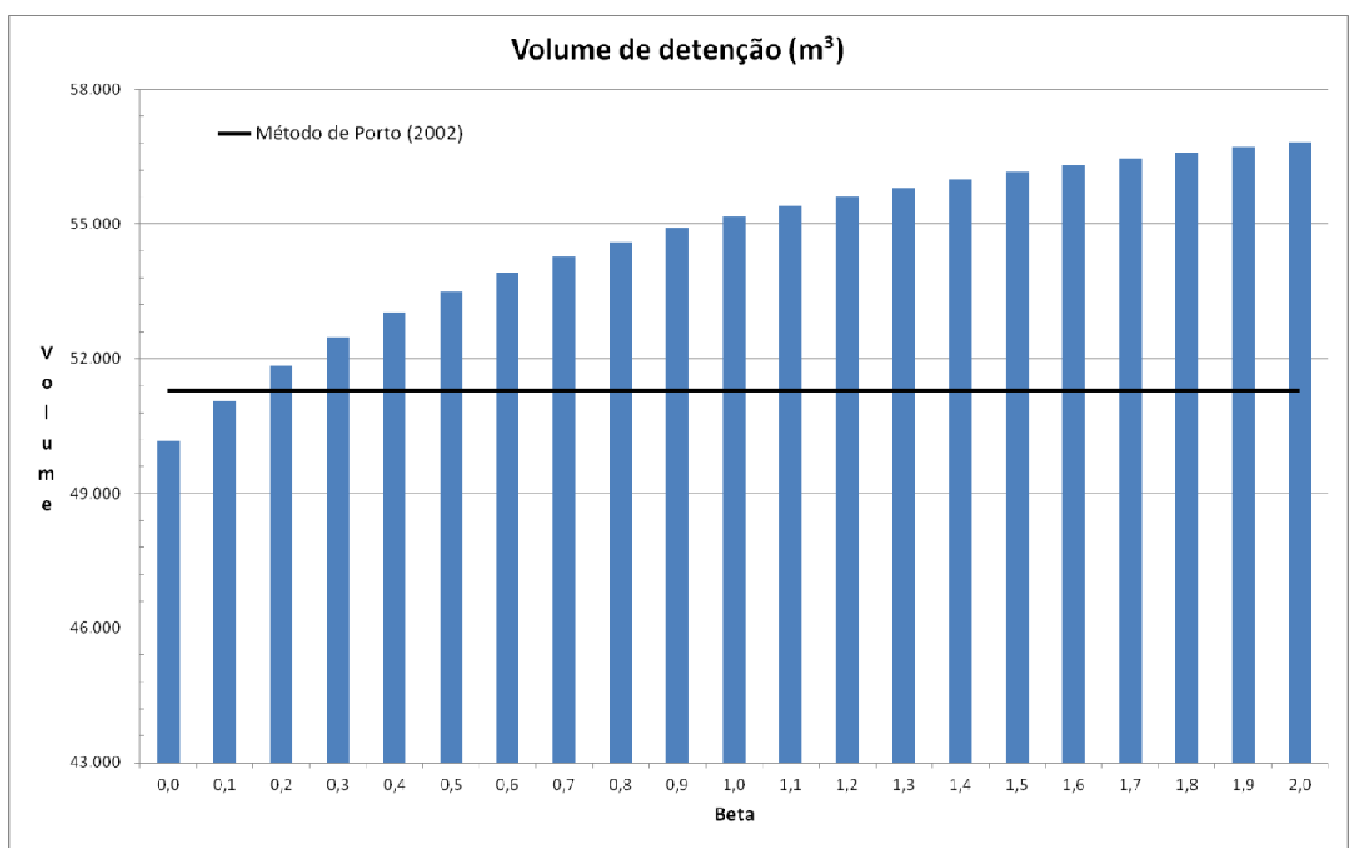

Figura 8.12: comparação entre volumes detido pela metodologia proposta e o método de Porto (2002) para tempo de retorno de 10 anos, duração de precipitação de 60 minutos e CN de 98.

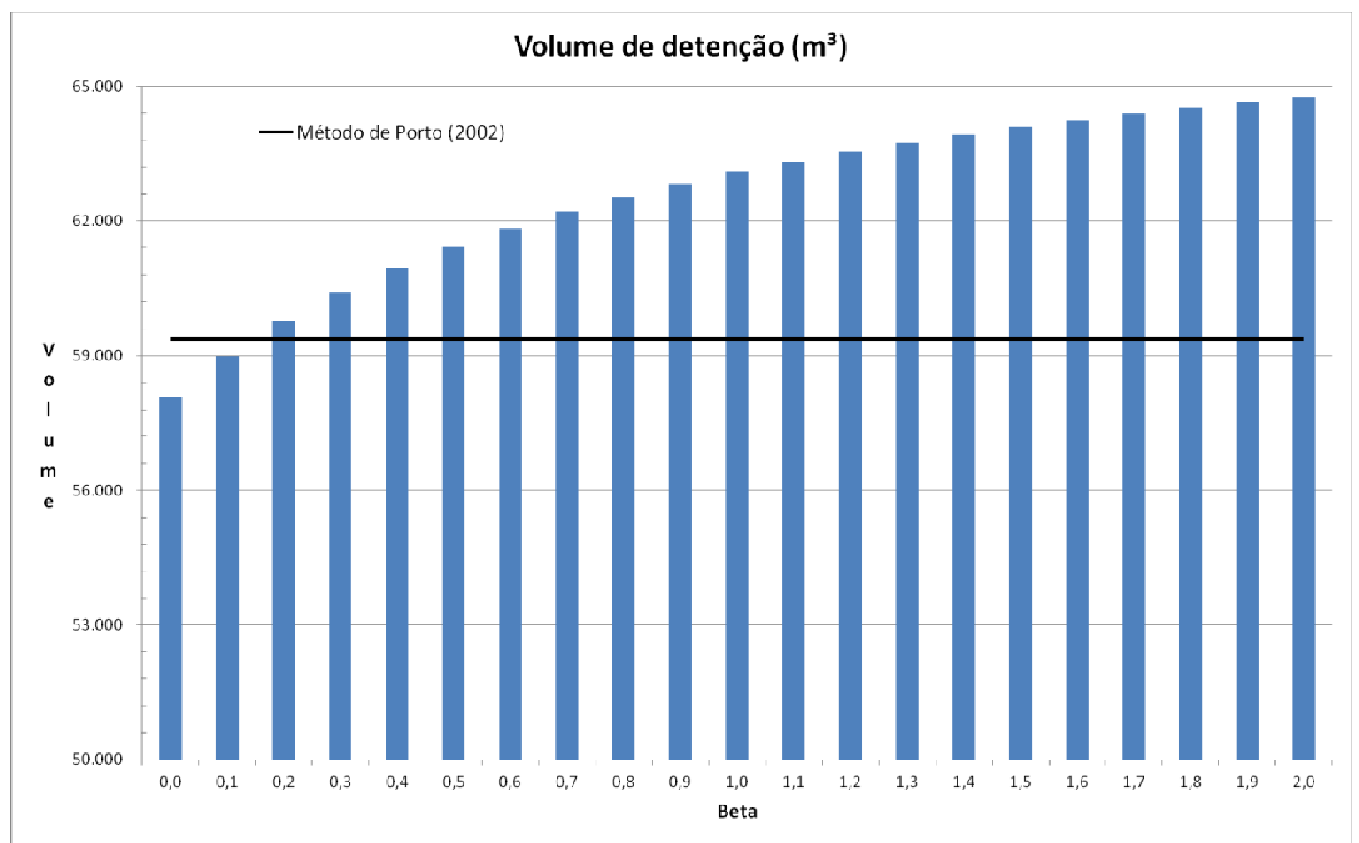

Figura 8.13: comparação entre volumes detido pela metodologia proposta e o método de Porto (2002) para tempo de retorno de 20 anos, duração de precipitação de 60 minutos e CN de 98. 


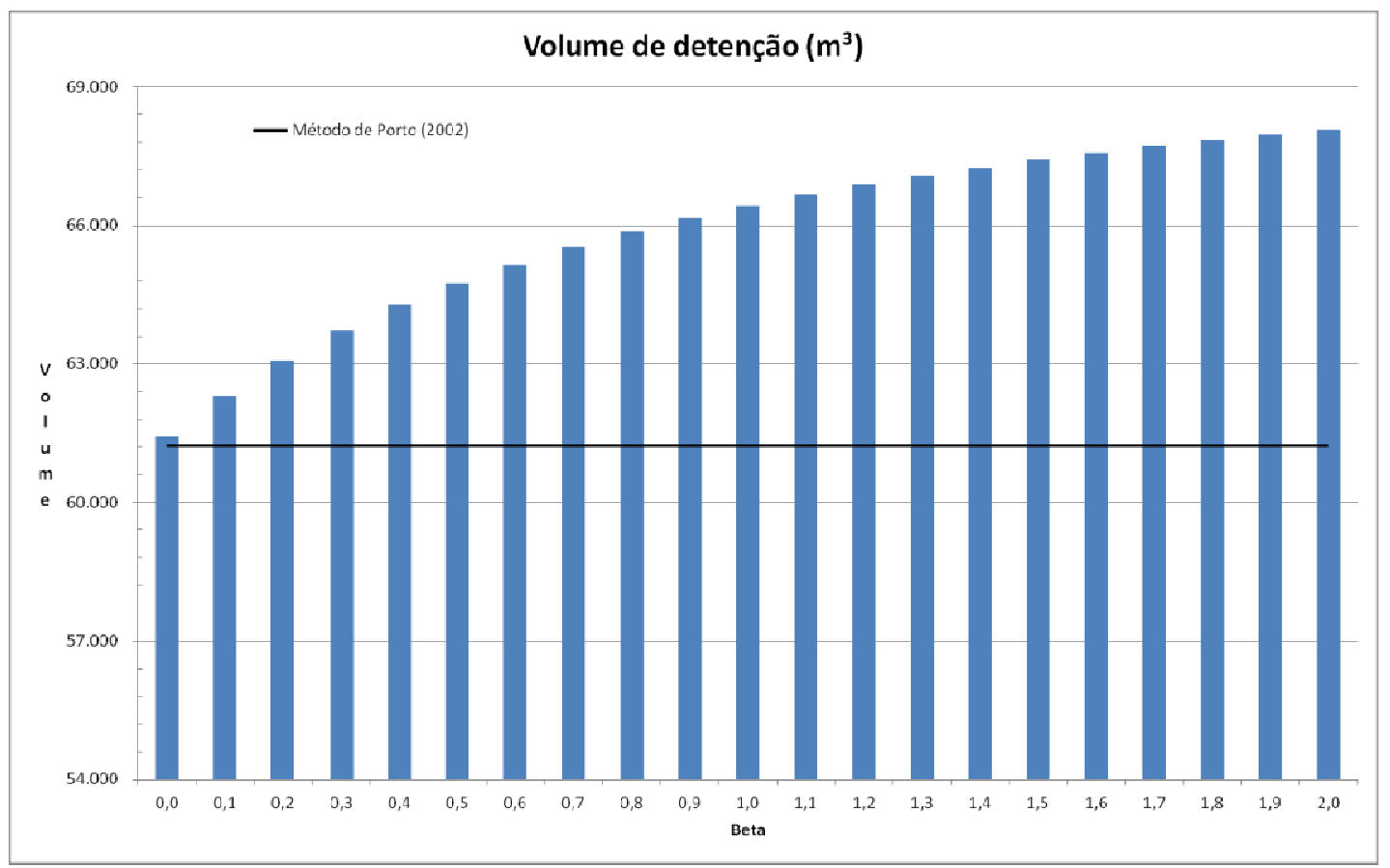

Figura 8.14: comparação entre volumes detido pela metodologia proposta e o método de Porto (2002) para tempo de retorno de 25 anos, duração de precipitação de 60 minutos e CN de 98.

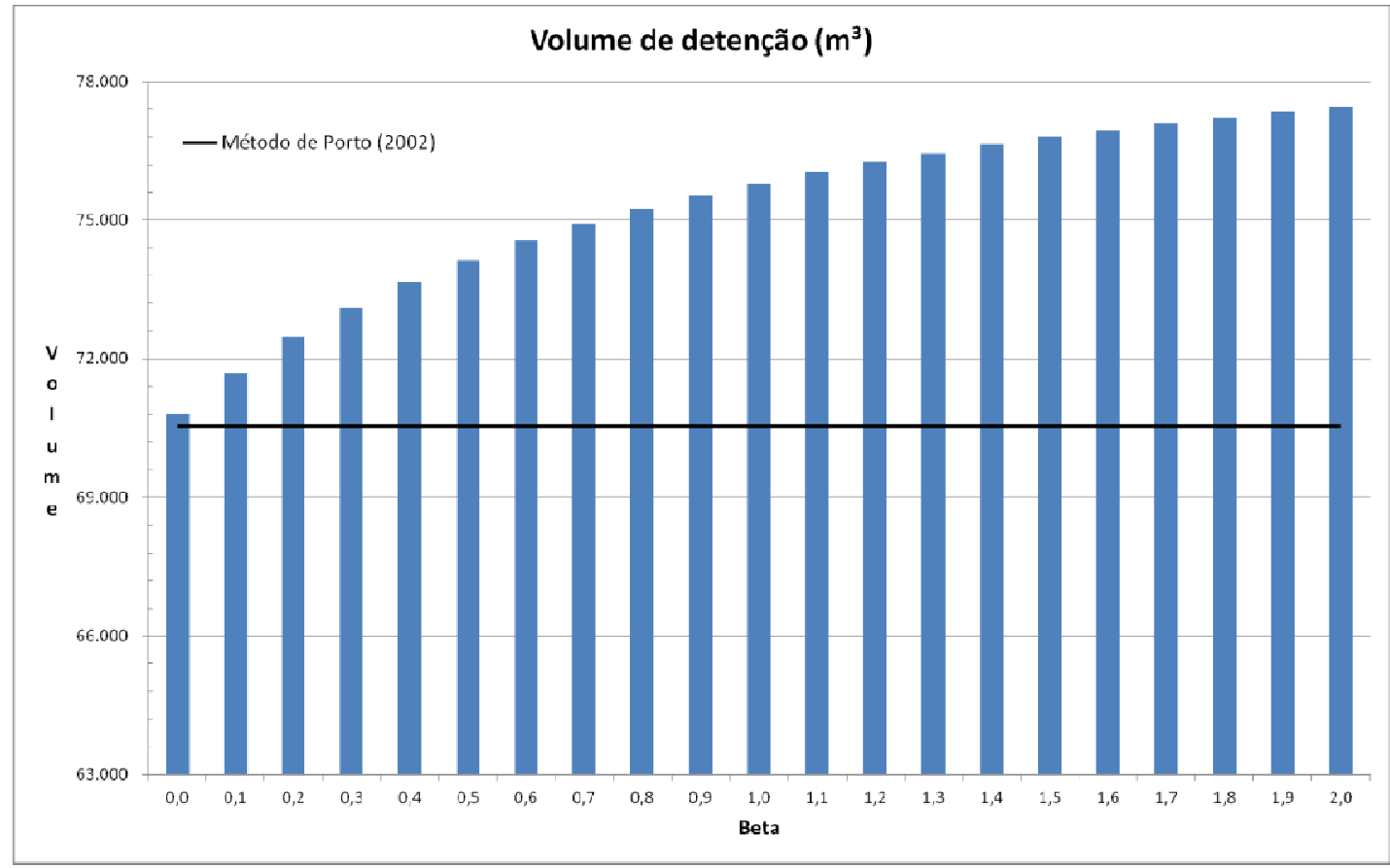

Figura 8.15: comparação entre volumes detido pela metodologia proposta e o método de Porto (2002) para tempo de retorno de 50 anos, duração de precipitação de 60 minutos e CN de 98. 


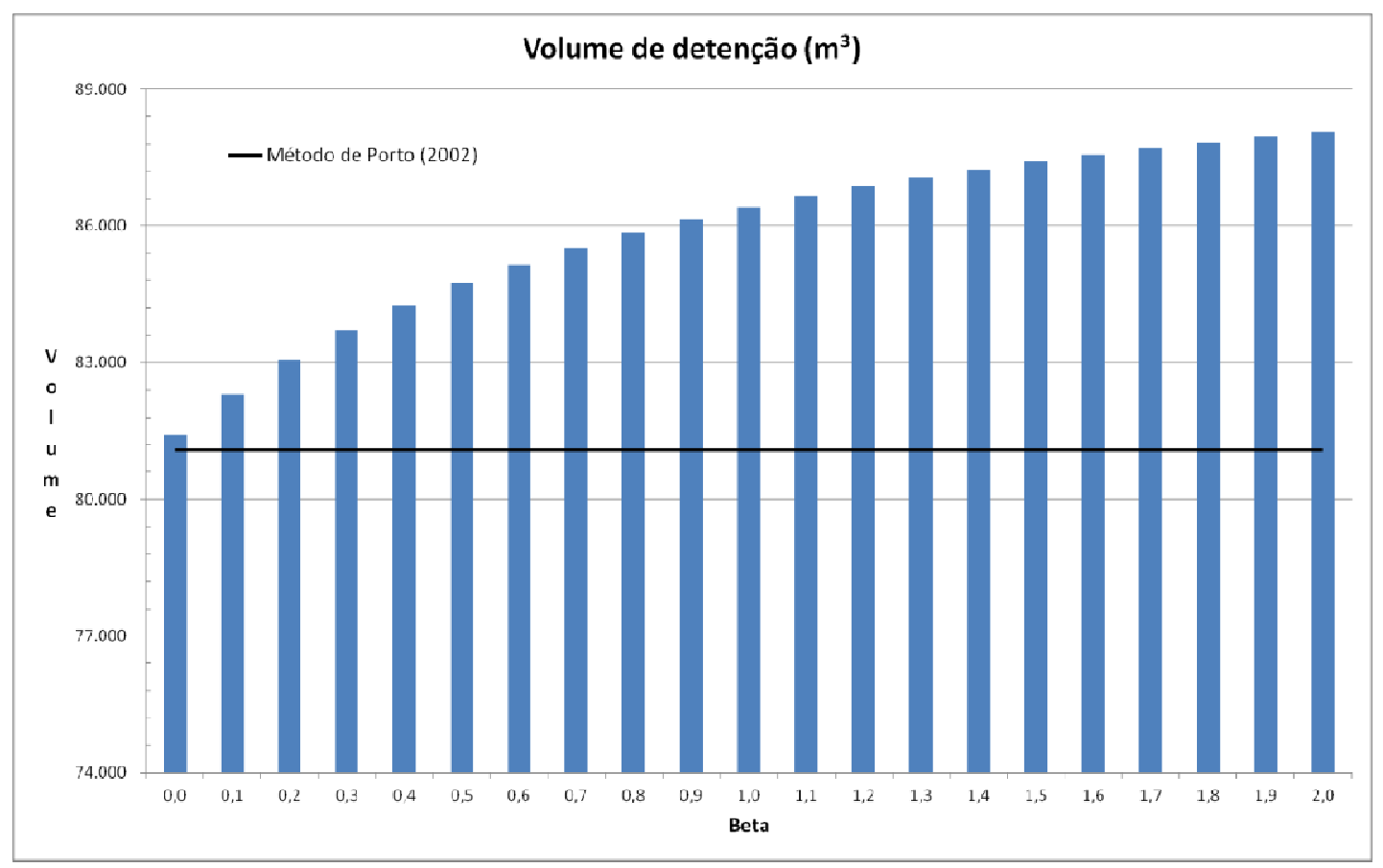

Figura 8.16: comparação entre volumes detido pela metodologia proposta e o método de Porto (2002) para tempo de retorno de 100 anos, duração de precipitação de 60 minutos e CN de 98.

Tabela 8.5: avaliação percentual dos volumes de detenção obtidos pelo método proposto e pela metodologia de Porto (2002) para $\mathrm{CN}=85$ e duração do evento de 90 minutos.

\begin{tabular}{|c|c|c|c|c|c|}
\hline \multirow{2}{*}{ Método } & \multicolumn{5}{|c|}{ Diferença percentual no volume de detenção } \\
\cline { 2 - 6 } & 10 & 20 & 25 & 50 & 100 \\
\hline & 25.648 & 30.586 & 32.771 & 42.770 & 53.251 \\
\hline $\begin{array}{c}\text { Volume Porto } \\
(2002)\end{array}$ & $-2,9 \%$ & $-2,9 \%$ & $-2,8 \%$ & $-2,6 \%$ & $-2,4 \%$ \\
\hline Beta $=0,0$ & $1,4 \%$ & $1,5 \%$ & $1,3 \%$ & $0,6 \%$ & $0,2 \%$ \\
\hline Beta $=0,1$ & $5,0 \%$ & $5,1 \%$ & $4,8 \%$ & $3,3 \%$ & $2,3 \%$ \\
\hline Beta $=0,2$ & $8,1 \%$ & $8,1 \%$ & $7,8 \%$ & $5,5 \%$ & $4,1 \%$ \\
\hline Beta $=0,3$ & $10,7 \%$ & $10,7 \%$ & $10,3 \%$ & $7,5 \%$ & $5,6 \%$ \\
\hline Beta $=0,4$ & $13,0 \%$ & $13,0 \%$ & $12,5 \%$ & $9,1 \%$ & $7,0 \%$ \\
\hline Beta $=0,5$ & $15,0 \%$ & $15,0 \%$ & $14,4 \%$ & $10,6 \%$ & $8,2 \%$ \\
\hline Beta $=0,6$ & $16,7 \%$ & $16,8 \%$ & $16,0 \%$ & $11,9 \%$ & $9,2 \%$ \\
\hline Beta $=0,7$ & $18,3 \%$ & $18,3 \%$ & $17,5 \%$ & $13,0 \%$ & $10,1 \%$ \\
\hline Beta $=0,8$ & $19,7 \%$ & $19,7 \%$ & $18,9 \%$ & $14,1 \%$ & $10,9 \%$ \\
\hline Beta $=0,9$ & $20,9 \%$ & $21,0 \%$ & $20,1 \%$ & $15,0 \%$ & $11,7 \%$ \\
\hline Beta $=1,0$ & $22,0 \%$ & $22,1 \%$ & $21,2 \%$ & $15,8 \%$ & $12,4 \%$ \\
\hline Beta $=1,1$ & $23,1 \%$ & $23,1 \%$ & $22,2 \%$ & $16,6 \%$ & $13,0 \%$ \\
\hline Beta $=1,2$ & $24,0 \%$ & $24,1 \%$ & $23,1 \%$ & $17,3 \%$ & $13,5 \%$ \\
\hline Beta $=1,3$ & $24,9 \%$ & $24,9 \%$ & $23,9 \%$ & $17,9 \%$ & $14,0 \%$ \\
\hline Beta $=1,4$ & $25,7 \%$ & $25,7 \%$ & $24,7 \%$ & $18,5 \%$ & $14,5 \%$ \\
\hline Beta $=1,5$ & $26,4 \%$ & $26,5 \%$ & $25,4 \%$ & $19,0 \%$ & $14,9 \%$ \\
\hline Beta $=1,6$ & $27,1 \%$ & $27,1 \%$ & $26,0 \%$ & $19,5 \%$ & $15,3 \%$ \\
\hline Beta $=1,7$ & & & & & \\
\hline & & & & \\
\hline
\end{tabular}


Tabela 7.5: (cont.) avaliação percentual dos volumes de detenção obtidos pelo método proposto e pela metodologia de Porto (2002) para $\mathbf{C N = 8 5}$ e duração do evento de 90 minutos.

\begin{tabular}{|c|c|c|c|c|c|}
\hline Beta $=1,8$ & $27,7 \%$ & $27,8 \%$ & $26,6 \%$ & $20,0 \%$ & $15,7 \%$ \\
\hline Beta $=1,9$ & $28,3 \%$ & $28,3 \%$ & $27,2 \%$ & $20,4 \%$ & $16,1 \%$ \\
\hline Beta $=2,0$ & $28,9 \%$ & $28,9 \%$ & $27,7 \%$ & $20,8 \%$ & $16,4 \%$ \\
\hline
\end{tabular}

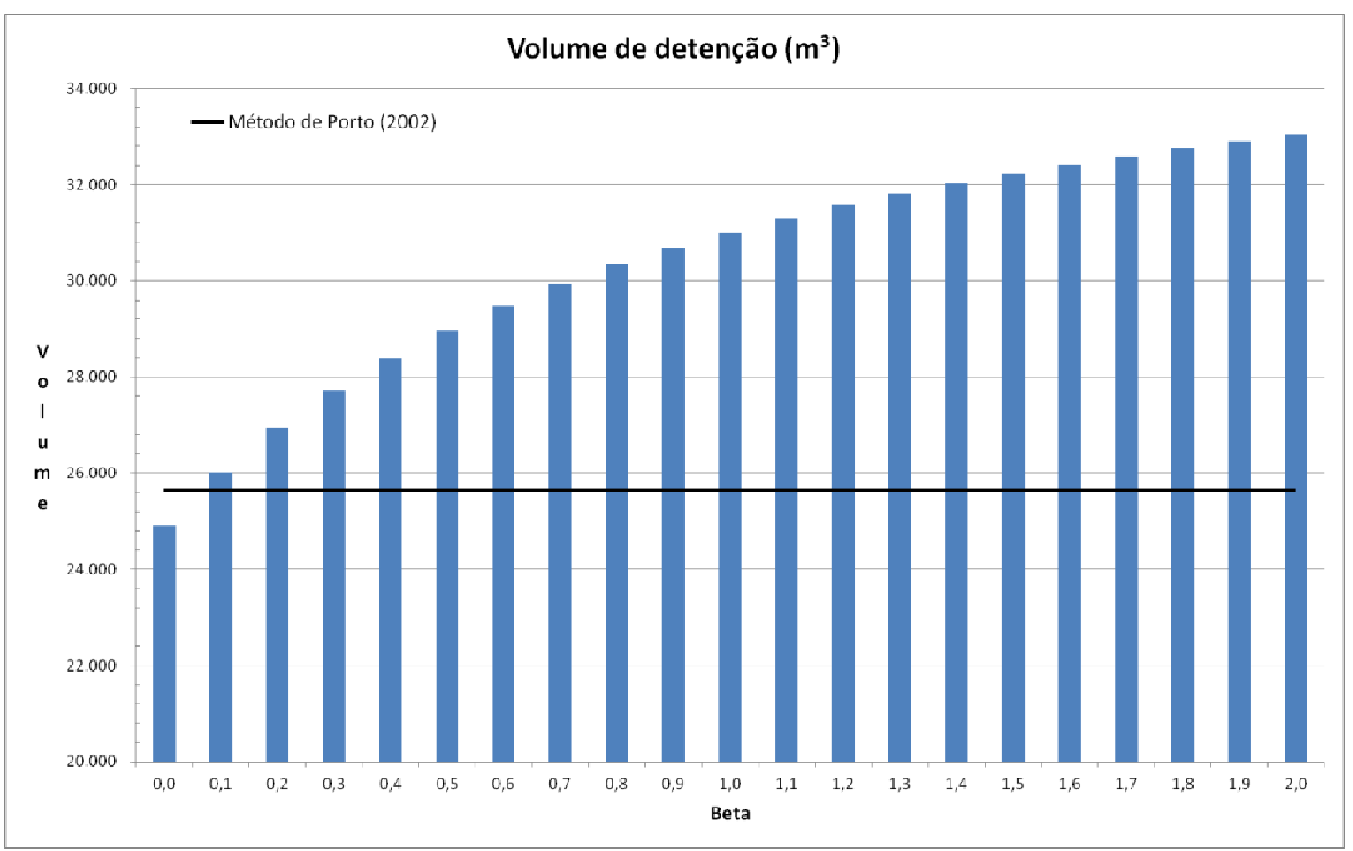

Figura 8.17: comparação entre volumes detido pela metodologia proposta e o método de Porto (2002) para tempo de retorno de 10 anos, duração de precipitação de 90 minutos e $\mathrm{CN}$ de 85.

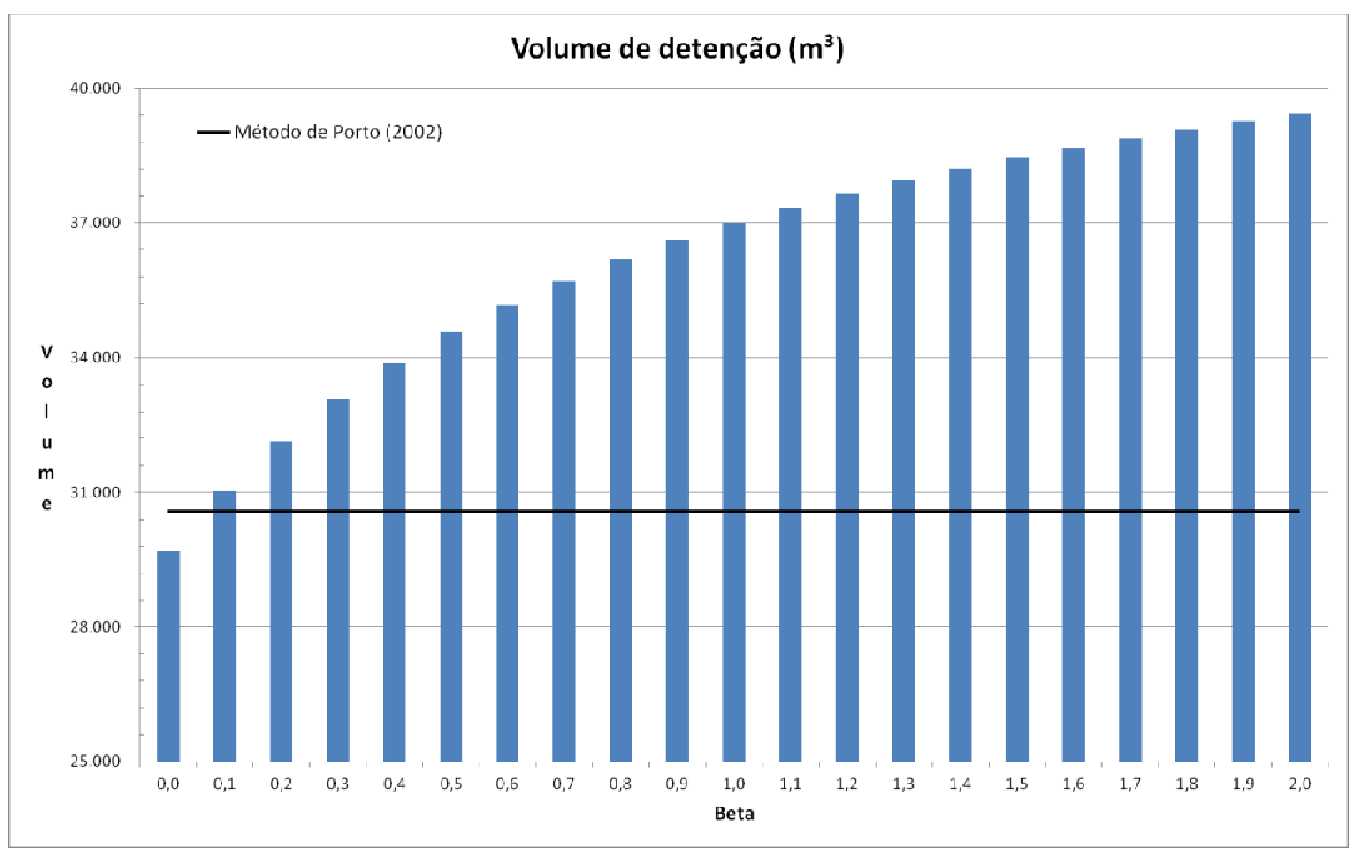

Figura 8.18: comparação entre volumes detido pela metodologia proposta e o método de Porto (2002) para tempo de retorno de 20 anos, duração de precipitação de 90 minutos e $\mathrm{CN}$ de 85. 


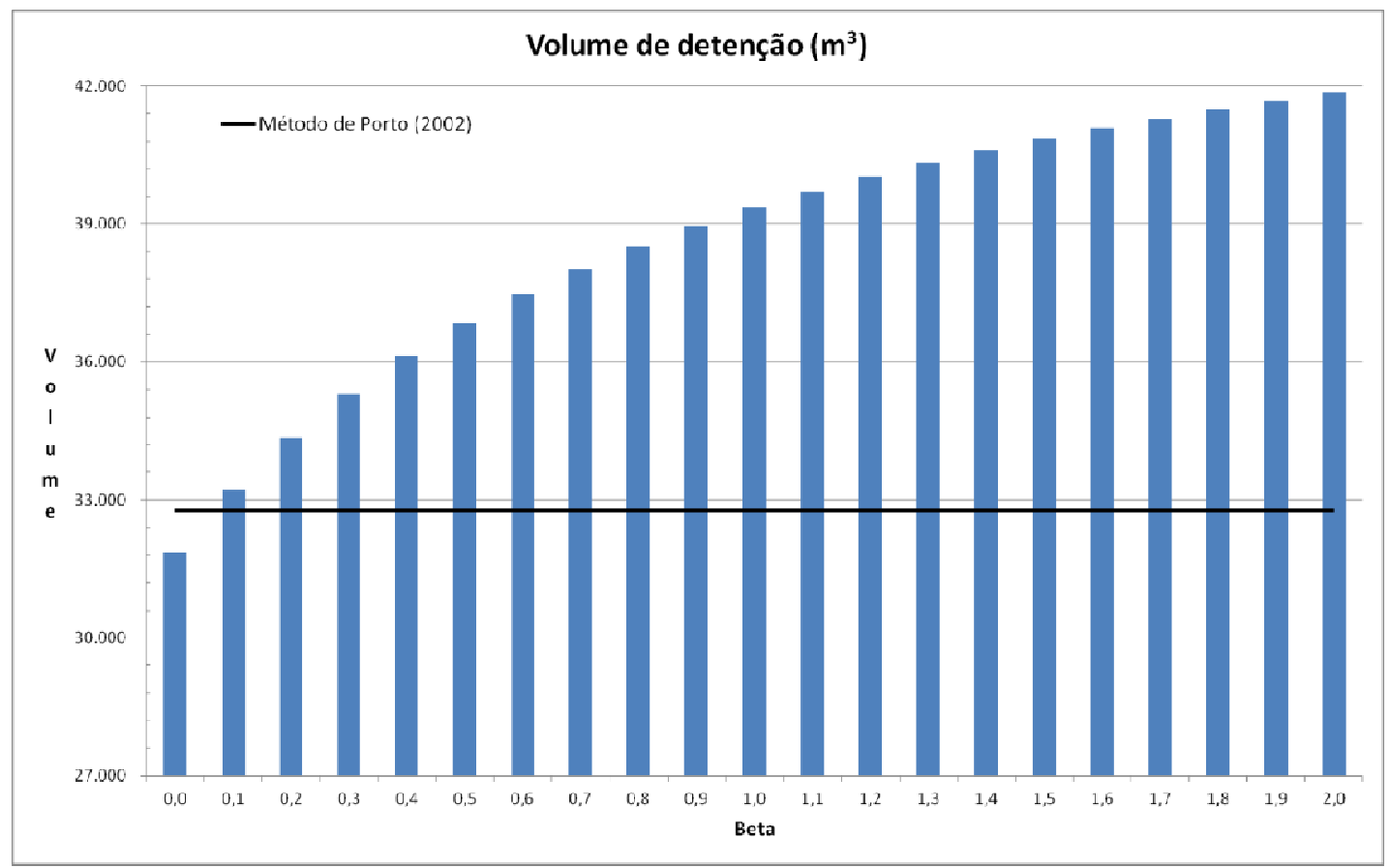

Figura 8.19: comparação entre volumes detido pela metodologia proposta e o método de Porto (2002) para tempo de retorno de 25 anos, duração de precipitação de 90 minutos e CN de 85.

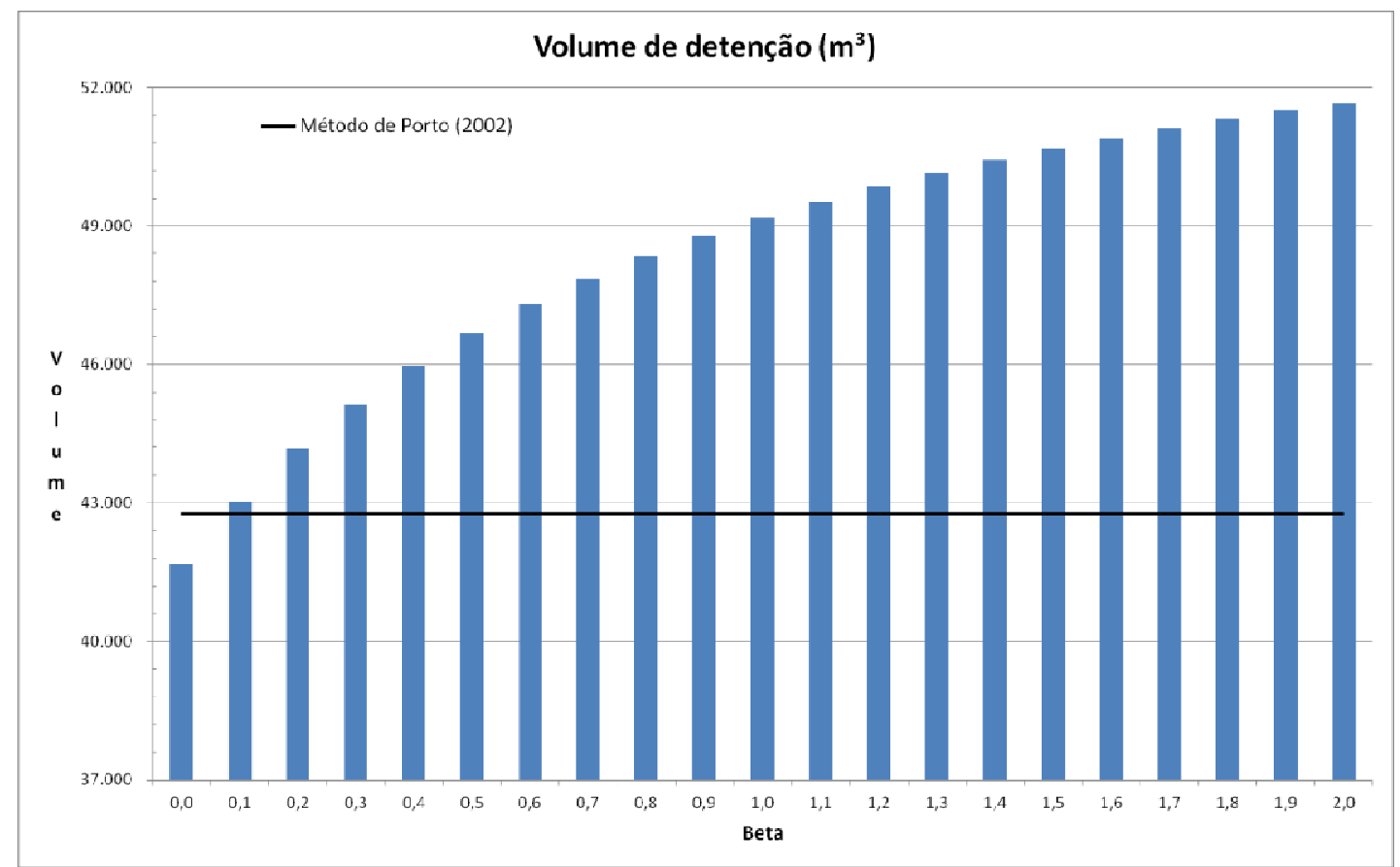

Figura 8.20: comparação entre volumes detido pela metodologia proposta e o método de Porto (2002) para tempo de retorno de 50 anos, duração de precipitação de 90 minutos e CN de 85. 


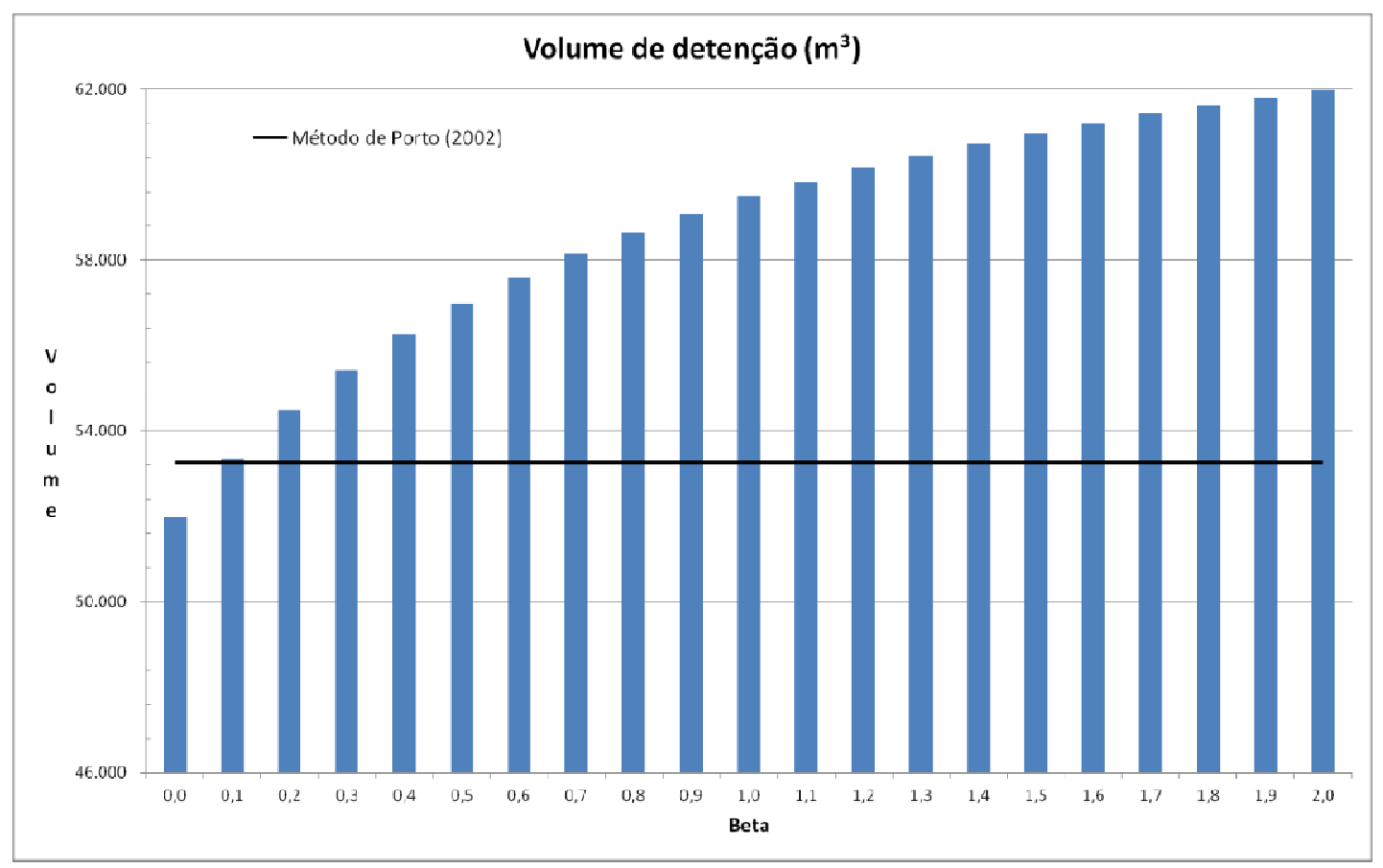

Figura 8.21: comparação entre volumes detido pela metodologia proposta e o método de Porto (2002) para tempo de retorno de 100 anos, duração de precipitação de 90 minutos e CN de 85.

Tabela 8.6: avaliação percentual dos volumes de detenção obtidos pelo método proposto e pela metodologia de Porto (2002) para $\mathrm{CN}=98$ e duração do evento de 90 minutos.

\begin{tabular}{|c|c|c|c|c|c|}
\hline \multirow{2}{*}{ Método } & \multicolumn{5}{|c|}{ Diferença percentual no volume de detenção } \\
\cline { 2 - 6 } & 10 & 20 & 25 & 50 & 100 \\
\hline $\begin{array}{c}\text { Volume Porto } \\
(2002)\end{array}$ & 57.276 & 66.761 & 69.756 & 81.957 & 94.641 \\
\hline Beta $=0,0$ & $-2,4 \%$ & $-2,3 \%$ & $-2,2 \%$ & $-2,2 \%$ & $-2,1 \%$ \\
\hline Beta $=0,1$ & $0,0 \%$ & $-0,2 \%$ & $-0,3 \%$ & $-0,5 \%$ & $-0,7 \%$ \\
\hline Beta $=0,2$ & $2,0 \%$ & $1,5 \%$ & $1,3 \%$ & $0,9 \%$ & $0,5 \%$ \\
\hline Beta $=0,3$ & $3,7 \%$ & $2,9 \%$ & $2,7 \%$ & $2,1 \%$ & $1,5 \%$ \\
\hline Beta $=0,4$ & $5,1 \%$ & $4,2 \%$ & $3,9 \%$ & $3,1 \%$ & $2,4 \%$ \\
\hline Beta $=0,5$ & $6,4 \%$ & $5,2 \%$ & $4,9 \%$ & $3,9 \%$ & $3,2 \%$ \\
\hline Beta $=0,6$ & $7,5 \%$ & $6,2 \%$ & $5,8 \%$ & $4,7 \%$ & $3,8 \%$ \\
\hline Beta $=0,7$ & $8,4 \%$ & $7,0 \%$ & $6,6 \%$ & $5,4 \%$ & $4,4 \%$ \\
\hline Beta $=0,8$ & $9,3 \%$ & $7,7 \%$ & $7,3 \%$ & $6,0 \%$ & $4,9 \%$ \\
\hline Beta $=0,9$ & $10,1 \%$ & $8,4 \%$ & $7,9 \%$ & $6,5 \%$ & $5,4 \%$ \\
\hline Beta $=1,0$ & $10,7 \%$ & $9,0 \%$ & $8,5 \%$ & $7,0 \%$ & $5,8 \%$ \\
\hline Beta $=1,1$ & $11,4 \%$ & $9,5 \%$ & $9,0 \%$ & $7,4 \%$ & $6,2 \%$ \\
\hline Beta $=1,2$ & $11,9 \%$ & $10,0 \%$ & $9,5 \%$ & $7,8 \%$ & $6,5 \%$ \\
\hline Beta $=1,3$ & $12,5 \%$ & $10,4 \%$ & $9,9 \%$ & $8,2 \%$ & $6,8 \%$ \\
\hline Beta $=1,4$ & $12,9 \%$ & $10,8 \%$ & $10,3 \%$ & $8,5 \%$ & $7,1 \%$ \\
\hline Beta $=1,5$ & $13,4 \%$ & $11,2 \%$ & $10,7 \%$ & $8,8 \%$ & $7,4 \%$ \\
\hline Beta $=1,6$ & $13,8 \%$ & $11,6 \%$ & $11,0 \%$ & $9,1 \%$ & $7,6 \%$ \\
\hline Beta $=1,7$ & $14,1 \%$ & $11,9 \%$ & $11,3 \%$ & $9,4 \%$ & $7,9 \%$ \\
\hline
\end{tabular}


Tabela 7.6: (cont.) avaliação percentual dos volumes de detenção obtidos pelo método proposto e pela metodologia de Porto (2002) para $\mathrm{CN=98}$ e duração do evento de 90 minutos.

\begin{tabular}{|c|c|c|c|c|c|}
\hline Beta $=1,8$ & $14,5 \%$ & $12,2 \%$ & $11,6 \%$ & $9,6 \%$ & $8,1 \%$ \\
\hline Beta $=1,9$ & $14,8 \%$ & $12,5 \%$ & $11,9 \%$ & $9,8 \%$ & $8,3 \%$ \\
\hline Beta $=2,0$ & $15,1 \%$ & $12,7 \%$ & $12,1 \%$ & $10,0 \%$ & $8,5 \%$ \\
\hline
\end{tabular}

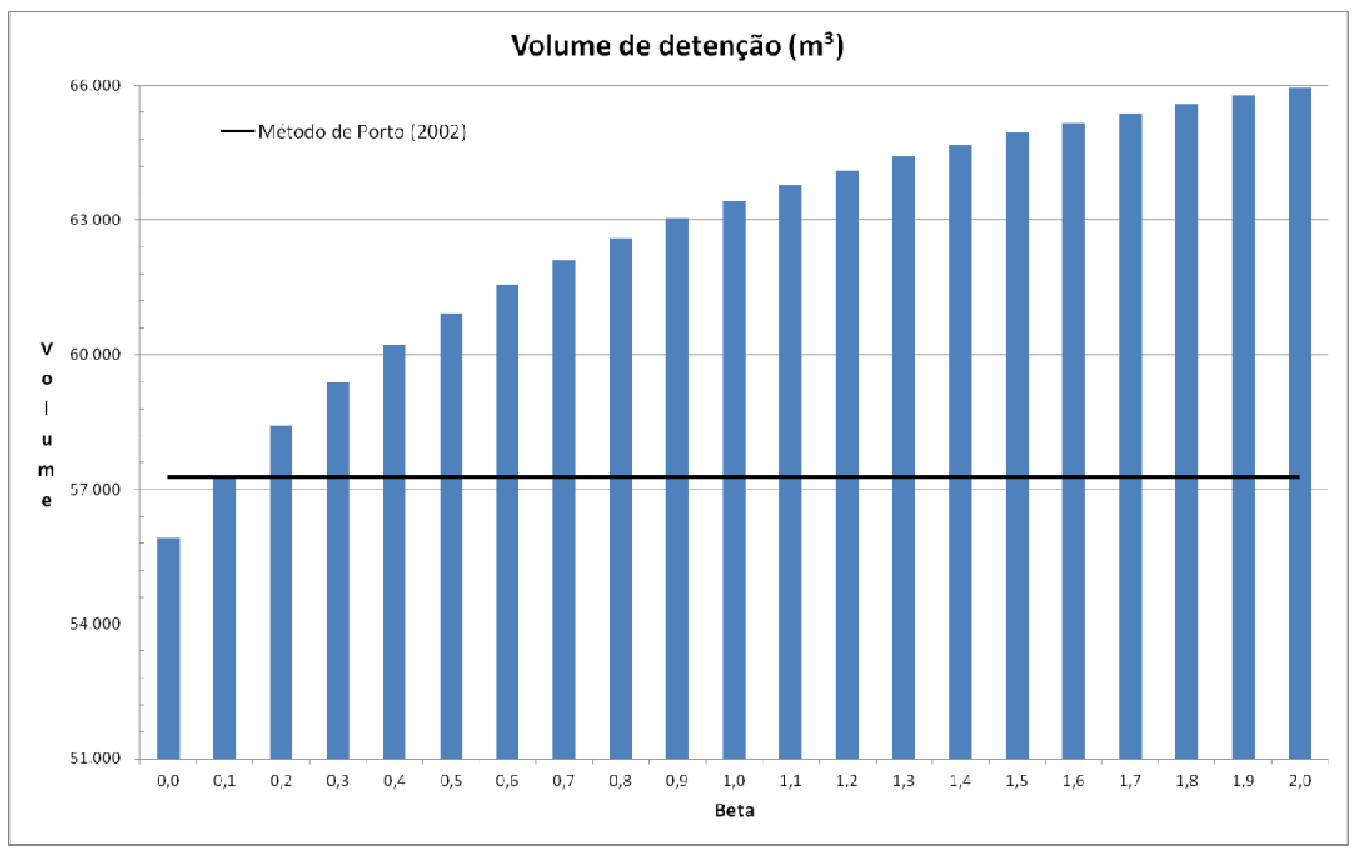

Figura 8.22: comparação entre volumes detido pela metodologia proposta e o método de Porto (2002) para tempo de retorno de 10 anos, duração de precipitação de 90 minutos e $\mathrm{CN}$ de 98.

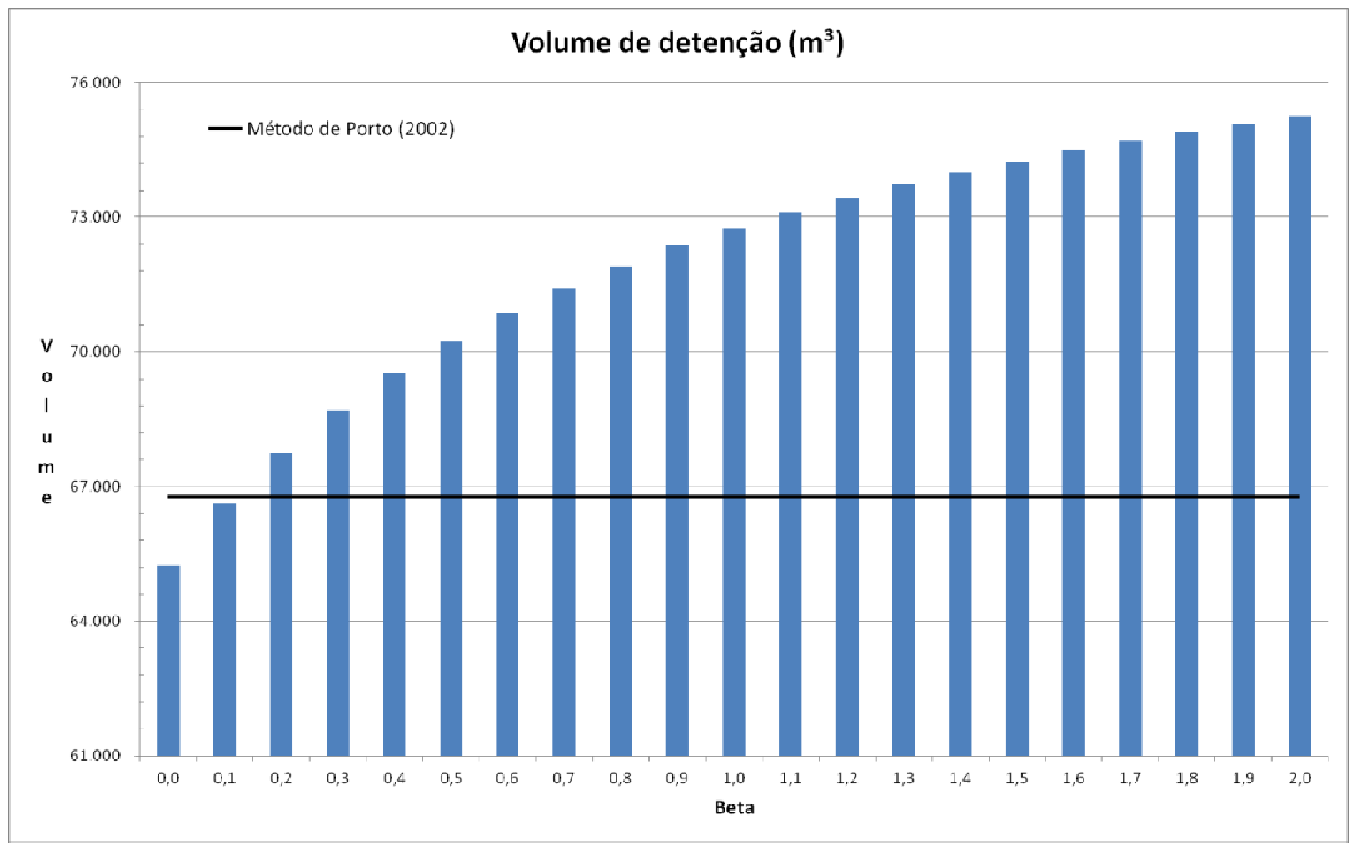

Figura 8.23: comparação entre volumes detido pela metodologia proposta e o método de Porto (2002) para tempo de retorno de 20 anos, duração de precipitação de 90 minutos e CN de 98. 


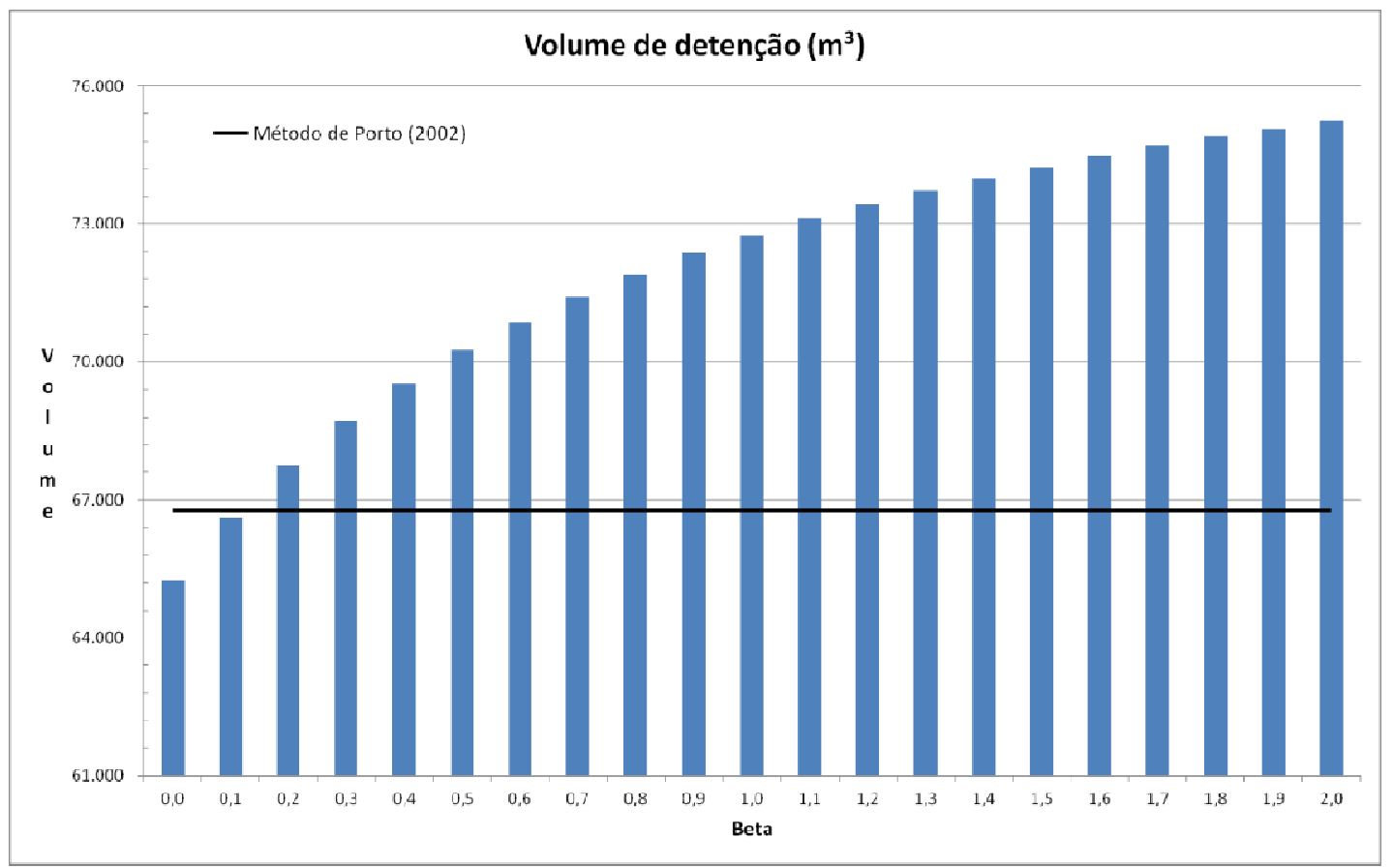

Figura 8.24: comparação entre volumes detido pela metodologia proposta e o método de Porto (2002) para tempo de retorno de 25 anos, duração de precipitação de 90 minutos e CN de 98.

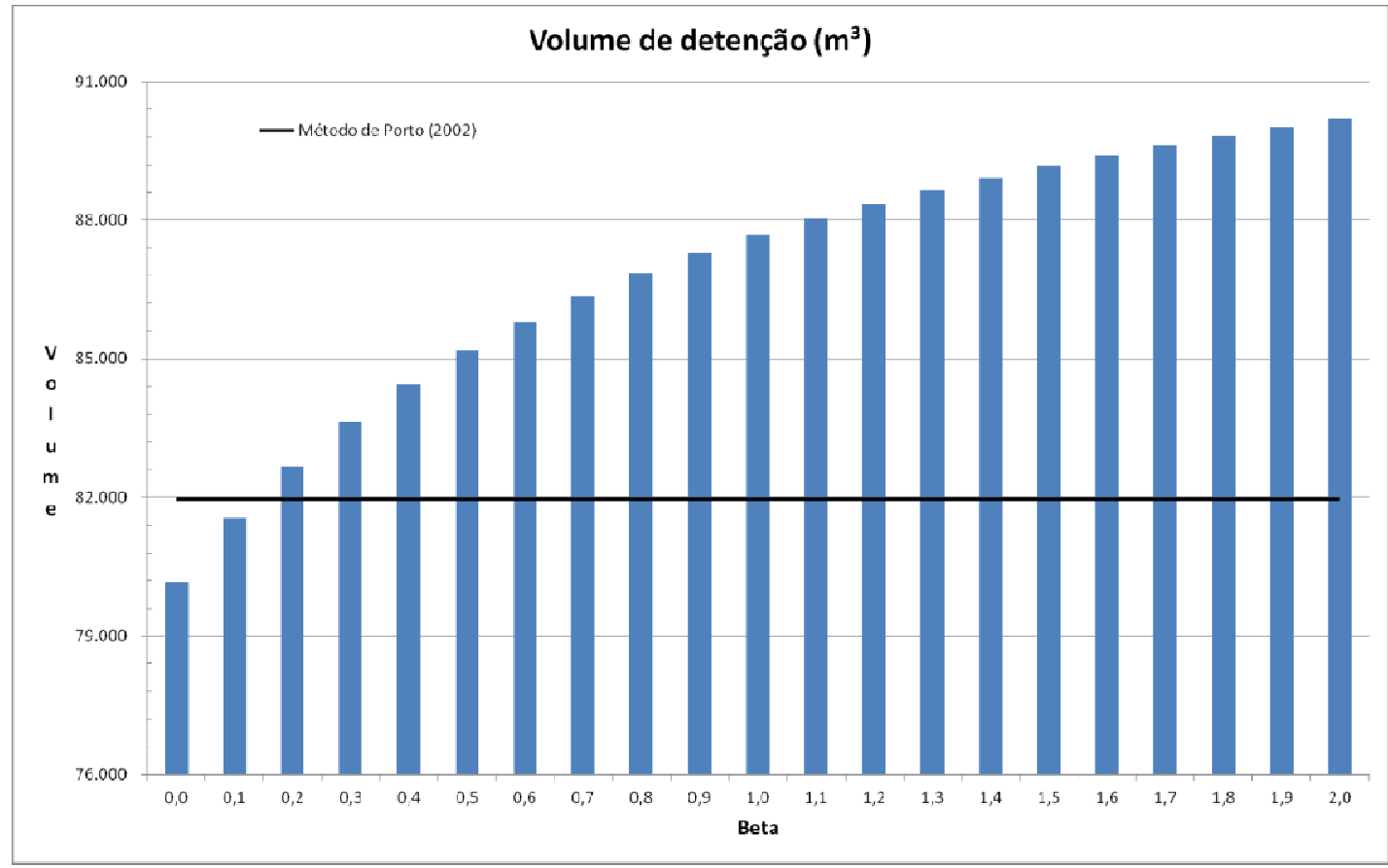

Figura 8.25: comparação entre volumes detido pela metodologia proposta e o método de Porto (2002) para tempo de retorno de 50 anos, duração de precipitação de 90 minutos e CN de 98. 


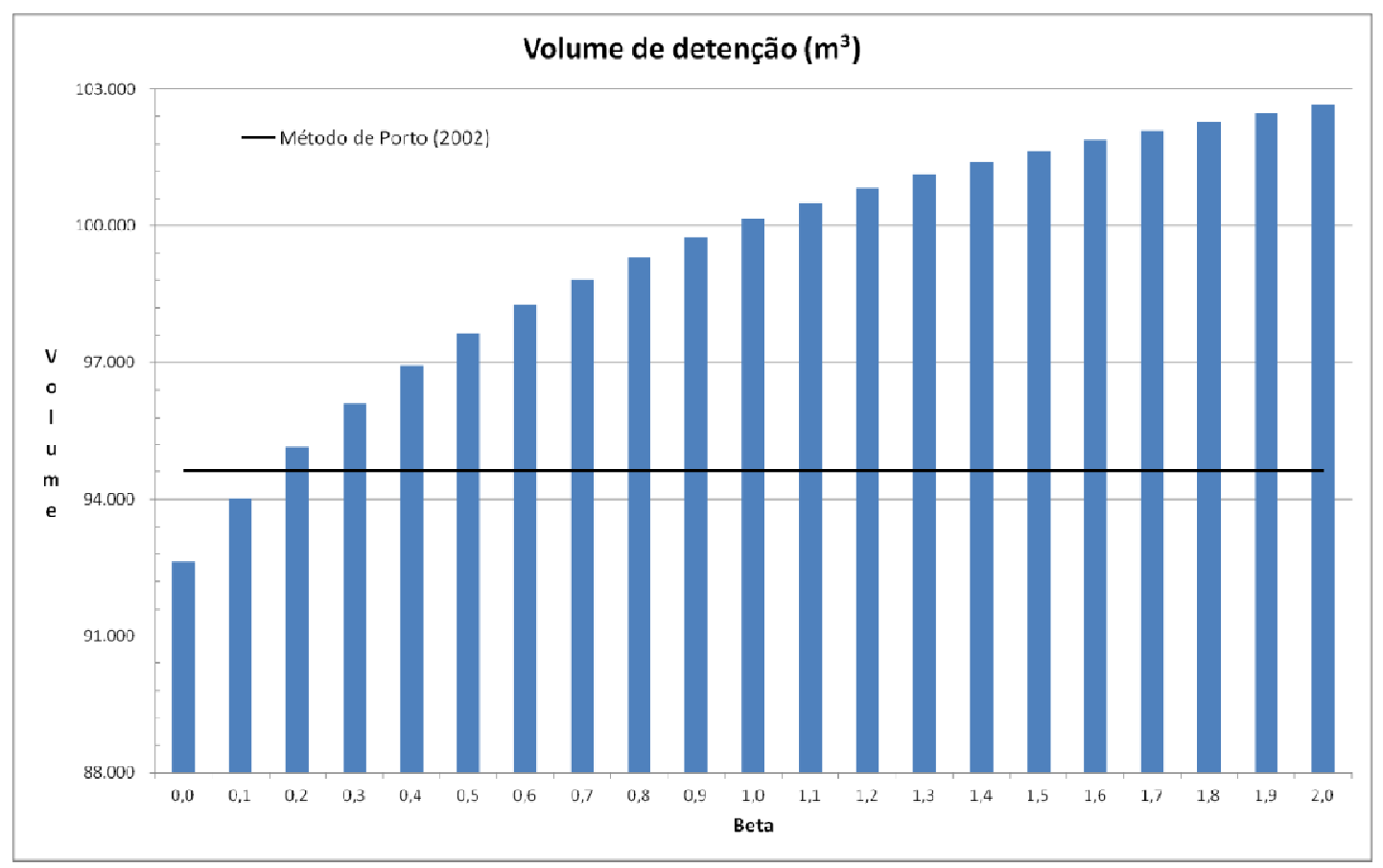

Figura 8.26: comparação entre volumes detido pela metodologia proposta e o método de Porto (2002) para tempo de retorno de 100 anos, duração de precipitação de 90 minutos e CN de 98.

Tabela 8.7: diferenças percentuais entre os processos de cálculo de volume de detenção, para tempo de concentração de 26 minutos, tempo de duração da chuva de 30 minutos e $\mathrm{CN}=85$.

\begin{tabular}{|c|c|c|c|c|c|}
\hline \multirow{5}{*}{ Vutor } & \multicolumn{4}{|c|}{ Tempo de Recorrência } \\
\cline { 2 - 6 } & 10 & 20 & 25 & 50 & 100 \\
\hline Volume Porto (2002) & 11.445 & 15.837 & 17.235 & 22.702 & 29.152 \\
\hline Mét. Proposto (valor médio) & $16,68 \%$ & $11,57 \%$ & $10,49 \%$ & $7,54 \%$ & $5,49 \%$ \\
\hline Mét. Proposto (melhor aj.) & $1,20 \%$ & $0,39 \%$ & $4,27 \%$ & $2,83 \%$ & $2,76 \%$ \\
\hline Mét. Proposto (pior aj.) & $26,38 \%$ & $18,58 \%$ & $16,93 \%$ & $12,43 \%$ & $9,30 \%$ \\
\hline Método SCS (1986) & $-64,30 \%$ & $-62,42 \%$ & $-57,82 \%$ & $-56,78 \%$ & $-54,18 \%$ \\
\hline Método da FAA & $-0,04 \%$ & $-0,51 \%$ & $-0,61 \%$ & $-0,88 \%$ & $-1,07 \%$ \\
\hline Método de Wycoff e Singh & $0,58 \%$ & $-1,36 \%$ & $-1,79 \%$ & $-3,00 \%$ & $-3,88 \%$ \\
\hline Mét. generalizado & $-21,05 \%$ & $-0,77 \%$ & $-11,71 \%$ & $-6,40 \%$ & $-2,27 \%$ \\
\hline Método Racional & $-1,29 \%$ & $-0,77 \%$ & $-0,64 \%$ & $-0,28 \%$ & $0,01 \%$ \\
\hline Método de Abt \& Grigg & $-32,93 \%$ & $-26,35 \%$ & $-24,80 \%$ & $-20,25 \%$ & $-16,75 \%$ \\
\hline Tsuchiya (1978) & $20,04 \%$ & $14,22 \%$ & $12,99 \%$ & $9,63 \%$ & $7,29 \%$ \\
\hline Maidment (1992) & $-1,02 \%$ & $-1,22 \%$ & $-1,55 \%$ & $-1,60 \%$ & $-1,80 \%$ \\
\hline Tucci (1998) & $-2,77 \%$ & $-2,49 \%$ & $-2,43 \%$ & $-2,26 \%$ & $-2,15 \%$ \\
\hline Tucci (2002) & $16,15 \%$ & $19,75 \%$ & $21,98 \%$ & $29,89 \%$ & $40,38 \%$ \\
\hline Mét. Numérico & $-28,90 \%$ & $-23,13 \%$ & $-21,81 \%$ & $-17,82 \%$ & $-14,79 \%$ \\
\hline Método Holandês & $-17,37 \%$ & $-13,65 \%$ & $-12,67 \%$ & $-8,92 \%$ & $-5,43 \%$ \\
\hline Mét. de Matias (2006) & $-35,09 \%$ & $-26,75 \%$ & $-24,92 \%$ & $-19,77 \%$ & $-16,05 \%$ \\
\hline Mét. De Akan (1989) & $23,25 \%$ & $28,81 \%$ & $31,99 \%$ & $30,25 \%$ & $27,65 \%$ \\
\hline
\end{tabular}




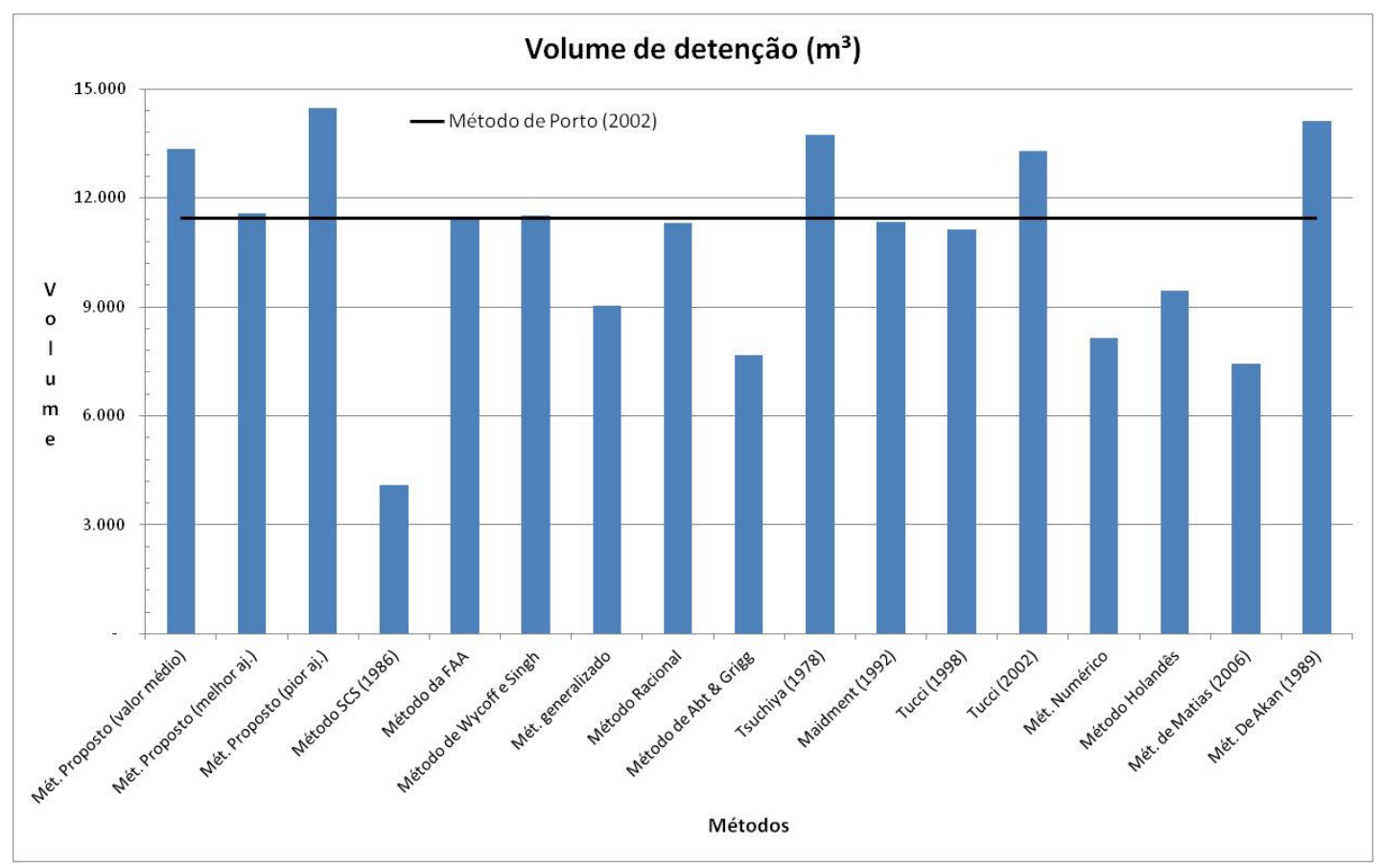

Figura 8.27: comparação gráfica de volumes de detenção para tempo de concentração de 26 minutos, duração da chuva de 30 minutos, $C N$ de 85 e tempo de recorrência de 10 anos.

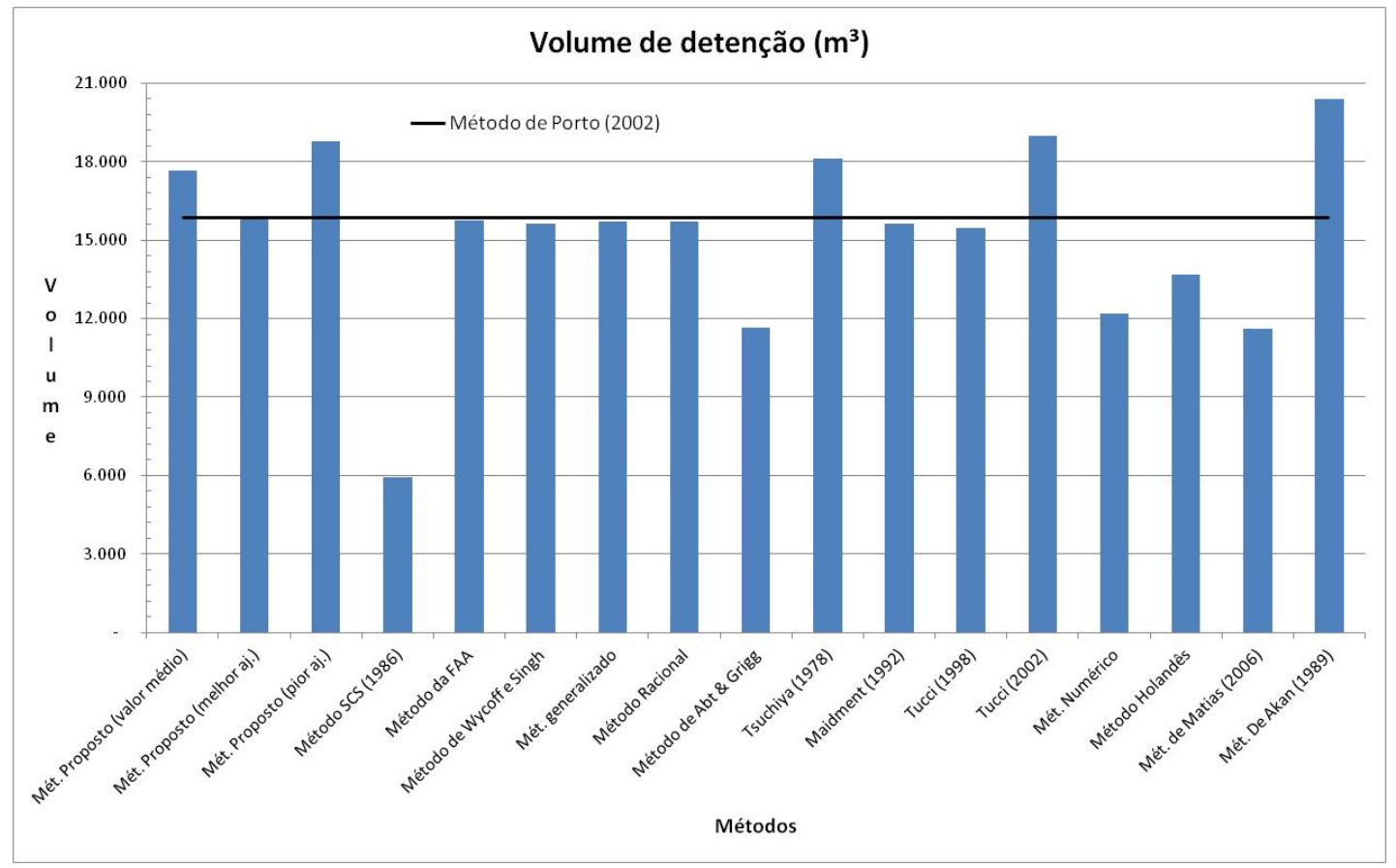

Figura 8.28: comparação gráfica de volumes de detenção para tempo de concentração de 26 minutos, duração da chuva de 30 minutos, $\mathrm{CN}$ de 85 e tempo de recorrência de 20 anos. 


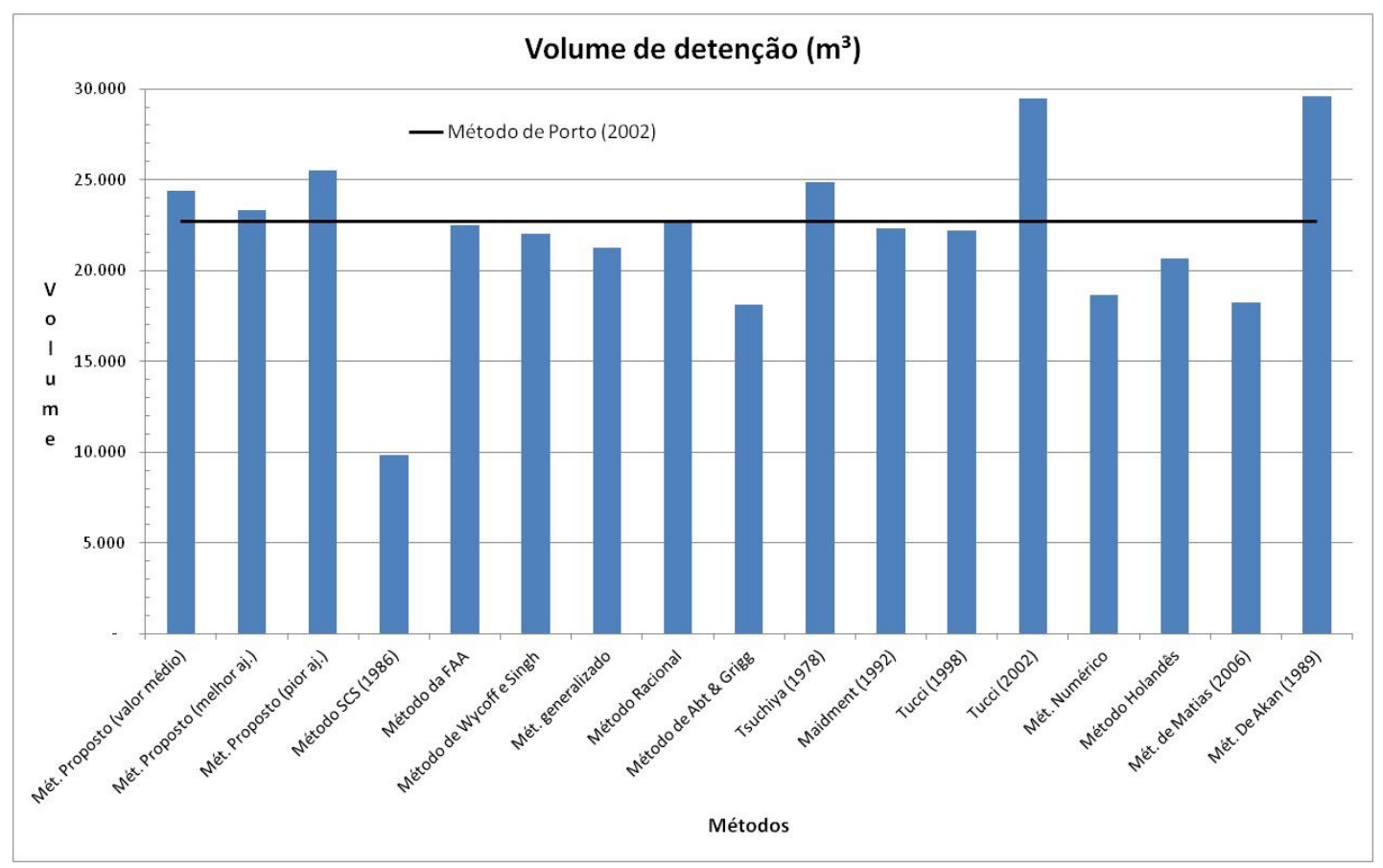

Figura 8.29: comparação gráfica de volumes de detenção para tempo de concentração de 26 minutos, duração da chuva de 30 minutos, $\mathrm{CN}$ de 85 e tempo de recorrência de 50 anos.

Tabela 8.8: diferenças percentuais entre os processos de cálculo de volume de detenção, para tempo de concentração de 26 minutos, tempo de duração da chuva de 60 minutos e $\mathrm{CN}=85$.

\begin{tabular}{|c|c|c|c|c|c|}
\hline \multirow{5}{*}{ Volume de detenção } \\
\cline { 2 - 6 } & \multicolumn{5}{|c|}{ Tempo de Recorrência } \\
\cline { 2 - 6 } & 10 & 20 & 25 & 50 & 100 \\
\hline Volume Porto (2002) & 19.214 & 25.927 & 27.397 & 35.483 & 43.930 \\
\hline Mét. Proposto (valor médio) & $20,20 \%$ & $14,52 \%$ & $16,12 \%$ & $12,60 \%$ & $10,30 \%$ \\
\hline Mét. Proposto (melhor aj.) & $1,77 \%$ & $3,78 \%$ & $-0,13 \%$ & $0,05 \%$ & $0,17 \%$ \\
\hline Mét. Proposto (pior aj.) & $31,76 \%$ & $23,08 \%$ & $24,23 \%$ & $18,86 \%$ & $15,36 \%$ \\
\hline Método SCS (1986) & $-44,83 \%$ & $-44,61 \%$ & $-42,83 \%$ & $-42,81 \%$ & $-39,63 \%$ \\
\hline Método da FAA & $11,68 \%$ & $8,21 \%$ & $10,15 \%$ & $7,99 \%$ & $6,58 \%$ \\
\hline Método de Wycoff e Singh & $-14,57 \%$ & $-16,29 \%$ & $-14,60 \%$ & $-15,77 \%$ & $-16,57 \%$ \\
\hline Mét. generalizado & $-26,38 \%$ & $-18,82 \%$ & $-14,83 \%$ & $-9,05 \%$ & $-4,80 \%$ \\
\hline Método Racional & $-51,27 \%$ & $-50,94 \%$ & $-49,62 \%$ & $-49,38 \%$ & $-49,19 \%$ \\
\hline Método de Abt \& Grigg & $-36,86 \%$ & $-30,29 \%$ & $-26,87 \%$ & $-21,95 \%$ & $-18,39 \%$ \\
\hline Tsuchiya (1978) & $24,06 \%$ & $17,58 \%$ & $19,08 \%$ & $15,07 \%$ & $12,45 \%$ \\
\hline Maidment (1992) & $0,16 \%$ & $-0,72 \%$ & $1,70 \%$ & $1,46 \%$ & $1,08 \%$ \\
\hline Tucci (1998) & $-2,97 \%$ & $-2,65 \%$ & $-0,13 \%$ & $0,05 \%$ & $0,17 \%$ \\
\hline Tucci (2002) & $-7,75 \%$ & $-5,34 \%$ & $-1,34 \%$ & $4,41 \%$ & $12,66 \%$ \\
\hline Mét. Numérico & $-17,65 \%$ & $-14,61 \%$ & $-11,71 \%$ & $-9,46 \%$ & $-7,86 \%$ \\
\hline Método Holandês & $-22,10 \%$ & $-20,40 \%$ & $-17,95 \%$ & $-16,12 \%$ & $-15,01 \%$ \\
\hline Mét. de Matias (2006) & $-21,77 \%$ & $-17,14 \%$ & $-13,97 \%$ & $-10,93 \%$ & $-8,87 \%$ \\
\hline Mét. De Akan (1989) & $23,70 \%$ & $24,97 \%$ & $29,97 \%$ & $35,15 \%$ & $33,69 \%$ \\
\hline
\end{tabular}




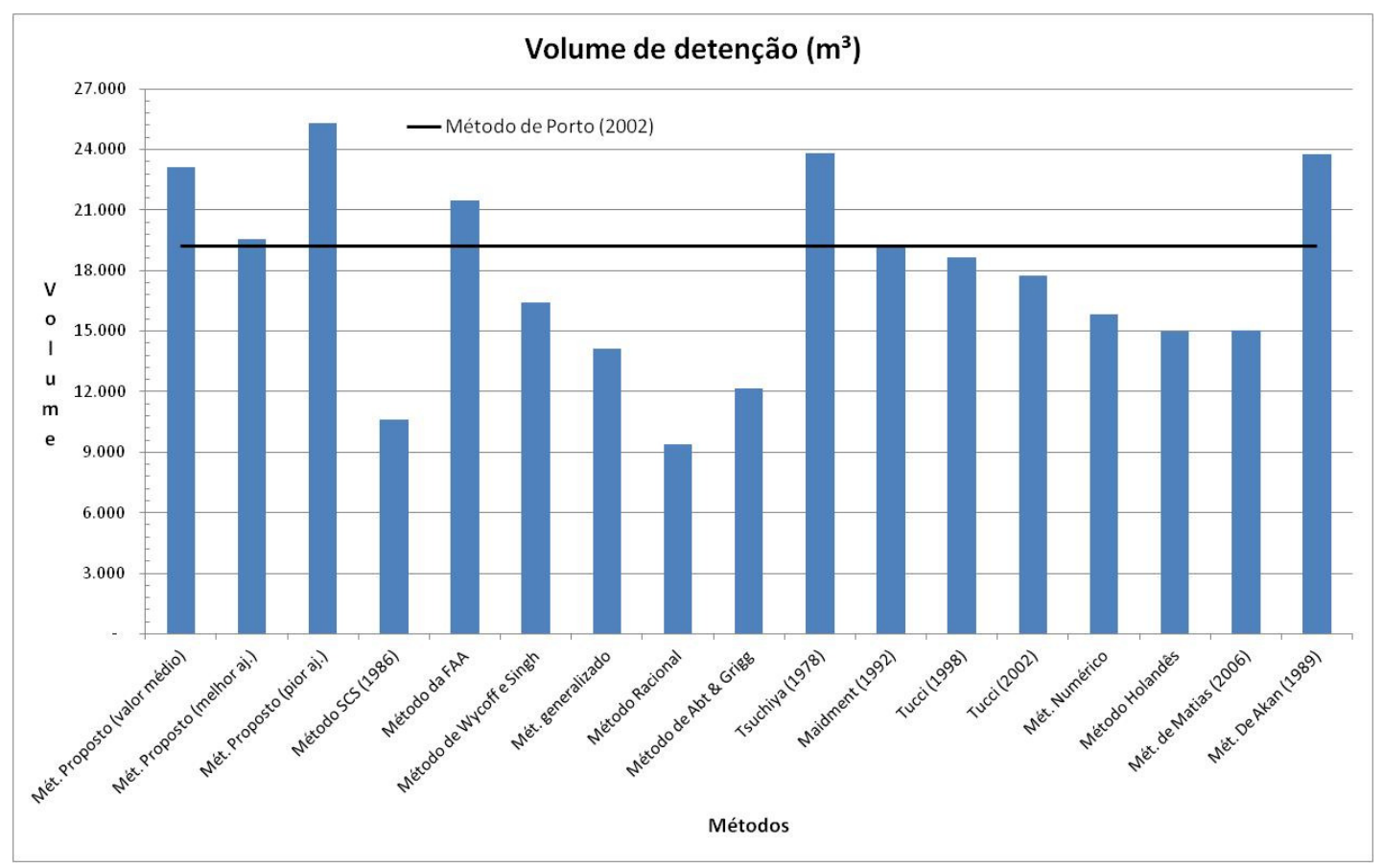

Figura 8.30: comparação gráfica de volumes de detenção para tempo de concentração de 26 minutos, duração da chuva de 60 minutos, $C N$ de 85 e tempo de recorrência de 10 anos.

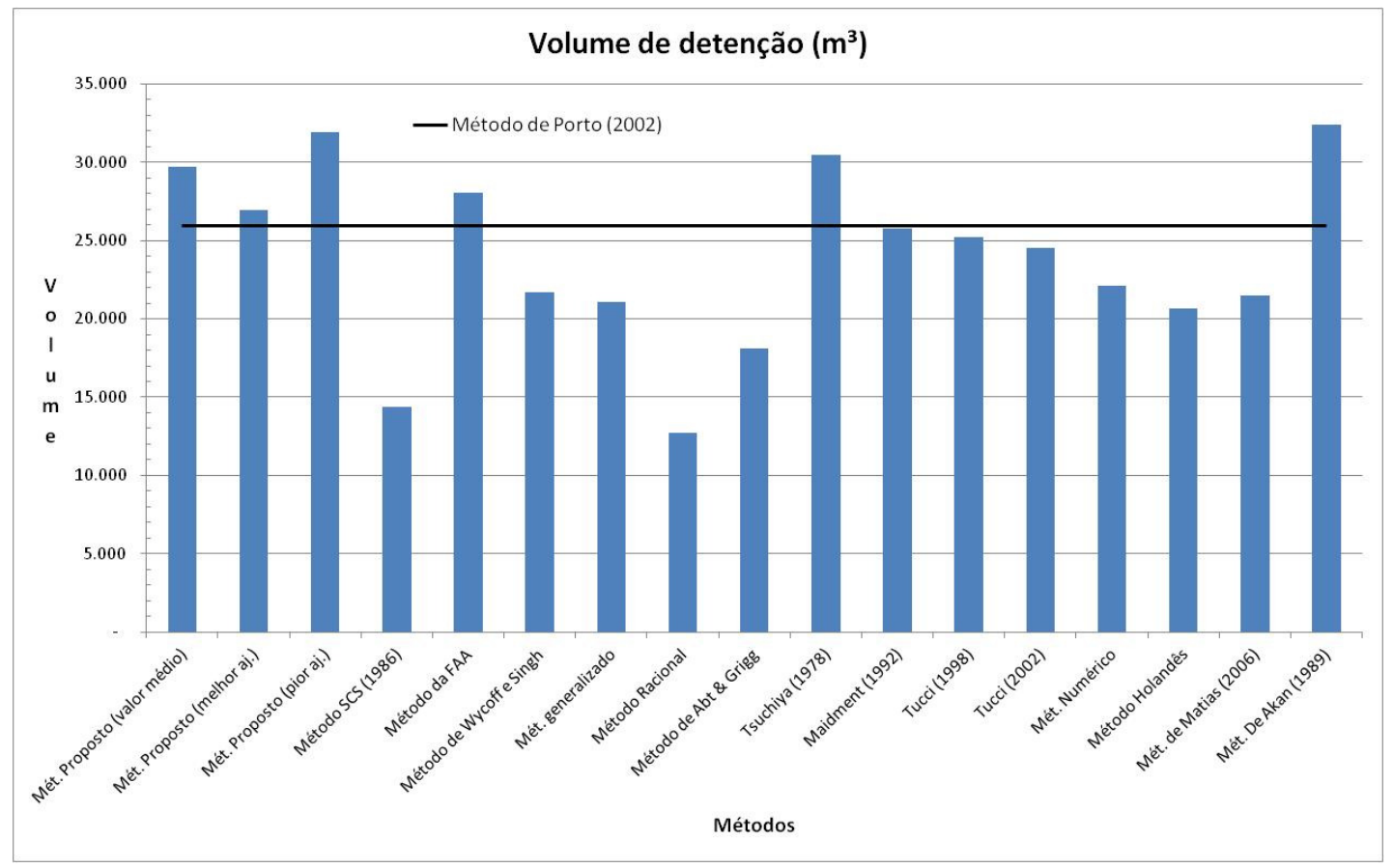

Figura 8.31: comparação gráfica de volumes de detenção para tempo de concentração de 26 minutos, duração da chuva de 60 minutos, $C N$ de 85 e tempo de recorrência de 20 anos. 


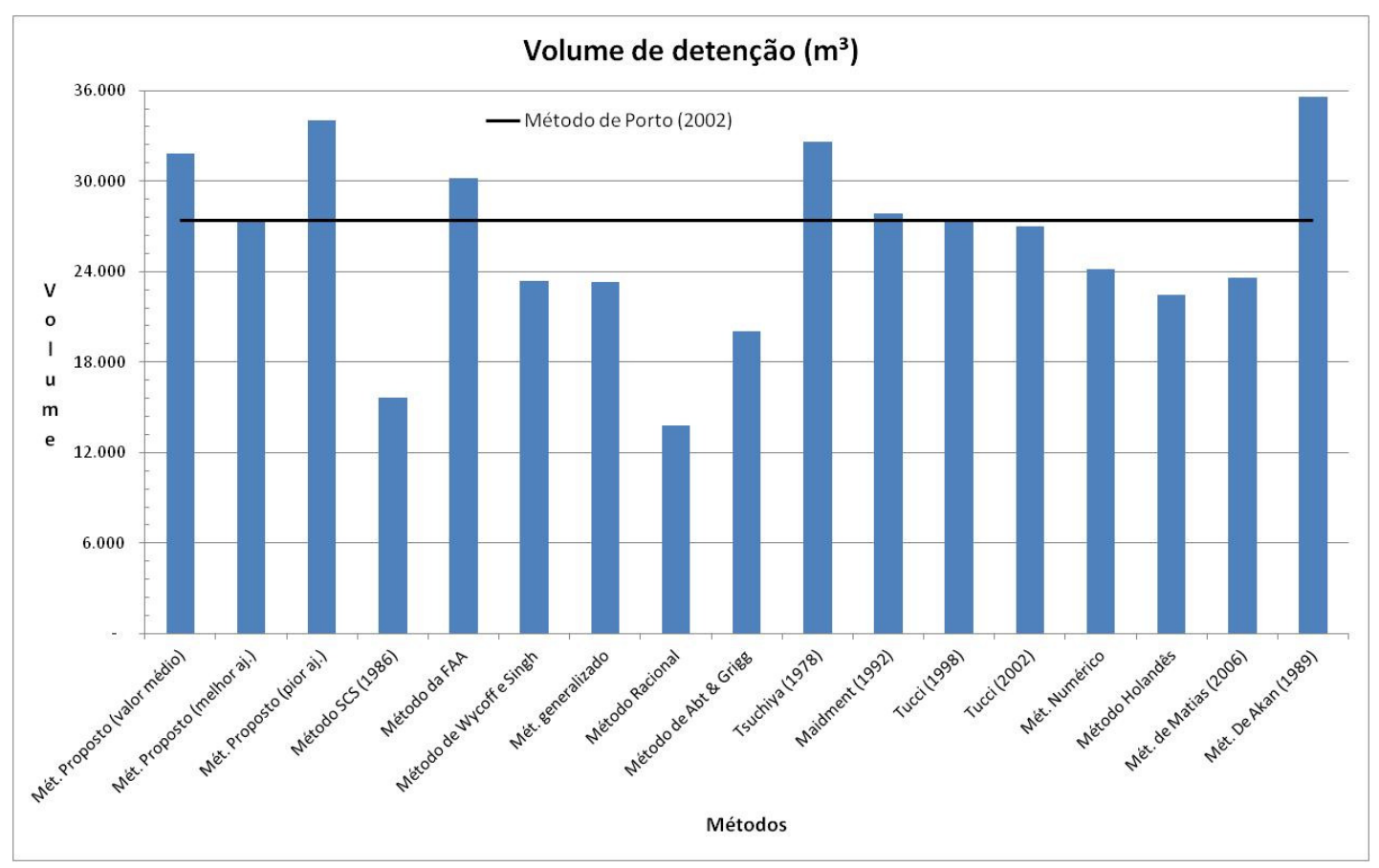

Figura 8.32: comparação gráfica de volumes de detenção para tempo de concentração de 26 minutos, duração da chuva de 60 minutos, CN de 85 e tempo de recorrência de 25 anos.

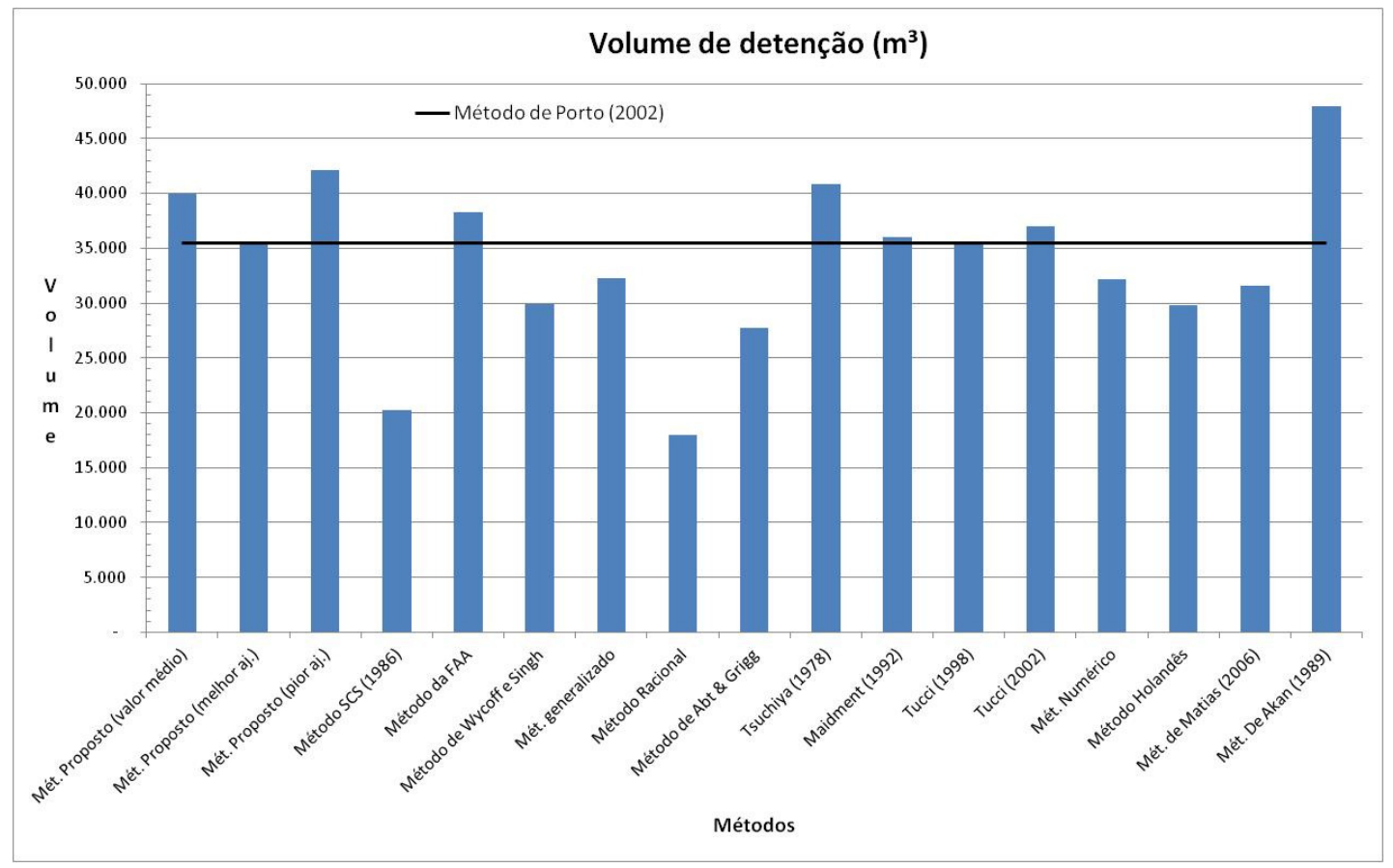

Figura 8.33: comparação gráfica de volumes de detenção para tempo de concentração de 26 minutos, duração da chuva de 60 minutos, $C N$ de 85 e tempo de recorrência de 50 anos. 


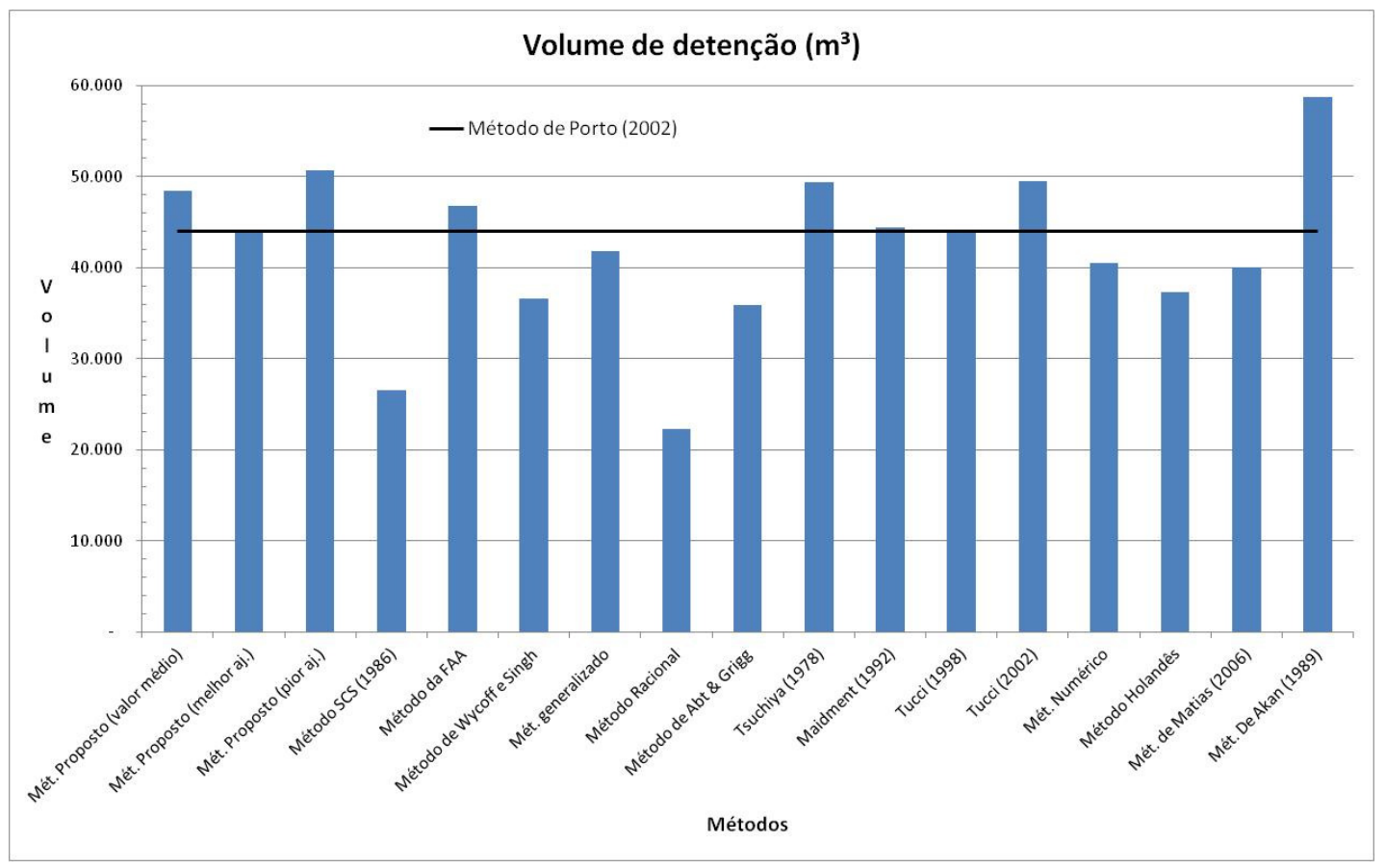

Figura 8.34: comparação gráfica de volumes de detenção para tempo de concentração de 26 minutos, duração da chuva de 60 minutos, $C N$ de 85 e tempo de recorrência de 100 anos.

Tabela 8.9: diferenças percentuais entre os processos de cálculo de volume de detenção, para tempo de concentração de 26 minutos, tempo de duração da chuva de 90 minutos e $\mathrm{CN}=85$.

\begin{tabular}{|c|c|c|c|c|c|}
\hline \multicolumn{5}{|c|}{ Volume de detenção } \\
\hline \multirow{2}{*}{ Autor } & \multicolumn{5}{|c|}{ Tempo de Recorrência } \\
\cline { 2 - 6 } & 10 & 20 & 25 & 50 & 100 \\
\hline Volume Porto (2002) & 25.648 & 30.586 & 32.771 & 42.770 & 53.251 \\
\hline Mét. Proposto (valor médio) & $18,28 \%$ & $18,32 \%$ & $17,55 \%$ & $13,04 \%$ & $10,13 \%$ \\
\hline Mét. Proposto (melhor aj.) & $1,43 \%$ & $1,47 \%$ & $1,35 \%$ & $0,62 \%$ & $2,29 \%$ \\
\hline Mét. Proposto (pior aj.) & $28,85 \%$ & $28,89 \%$ & $27,72 \%$ & $20,83 \%$ & $16,39 \%$ \\
\hline Método SCS (1986) & $-39,64 \%$ & $-34,40 \%$ & $-33,56 \%$ & $-35,04 \%$ & $-34,09 \%$ \\
\hline Método da FAA & $13,97 \%$ & $14,01 \%$ & $13,40 \%$ & $9,86 \%$ & $7,58 \%$ \\
\hline Método de Wycoff e Singh & $-24,95 \%$ & $-24,92 \%$ & $-25,13 \%$ & $-26,38 \%$ & $-27,23 \%$ \\
\hline Mét. generalizado & $-24,33 \%$ & $-24,51 \%$ & $-23,53 \%$ & $-17,02 \%$ & $-12,14 \%$ \\
\hline Método Racional & $-67,55 \%$ & $-67,61 \%$ & $-67,59 \%$ & $-67,38 \%$ & $-67,22 \%$ \\
\hline Método de Abt \& Grigg & $-34,84 \%$ & $-34,82 \%$ & $-33,95 \%$ & $-28,37 \%$ & $-24,28 \%$ \\
\hline Tsuchiya (1978) & $21,88 \%$ & $21,92 \%$ & $21,05 \%$ & $15,90 \%$ & $12,58 \%$ \\
\hline Maidment (1992) & $0,92 \%$ & $0,95 \%$ & $0,39 \%$ & $-0,46 \%$ & $-1,00 \%$ \\
\hline Tucci (1998) & $-2,89 \%$ & $-2,86 \%$ & $-2,82 \%$ & $-2,57 \%$ & $-2,41 \%$ \\
\hline Tucci (2002) & $-22,26 \%$ & $-12,47 \%$ & $-10,19 \%$ & $-6,31 \%$ & $0,08 \%$ \\
\hline Mét. Numérico & $-12,07 \%$ & $-12,12 \%$ & $-11,80 \%$ & $-10,02 \%$ & $-8,72 \%$ \\
\hline Método Holandês & $-20,35 \%$ & $-21,08 \%$ & $-21,42 \%$ & $-21,13 \%$ & $-21,08 \%$ \\
\hline Mét. de Matias (2006) & $-14,50 \%$ & $-14,47 \%$ & $-14,04 \%$ & $-11,45 \%$ & $-9,71 \%$ \\
\hline Mét. De Akan (1989) & $23,30 \%$ & $23,34 \%$ & $23,42 \%$ & $29,25 \%$ & $32,54 \%$ \\
\hline
\end{tabular}




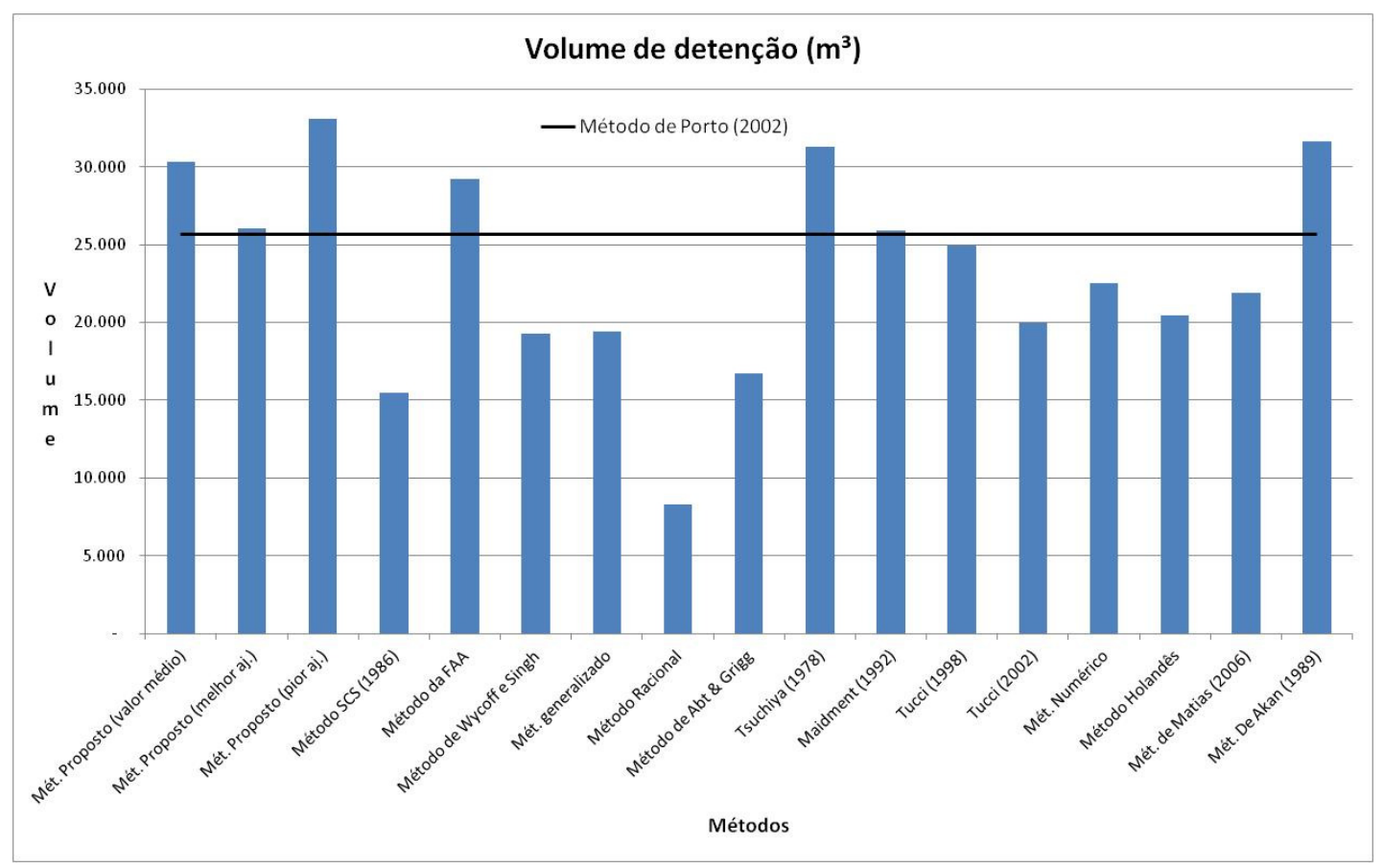

Figura 8.35: comparação gráfica de volumes de detenção para tempo de concentração de 26 minutos, duração da chuva de 90 minutos, CN de 85 e tempo de recorrência de 10 anos.

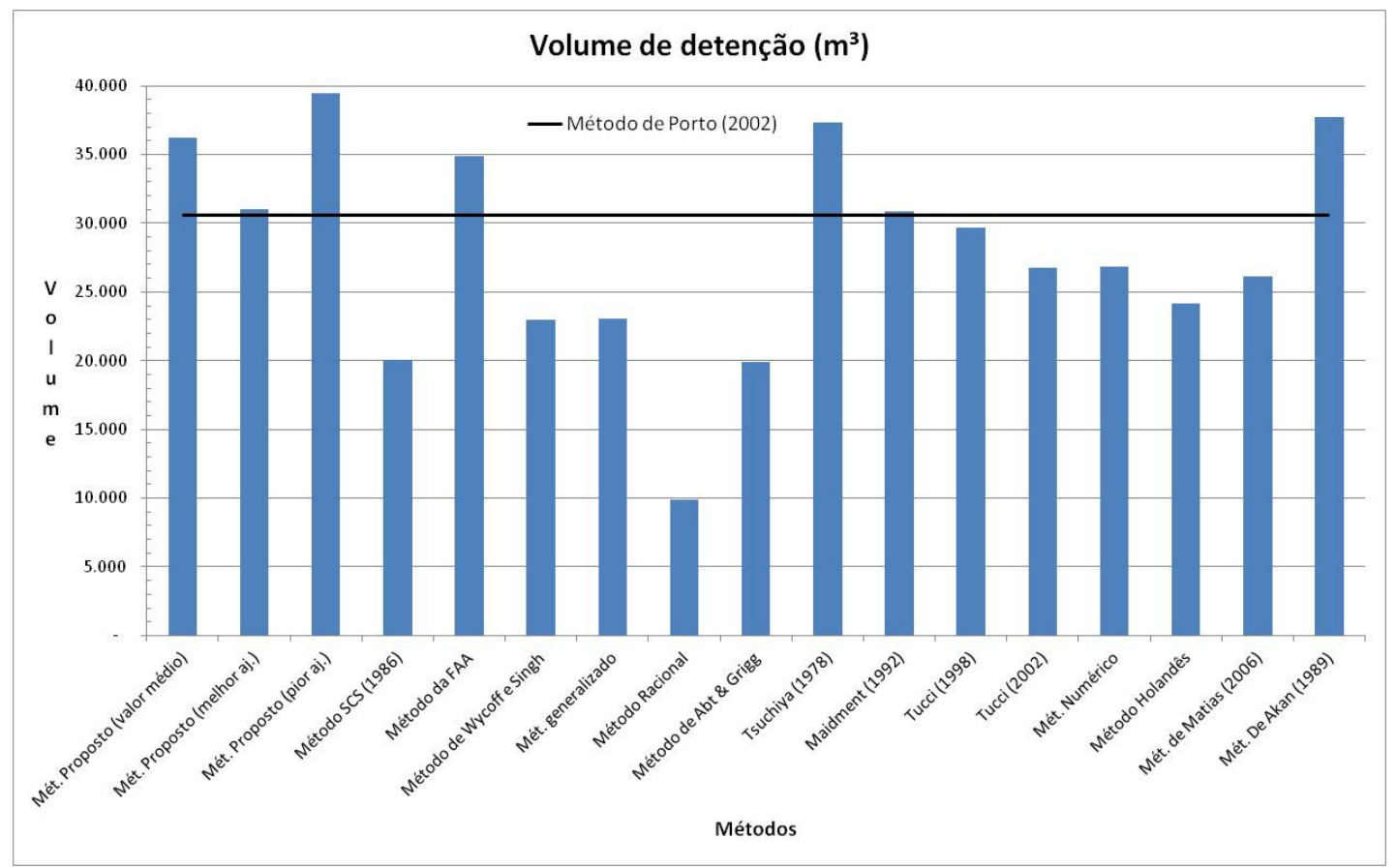

Figura 8.36: comparação gráfica de volumes de detenção para tempo de concentração de 26 minutos, duração da chuva de 90 minutos, CN de 85 e tempo de recorrência de 20 anos. 


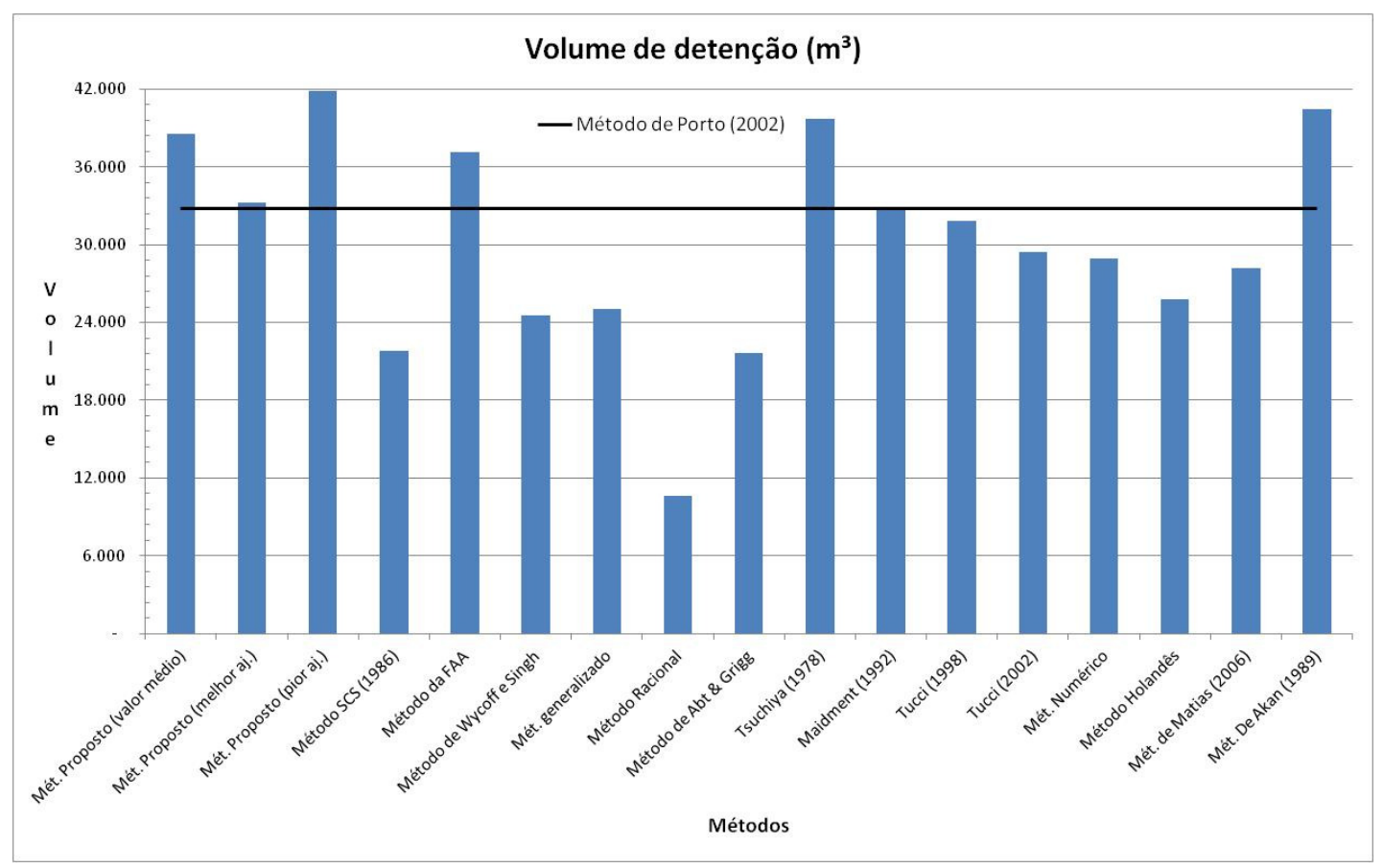

Figura 8.37: comparação gráfica de volumes de detenção para tempo de concentração de 26 minutos, duração da chuva de 90 minutos, CN de 85 e tempo de recorrência de 25 anos.

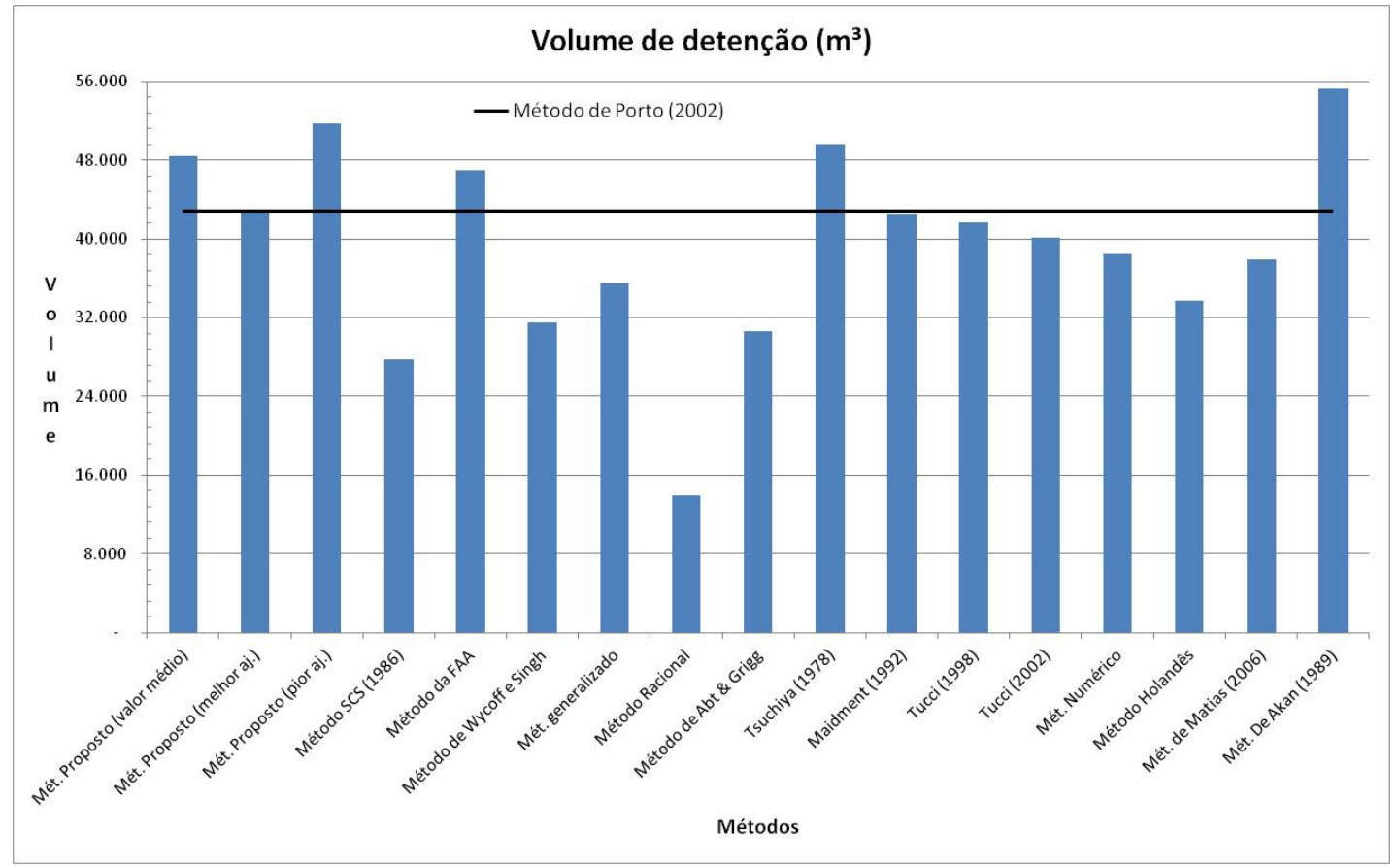

Figura 8.38: comparação gráfica de volumes de detenção para tempo de concentração de 26 minutos, duração da chuva de 90 minutos, $\mathrm{CN}$ de 85 e tempo de recorrência de 50 anos. 


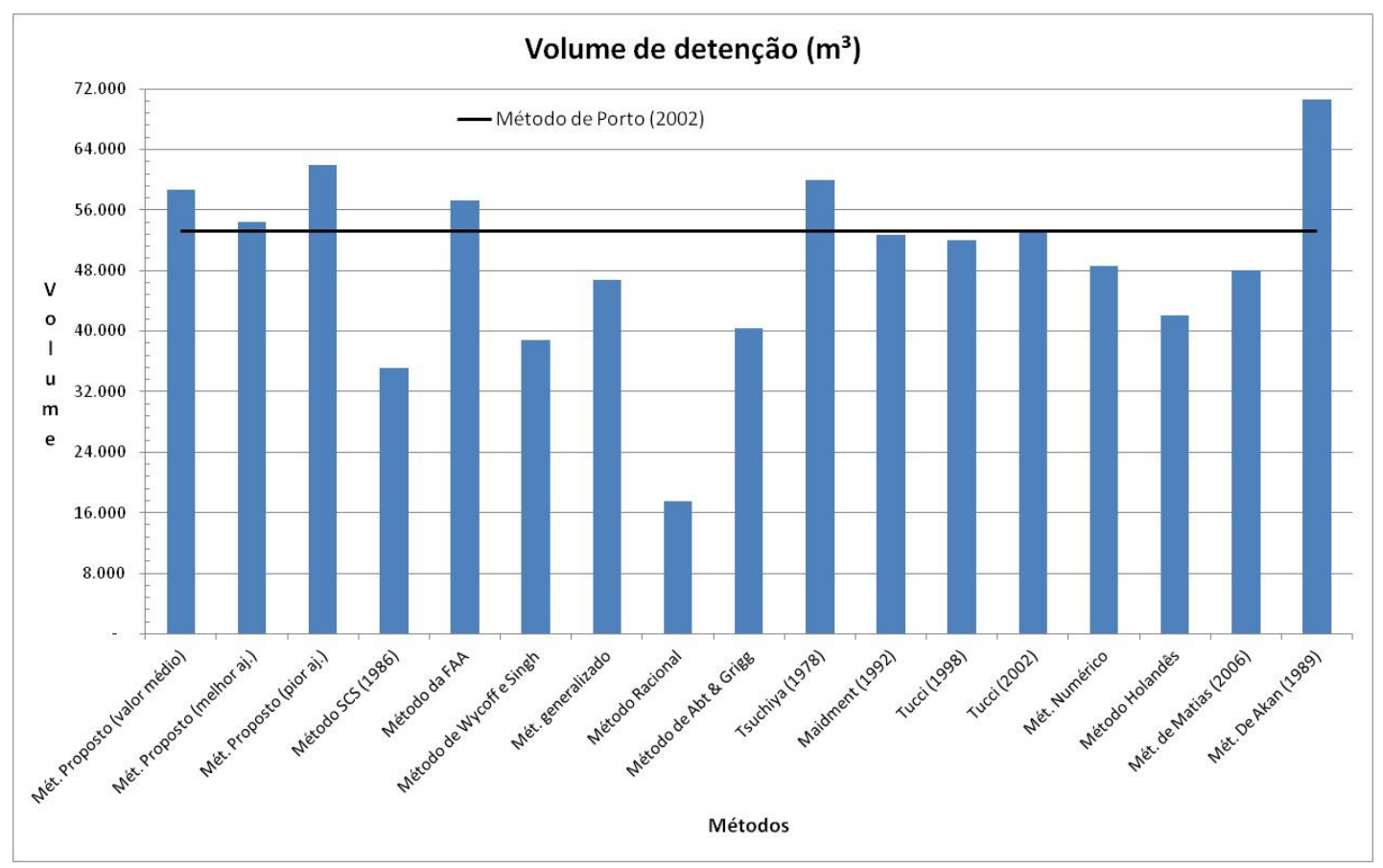

Figura 8.39: comparação gráfica de volumes de detenção para tempo de concentração de 26 minutos, duração da chuva de 90 minutos, CN de 85 e tempo de recorrência de 100 anos.

Tabela 8.10: diferenças percentuais entre os processos de cálculo de volume de detenção, para tempo de concentração de 26 minutos, tempo de duração da chuva de 30 minutos e $\mathrm{CN}=98$.

\begin{tabular}{|c|c|c|c|c|c|}
\hline \multirow{5}{*}{ Autor } & \multicolumn{5}{|c|}{ Tempo de Recorrência } \\
\cline { 2 - 6 } & 10 & 20 & 25 & 50 & 100 \\
\hline Volume Porto (2002) & 38.262 & 44.604 & 47.056 & 53.925 & 62.484 \\
\hline Mét. Proposto (valor médio) & $3,77 \%$ & $2,98 \%$ & $2,74 \%$ & $2,16 \%$ & $1,63 \%$ \\
\hline Mét. Proposto (melhor aj.) & $-0,86 \%$ & $-0,99 \%$ & $0,46 \%$ & $0,18 \%$ & $0,36 \%$ \\
\hline Mét. Proposto (pior aj.) & $6,67 \%$ & $5,47 \%$ & $5,10 \%$ & $4,22 \%$ & $3,41 \%$ \\
\hline Método SCS (1986) & $-50,01 \%$ & $-47,60 \%$ & $-47,05 \%$ & $-45,08 \%$ & $-43,87 \%$ \\
\hline Método da FAA & $-1,23 \%$ & $-1,31 \%$ & $-1,33 \%$ & $-1,38 \%$ & $-1,43 \%$ \\
\hline Método de Wycoff e Singh & $-4,65 \%$ & $-5,00 \%$ & $-5,12 \%$ & $-5,38 \%$ & $-5,63 \%$ \\
\hline Mét. generalizado & $0,60 \%$ & $-0,29 \%$ & $3,17 \%$ & $4,69 \%$ & $6,13 \%$ \\
\hline Método Racional & $-0,56 \%$ & $-0,29 \%$ & $-0,20 \%$ & $0,03 \%$ & $0,23 \%$ \\
\hline Método de Abt \& Grigg & $-13,59 \%$ & $-12,07 \%$ & $-11,59 \%$ & $-10,44 \%$ & $-9,34 \%$ \\
\hline Tsuchiya (1978) & $5,32 \%$ & $4,43 \%$ & $4,15 \%$ & $3,50 \%$ & $2,89 \%$ \\
\hline Maidment (1992) & $-1,53 \%$ & $-1,56 \%$ & $-1,67 \%$ & $-1,68 \%$ & $-1,77 \%$ \\
\hline Tucci (1998) & $-2,05 \%$ & $-2,01 \%$ & $-1,99 \%$ & $-1,96 \%$ & $-1,93 \%$ \\
\hline Tucci (2002) & $-8,51 \%$ & $1,29 \%$ & $4,67 \%$ & $16,37 \%$ & $29,47 \%$ \\
\hline Mét. Numérico & $-12,04 \%$ & $-10,70 \%$ & $-10,27 \%$ & $-9,28 \%$ & $-8,34 \%$ \\
\hline Método Holandês & $15,91 \%$ & $22,53 \%$ & $24,46 \%$ & $27,98 \%$ & $30,91 \%$ \\
\hline Mét. de Matias (2006) & $-12,82 \%$ & $-11,32 \%$ & $-10,84 \%$ & $-9,73 \%$ & $-8,68 \%$ \\
\hline Mét. De Akan (1989) & $23,22 \%$ & $21,20 \%$ & $20,57 \%$ & $19,10 \%$ & $17,72 \%$ \\
\hline
\end{tabular}




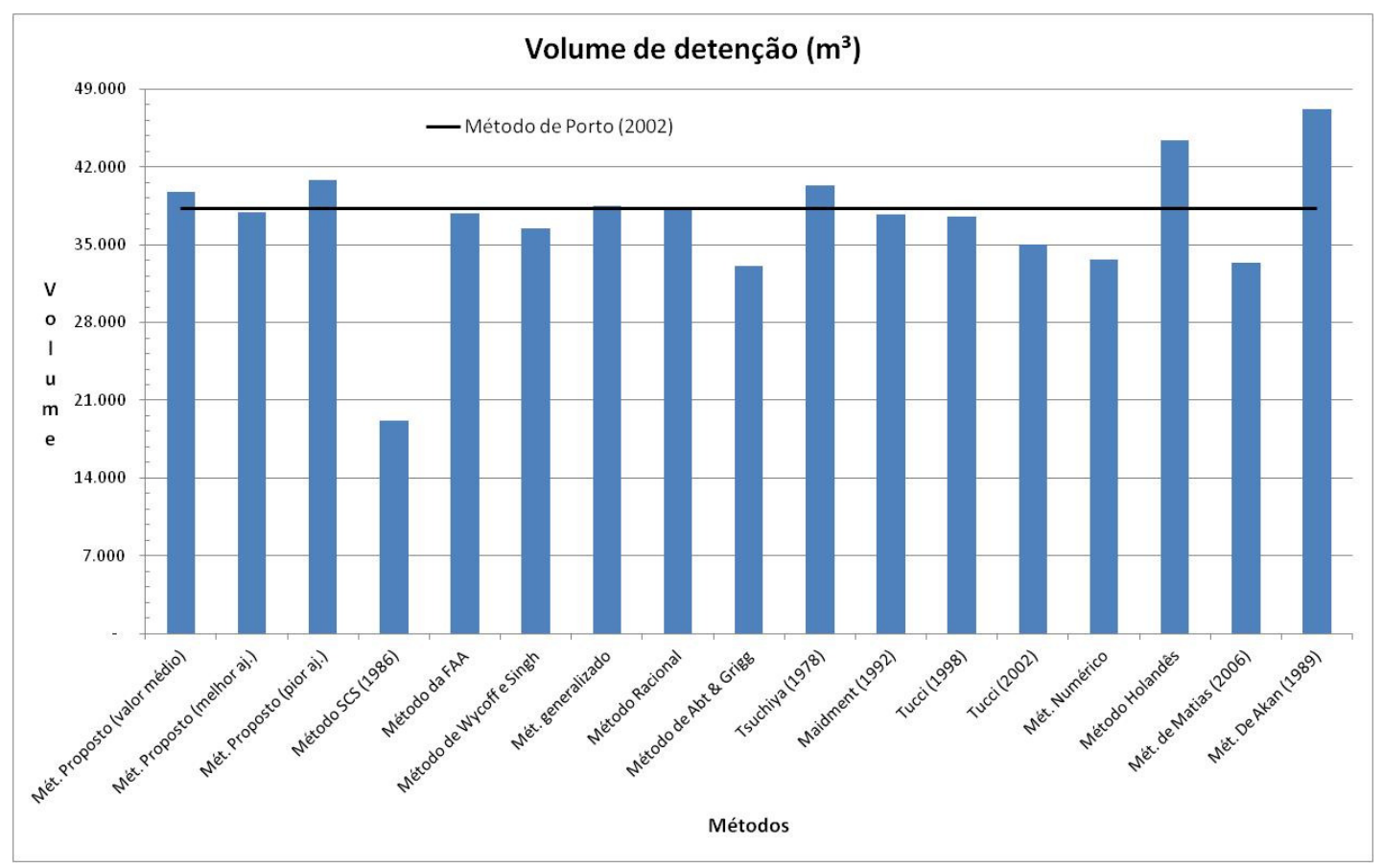

Figura 8.40: comparação gráfica de volumes de detenção para tempo de concentração de 26 minutos, duração da chuva de 30 minutos, CN de 98 e tempo de recorrência de 10 anos.

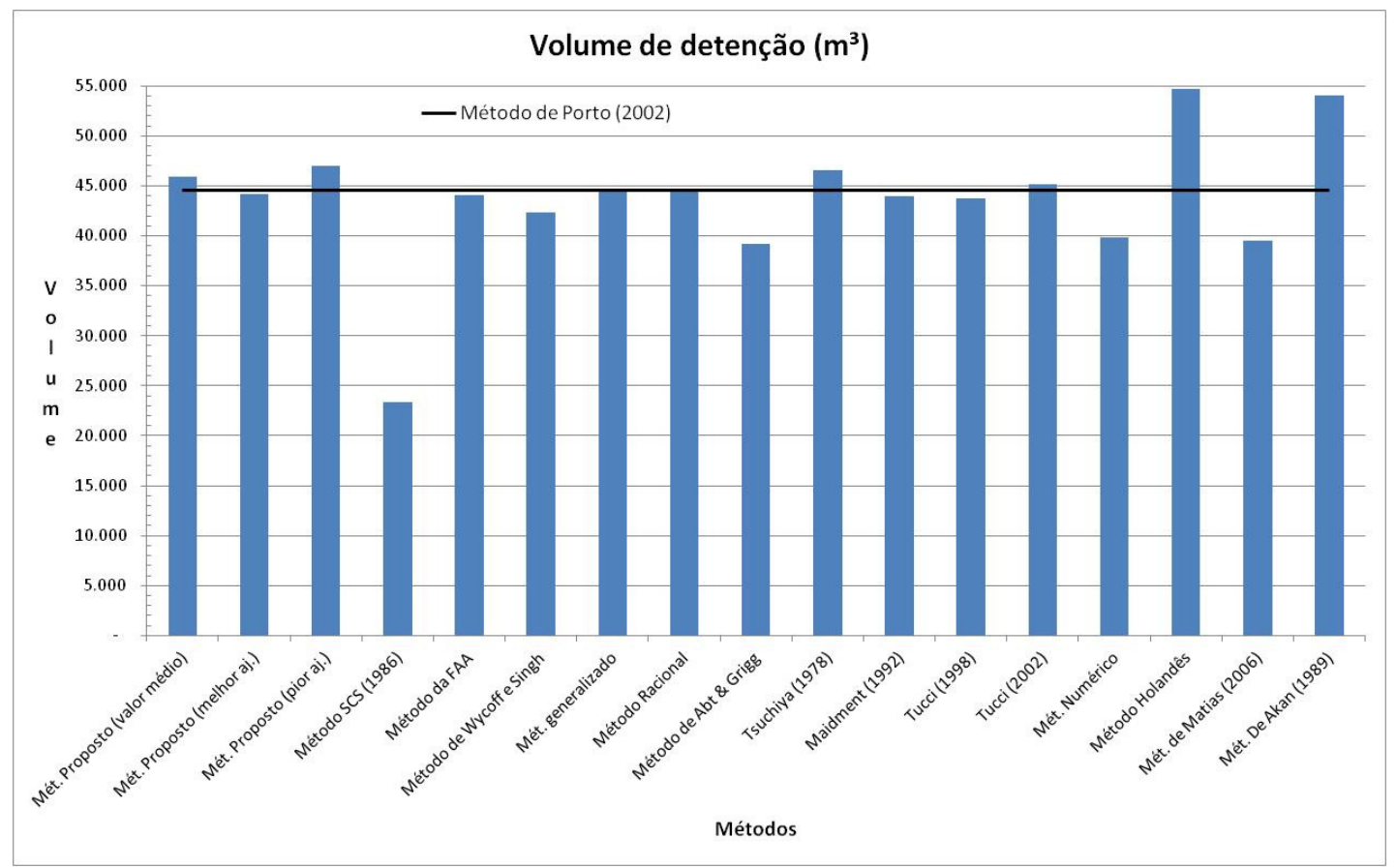

Figura 8.41: comparação gráfica de volumes de detenção para tempo de concentração de 26 minutos, duração da chuva de 30 minutos, $\mathrm{CN}$ de 98 e tempo de recorrência de 20 anos. 


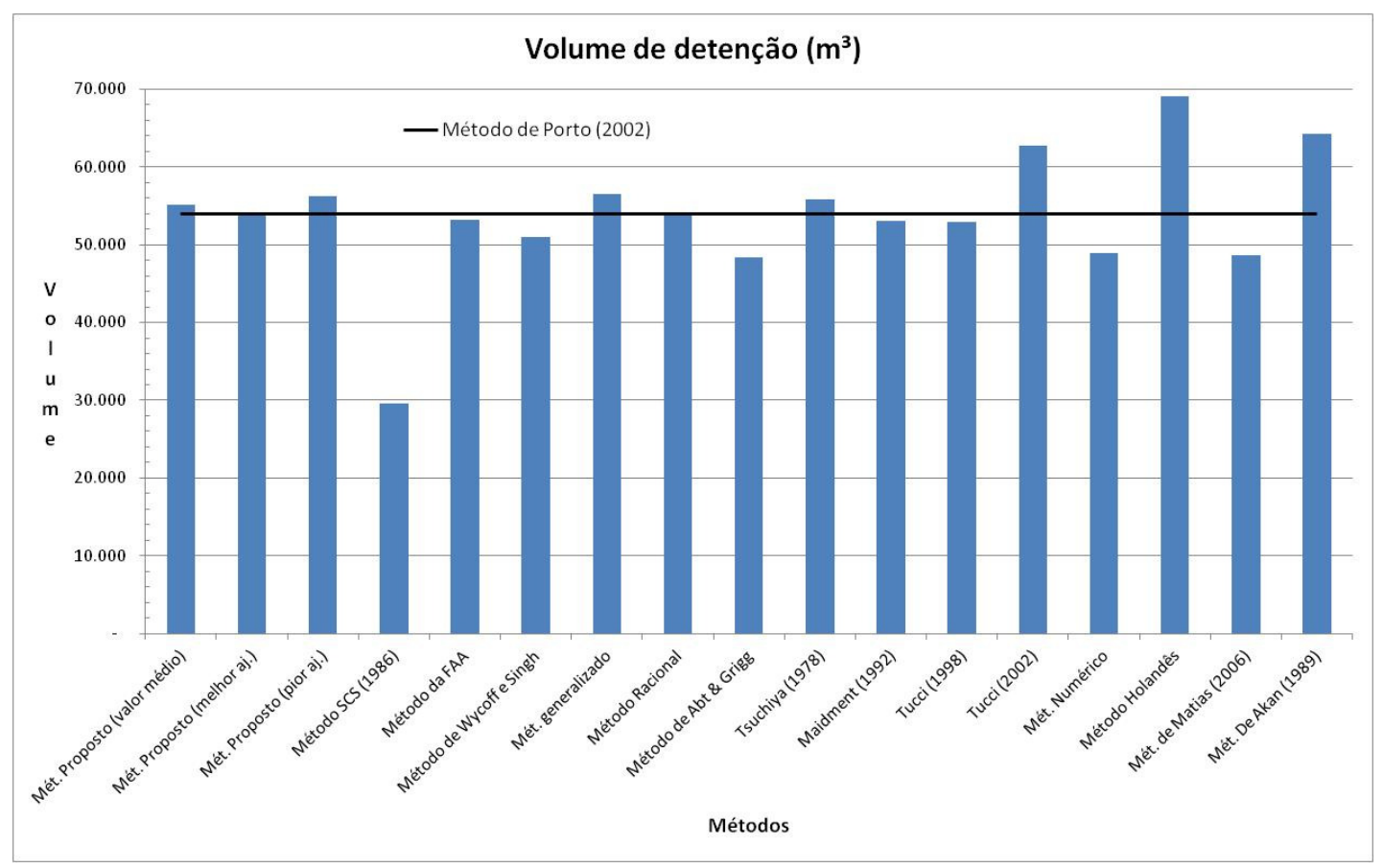

Figura 8.42: comparação gráfica de volumes de detenção para tempo de concentração de 26 minutos, duração da chuva de 30 minutos, $\mathrm{CN}$ de 98 e tempo de recorrência de 50 anos.

Tabela 8.11: diferenças percentuais entre os processos de cálculo de volume de detenção, para tempo de concentração de 26 minutos, tempo de duração da chuva de 60 minutos e $\mathrm{CN}=98$.

\begin{tabular}{|c|c|c|c|c|c|}
\hline \multirow{5}{*}{ Autor } & \multicolumn{5}{|c|}{ Tempo de Recorrência } \\
\cline { 2 - 6 } & 10 & 20 & 25 & 50 & 100 \\
\hline Volume Porto (2002) & 51.290 & 59.355 & 61.223 & 70.544 & 81.078 \\
\hline Mét. Proposto (valor médio) & $6,48 \%$ & $5,36 \%$ & $7,58 \%$ & $6,67 \%$ & $5,89 \%$ \\
\hline Mét. Proposto (melhor aj.) & $-0,43 \%$ & $0,67 \%$ & $0,31 \%$ & $0,36 \%$ & $0,40 \%$ \\
\hline Mét. Proposto (pior aj.) & $10,81 \%$ & $9,10 \%$ & $11,21 \%$ & $9,81 \%$ & $8,62 \%$ \\
\hline Método SCS (1986) & $-40,40 \%$ & $-39,04 \%$ & $-38,39 \%$ & $-36,95 \%$ & $-36,63 \%$ \\
\hline Método da FAA & $3,29 \%$ & $2,60 \%$ & $4,91 \%$ & $4,35 \%$ & $3,87 \%$ \\
\hline Método de Wycoff e Singh & $-19,01 \%$ & $-19,42 \%$ & $-17,56 \%$ & $-17,90 \%$ & $-18,20 \%$ \\
\hline Mét. generalizado & $-5,98 \%$ & $-3,46 \%$ & $-0,17 \%$ & $2,02 \%$ & $3,97 \%$ \\
\hline Método Racional & $-50,88 \%$ & $-50,68 \%$ & $-49,40 \%$ & $-49,23 \%$ & $-49,07 \%$ \\
\hline Método de Abt \& Grigg & $-18,47 \%$ & $-16,52 \%$ & $-13,75 \%$ & $-12,07 \%$ & $-10,60 \%$ \\
\hline Tsuchiya (1978) & $8,41 \%$ & $7,14 \%$ & $9,35 \%$ & $8,31 \%$ & $7,42 \%$ \\
\hline Maidment (1992) & $-1,03 \%$ & $-1,30 \%$ & $1,13 \%$ & $1,07 \%$ & $0,89 \%$ \\
\hline Tucci (1998) & $-2,20 \%$ & $-2,14 \%$ & $0,31 \%$ & $0,36 \%$ & $0,40 \%$ \\
\hline Tucci (2002) & $-27,43 \%$ & $-20,12 \%$ & $-15,63 \%$ & $-6,75 \%$ & $3,30 \%$ \\
\hline Mét. Numérico & $-9,23 \%$ & $-8,36 \%$ & $-5,76 \%$ & $-5,02 \%$ & $-4,36 \%$ \\
\hline Método Holandês & $-4,64 \%$ & $-0,56 \%$ & $3,22 \%$ & $5,46 \%$ & $6,63 \%$ \\
\hline Mét. de Matias (2006) & $-10,03 \%$ & $-8,97 \%$ & $-6,34 \%$ & $-5,47 \%$ & $-4,71 \%$ \\
\hline Mét. De Akan (1989) & $28,87 \%$ & $27,32 \%$ & $29,46 \%$ & $27,12 \%$ & $25,12 \%$ \\
\hline
\end{tabular}




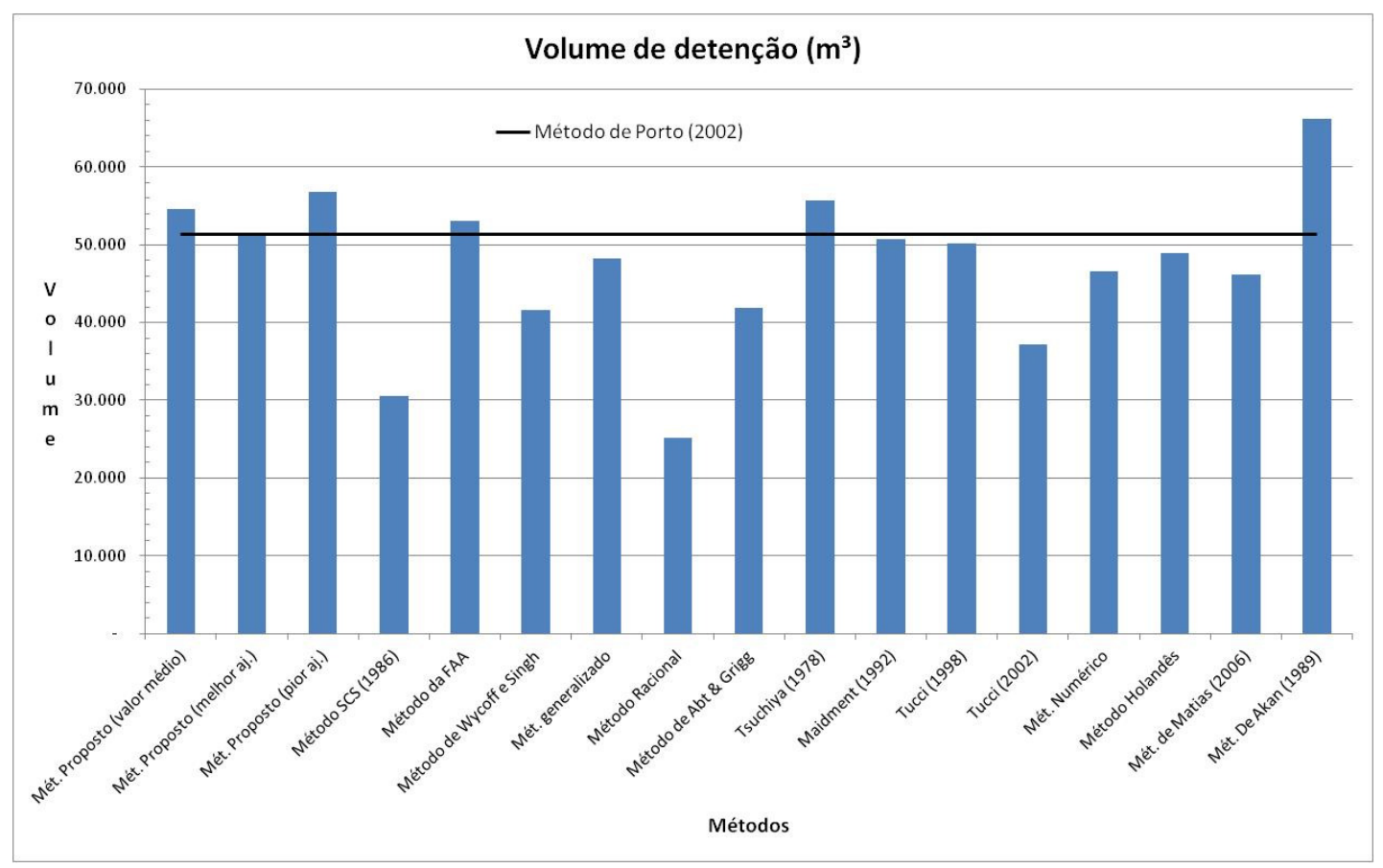

Figura 8.43: comparação gráfica de volumes de detenção para tempo de concentração de 26 minutos, duração da chuva de 60 minutos, $\mathrm{CN}$ de 98 e tempo de recorrência de 10 anos.

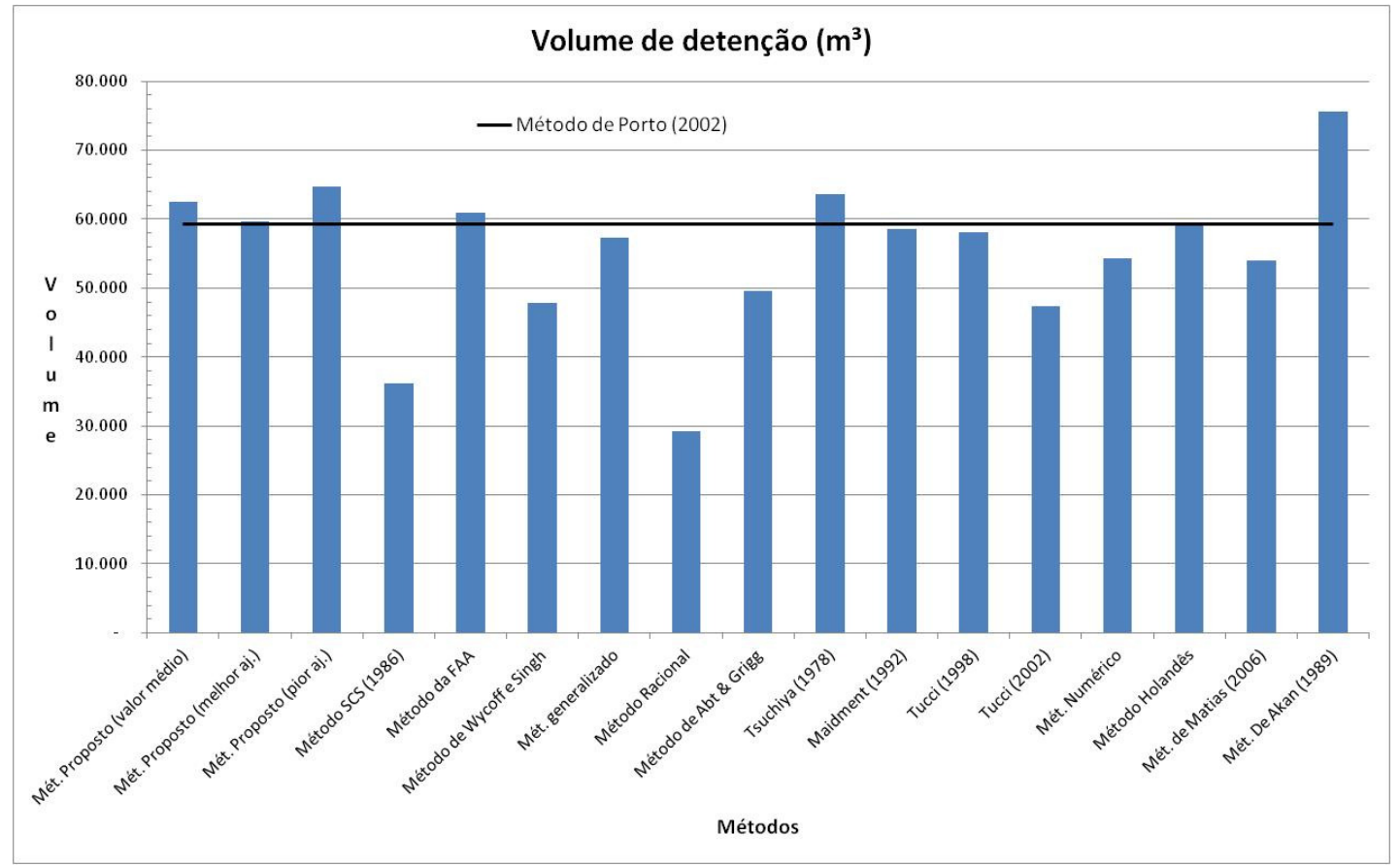

Figura 8.44: comparação gráfica de volumes de detenção para tempo de concentração de 26 minutos, duração da chuva de 60 minutos, $\mathrm{CN}$ de 98 e tempo de recorrência de 20 anos. 


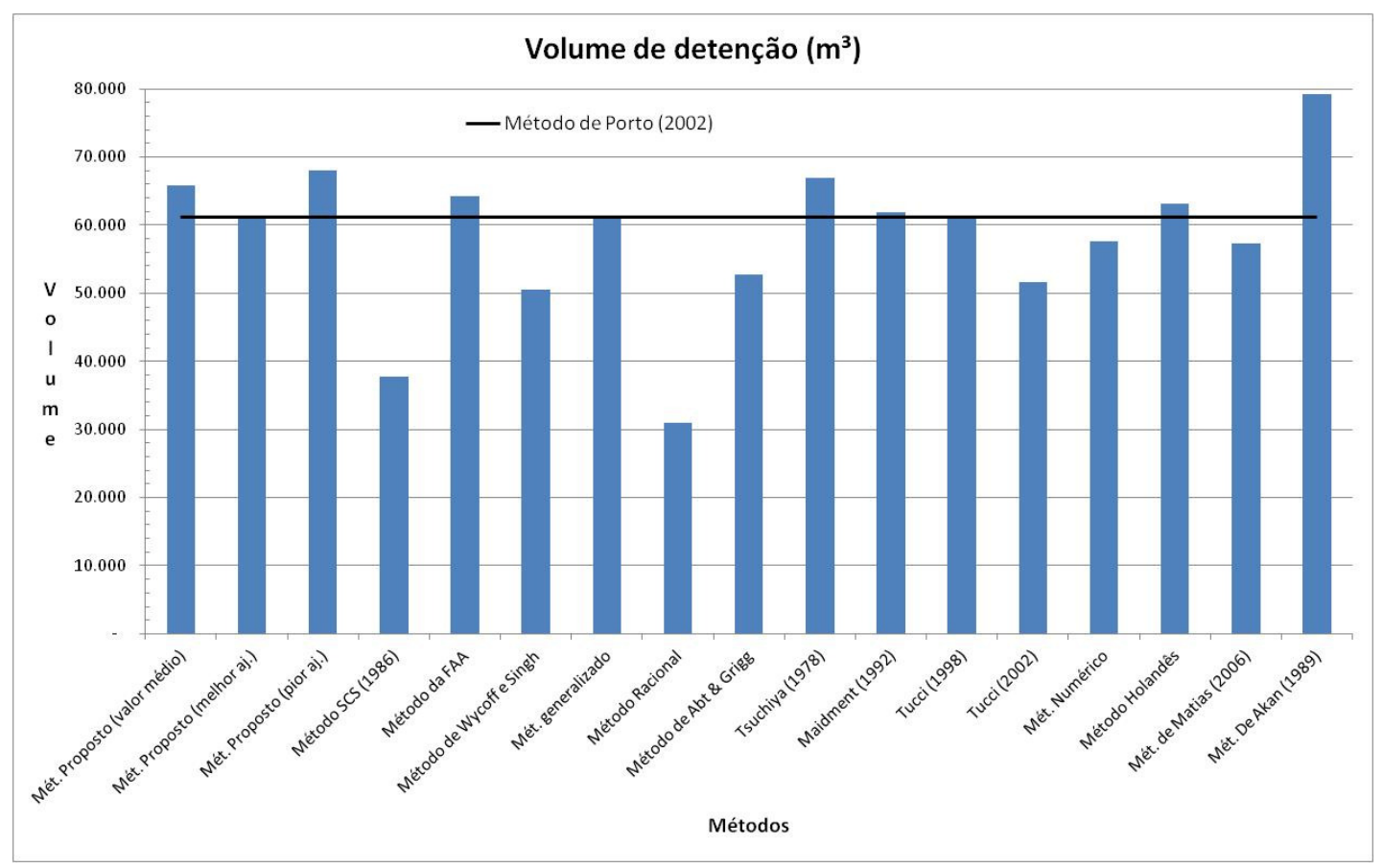

Figura 8.45: comparação gráfica de volumes de detenção para tempo de concentração de 26 minutos, duração da chuva de 60 minutos, CN de 98 e tempo de recorrência de 25 anos.

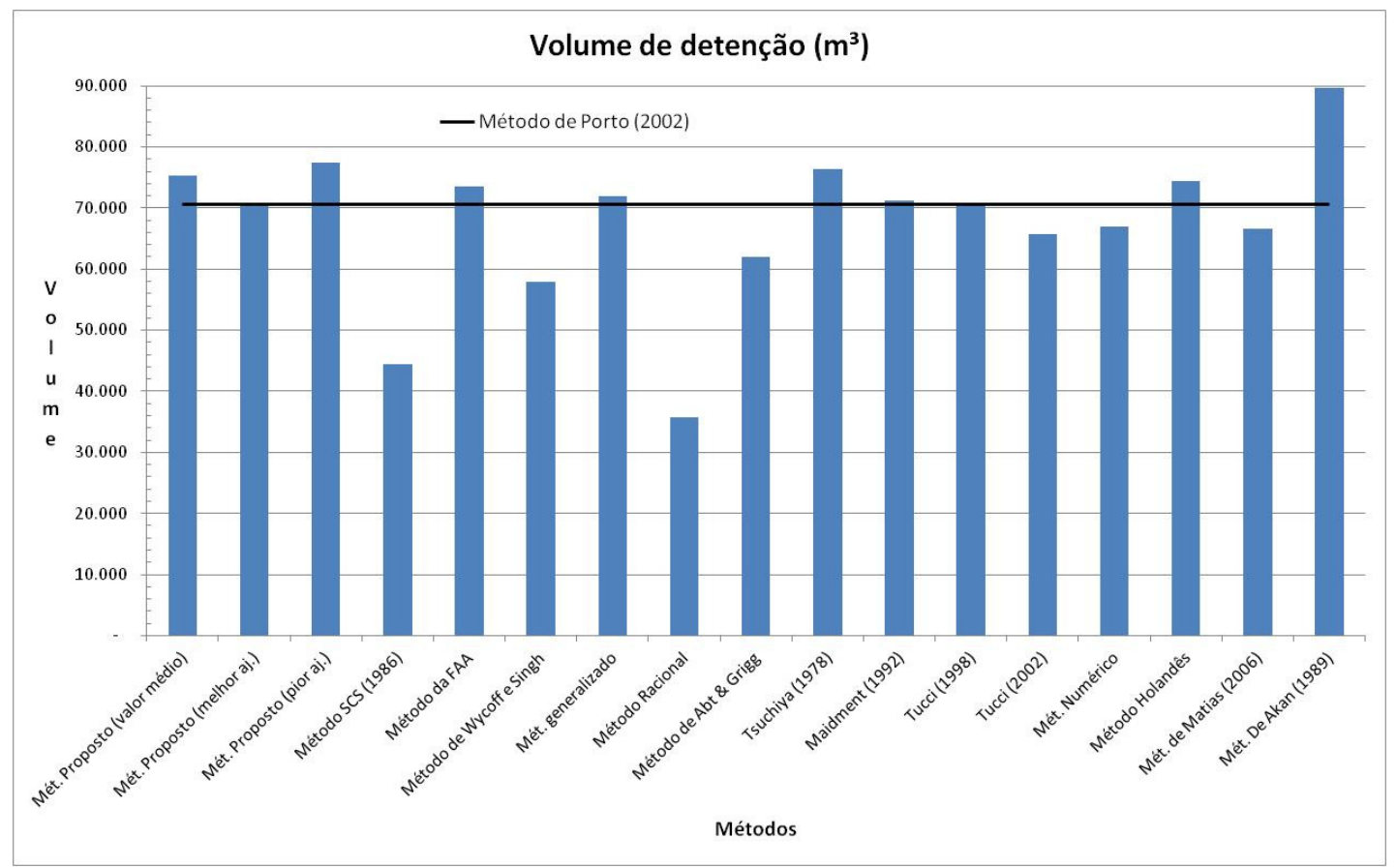

Figura 8.46: comparação gráfica de volumes de detenção para tempo de concentração de 26 minutos, duração da chuva de 60 minutos, $\mathrm{CN}$ de 98 e tempo de recorrência de 50 anos. 


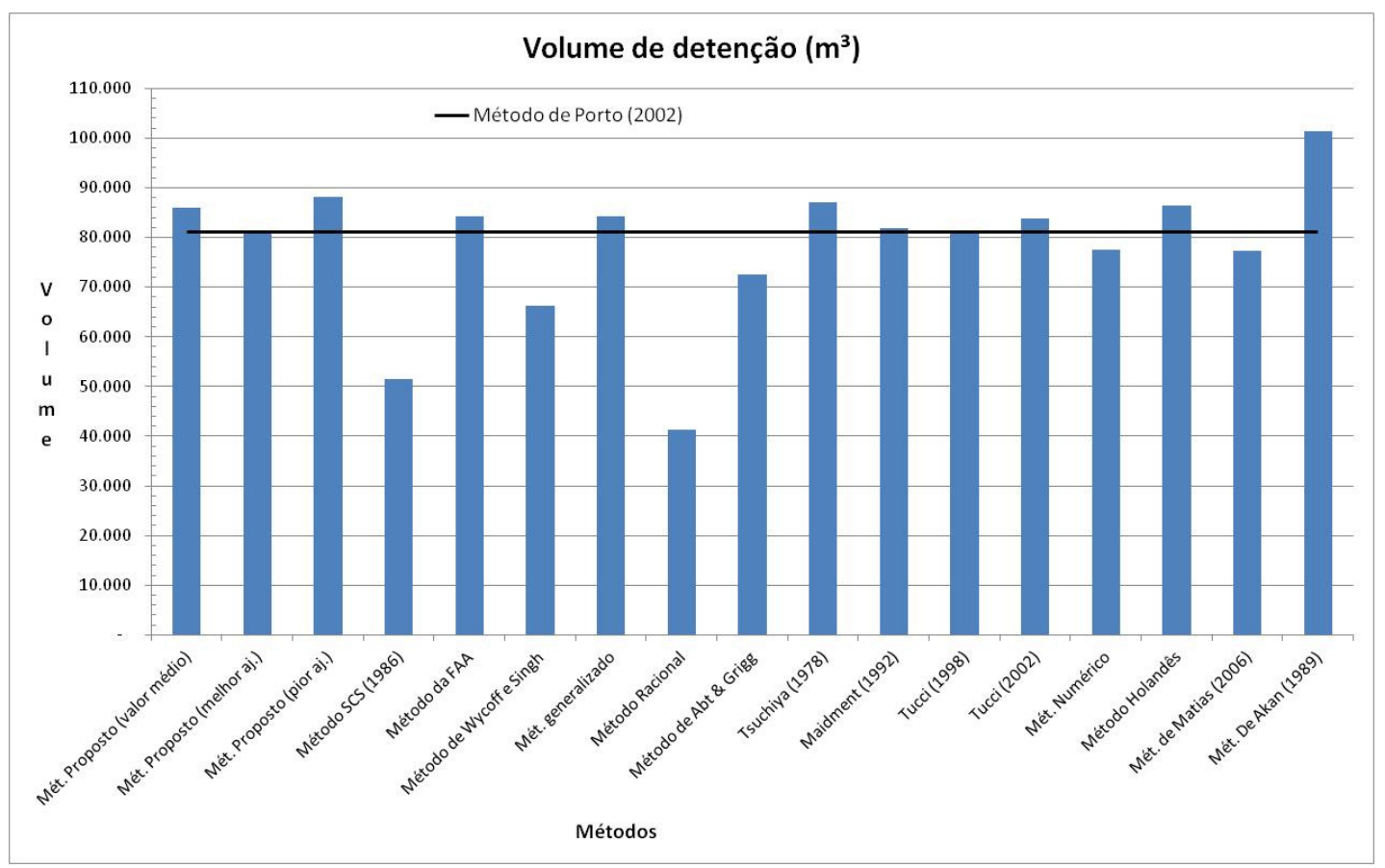

Figura 8.47: comparação gráfica de volumes de detenção para tempo de concentração de 26 minutos, duração da chuva de 60 minutos, CN de 98 e tempo de recorrência de 100 anos.

Tabela 8.12: diferenças percentuais entre os processos de cálculo de volume de detenção, para tempo de concentração de 26 minutos, tempo de duração da chuva de 90 minutos e $\mathbf{C N = 9 8 . ~}$

\begin{tabular}{|c|c|c|c|c|c|}
\hline \multirow{5}{*}{ Autor } & \multicolumn{5}{|c|}{ Tempo de Recorrência } \\
\cline { 2 - 6 } & 10 & 20 & 25 & 50 & 100 \\
\hline Volume Porto (2002) & 57.276 & 66.761 & 69.756 & 81.957 & 94.641 \\
\hline Mét. Proposto (valor médio) & $9,30 \%$ & $7,73 \%$ & $7,32 \%$ & $5,97 \%$ & $4,94 \%$ \\
\hline Mét. Proposto (melhor aj.) & $0,02 \%$ & $-0,23 \%$ & $-0,29 \%$ & $-0,51 \%$ & $0,53 \%$ \\
\hline Mét. Proposto (pior aj.) & $15,11 \%$ & $12,72 \%$ & $12,10 \%$ & $10,04 \%$ & $8,46 \%$ \\
\hline Método SCS (1986) & $-34,66 \%$ & $-33,89 \%$ & $-34,09 \%$ & $-35,23 \%$ & $-35,34 \%$ \\
\hline Método da FAA & $6,92 \%$ & $5,69 \%$ & $5,37 \%$ & $4,31 \%$ & $3,50 \%$ \\
\hline Método de Wycoff e Singh & $-27,48 \%$ & $-27,96 \%$ & $-28,09 \%$ & $-28,52 \%$ & $-28,86 \%$ \\
\hline Mét. generalizado & $-11,98 \%$ & $-8,82 \%$ & $-7,95 \%$ & $-5,02 \%$ & $-2,62 \%$ \\
\hline Método Racional & $-67,62 \%$ & $-67,45 \%$ & $-67,40 \%$ & $-67,25 \%$ & $-67,12 \%$ \\
\hline Método de Abt \& Grigg & $-23,02 \%$ & $-20,55 \%$ & $-19,89 \%$ & $-17,60 \%$ & $-15,77 \%$ \\
\hline Tsuchiya (1978) & $11,63 \%$ & $9,84 \%$ & $9,38 \%$ & $7,84 \%$ & $6,66 \%$ \\
\hline Maidment (1992) & $-0,26 \%$ & $-0,47 \%$ & $-0,74 \%$ & $-1,08 \%$ & $-1,32 \%$ \\
\hline Tucci (1998) & $-2,36 \%$ & $-2,27 \%$ & $-2,25 \%$ & $-2,17 \%$ & $-2,12 \%$ \\
\hline Tucci (2002) & $-33,47 \%$ & $-27,31 \%$ & $-25,09 \%$ & $-17,89 \%$ & $-9,50 \%$ \\
\hline Mét. Numérico & $-8,32 \%$ & $-7,55 \%$ & $-7,33 \%$ & $-6,63 \%$ & $-6,05 \%$ \\
\hline Método Holandês & $-11,34 \%$ & $-8,25 \%$ & $-7,72 \%$ & $-5,87 \%$ & $-5,32 \%$ \\
\hline Mét. de Matias (2006) & $-9,20 \%$ & $-8,22 \%$ & $-7,96 \%$ & $-7,10 \%$ & $-6,42 \%$ \\
\hline Mét. De Akan (1989) & $31,89 \%$ & $30,72 \%$ & $29,69 \%$ & $27,59 \%$ & $26,23 \%$ \\
\hline
\end{tabular}




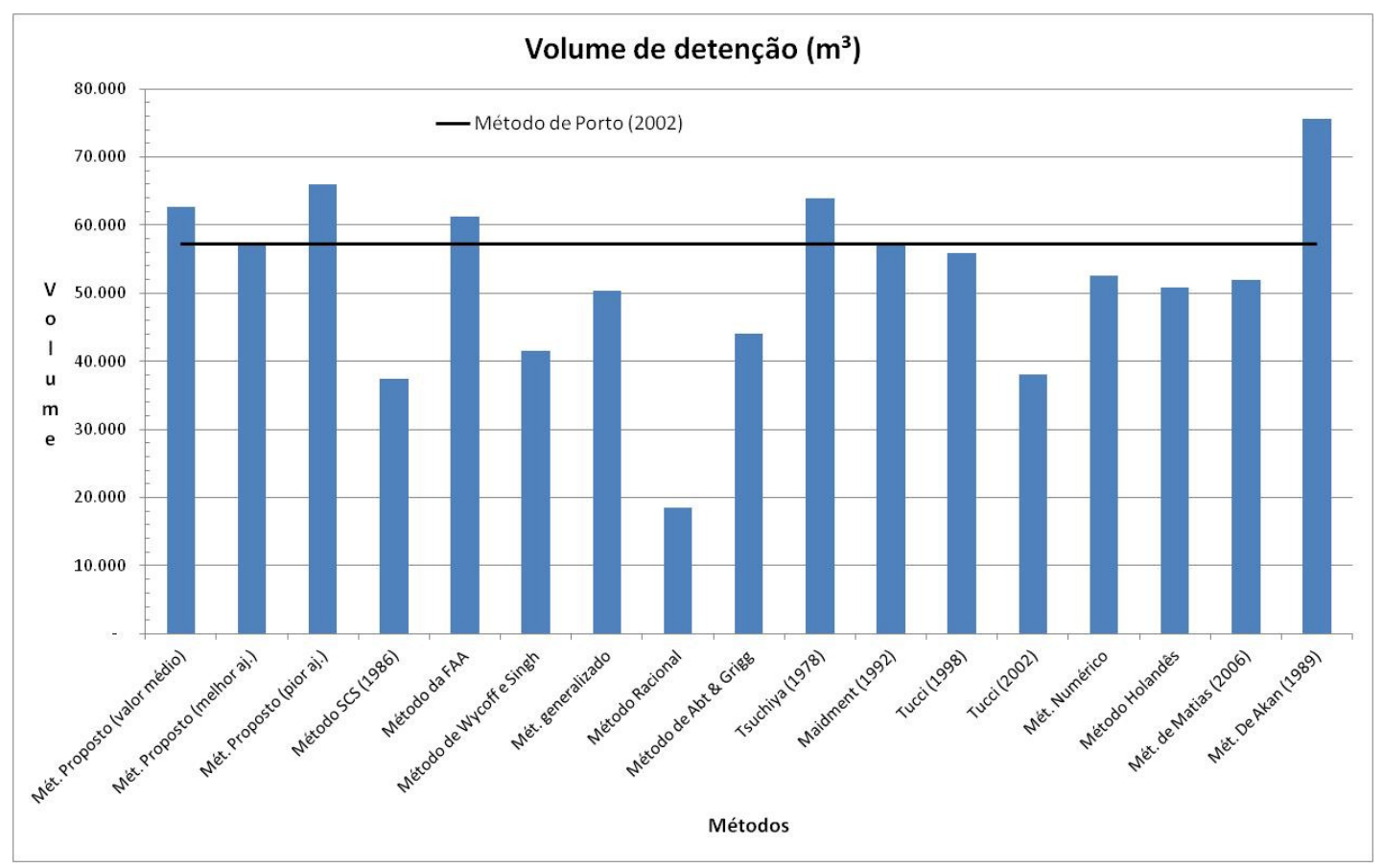

Figura 8.48: comparação gráfica de volumes de detenção para tempo de concentração de 26 minutos, duração da chuva de 90 minutos, CN de 98 e tempo de recorrência de 10 anos.

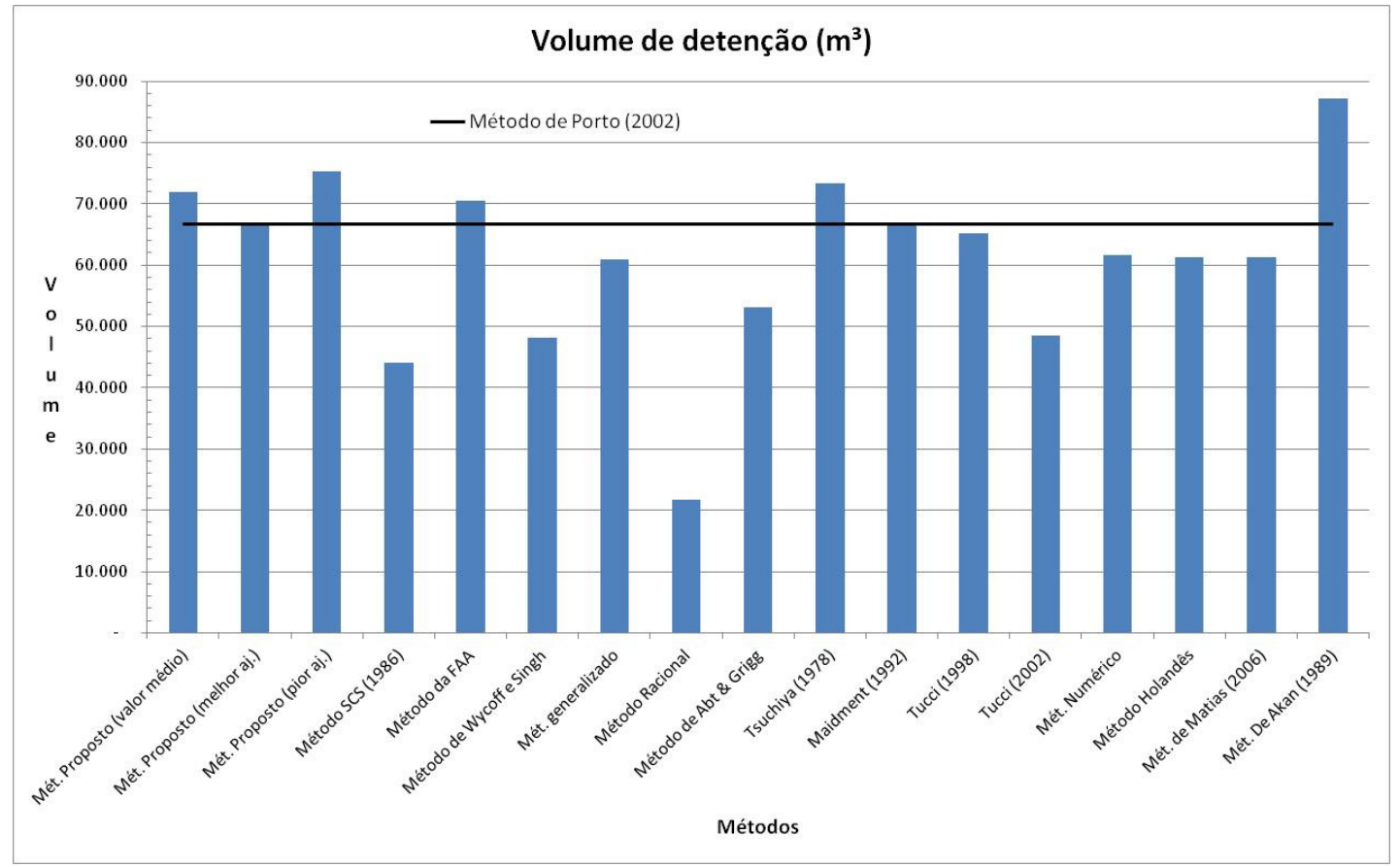

Figura 8.49: comparação gráfica de volumes de detenção para tempo de concentração de 26 minutos, duração da chuva de 90 minutos, $\mathrm{CN}$ de 98 e tempo de recorrência de 20 anos. 


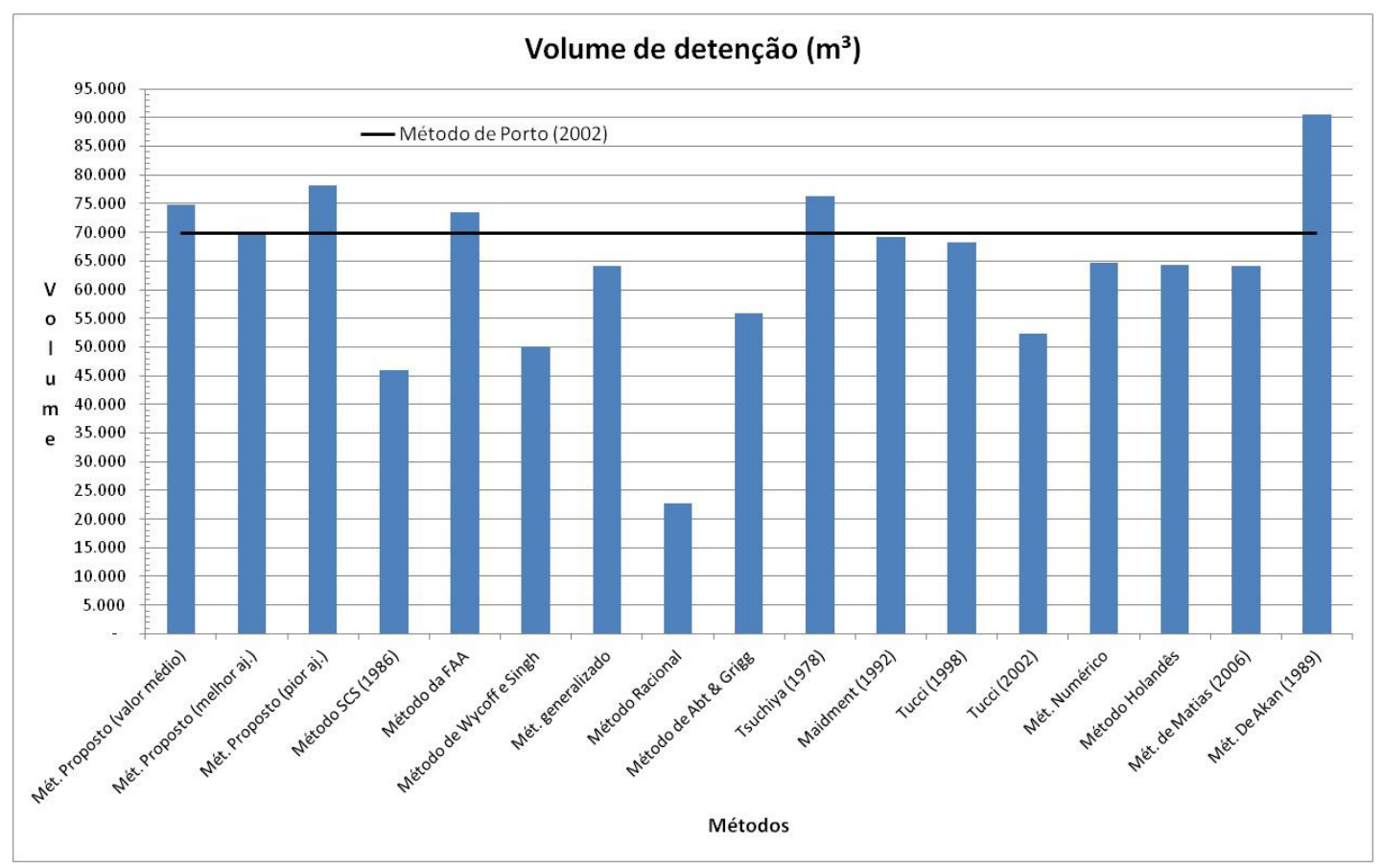

Figura 8.50: comparação gráfica de volumes de detenção para tempo de concentração de 26 minutos, duração da chuva de 90 minutos, $\mathrm{CN}$ de 98 e tempo de recorrência de 25 anos.

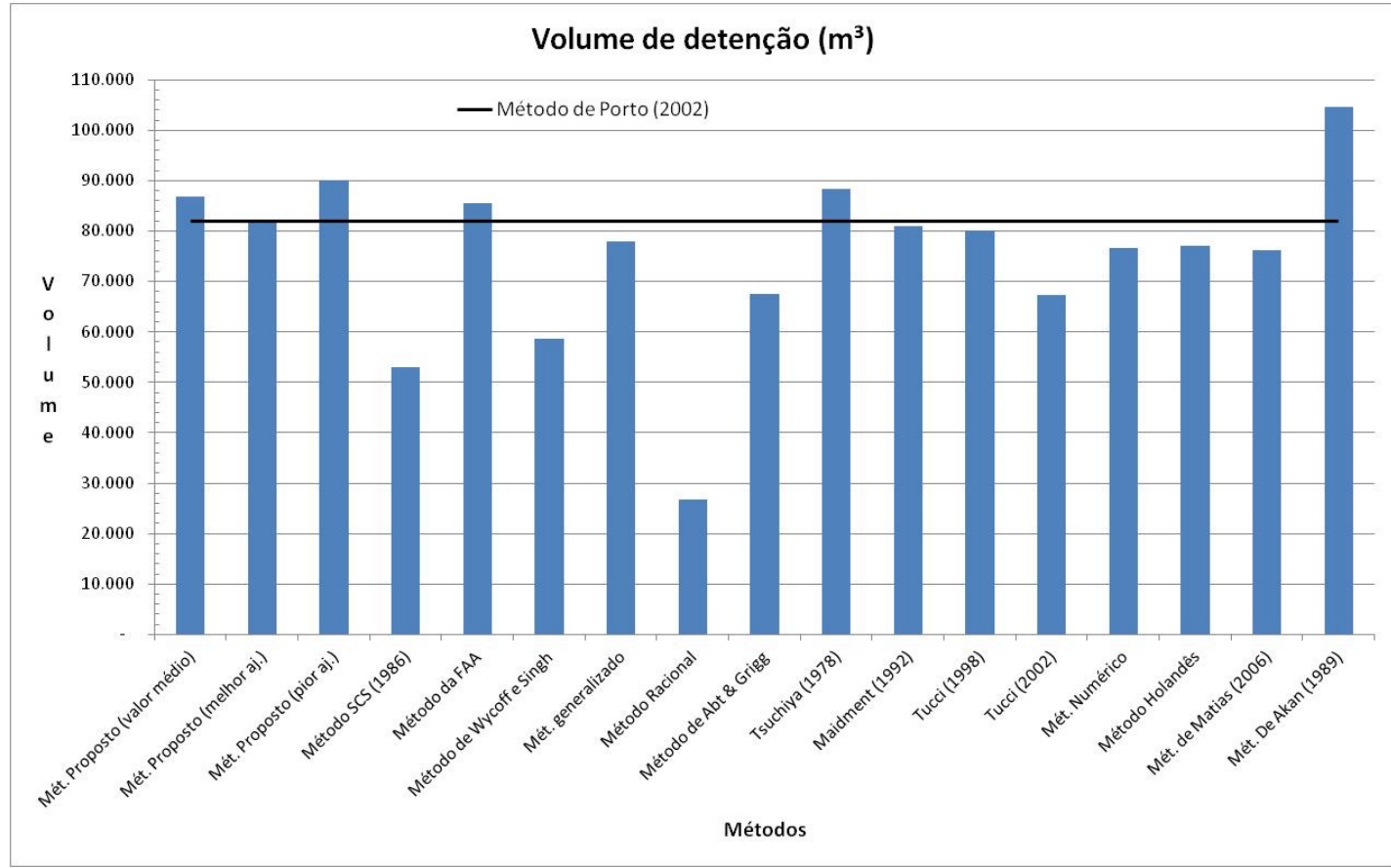

Figura 8.51: comparação gráfica de volumes de detenção para tempo de concentração de 26 minutos, duração da chuva de 90 minutos, $\mathrm{CN}$ de 98 e tempo de recorrência de 50 anos. 


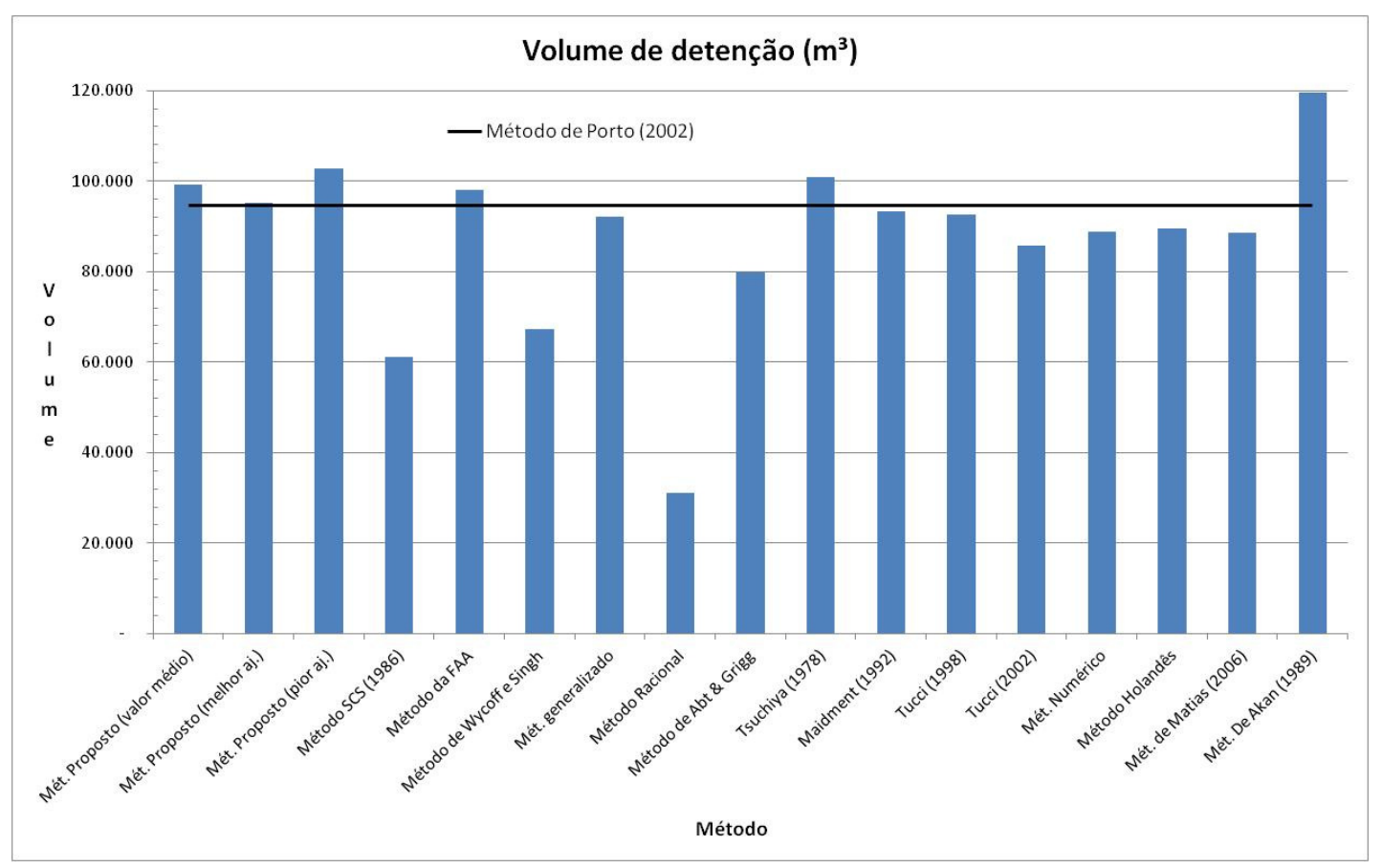

Figura 8.52: comparação gráfica de volumes de detenção para tempo de concentração de 26 minutos, duração da chuva de 90 minutos, $\mathrm{CN}$ de 98 e tempo de recorrência de 100 anos. 